\title{
Nitrogen metabolism and hepatocellular injury during liver resection
}

Citation for published version (APA):

van de Poll, M. C. G. (2008). Nitrogen metabolism and hepatocellular injury during liver resection. [Doctoral Thesis, Maastricht University]. Datawyse / Universitaire Pers Maastricht. https://doi.org/10.26481/dis.20081017mp

Document status and date:

Published: 01/01/2008

DOI:

10.26481/dis.20081017mp

Document Version:

Publisher's PDF, also known as Version of record

\section{Please check the document version of this publication:}

- A submitted manuscript is the version of the article upon submission and before peer-review. There can be important differences between the submitted version and the official published version of record.

People interested in the research are advised to contact the author for the final version of the publication, or visit the DOI to the publisher's website.

- The final author version and the galley proof are versions of the publication after peer review.

- The final published version features the final layout of the paper including the volume, issue and page numbers.

Link to publication

\footnotetext{
General rights rights.

- You may freely distribute the URL identifying the publication in the public portal. please follow below link for the End User Agreement:

www.umlib.nl/taverne-license

Take down policy

If you believe that this document breaches copyright please contact us at:

repository@maastrichtuniversity.nl

providing details and we will investigate your claim.
}

Copyright and moral rights for the publications made accessible in the public portal are retained by the authors and/or other copyright owners and it is a condition of accessing publications that users recognise and abide by the legal requirements associated with these

- Users may download and print one copy of any publication from the public portal for the purpose of private study or research.

- You may not further distribute the material or use it for any profit-making activity or commercial gain

If the publication is distributed under the terms of Article $25 \mathrm{fa}$ of the Dutch Copyright Act, indicated by the "Taverne" license above, 
Nitrogen metabolism and hepatocellular injury during liver resection 
(C) copyright M.C.G. van de Poll, Maastricht 2008

Universitaire Pers Maastricht

\section{ISBN 978-90-5278-756-5}

Cover design: Jean Scheijen 


\title{
Nitrogen metabolism and hepatocellular injury during liver resection
}

\author{
PROEFSCHRIFT \\ ter verkrijging van de graad van doctor \\ aan de Universiteit Maastricht, \\ op gezag van de Rector Magnificus, Prof. mr. G.P.M.F. Mols \\ volgens het besluit van het College van Decanen, \\ in het openbaar te verdedigen \\ op vrijdag 17 oktober 2008 om 16.00 uur
}

door

Marcel Coenraad Gerhard van de Poll 


\section{Promotores}

Prof. dr. C.H.C. Dejong

Prof. dr. P.B. Soeters

Beoordelingscommissie

Prof. dr. C.D.A. Stehouwer (voorzitter)

Prof. dr. L. Cynober (Université Paris Descartes)

Prof. dr. T.M. van Gulik (Universiteit van Amsterdam)

Prof. dr. A.A.M. Masclee

Prof. dr. J. Rosing

Marcel van de Poll is supported by an AGIKO stipendium from The Netherlands Organization for Health Research and Development (ZON-MW) (920-03-317) 


\section{Contents}

1 General Introduction $\quad 7$

Intermediary nitrogen metabolism during liver surgery

$2 \quad$ Urea synthesis before and after major hepatectomy 23

3 Hepatosplanchnic and renal ammonia release before and after 43 major hepatectomy

4 Interorgan exchange of glutamine, citrulline and arginine 57

5 Intestinal and hepatic metabolism of isotopically labelled 71 glutamine and citrulline

Effects of hepatic ischemia reperfusion during liver surgery

$6 \quad$ Causes of hepatocellular injury during liver surgery 89

7 Hepatocellular injury, arginase-1 release and plasma arginase 103 activity during liver surgery

8 Glutathione oxidation and oxidative stress during intermittent 123 Pringle manoeuvre

9 Expression of cell chaperones during intermittent Pringle 139 manoeuvre

10 General Discussion

11 Summary/Samenvatting $\quad 167$

$\begin{array}{lr}\text { Dankwoord } & 177\end{array}$

$\begin{array}{lr}\text { Curriculum Vitae } & 181\end{array}$

$\begin{array}{lc}\text { Publications } & 183\end{array}$ 



\section{Chapter 1}

\section{General Introduction}

Parts of this chapter were published in:

MCG van de Poll, PB Soeters, NEP Deutz, KCH Fearon, CHC Dejong Renal amino acid metabolism: its role in inter-organ amino acid and nitrogen exchange

Am J Clin Nutr 2004;79(2):185-197

MCG van de Poll, CHC Dejong, PB Soeters Adequacy range for sulphur-containing amino acids and biomarkers for their excess: lessons of parenteral and enteral nutrition.

J Nutr 2006;136:1S-7S

MCG van de Poll, YC Luiking, CHC Dejong, PB Soeters Amino acids; specific functions

Caballero B, Allen $L$ and Prentice A, eds. Encyclopedia of human nutrition. San Diego: Academic Press, 2nd ed 2005. 92-100 


\section{Introduction}

The first successful liver resection was performed in 1887 by surgical pioneer Carl Langenbuch (1). Until the 1960's liver surgery was performed infrequently due to a high mortality caused by intraoperative haemorrhage and due to disappointing long-term results caused by inappropriate patient selection $(2,3)$. Improvements in anatomical knowledge $(4,5)$, surgical technique $(6,7)$, anaesthetic and hemodynamic management (7) have rendered liver resection a safe procedure which can be performed at present with low mortality (8-10). Especially patients with colorectal liver metastases have been proven to benefit from liver resection and in the western world this is the most important indication for hepatectomy (8).

Since 1990 liver surgery is also performed at the University Hospital Maastricht. Until 2000, on average 7 liver resections were annually performed. Based upon the incidence of colorectal cancer in the region Limburg (11), the incidence of liver metastases in colorectal cancer (50\%) (12) and the predicted resectability rate of these liver metastases (15-25\%) (13-15), it can be estimated that annually 35-90 patients with colorectal liver metastases may have been eligible for liver surgery in this area between 1990 and 2005 (Figure 1).

The apparent discrepancy between the number of patients that might benefit from liver surgery and the number of patients actually undergoing liver surgery (Figure 1) has raised concern which has led to the institution in Maastricht of a multidisciplinary regional collaborative liver workgroup in 2000, aiming at allowing more patients to benefit from liver resections. Simultaneously more liberal indications and contra-indications were introduced according to progressing insight acquired from increasing experience in our unit and from the literature (15). This more aggressive approach did not decrease oncological benefit, probably partly due to the use of adjuvant chemotherapy (16). These efforts have resulted in a sharp increase of the annual number of liver resections performed at the University Hospital Maastricht. Currently the number of liver resections approaches the number of potential candidates for liver resection in the affluent area of the University Hospital Maastricht (Figure 1).

This development has enabled the establishment of a clinical research line in patients undergoing liver surgery. The primary focus of this research line was to study the effects of liver surgery on liver function, but in addition advantage was taken of the unique possibility to access intra-abdominal blood vessels and tissues during liver surgery to study physiological aspects of intermediary metabolism in man. 


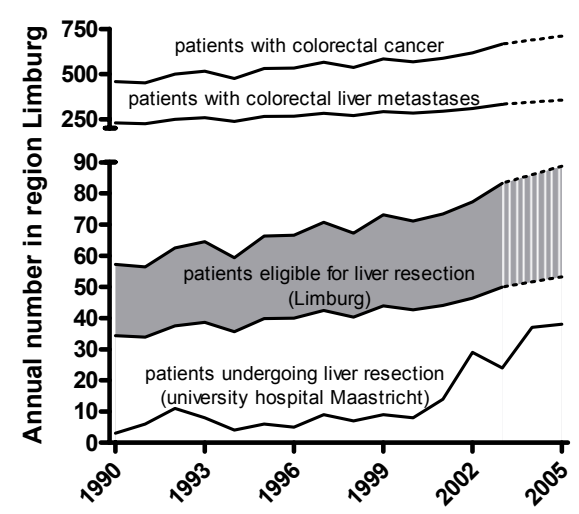

Figure 1. Trends in colorectal cancer incidence in region Limburg 1990-2005 with approximately 900.000 inhabitants (interrupted lines and areas represent predicted incidence). Fifteen to twenty-five percent of all colorectal cancer patients should become candidate for liver resection, which amounts to an annual number of 35-90 patients in our region between 1990 and 2005. Clearly this number is not met by the number of liver resections actually performed. After the institution of a multidisciplinary regional collaboration in 2000 , the number of liver resections increased sharply.

\section{Effects of liver surgery on liver function}

Liver function following liver surgery is grossly determined by two factors: the remnant liver volume and the functional capacity of the remnant liver. The remnant liver volume is determined by the anatomical position of the lesions that are resected and can be accurately predicted using CT-volumetry $(17,18)$. The functional capacity of the remnant liver is far more difficult to define.

The term liver function is a very crude denominator for a range of functions that includes ammonia detoxification and urea synthesis, protein synthesis, bile synthesis and secretion, gluconeogenesis and clearance or detoxification of drugs, bacterial toxins and bacteria (19). After reduction of liver cell mass by liver resection or chronic or acute liver disease, a "survival program" is initiated within the liver, prioritizing liver functions that are vitally important over those that are not $(20,21)$. In addition, it has been shown that some functions such as ammonia clearance and glucose production can be (partly) taken over by other organs such as the kidney (22-25) and skeletal muscle (26) during chronic liver disease or during experimental liver failure as outlined below. It has not been addressed to what extent extrahepatic ammonia clearance plays a role in ammonia homeostasis after liver resection. 
Identification of liver functions that limit the liver volume that can be resected safely, and assessment of the maximum capacity of liver function per gram liver may theoretically lead to a method that enables calculation of the minimally required liver volume. It should be taken into account however, that the preoperative functional capacity per gram liver can become impaired by per- or postoperative hepatocellular injury, due to e.g. organ manipulation (27-29), ischemia-reperfusion $(30,31)$ or postoperative infections $(32)$.

\section{Renal ammonia metabolism during liver failure}

The kidney plays a role in ammonia clearance and regulation of ammonia levels by virtue of its ability to simultaneously produce and excrete ammonia. This role becomes apparent when hepatic ammonia detoxification by urea synthesis is diminished due to acidosis or during other conditions leading to hyperammonemia. Much experimental work concerning renal ammonia metabolism has been performed in the past. The amino acid glutamine plays a crucial role as a non-toxic carrier of nitrogen between organs $(33,34)$. In the normal fasted state, the kidney takes up glutamine from blood $(22,23,26,35-$ 44). Renal uptake of glutamine ranges between 7 and 10 grams per day in man, which means $10-15 \%$ of whole body glutamine flux $(39,40,45,46)$. After being taken up, glutamine is metabolised primarily by the intramitochondrial phosphate dependent enzyme glutaminase. This yields ammonia and glutamate $(38,47)$. The ammonia generated in the glutaminase reaction can be excreted either in the urine or released into the renal vein $(26,48-53)$. In the healthy physiological situation, about $70 \%$ of all ammonia generated in this reaction is released into the renal vein, and the remaining $30 \%$ is excreted in the urine $(48$, 54-56) (Figure 2).

In the normal in vivo situation, the kidney is therefore an organ that releases ammonia into the systemic circulation because it releases more ammonia in the renal vein than is excreted in the urine $(51,57)$. However in situations with high arterial ammonia concentrations such as during metabolic acidosis, ammonia excretion in urine exceeds ammonia excretion in the renal vein, making the kidneys net excretors of ammonia $(22,23,36,37,58-61)$.

The changes that take place during acidosis $(48,53,54,60,62-65)$ illustrate the role of the kidney in interorgan metabolite exchange. Acute or chronic acidosis induces an increase in the renal uptake and breakdown of glutamine $(41,55$, $56,58,66,67)$. This leads to enhanced renal ammoniagenesis mediated by an increased activity of the glutaminase enzyme (47). In addition, the normal physiological ratio of renal venous ammonia release versus urinary excretion is 


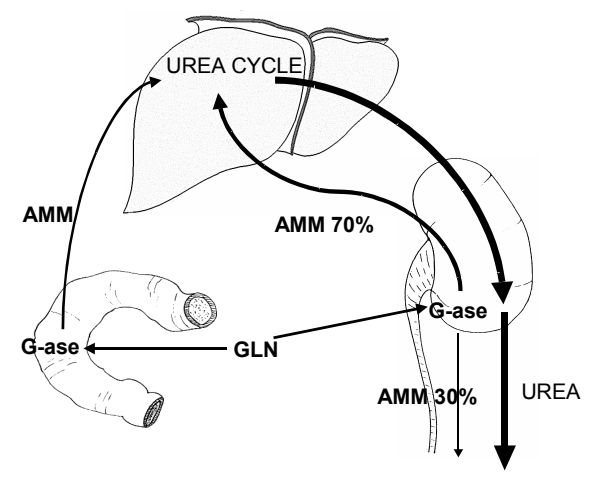

Figure 2. The role of the kidney in inter-organ glutamine (GLN) exchange under physiological circumstances. GLN is taken up by the gut and kidney and metabolised by the glutaminase (G-ase) pathway to yield ammonia (AMM). AMM generated by the kidney is excreted in the urine or released into the renal vein. Renal $A M M$ released into the circulation as well as AMM generated by the gut is metabolised in the liver in periportal hepatocytes to form urea, that is excreted in the urine.

reversed. Hence, during acidosis, $70 \%$ of all ammonia generated in the kidney is excreted in the urine, the remainder being released back into the renal vein $(53,54)$. As a consequence, during acidosis the kidney becomes an organ of net ammonia excretion (Figure 3). During hyperammonemia ammonia is taken up by skeletal muscle with glutamate and converted to glutamine by the enzyme glutamine synthetase $(26,68)$. Glutamine in turn functions as a non-toxic nitrogen carrier and will be partly taken up by the kidney. Renal breakdown of glutamine yields ammonia, which can subsequently be excreted in the urine (Figure 2 and 3 ).

The inaccessibility of the portal vein is a drawback to measure balances across the intestines and the liver in humans. The only human studies that actually address renal, intestinal and hepatic ammonia exchange simultaneously were conducted in patients with liver cirrhosis, needing portosystemic shunting to relieve portal hypertension (26). Through this portosystemic shunt the blood from the portal vein could be sampled, allowing separate assessment of the contribution of the intestine and the liver, but selfevidently these studies cannot be used to study hepatic metabolism in the "normal" human liver.

Preservation of hepatocellular integrity is important to preserve liver function, especially after extensive hepatectomy. Hepatocellular injury is regularly encountered during and after liver resection, evidenced by increased postoperative plasma levels of cytosolic hepatocellular proteins such as aminotransferases, glutathione-s-transferase and arginase-1 $(69,70)$. In most cases peri- and postoperative hepatocellular injury is ascribed to the effects of 


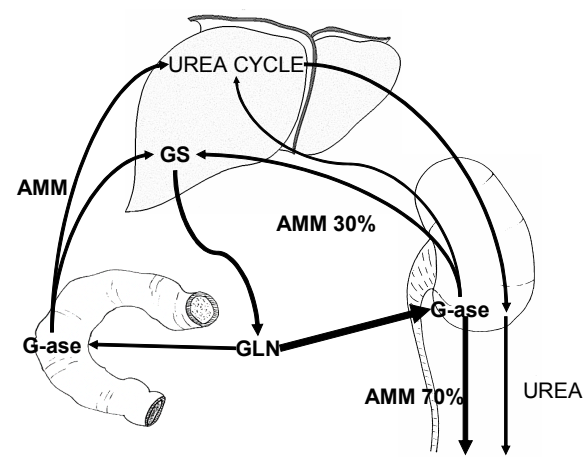

Figure 3. The role of the kidney in inter-organ glutamine exchange during acidosis (cf. also fig. 2). Urea synthesis is diminished during acidosis. AMM derived from the gut or kidneys escaping periportal urea synthesis is subsequently scavenged in the perivenous hepatocytes in the glutamine synthetase pathway (GS) to form GLN. GLN in turn is released back into the circulation and subsequently undergoes degradation by G-ase in gut and kidney. During acidosis, more AMM is generated in the kidney and a greater fraction is excreted in the urine.

ischemia and reperfusion (30). Recent data however show that plasma markers of liver injury increase already before the induction of liver ischemia, when the only "hit" to the liver has been induced by induction of anesthesia and manipulation during mobilization of the liver. Organ manipulation during abdominal surgery is inevitable and its harm at first glance seems negligible compared with other factors such as ischemia-reperfusion and organ transection. The impact of organ manipulation on local and systemic cell injury and inflammation however, is slowly gaining recognition. Most attention is paid to effects of intestinal manipulation $(29,71,72)$, but in animal reports the occurrence of an inflammatory response after manipulation of the liver is described $(28,29)$.

Recognition of factors and mechanisms causing cell injury during liver surgery is crucial to develop strategies to enhance cell survival and liver function following liver surgery. Potential targets for such interventions include supplementation of antioxidants that may become depleted during ischemiareperfusion or induction of endogenous cytoprotective mechanisms such as heat-shock protein expression.

\section{Ischemia-reperfusion and oxidative stress}

Ischemia and reperfusion by temporary hepatic inflow occlusion is frequently applied to reduce blood loss during parenchymal transection. Hepatic inflow occlusion is achieved by cross clamping of the hepatoduodenal ligament 
containing the hepatic artery, portal vein and common bile duct (Pringle manoeuvre) (73) (Figure 4). Ischemia is typically characterized by ATP depletion and necrotic cell death (74). Upon reperfusion a multifactorial process leading to apoptotic cell death is initiated that further aggravates cell injury already initiated by plain ischemia. An important factor in this process is the formation of large quantities of reactive oxygen species (ROS) immediately after reperfusion (75-77). This so-called oxidative burst may induce peroxidation of membrane phospholipids (27) and intracellular proteins (76), triggering a cascade leading to caspase activation and apoptotic cell death (78). Oxidative injury can be limited by the intracellular antioxidant glutathione (GSH) that contains a sulfhydryl group which can reduce ROS upon oxidation to glutathione disulfide (GSSG) (79). Increased oxidative stress induces a right shift in the GSH:GSSG ratio. GSSG can be reduced to GSH by the $\mathrm{NADPH} / \mathrm{NADP}+$ dependent enzyme glutathione reductase to restore the redox potential but this activity can be inhibited by decreased NADPH levels. In this situation GSSG is exported from the cell, instead of reduced to GSH (80) and maintenance of intracellular GSH pools becomes dependent on GSH de novo synthesis (81) from glutamate, glycine and cysteine (Figure 5). When GSH oxidation exceeds GSSG reduction and GSH de novo synthesis however, depletion of intracellular GSH is imminent. It has been suggested from animal experiments and from circumstantial evidence from human studies that such

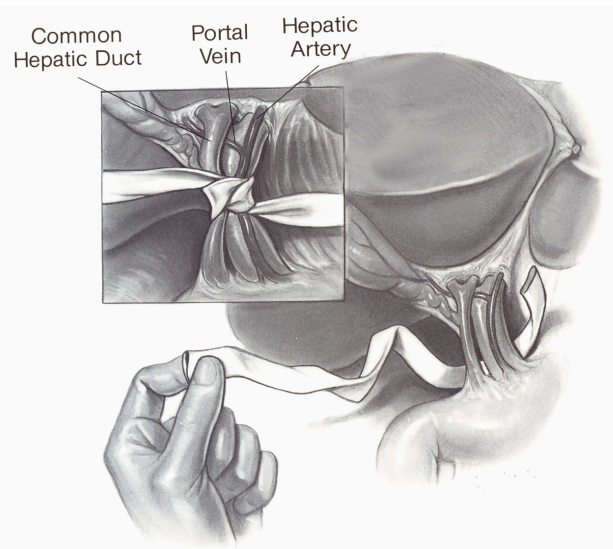

Figure 4. Pringle manoeuvre. By clamping or temporal ligation of the hepatoduodenal ligament, hepatic inflow can be occluded. Thus blood flow through the liver is impaired, which diminishes blood loss during parenchymal transection, but which also may give rise to hepatic ischemia and reperfusion injury. (From: Warren, Jenkins, Steele, eds. Atlas of Surgery of the Liver, Pancreas and Biliary Tract. Norwalk, CT: Appleton and Lange, 1991) 


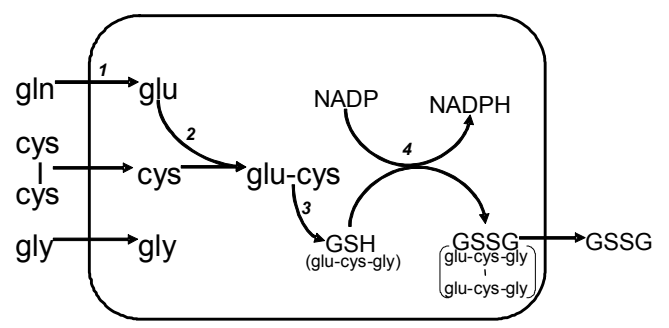

Figure 5. Intracellular glutathione metabolism. Glutamine (gIn), cystine (cys-cys) and glycine (gly) are taken up from the circulation, gln and cys-cys are converted to glutamate (glu) (by glutaminase, 1) and cysteine (cys). Glu, cys and gly form glutathione (GSH) in a two-step reaction catalyzed by glutamylcysteinyl synthetase (2) and glutathione synthetase (3). GSH reduces reactive oxygen species (ROS) by oxidation of the cysteine sulfhydryl group, forming glutathione disulfide (GSSG). GSSG subsequently becomes reduced by the $N A D P H$-dependent enzyme glutathione reductase (4) or is exported from the cell.

GSH depletion occurs during hepatic ischemia and reperfusion, but no data are at hand concerning the effect of the intermittent Pringle manoeuvre, on GSH status in clinical practice. When GSH depletion actually occurs in patients, stimulation of GSH synthesis by supplementation of GSH precursors may be indicated.

\section{Ischemia-reperfusion and heat shock protein expression}

It has been repeatedly shown in laboratory animals (82-84) and in humans (30) that intermittent hepatic inflow occlusion results in less apoptotic signalling, oxidative stress and cell death, and to increased survival, compared with continuous clamping. Although these endpoints are clearly established, the actual mechanisms underlying the superiority of intermittent over continuous inflow occlusion are not exactly known.

It is possible that regular reoxygenation of the liver is favourable compared to continous oxygen and nutrient deprivation (85). There is also evidence however, that the protective effects of intermittent Pringle manoeuvre against ischemia-reperfusion injury are (partly) mediated by active processes. During a short period of ischemia and reperfusion, molecular processes are initiated within affected cells that render them more resistant to a subsequent period of prolonged ischemia. This so-called ischemic preconditioning (86-88) was first described in dogs with myocardial ischemia $(85,89)$. Classically, effects of ischemic preconditioning are categorized in "early" and "late". Early effects are thought to be mediated by factors that are rapidly synthesized during ischemia and reperfusion such as nitric oxide, reactive oxygen species and adenosine. After ischemia, these factors activate processes aimed at opposing changes in 
cellular energy metabolism, normally occurring during ischemia such as increased glycolysis, acidosis and cell swelling by $\mathrm{K}^{+}$efflux and concomitant $\mathrm{Na}^{+}$influx (87). These early changes in cellular energy homeostasis persist for 2-3 hours. Late effects of ischemic preconditioning last up to 4 days (90) and are thought to be primarily mediated by the induction and expression of heat shock proteins. These ubiquitously expressed proteins are upregulated by various forms of cellular stress (a.o. heat shock, ischemia, endotoxin exposure) and exert cytoprotective functions through several mechanisms, many of which remain unknown. HSP expression may protect hepatocytes during intermittent Pringle manoeuvre, but the occurrence of activation of HSP expression during hepatic ischemia and reperfusion in humans has not been studied.

\section{Systemic effects of hepatocyte injury: inflammation and arginase-1 release}

As outlined above, hepatocellular injury may bear consequences for liver function, but it may also exert systemic effects that can impair postoperative recovery. For example, it has been shown in vitro that proteins and nucleotides released from injured cells can activate the immune system and elicit a local and even systemic inflammatory response (91). It can be conceived that by this mechanism, hepatocellular injury, occurring during liver surgery contributes to the postoperative systemic inflammatory response. Moreover injured hepatocytes release the enzyme arginase-1 into the circulation (92-95). This enzyme normally converts arginine to ornithine and urea and it has been shown that increased plasma levels of arginase lead to arginine breakdown and low arginine plasma levels following liver transplantation $(94,96)$. Although the concept of arginine deficiency due to inappropriately increased arginase-1 activity in plasma has become widely embraced (97) in several disease states, its actual occurrence and its potential clinical relevance has remained unaddressed in most conditions including during liver resection.

\section{Aim and outline of the thesis}

Liver surgery may lead to changes in liver function, interorgan trafficking of nitrogenous compounds, hepatocellular injury and in local and systemic cellular and molecular processes that accompany tissue injury. The aim of this thesis was to characterize the consequences of liver surgery for the functional status of the remnant liver. We specifically addressed the role of the liver in the 
interorgan exchange of nitrogenous compounds such as ammonia, urea, glutamine and arginine.

In the first part of this thesis (Chapters 2-5) the effect of liver resection on the role of the liver in amino acid and nitrogen metabolism is studied. In this respect urea synthesis and ammonia clearance are important aspects, which will be described in chapter 2. In addition the liver plays a crucial role in the interorgan exchange of amino acids such as glutamine, arginine and citrulline between the gut and the kidney. The role of the liver in interorgan metabolism of glutamine, citrulline and arginine is hitherto not thoroughly explored in humans with a normal liver function and is described in chapter 4 and 5 . In Chapter 3 the changes in interorgan ammonia and amino acid metabolism due to liver resection are outlined.

In the second part of this thesis (Chapters 6-9) causes and consequences of hepatocellular injury during liver resection are studied. In chapter 6 potential causes of hepatocellular injury during liver surgery such as hepatotoxic drugs, ischemia-reperfusion and liver manipulation are identified. Since hepatocyte injury is an important determinant of the functional capacity of the remnant liver, recognition of causes of hepatocyte injury may aid to improve liver function following liver surgery. In chapter 7 a potentially detrimental systemic consequence of hepatocellular demise, namely arginase-1 release and inappropriate breakdown of plasma arginine is studied. This may be particularly important since arginine deficiency may cause microcirculatory disturbances, which have been implied in post-hepatectomy liver failure. Glutathione oxidation and heat shock protein expression are important endogenous defence mechanisms against ischemic liver injury. Modulation of endogenous cytoprotective mechanisms may be a promising approach to improve liver function following major hepatectomy. In chapters 8 and 9 the effect of hepatic ischemia and reperfusion on GSH oxidation and HSP expression will be described. In chapter 10 the thesis will be concluded with a comprehensive discussion of the results of the first and second part. 


\section{References}

1. Langenbuch C. Ein Fall von Resektion eines linksseitigen Schnürlappens der Leber. Heilung. Berliner Klinische Wochenschrift 1888;25:37-8.

2. Brunschwig A. Hepatic lobectomy for metastatic cancer. Cancer 1963;16:277-81.

3. Gaston EA. Liver resections for embolic metastases from cancer of the colon and rectum. Dis Colon Rectum 1966;9:189-96.

4. McClusky DA, 3rd, Skandalakis LJ, Colborn GL, Skandalakis JE. Hepatic surgery and hepatic surgical anatomy: historical partners in progress. World J Surg 1997;21:330-42.

5. Couinaud C. Le foie: études anatomiques et chirurgicales. Paris: Masson, 1957.

6. Foster JH. History of liver surgery. Arch Surg 1991;126:381-7.

7. DeMatteo RP, Fong $Y$, Jarnagin WR, Blumgart $L H$. Recent advances in hepatic resection. Semin Surg Oncol 2000;19:200-7.

8. Dimick JB, Cowan JA, Jr., Knol JA, Upchurch GR, Jr. Hepatic resection in the United States: indications, outcomes, and hospital procedural volumes from a nationally representative database. Arch Surg 2003;138:185-91.

9. Finch MD, Crosbie JL, Currie E, Garden OJ. An 8-year experience of hepatic resection: indications and outcome. Br J Surg 1998;85:315-9.

10. Lodge JP, Menon KV, Fenwick SW, Prasad KR, Toogood GJ. In-contiguity and nonanatomical extension of right hepatic trisectionectomy for liver metastases. $\mathrm{Br} J$ Surg 2005;92:340-7.

11. www.VIKC.nl. accessed 2008-05-28.

12. August DA, Ottow RT, Sugarbaker PH. Clinical perspective of human colorectal cancer metastasis. Cancer Metastasis Rev 1984;3:303-24.

13. Ruers $T$, Bleichrodt RP. Treatment of liver metastases, an update on the possibilities and results. Eur J Cancer 2002;38:1023-33.

14. Leporrier J, Maurel J, Chiche L, Bara S, Segol P, Launoy G. A population-based study of the incidence, management and prognosis of hepatic metastases from colorectal cancer. $\mathrm{Br} \mathrm{J}$ Surg 2006;93:465-74.

15. Fusai G, Davidson BR. Management of colorectal liver metastases. Colorectal Dis 2003;5:223.

16. Mackay HJ, Billingsley $K$, Gallinger S, et al. A multicenter phase II study of "adjuvant" irinotecan following resection of colorectal hepatic metastases. Am J Clin Oncol 2005;28:54754.

17. Dello SWAG, van Dam RM, Slangen J, et al. Liver volumetry plug and play, do-it-yourself with ImageJ. World J Surg 2007;31:2215-21.

18. Wigmore SJ, Redhead DN, Yan XJ, et al. Virtual hepatic resection using three-dimensional reconstruction of helical computed tomography angioportograms. Ann Surg 2001;233:221-6.

19. Guyton AC, Hall JE. The liver as an organ. In: Textbook of Medical Physiology. Philadelphia: W.B. Saunders, 1996:883-8.

20. Tygstrup N, Bak S, Krog B, Pietrangelo A, Shafritz DA. Gene expression of urea cycle enzymes following two-thirds partial hepatectomy in the rat. $J$ Hepatol 1995;22:349-55.

21. Taub R. Liver regeneration: from myth to mechanism. Nat Rev Mol Cell Biol 2004;5:836-47.

22. Dejong $\mathrm{CH}$, Deutz NE, Soeters PB. Metabolic adaptation of the kidney to hyperammonemia during chronic liver insufficiency in the rat. Hepatology 1993;18:890-902.

23. Dejong $\mathrm{CH}$, Deutz NE, Soeters PB. Renal ammonia and glutamine metabolism during liver insufficiency-induced hyperammonemia in the rat. J Clin Invest 1993;92:2834-40.

24. Battezzati A, Caumo A, Martino F, et al. Nonhepatic glucose production in humans. Am J Physiol Endocrinol Metab 2004;286:E129-35. 
25. Joseph SE, Heaton N, Potter D, Pernet A, Umpleby MA, Amiel SA. Renal glucose production compensates for the liver during the anhepatic phase of liver transplantation. Diabetes 2000;49:450-6.

26. Olde Damink SW, Jalan R, Redhead DN, Hayes PC, Deutz NE, Soeters PB. Interorgan ammonia and amino acid metabolism in metabolically stable patients with cirrhosis and a TIPSS. Hepatology 2002;36:1163-71.

27. Fukai M, Hayashi T, Yokota R, et al. Lipid peroxidation during ischemia depends on ischemia time in warm ischemia and reperfusion of rat liver. Free Radic Biol Med 2005;38:1372-81.

28. Schemmer P, Enomoto N, Bradford BU, et al. Activated Kupffer cells cause a hypermetabolic state after gentle in situ manipulation of liver in rats. Am J Physiol Gastrointest Liver Physiol 2001;280:G1076-82.

29. Hiki N, Shimizu N, Yamaguchi $H$, et al. Manipulation of the small intestine as a cause of the increased inflammatory response after open compared with laparoscopic surgery. Br J Surg 2006;93:195-204.

30. Belghiti J, Noun R, Malafosse R, et al. Continuous versus intermittent portal triad clamping for liver resection: a controlled study. Ann Surg 1999;229:369-75.

31. Clavien PA, Selzner M, Rudiger HA, et al. A prospective randomized study in 100 consecutive patients undergoing major liver resection with versus without ischemic preconditioning. Ann Surg 2003;238:843-50; discussion 851-2.

32. Schindl MJ, Redhead DN, Fearon KC, Garden OJ, Wigmore SJ. The value of residual liver volume as a predictor of hepatic dysfunction and infection after major liver resection. Gut 2005;54:289-96.

33. Lacey JM, Wilmore DW. Is glutamine a conditionally essential amino acid? Nutr. Rev. 1990;48:297-309.

34. O'Dwyer ST, Smith RJ, Hwang TL, Wilmore DW. Maintenance of small bowel mucosa with glutamine-enriched parenteral nutrition. JPEN 1989;13:579-585.

35. Dejong CHC, Welters CFM, Deutz NEP, Heineman E, Soeters PB. Renal arginine metabolism in fasted rats with subacute short bowel syndrome. Clin. Sci. 1998;95:409-418.

36. Dejong $C H C$, Deutz NEP, Soeters PB. Ammonia and glutamine metabolism during liver insufficiency: the role of kidney and brain in interorgan nitrogen exchange. Scand. J. Gastroenterol 1996;218:61-77.

37. Heeneman S, Dejong CHC, Deutz NEP, Soeters PB. Effects of methionine sulfoximine treatment on renal amino acid and ammonia metabolism in the rat. Pflugers Arch. 1994;427:524-532.

38. Silbernagl S. The renal handling of amino acids and oligopeptides. Physiol. Rev. 1988;68:9111007.

39. Tizianello A, De Ferrari G, Garibotto G, Gurreri G, Robaudo C. Renal metabolism of amino acids and ammonia in subjects with normal renal function and in patients with chronic renal insufficiency. J Clin Invest 1980;65:1162-73.

40. Tizianello A, Deferrari G, Garibotto G, Robaudo C, Salvidio G, Saffioti S. Renal ammoniagenesis in the postprandial period. Contrib Nephrol 1985;47:44-57.

41. Schrock H, Cha C-JM, Goldstein L. Glutamine release from hindlimb and uptake by the kidney in the acutely acidotic rat. Biochem. J. 1980;188:557-560.

42. Warter JM, Brandt C, Marescaux C, et al. The renal origin of sodium valproate-induced hyperammonemia in fasting humans. Neurology 1983;33:1136-1140.

43. Warter JM, Imler M, Marescaux C, et al. Sodium valproate-induced hyperammonemia in the rat: the role of the kidney. Eur. J. Pharmacol. 1983;87:177-182.

44. Imler M, Chabrier G, Marescaux C, Warter JM. Effects of 2,4-dinitrophenol on renal ammoniagenesis in the rat. Eur. J. Pharmacol. 1986;123:175-179. 
45. Rennie MJ, Lavery GG, Scott A, et al. Consensus workshop on enteral feeding of ICU patients. How important is the role of glutamine? Br. J. Intens. Care, supplement December 1993.

46. Souba WW, Wilmore DW. Postoperative alteration of arteriovenous axchange of amino acids across the gastrointestinal tract. Surgery 1983;94:342-350.

47. Pitts RF, Stone WJ. Renal metabolism of alanine. J Clin Invest 1967;46:530-8.

48. Vinay $P$, Allignet $E$, Pichette $C$, Watford M, Lemieux G, Gougoux A. Changes in renal metabolite profile and ammoniagenesis during acute and chronic metabolic acidosis in dog and rat. Kidney Int. 1980;17:312-325.

49. Tyor MP, Owen EE, Berry JN, Flanagan JF. The relative role of extremity, liver and kidney as ammonia receivers and donors in patients with liver disease. Gastroenterology 1960;39:420424.

50. Berry JN, Flanagan JF, Owen EE, Tyor MP. The kidney as a source of blood ammonia in resting and hyperventilated cirrhotics. Clin. Res. 1959;7:154-155.

51. Imler $M$, Schlienger J-L, Chabrier G, Simon C. Arterial ammonemia changes of renal origin induced in the rat by acid and alkaline diets. Res. Exp. Med. 1986;186:353-363.

52. Owen EE, Tyor MP, Flanagan JF, Berry JN. The kidney as a source of blood ammonia in patients with liver disease: the effect of acetazolamide. J. Clin. Invest. 1960;39:288-294.

53. Halperin ML, Ethier JH, Kamel KS. The excretion of ammonium ions and acid base balance. Clin. Biochem. 1990;23:185-188.

54. Halperin ML, Kamel KS, Ethier JH, Stinebaugh BJ, Jungas RL. Biochemistry and physiology of ammonium excretion. In: Seldin DW, Giebisch G, eds. The Kidney: Physiology and pathophysiology. 2nd ed. New York: Raven Press Ltd, 1992:2645-2679.

55. Welbourne TC. Effect of metabolic acidosis on hindquarter glutamine and alanine release. Metabolism 1986;35:614-618.

56. Welbourne TC, Childress D, Givens G. Renal regulation of interorganal glutamine flow in metabolic acidosis. Am. J. Physiol. 1986;251:R859-866.

57. Imler $M$, Schlienger J-L, Chabrier G, Comte F. Origine renale de l'hyperammoniemie provoquee par un regime hyperprotidique chez le rat normal ou porteur d'une stricture portale. Gastroenterol. Clin. Biol. 1983;7:740-745.

58. Owen EE, Robinson RR. Amino acid extraction and ammonia metabolism by the kidney during prolonged administration of ammonium chloride. J. Clin. Invest. 1963;42:263-276.

59. Owen EE, Johnson JH, Tyor MP. The effect of induced hyperammonemia on renal ammonia metabolism. J. Clin. Invest. 1961;40:215-221.

60. Tannen RL. Ammonia metabolism. Am. J. Physiol. 1978;235:F265-277.

61. Welbourne TC, Weber M, Bank N. The effect of glutamine administration on urinary ammonium excretion in normal subjects and patients with renal disease. J. Clin. Invest. 1972;51:1852-1860.

62. Heitman RN, Bergman EN. Glutamine metabolism, interorgan transport and glucogenicity in the sheep. Am. J. Physiol. 1978;234:E197-203.

63. Schoolwerth AC. Regulation of renal ammoniagenesis in metabolic acidosis. Kidney Int. 1991;40:961-973.

64. Chobanian MC. Hormonal control of renal ammoniagenesis: a review. Am. J. Kidney Dis. 1989;14:248-252.

65. Halperin ML, Ethier JH, Kamel KS. Ammonium excretion in chronic metabolic acidosis: benefits and risks. Am. J. Kidney Dis. 1989;14:267-271.

66. Phromphetcharat $V$, Welbourne TC. Renal glutamine extraction and gut/liver interaction in glutamine homeostasis. Contrib. Nephrol. 1985;47:9-14.

67. Welbourne TC. Hepatic glutaminase flux regulation of glutamine homeostasis. Biol. Chem. Hoppe Seyler 1986;367:301-305. 
68. Olde Damink SW, Deutz NE, Dejong $\mathrm{CH}$, Soeters $P B$, Jalan $R$. Interorgan ammonia metabolism in liver failure. Neurochem Int 2002;41:177-88.

69. Chouker A, Martignoni A, Schauer RJ, et al. -Gluthathione S-transferase as an early marker of hepatic ischemia/reperfusion injury after liver resection. World J Surg 2005;29:528-34.

70. Aronsen KF, Ericsson B, Pihl B. Metabolic changes following major hepatic resection. Ann Surg 1969;169:102-10.

71. de Jonge WJ, van den Wijngaard RM, The FO, et al. Postoperative ileus is maintained by intestinal immune infiltrates that activate inhibitory neural pathways in mice. Gastroenterology 2003;125:1137-47.

72. Kalff JC, Turler A, Schwarz NT, et al. Intra-abdominal activation of a local inflammatory response within the human muscularis externa during laparotomy. Ann Surg 2003;237:30115.

73. Pringle JH. Notes on the arrest of hepatic hemorrhage due to trauma. Ann Surg 1908;48:5419.

74. Malhi H, Gores GJ, Lemasters JJ. Apoptosis and necrosis in the liver: A tale of two deaths? Hepatology 2006;43:S31-44.

75. de Groot $H$, Brecht M. Reoxygenation injury in rat hepatocytes: mediation by $\mathrm{O} 2 / \mathrm{H} 2 \mathrm{O} 2$ liberated by sources other than xanthine oxidase. Biol Chem Hoppe Seyler 1991;372:35-41.

76. Caraceni P, De Maria N, Ryu HS, et al. Proteins but not nucleic acids are molecular targets for the free radical attack during reoxygenation of rat hepatocytes. Free Radic Biol Med 1997;23:339-44.

77. Caraceni $P$, Ryu HS, van Thiel $D H$, Borle $A B$. Source of oxygen free radicals produced by rat hepatocytes during postanoxic reoxygenation. Biochim Biophys Acta 1995;1268:249-54.

78. Leist $M$, Jaattela M. Four deaths and a funeral: from caspases to alternative mechanisms. Nat Rev Mol Cell Biol 2001;2:589-98.

79. Anderson ME. Glutathione: an overview of biosynthesis and modulation. Chem Biol Interact 1998;111-112:1-14.

80. Eklow L, Moldeus $P$, Orrenius S. Oxidation of glutathione during hydroperoxide metabolism. A study using isolated hepatocytes and the glutathione reductase inhibitor 1,3-bis(2chloroethyl)-1-nitrosourea. Eur J Biochem 1984;138:459-63.

81. Dickinson DA, Forman HJ. Glutathione in defense and signaling: lessons from a small thiol. Ann N Y Acad Sci 2002;973:488-504.

82. van Wagensveld BA, van Gulik TM, Gelderblom HC, et al. Prolonged continuous or intermittent vascular inflow occlusion during hemihepatectomy in pigs. Ann Surg 1999;229:376-84.

83. Hewitt G, Halliday I, McCaigue M, Campbell G, Rowlands B, Diamond T. Mortality, endotoxaemia and cytokine expression after intermittent and continuous hepatic ischaemia. Br J Surg 1995;82:1424-6.

84. Kang KJ, Jang JH, Lim TJ, et al. Optimal cycle of intermittent portal triad clamping during liver resection in the murine liver. Liver Transpl 2004;10:794-801.

85. Reimer KA, Murry CE, Yamasawa I, Hill ML, Jennings RB. Four brief periods of myocardial ischemia cause no cumulative ATP loss or necrosis. Am J Physiol 1986;251:H1306-15.

86. Pasupathy S, Homer-Vanniasinkam S. Ischaemic preconditioning protects against ischaemia/reperfusion injury: emerging concepts. Eur J Vasc Endovasc Surg 2005;29:106-15.

87. Carini R, Albano E. Recent insights on the mechanisms of liver preconditioning. Gastroenterology 2003;125:1480-91.

88. Banga NR, Homer-Vanniasinkam S, Graham A, Al-Mukhtar A, White SA, Prasad KR. Ischaemic preconditioning in transplantation and major resection of the liver. $\mathrm{Br} J$ Surg 2005;92:528-38.

89. Murry CE, Jennings RB, Reimer KA. Preconditioning with ischemia: a delay of lethal cell injury in ischemic myocardium. Circulation 1986;74:1124-36. 
90. Kume M, Yamamoto $Y$, Saad S, et al. Ischemic preconditioning of the liver in rats: implications of heat shock protein induction to increase tolerance of ischemia-reperfusion injury. J Lab Clin Med 1996;128:251-8.

91. Matzinger $P$. The danger model: a renewed sense of self. Science 2002;296:301-5.

92. Panis Y, McMullan DM, Emond JC. Progressive necrosis after hepatectomy and the pathophysiology of liver failure after massive resection. Surgery 1997;121:142-9.

93. Ikemoto M, Tsunekawa S, Awane $M$, et al. A useful ELISA system for human liver-type arginase, and its utility in diagnosis of liver diseases. Clin Biochem 2001;34:455-61.

94. Roth E, Steininger R, Winkler $S$, et al. L-arginine deficiency after liver transplantation as an effect of arginase efflux from the graft. Transplantation 1994;57:665-9.

95. Cheng PN, Leung YC, Lo WH, Tsui SM, Lam KC. Remission of hepatocellular carcinoma with arginine depletion induced by systemic release of endogenous hepatic arginase due to transhepatic arterial embolisation, augmented by high-dose insulin: arginase as a potential drug candidate for hepatocellular carcinoma. Cancer Lett 2005;224:67-80.

96. Langle $F$, Steininger $R$, Roth $R$, et al. L-arginine deficiency and hemodynamic changes as a result of arginase efflux following orthotopic liver transplantation. Transplant Proc 1995;27:2872-3.

97. Morris SM, Jr. Arginine metabolism: boundaries of our knowledge. J Nutr 2007;137:1602S1609S. 



\section{Chapter 2}

The effect of major liver resection on hepatic ureagenesis in man

MCG van de Poll, SJ Wigmore, DN Redhead, RGH Beets-Tan, OJ Garden, JWM Greve, PB Soeters, NEP Deutz, KCH Fearon, CHC Dejong 


\section{Abstract}

Changes in hepatic ureagenesis following major hepatectomy are not well characterized. We studied the relation between urea synthesis and liver mass before and after major hepatectomy in man. Fifteen patients scheduled for resection of malignancies in otherwise healthy livers were studied. Pre- and postoperative liver volume was assessed by CT-volumetry. During surgery, a primed, continuous infusion of $\left[{ }^{13} \mathrm{C}\right]$-urea was administered intravenously and arterial blood samples were obtained hourly. ICG clearance was determined before and after resection. Seven patients underwent major hepatectomy, 8 patients underwent minor $(<5 \%$ functional liver volume (total volume minus tumour volume)) or no resection, serving as controls. Resected functional liver volume in the major hepatectomy group averaged $60 \%$. Urea synthesis per gram of functional liver tissue increased 2.6-fold following major hepatectomy maintaining whole body urea synthesis. Arterial ammonia remained unchanged throughout the study whereas following hepatectomy a hyperaminoacidemia occurred. In conclusion, immediately following major hepatectomy, urea synthesis per gram of functional liver tissue increases rapidly and proportionately to the amount of liver tissue resected, maintaining whole body urea synthesis at preoperative levels. This rapid and complete adaptation suggests that the capacity of urea synthesis is not limiting the maximum resectable volume in otherwise healthy livers. 


\section{Introduction}

Partial hepatectomy is currently the only curative treatment option for patients with colorectal liver metastases (1). Only $20 \%$ of these patients are eligible for hepatectomy with curative intent, often because radical resection would leave insufficient liver mass, leading to liver failure (2), an almost invariably lethal complication $(2,3)$. It is believed that diminished ammonia detoxification in this situation, leading to hyperammonemia, is of crucial importance. In patients without liver disease, resections of up to $70-80 \%$ are generally well tolerated (4, $5)$. In patients with underlying liver disease however, much smaller resections have been shown to induce liver failure (6). This points out the importance of both remnant liver volume and functional status of the liver following hepatectomy.

Many efforts have been made in the past to develop a tool that identifies patients at risk for liver failure following hepatectomy or that predicts the maximum resectable volume without inducing liver failure. In this respect both volumetric and functional tests as well as combinations of these have been investigated. The indocyanine green (ICG) clearance test (6) is currently considered to be the best prognostic tool, but its specificity and sensitivity are low (7). To develop a reliable tool it is probably necessary to gain insight in changes in liver physiology and mechanisms of liver failure following hepatectomy. In this way investigations for prognostic tools can be directed at factors that are truly limiting the resectable volume. In addition awareness of changes in liver physiology following liver resection is crucial to advance postoperative care. We recently showed that the hepatic reticuloendothelial system undergoes a functional adaptation following major hepatectomy but actually reaches a maximum function per gram liver, resulting in a decrease of total reticuloendothelial function (8).

Hepatocellular adaptation following major hepatectomy is not well characterized. One of the most important hepatocellular functions is the synthesis of urea from ammonia and amino acids. Diminished urea synthesis capacity in liver insufficiency leads to hyperammonemia and hepatic encephalopathy (9). Furthermore, since urea synthesis is a unique liver function (10), whole body urea synthesis can readily be related to the liver volume before and after major hepatectomy. For these reasons, it seemed important to explore the effects of major hepatectomy on urea synthesis.

We have previously demonstrated that pre- and postoperative liver volume can be measured and predicted using three-dimensionally reconstructed computerized tomography (CT) scans (11). These volumetric techniques were applied in the present study to investigate changes in urea synthesis measured 
by $\left[{ }^{13} \mathrm{C}\right]$-urea infusion, both on whole body level and per gram of functional liver tissue.

\section{Methods}

\section{Patients}

Fifteen patients scheduled for hepatectomy for secondary $(n=13)$ or primary hepatic cancer $(n=2)$ in otherwise healthy livers were included. This study was started at the Royal Infirmary of Edinburgh, Scotland, where 7 patients were enrolled. For practical reasons the study was finished at the University Hospital Maastricht, the Netherlands, where another 8 patients were studied. Surgery was performed after an overnight fast while subjects were on their standard diet in the pre-study period. As part of standard care all patients had radial artery, jugular vein and urinary catheters inserted prior to surgery. Ethical permission for the study was obtained from Ethics Committees in Edinburgh and Maastricht. Written informed consent was obtained from each individual.

\section{Surgical procedure}

Liver resection was performed as detailed previously $(12,13)$. Briefly, mobilization of the liver was followed by intraoperative ultrasound (USS) following which a decision was made regarding the appropriate surgical procedure. Major resection (defined as removal of 3 or more segments) was based on segment-oriented anatomy (13). During the resection central venous pressure was maintained below $5 \mathrm{~mm} \mathrm{Hg}$. Liver transection was performed following extrahepatic ligation of portal pedicle structures and hepatic veins using a Cavitron Ultrasonic Surgical Aspirator (CUSA system 200 Macrodissector, Cavitron Surgical Systems, Stamford, CT). Argon beam coagulation (Force GSU System; Valleylab, Boulder, CO), clips and sutures were used for haemostasis. Only in one case hepatic inflow was temporarily occluded for 15 minutes, blood flow was restored 30 minutes before the hourly arterial sample.

\section{CT imaging and volumetry}

Pre-operative liver imaging was performed according to local clinical routines. In Edinburgh computerized tomography angioportography (CTAP) was performed as described before (11). In Maastricht liver imaging was performed by 4-phase spiral-CT scans, made after the injection of contrast via an elbow vein (120-140 
cc; Omnipaque 354, Nycomed Ireland LTD, Cork, Ireland; flow rate $=4 \mathrm{~mL} / \mathrm{s}$, scan delay = 25-70-300 s), using a Toshiba Aquillion (Japan) or Elscint Twin RTS, Philips Medical Systems (Best, The Netherlands). CT-volumetry was performed as described previously (11). Liver and tumour volumes were calculated and the model was subjected to virtual resection along anatomical planes according to the intended surgical procedure. Functional liver weight was calculated by subtracting tumour volume from total liver volume, assuming a volume to weight ratio of $1 \mathrm{ml}: 1 \mathrm{~g}(11)$.

\section{Isotope studies}

Before surgery baseline blood samples were taken and a primed continuous infusion of $\left[{ }^{13} \mathrm{C}\right]$-urea (Eurisotop, Saint Aubin, France) was started and continued for six hours regardless of the course and duration of the operation (priming dose $36.5 \mu \mathrm{mol} / \mathrm{kg}$, infusion rate $7.42 \mu \mathrm{mol} / \mathrm{kg} / \mathrm{h}$ ). Isotopic steady state was defined as a variation between tracer to tracee ratios at three consecutive time-points that did not exceed $5.9 \%$, which is the coefficient of variation of the laboratory analysis.

\section{Blood sampling and processing}

Arterial blood was sampled hourly and processed as described earlier (14). Briefly, plasma proteins were precipitated using sulphosalicylic acid for amino acid assays and trichloroacetic acid for ammonia and urea assays (14). All samples were stored at $-80^{\circ} \mathrm{C}$. Samples obtained in Edinburgh were shipped on dry ice to Maastricht for analysis.

\section{Laboratory analysis}

Urea tracer-tracee ratio's were determined using liquid chromatography-mass spectrometry (15). Amino acid concentrations were measured using high performance-liquid chromatography (16), ammonia and urea concentrations with spectrophotometry (Cobas Mira S (Roche Diagnostics, Basel, Switzerland)). Arterial $\mathrm{pH}$ and $\mathrm{HCO}_{3}^{-}$was measured using an automated analyzer (GEM Premier 3000, Instrumentation Laboratory, Breda, the Netherlands). Amino acids and ammonia levels were measured in the baseline samples and in the samples obtained at the end of the experiment. 


\section{Calculations}

Isotopic enrichment $(E)$ was calculated by subtracting the tracer-tracee ratio at baseline (TTR0) from the TTR at the respective time points during the infusion:

$E=T T R-T T R 0$

[13C]-Urea infusion provides an accurate method to measure urea synthesis rate $(Q)$ during steady state conditions, using a simple standard equation for single pool steady state situations (17):

$Q=I / E$

where $I$ is the infusion rate of the tracer. We anticipated that following major hepatectomy, whole body urea synthesis rate could be decreased. Given the large pool size of urea, prohibiting a fast equilibration towards a new isotopic steady state (18), we applied a non-steady state approach to calculate the rate of urea synthesis for the second part of the tracer infusion as proposed by Steele $(19,20)$. This approach takes into account changes in urea enrichment over time $(\mathrm{dE}(\mathrm{t}) / \mathrm{dt})$ and the mean size of the urea pool $((V x \bar{u})$, where $V$ is the volume of urea distribution (total body water or $0.6 \times$ body mass) and $\bar{u}$ is the mean urea concentration over time):

$Q=[I-V \times \bar{u} \times(d E(t) / d t)] / \bar{E}$

where $\bar{E}$ is the mean urea enrichment over time. We (21) and others (18) have shown before that this approach is sensitive to relatively minor changes in urea synthesis. It is however also valid in steady state situations since $\mathrm{dE}(\mathrm{t})$ then equals zero, rendering equation 3 equal to equation 2 .

\section{Hepatic nitrogen clearance}

The ratio between urea synthesis rate and plasma a-amino nitrogen concentration (the sum of all amino acids) was calculated as a reflection of hepatic nitrogen clearance (HNC). This approach is a modification of the original calculation of functional hepatic clearance during a nitrogen challenge introduced by Vilstrup et al (22). 


\section{Indocyanine green clearance}

ICG clearance was measured before and immediately after liver resection. ICG (Akorn Inc. Buffalo Grove, IL) $(0.5 \mathrm{mg} / \mathrm{kg}$ ) was administered intravenously and absorbance of plasma at $805 \mathrm{~nm}$ was measured after 10,15 and 20 minutes using an Uvikon 923 double beam UV/VIS spectrophotometer (Kontron instruments, Watford, UK). ICG retention at 15 minutes was calculated by expressing the extinction at 15 minutes as a percentage of the theoretical extinction at 0 minutes calculated by logarithmic regression analysis.

\section{Statistics}

Results are expressed as means (SEM) or median (range) as indicated. Statistical tests used were the Mann-Whitney $U$ test and the Wilcoxon signed ranks test. Values obtained in serial measurements (before hepatectomy, after hepatectomy) were summarized to single means for each individual (23), which were subsequently tested non-parametrically. Correlations were calculated with Spearman's test for non-parametric correlations. Statistical calculations were made using SPSS 11.0 for Windows (SPSS Inc. Chicago, IL). A p-value $<0.05$ was considered to indicate statistical significance.

\section{Results}

\section{Patients}

Seven patients underwent major hepatectomy and 8 patients underwent either no $(n=4)$ or only minor $(<5 \%)$ hepatectomy (Table 1,2$)$. These 8 patients were Edinburgh or Maastricht or between major hepatectomy and control patients. There was no major morbidity or mortality in the 15 patients studied and no liver insufficiency was observed in the major hepatectomy group. Mean (SEM) arterial $\mathrm{pH}$ was $7.4(0.04)$ and remained unchanged following hepatectomy, mean (SEM) arterial $\mathrm{HCO}_{3}{ }^{-}$concentration was $22.4(0.5) \mathrm{mmol} / \mathrm{l}$ and also remained unchanged following hepatectomy.

\section{Liver volumes}

Mean liver volume in the whole group $(n=15)$ was 1989 (158) mls, mean functional liver volume (liver volume minus tumour volume) was 1757 (137) mls.In the major hepatectomy group $(n=7)$, total liver volume was 1763 (249) mls, functional liver volume was 1512 (178) mls, resected functional volume 


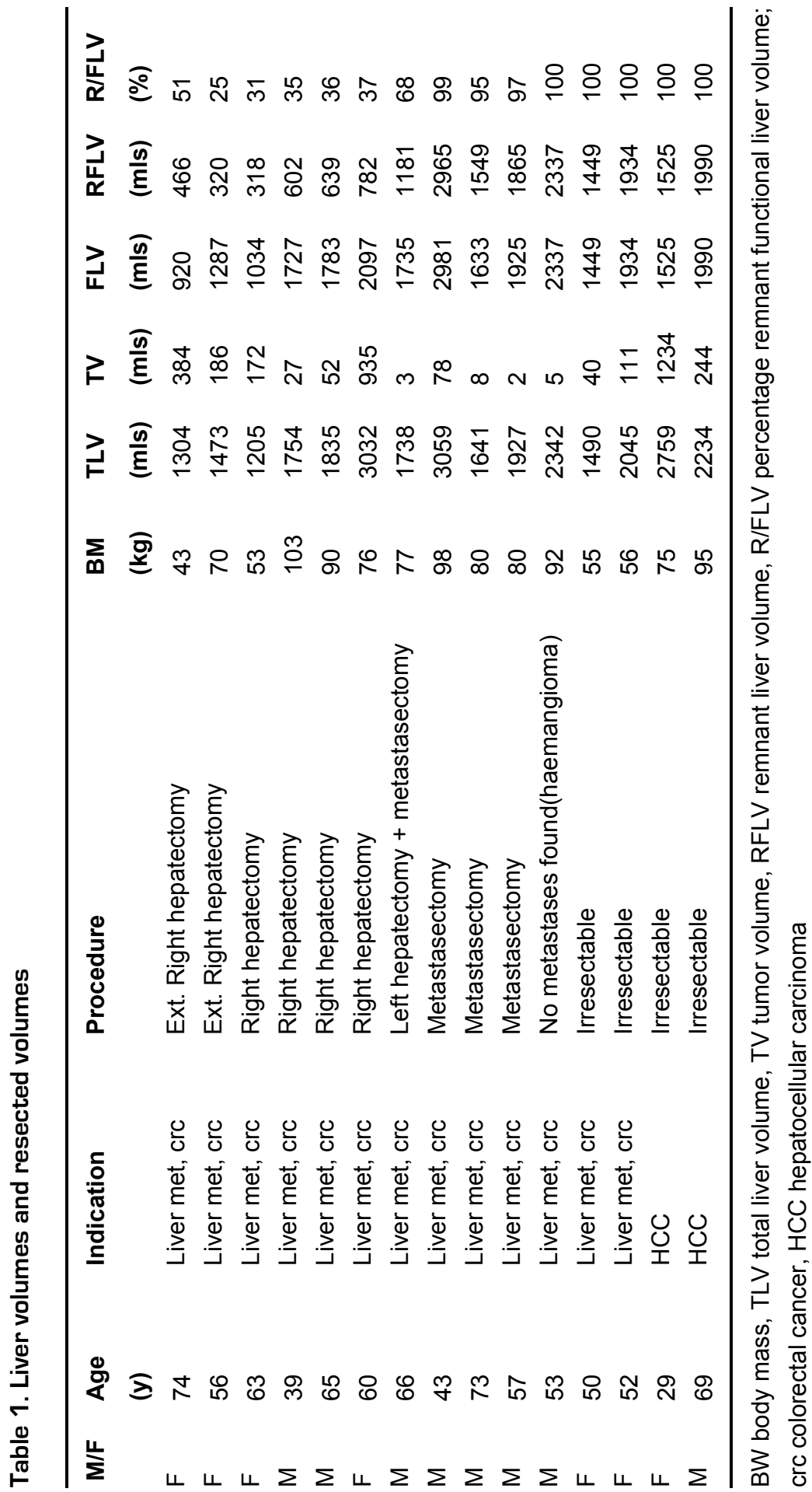


Table 2. Patient Characteristics

\begin{tabular}{llll}
\hline & $\begin{array}{l}\text { Major } \\
\text { hepatectomy }\end{array}$ & Controls & p-value \\
& $3: 4$ & $3: 5$ & 0.486 \\
Female:male & $60(11.0)$ & $53(13.9)$ & 0.281 \\
Age (years) & $25.2(4.5)$ & $26.3(5.3)$ & 0.563 \\
BMl (kg·m-2) & $190(10)$ & $150(27)$ & 0.315 \\
Duration operation (min) & $539(139)$ & $374(213)$ & 0.494 \\
Blood loss (ml) & $33.7(16.2)$ & $61.2(41.3)$ & 0.643 \\
Alanine aminotransferase (U/L) & $101(15.3)$ & $138(26.0)$ & 0.344 \\
Alkaline phosphatase (U/L) & $44.5(0.5)$ & $37.3(4.4)$ & 0.370 \\
Albumin (g/L) & & & \\
\hline
\end{tabular}

was $896(133) \mathrm{mls}(60$ (6) \%) and the residual volume 429 (134) mls. In the control group, $<5 \%$ of functional liver volume was resected (mean $1.3(0.8) \%$ ). The correlation between predicted and actual resected liver weight (not shown) was consistent with our previous findings (11).

\section{Urea synthesis rate}

In all patients isotopic steady state was initially present during the experiment (Figure 1). After three hours, a small increase of $\left[{ }^{13} \mathrm{C}\right]$-urea enrichment was found, which was similar in both groups (Figure 1). Before hepatectomy, mean whole body urea synthesis rate calculated from isotope data was not significantly different between major hepatectomy patients and controls $(p=0.61)$. Following major hepatectomy whole body urea synthesis

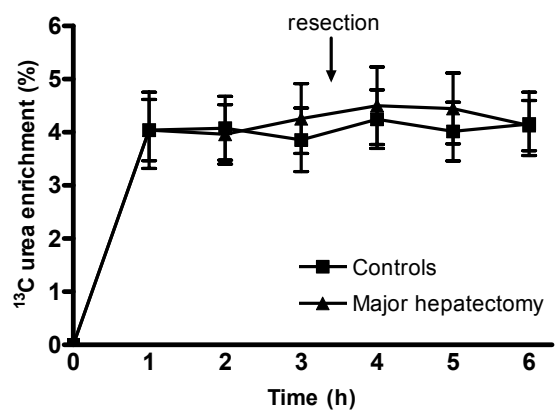

Figure 1. Mean (SEM) isotopic enrichment in control patients ( $\mathbf{\square}$ ) and patients undergoing major hepatectomy $(\mathbf{\Delta})$. The arrow indicates the time point of hepatectomy. In all patients isotopic steady state was achieved before liver resection, thereafter a small increase of isotopic enrichment occurred. No differences were observed between both groups. (2-way ANOVA; $p=0.003$ for "time effect", $p=0.67$ for "group effect", $p=0.56$ for "interaction"). 
decreased slightly $(p=0.007)$. The absolute value $(p=0.96)$ and the decrease in whole body urea synthesis was similar in patients who underwent major hepatectomy (from 223 (24) to 203 (23) $\mu \mathrm{mol} / \mathrm{kg} / \mathrm{h}$ ) and in control patients (from $206(20)$ to $196(19) \mu \mathrm{mol} / \mathrm{kg} / \mathrm{h})(p=0.35)$ (Figure 2). However, when calculated per gram of functional liver tissue calculated from the CT-scans, urea synthesis per gram of liver increased 2.6-fold $(p=0.02)$ immediately following major liver resection (Figure 3 ). Mean whole body urea synthesis rate at steady state for all patients at baseline was 214.7 (8.4) $\mu \mathrm{mol} / \mathrm{kg}$ body weight/h and mean urea synthesis rate per gram liver at baseline was 9.5 (1.3) $\mu \mathrm{mol} / \mathrm{g}$ liver/h.

\section{Ammonia and urea concentrations}

Arterial ammonia concentrations were similar before and immediately after hepatectomy and in both groups (Table 3). Urea concentrations did not change significantly during the study in both groups: from $3.82(0.5) \mathrm{mmol} / \mathrm{l}$ to $3.75(0.5)$ $\mathrm{mmol} / \mathrm{l}$ in the major hepatectomy group $(\mathrm{p}=0.4)$ and from $3.63(0.3) \mathrm{mmol} / \mathrm{l}$ to $3.39(0.2) \mathrm{mmol} / \mathrm{l}$ in the control group $(p=0.3)$.

\section{Plasma amino acids and nitrogen clearance}

Following major hepatectomy a generalized hyperaminoacidemia (mean [a-AN] $+53(26) \%$ from baseline value, $p=0.046)$ occurred whereas the $a-A N$ concentration in the control group decreased $(-17(7) \%), p<0.05)$. Urea synthesis rates were significantly correlated with total $\alpha-A N$ at baseline (Spearman's rho=0.836, $\mathrm{p}<0.001$ ) (figure 4). This correlation was maintained in control patients but in patients undergoing major hepatectomy a significant decrease in the ratio between urea synthesis and a-AN concentration occurred (Figure $5 \mathrm{~A}$ ), indicating that hepatic nitrogen clearance is impaired following major hepatectomy (Figure 5B).

\section{Indocyanine green clearance and hepatic plasma flow}

Immediately following major hepatectomy median (range) ICG retention at 15 minutes (ICGR15) was 21.7 (5.7) \%. This was not significantly different from ICGR15 before liver resection (21.6 (6.2) \%) or from ICGR15 in the control group (22.0 (5.6) \%) (Figure 6). Since ICG clearance is dependent on and therefore a measure for hepatic plasma flow it can be concluded that total hepatic plasma flow remains unchanged following major hepatectomy but that hepatic plasma flow per gram liver increased proportionate to the resected volume. 


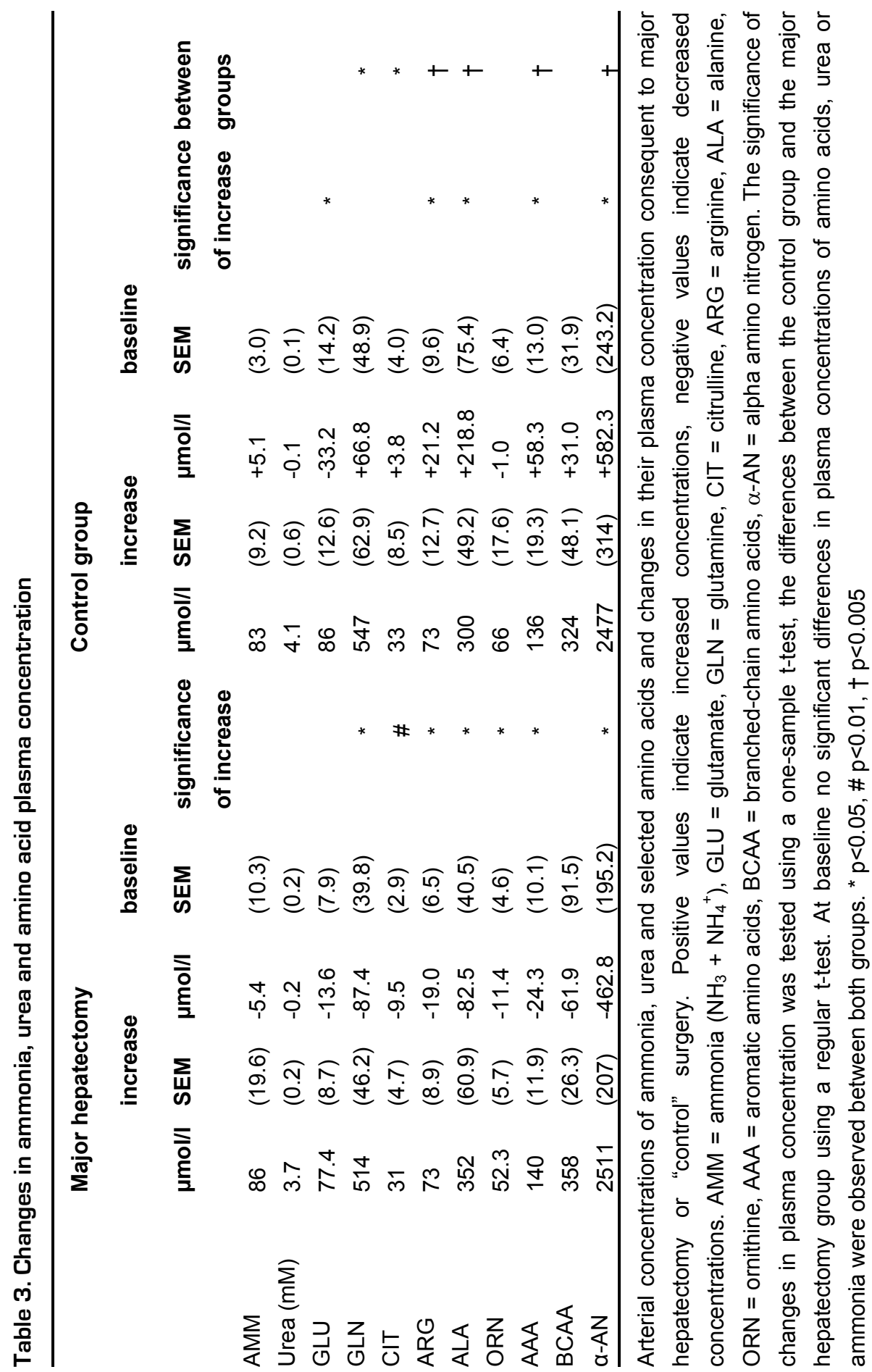




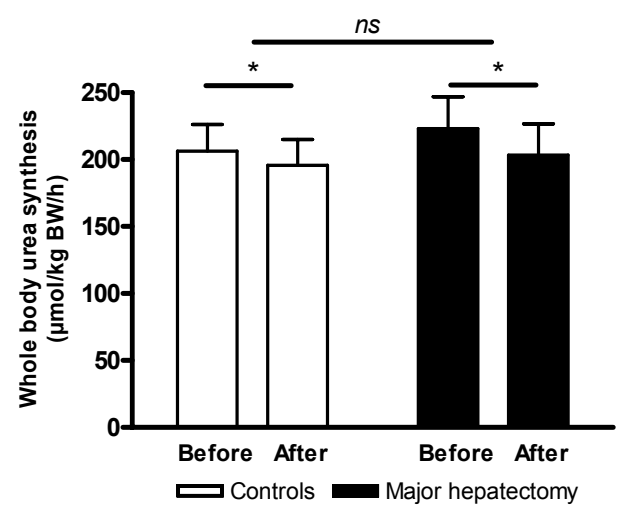

Figure 2. Whole body urea synthesis rate before and after hepatectomy expressed as the mean (SEM) of the individual means at isotopic steady state. A small but statistically significant difference was observed in both groups but major hepatectomy did not affect whole body urea synthesis rate compared with the control group. BW = body weight

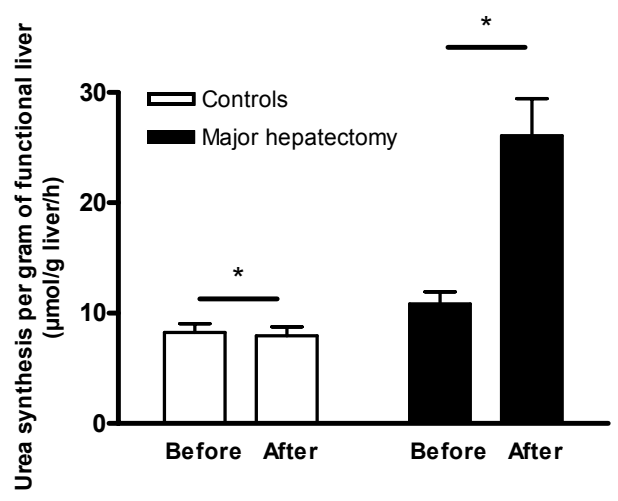

Figure 3. Urea synthesis per gram liver before and after major hepatectomy. Urea synthesis per gram liver increases proportionate to the volume resected $(p=0.018)$.

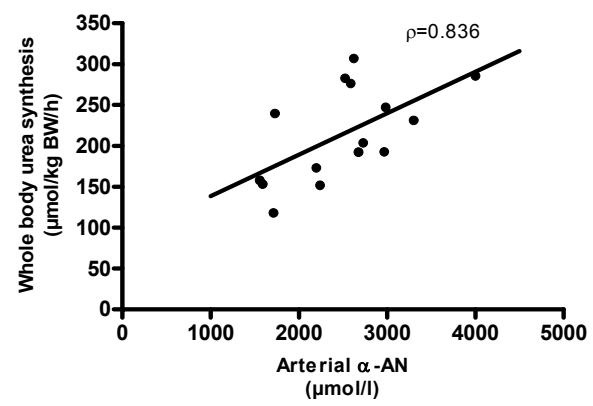

Figure 4. Significant correlation at baseline between $\alpha-A N$ and urea synthesis rate (Spearman's rho=0.836, p<0.001). BW = body weight 


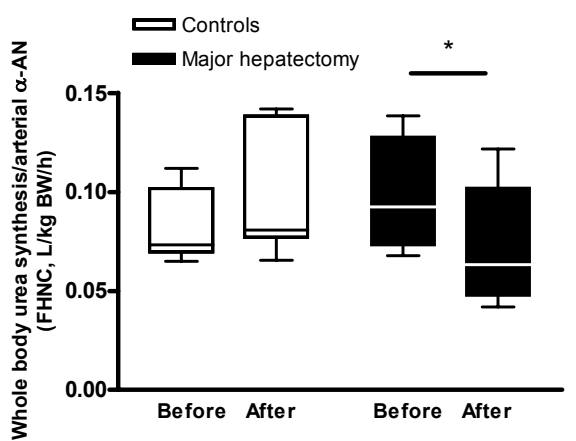

$A$

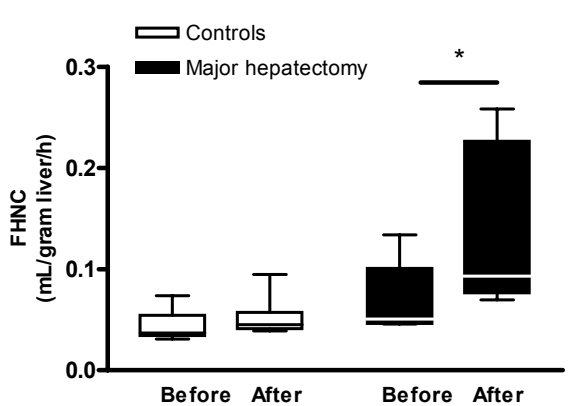

B

Figure 5

Median (range) ratio between $\alpha-A N$ levels and ureagenesis as a measure for hepatic nitrogen clearance (HNC) on whole body level $(A)$ and expressed per gram of functional liver tissue (B). Whole body HNC was unchanged in the control group since both $\alpha-A N$ and ureagenesis decreased. Following major hepatectomy, HNC decreased significantly $(p=0.046)$, requiring a significant increase in $\alpha-A N$ levels to maintain urea synthesis. HNC per gram liver increased significantly following major hepatectomy indicating hepatocellular functional adaptation. $B W=$ body weight

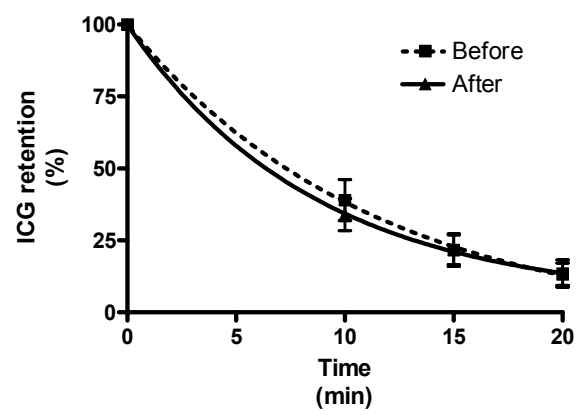

Figure 6. ICG clearance in 7 patients undergoing major hepatectomy, measured before and immediately after hepatectomy expressed as retention (\%) over time. The clearance rate of ICG remained unchanged.

\section{Discussion}

This study was designed to investigate changes in nitrogen metabolism and urea synthesis induced by major hepatectomy in man. We found increased plasma concentrations of a.o. glutamine, alanine, aromatic amino acids and 
alpha-amino nitrogen which are characteristic changes, indicative for loss of liver function. Moreover, plasma levels of glutamate, an important product of hepatic amino acid metabolism decreased significantly following major hepatectomy, also suggesting hepatic dysfunction. Whole body urea synthesis rates, measured one hour after major hepatectomy were slightly decreased compared to those measured before major hepatectomy but similar to controls, suggesting that this decrease is due to the gross surgical trauma and not to the hepatectomy. Moreover a functional adaptation occurred, increasing urea synthesis per gram liver up to 2.6 -fold, proportionate to the resected volume.

Whole body urea synthesis rate measured by $\left[{ }^{13} \mathrm{C}\right]$-urea infusion (approximately $215 \mu \mathrm{mol} / \mathrm{kg} / \mathrm{h}$ ) is comparable to literature data (17). Urea synthesis rate per gram of functional liver calculated by CT volumetry approximates $10 \mu \mathrm{mol} / \mathrm{g}$ liver/h. Following resection of $60 \%$ functional liver volume, this value increases to about $26 \mu \mathrm{mol} / \mathrm{g}$ liver/h. This adaptation occurs exceedingly rapidly, at least within 60 minutes but probably instantaneously. To our knowledge, this is the first study where in vivo in man absolute values for urea synthesis per gram of liver have been calculated.

Expressing liver function per gram liver and predicting post-hepatectomy liver volume may open new perspectives in the pre-operative assessment of patients considered for hepatectomy. If the preoperative as well as the maximum rate per gram liver of a specific function is known, it can be calculated how much liver function per gram will be needed to maintain homeostasis. To successfully apply volumetric and functional assessment as a sensitive pre-operative selection tool, it will be necessary to identify liver functions that are truly limiting the maximum resectable volume. From the present observations it becomes clear that the urea cycle can adapt amply sufficient following major hepatectomy.

The maximum rate of urea synthesis in man is unknown, but urea synthesis can increase at least $800 \%$ in healthy subjects and $600 \%$ in patients with liver cirrhosis during an intravenous nitrogen challenge (22). This is very well in concordance with the present study, showing that resection of up to $75 \%$ of the functional liver volume leads to a rapid and complete adaptation of urea synthesis per gram liver. To force urea synthesis to an $800 \%$ increase per gram liver by hepatectomy, however, would require a resection of almost $90 \%$ of the functional liver volume (Figure 7), provided that the capacity of urea synthesis per gram liver is maintained following hepatectomy. Clearly such an extensive resection would almost invariably lead to liver insufficiency with potentially lethal consequences (24). We have shown recently that in patients with a normal liver, resection of $73.4 \%$ or more of the functional liver volume is predictive of liver dysfunction following hepatectomy with high positive and negative predictive values (25). Such a "maximal" resection would require an increase of urea 


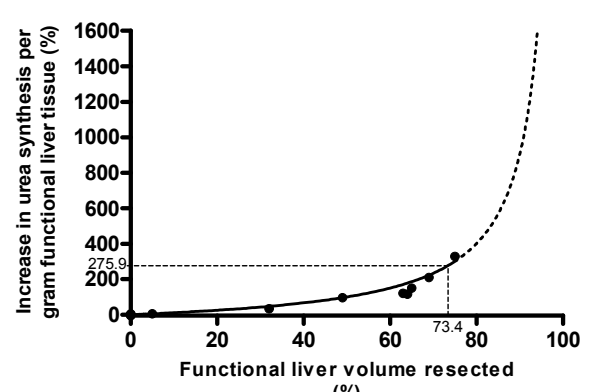

(\%)

Figure 7. Increase in urea synthesis per gram liver in relation to the resected liver volume. The dots represent individual patients in the present study. From the theoretical prediction line it can be conceived that beyond 70-80 \% hepatectomy the demanded functional adaptation increases exponentially, rapidly increasing the risk of liver failure. The value of $74.4 \%$ is derived from recent work from our group (25). In that study a residual functional liver volume of $26.6 \%$ or less in patients with a normal liver was found to be predictive of liver insufficiency following hepatectomy. In this case urea synthesis per gram liver has to increase almost $300 \%$.

synthesis per gram liver of "only" $290 \%$, suggesting that the capacity of urea synthesis is not a priori limiting the maximum tolerated extent of resection in patients with a normal liver. It should be realized however, that the aforementioned nitrogen challenges (22) were conducted in conscious subjects and that factors like anesthesia, surgical stress and the metabolic burden of liver regeneration may very well limit the maximum capacity for urea synthesis. Therefore the actual maximum urea synthesis rate per gram liver following hepatectomy still is unknown. Moreover it remains unknown whether urea synthesis may be limiting the maximum resectable volume in patients with liver disease. Similar studies as the present one in patients with different grades of cirrhosis could shed light on this issue.

We recently showed that the clearance capacity of the hepatic reticuloendothelial system (RES) increases per gram liver following liver surgery. Following major hepatectomy however, this response is only incomplete, resulting in diminished total RES activity (8). Although RES-function is not immediately vital for homeostasis, it is important in coping with postoperative endotoxemia and bacteremia. RES dysfunction may predispose for infections and may as such indirectly affect hepatocellular synthetic capacity (25). Regarding its early saturability it may be an important factor limiting the resectable liver volume.

The mechanism behind the rapid functional adaptation of the liver following hepatectomy has been subject of many studies. Most of these have focused on changes in gene expression within the first few hours following hepatectomy. It 
has become clear that there is a reprioritization of liver functions with a downregulation of genes that are not vital for homeostasis or liver regeneration and an upregulation of genes that are $(26,27)$. Although there is a rapid activation of transcription factors and mRNA expression (27-29), no changes in protein expression have been observed earlier than 2 hours after hepatectomy in the rat (29). The swiftness of the events in the present study demonstrates for the first time that there is no absolute need for gene transcription and protein expression to initiate the metabolic response and to maintain urea homeostasis. The rate of urea synthesis is directly dependent on nitrogen intake and protein breakdown, reflected by the plasma concentration of $\alpha-A N(22,30-32)$. This was also shown in the present study by the correlation between $\alpha-A N$ levels and urea synthesis rate. Plasma levels of $\alpha-A N$ needed to maintain ureagenesis are dependent on liver function and are increased in patients with liver disease. We hypothesize that $\alpha$-AN levels increased following major hepatectomy due to an acute temporary reduction of ureagenesis. Simultaneously these increasing systemic and portal vein a-AN levels stimulate hepatic ureagenesis, leading to a rapid complete restoration of whole body urea synthesis, apparently within one hour from liver resection. This effect may be accelerated because all portal blood is now redirected to the small liver remnant. In addition increased ammonia load to the remnant liver may stimulate glutaminase activity, leading to a feed forward stimulation of urea synthesis (33).

By measuring ICG clearance before and after major hepatectomy we evidenced an immediate increase in blood flow per gram liver. This probably enhances substrate supply, limiting the increase in plasma $\alpha-A N$ levels needed to maintain urea synthesis. This view is supported by an increased hepatic nitrogen clearance per gram liver following major hepatectomy. The importance of preservation of hepatic blood flow following major hepatectomy is also supported by clinical data $(34,35)$.

Arterial ammonia levels remained unchanged in both groups, implying that arterial ammonia is not a driving force for hepatic ureagenesis and that following major hepatectomy the liver remains capable of adequately removing intestinal derived ammonia.

\section{Summary}

In this study we have shown for the first time in man that liver function and liver volume can simultaneously be assessed in vivo, yielding absolute data on liver function per gram liver tissue. This method is useful to study physiological changes following major hepatectomy and may be applied to assess candidates for major hepatectomy. Following major hepatectomy urea synthesis per gram liver increases rapidly due to an increased $\alpha$-AN plasma concentration and an 
increased hepatic blood flow per gram liver. Since the adaptive capacity of the urea cycle apparently exceeds the maximum resectable liver volume, it is not likely that urea synthesis limits the maximal extent of hepatectomy. 


\section{References}

1. Ruers T, Bleichrodt RP. Treatment of liver metastases, an update on the possibilities and results. Eur J Cancer 2002;38:1023-33.

2. Pol B, Campan P, Hardwigsen J, Botti G, Pons J, Le Treut YP. Morbidity of major hepatic resections: a 100-case prospective study. Eur J Surg 1999;165:446-53.

3. Shirabe K, Shimada M, Gion T, et al. Postoperative liver failure after major hepatic resection for hepatocellular carcinoma in the modern era with special reference to remnant liver volume. J Am Coll Surg 1999;188:304-9.

4. Shoup M, Gonen M, D'Angelica M, et al. Volumetric analysis predicts hepatic dysfunction in patients undergoing major liver resection. J Gastrointest Surg 2003;7:325-30.

5. Nagasue $N$, Yukaya $H$, Ogawa $Y$, Kohno $H$, Nakamura $T$. Human liver regeneration after major hepatic resection. A study of normal liver and livers with chronic hepatitis and cirrhosis. Ann Surg 1987;206:30-9.

6. Kubota K, Makuuchi M, Kusaka K, et al. Measurement of liver volume and hepatic functional reserve as a guide to decision-making in resectional surgery for hepatic tumors. Hepatology 1997;26:1176-81.

7. Schneider PD. Preoperative assessment of liver function. Surg Clin North Am 2004;84:35573.

8. Schindl MJ, Millar A, Redhead DN, et al. The adaptive response of the reticulo-endothelial system to major liver resection in man. Ann Surg 2006;243:507-14.

9. Olde Damink SW, Deutz NE, Dejong $C H$, Soeters $P B$, Jalan $R$. Interorgan ammonia metabolism in liver failure. Neurochem Int 2002;41:177-88.

10. Meijer AJ, Lamers WH, Chamuleau RA. Nitrogen metabolism and ornithine cycle function. Physiol Rev 1990;70:701-48.

11. Wigmore SJ, Redhead DN, Yan XJ, et al. Virtual hepatic resection using three-dimensional reconstruction of helical computed tomography angioportograms. Ann Surg 2001;233:221-6.

12. Dejong CHC, Garden OJ. Neoplasms of the liver. In: Majid AA, Kingsnorth A, eds. Advanced surgical practice. London: Greenwich Medical Media, 2003:146-156.

13. Finch MD, Crosbie JL, Currie E, Garden OJ. An 8-year experience of hepatic resection: indications and outcome. Br J Surg 1998;85:315-9.

14. Olde Damink SW, Jalan R, Deutz NE, et al. The kidney plays a major role in the hyperammonemia seen after simulated or actual Gl bleeding in patients with cirrhosis. Hepatology 2003;37:1277-85.

15. van Eijk HM, Rooyakkers DR, Soeters PB, Deutz NE. Determination of amino acid isotope enrichment using liquid chromatography-mass spectrometry. Anal Biochem 1999;271:8-17.

16. van Eijk HM, Rooyakkers DR, Deutz NE. Rapid routine determination of amino acids in plasma by high-performance liquid chromatography with a 2-3 microns Spherisorb ODS II column. J Chromatogr 1993;620:143-8.

17. Jahoor F, Wolfe RR. Reassessment of primed constant-infusion tracer method to measure urea kinetics. Am J Physiol 1987;252:E557-64.

18. Hamadeh MJ, Hoffer LJ. Tracer methods underestimate short-term variations in urea production in humans. Am J Physiol 1998;274:E547-53.

19. Steele R. Influences of glucose loading and of injected insulin on hepatic glucose output. Ann N Y Acad Sci 1959;82:420-30.

20. Gastaldelli A, Coggan AR, Wolfe RR. Assessment of methods for improving tracer estimation of non-steady-state rate of appearance. J Appl Physiol 1999;87:1813-22.

21. Engelen MP, Deutz NE, Mostert R, Wouters EF, Schols AM. Response of whole-body protein and urea turnover to exercise differs between patients with chronic obstructive pulmonary disease with and without emphysema. Am J Clin Nutr 2003;77:868-74. 
22. Vilstrup $H$. Synthesis of urea after stimulation with amino acids: relation to liver function. Gut 1980;21:990-5.

23. Matthews JN, Altman DG, Campbell MJ, Royston P. Analysis of serial measurements in medical research. Bmj 1990;300:230-5.

24. Lodge JP, Menon KV, Fenwick SW, Prasad KR, Toogood GJ. In-contiguity and nonanatomical extension of right hepatic trisectionectomy for liver metastases. $\mathrm{Br} J$ Surg 2005;92:340-7.

25. Schindl MJ, Redhead DN, Fearon KC, Garden OJ, Wigmore SJ. The value of residual liver volume as a predictor of hepatic dysfunction and infection after major liver resection. Gut 2005;54:289-96.

26. Taub R. Liver regeneration: from myth to mechanism. Nat Rev Mol Cell Biol 2004;5:836-47.

27. Tygstrup N, Bak S, Krog B, Pietrangelo A, Shafritz DA. Gene expression of urea cycle enzymes following two-thirds partial hepatectomy in the rat. $J$ Hepatol 1995;22:349-55.

28. Leu JI, Crissey MA, Leu JP, Ciliberto G, Taub R. Interleukin-6-induced STAT3 and AP-1 amplify hepatocyte nuclear factor 1-mediated transactivation of hepatic genes, an adaptive response to liver injury. Mol Cell Biol 2001;21:414-24.

29. Haber BA, Chin S, Chuang E, Buikhuisen W, Naji A, Taub R. High levels of glucose-6phosphatase gene and protein expression reflect an adaptive response in proliferating liver and diabetes. J Clin Invest 1995;95:832-41.

30. Bianchi G, Marchesini G, Vilstrup H, et al. Hepatic amino-nitrogen clearance to urea-nitrogen in control subjects and in patients with cirrhosis: a simplified method. Hepatology 1991;13:460-6.

31. Rafoth RJ, Onstad GR. Urea synthesis after oral protein ingestion in man. $J$ Clin Invest 1975;56:1170-4.

32. Hamberg $\mathrm{O}$, Nielsen $\mathrm{K}$, Vilstrup $\mathrm{H}$. Effects of an increase in protein intake on hepatic efficacy for urea synthesis in healthy subjects and in patients with cirrhosis. J Hepatol 1992;14:237-43.

33. Haussinger D. Regulation of hepatic ammonia metabolism: the intercellular glutamine cycle. Adv Enzyme Regul 1986;25:159-80.

34. Bruix J, Castells A, Bosch J, et al. Surgical resection of hepatocellular carcinoma in cirrhotic patients: prognostic value of preoperative portal pressure. Gastroenterology 1996;111:101822.

35. Kawasaki T, Moriyasu F, Kimura T, Someda H, Fukuda Y, Ozawa K. Changes in portal blood flow consequent to partial hepatectomy: Doppler estimation. Radiology 1991;180:373-7. 



\section{Chapter 3}

\section{Hepatosplanchnic and}

\section{renal ammonia release}

before and after major

hepatectomy

MCG van de Poll, GC Ligthart-Melis, SWM Olde Damink, PAM van Leeuwen, RGH Beets-Tan, NEP Deutz, SJ Wigmore, PB Soeters, CHC Dejong 


\section{Abstract}

The gut is classically seen as the main source of circulating ammonia; however the contribution of the intestines to systemic ammonia production may be limited by hepatic extraction of portal-derived ammonia. Recent data suggest that the kidney may be more important than the gut for systemic ammonia production. Aim of this study was to quantify the role of the kidney, intestines and liver in interorgan ammonia trafficking in humans with a normal liver function. In addition, we studied changes in interorgan nitrogen metabolism caused by major hepatectomy. From twenty-one patients undergoing surgery, blood was sampled from the portal, hepatic and renal veins to assess intestinal, hepatic and renal ammonia metabolism, in 7 cases blood sampling was repeated after major hepatectomy. Intestinal ammonia release was equalled by hepatic ammonia uptake, precluding systemic release of intestinal-derived ammonia. In contrast, the kidneys released ammonia to the systemic circulation. Major hepatectomy led to increased concentrations of ammonia and amino acids in the systemic circulation. However transsplanchnic concentration gradients after major hepatectomy were similar to baseline values, indicating the rapid institution of a new metabolic equilibrium. In conclusion, systemic ammonia release is determined by the kidney and not by the intestines in humans with a normal liver. After major hepatectomy, hepatic ammonia clearance is well-preserved. 


\section{Introduction}

The gut is the major ammonia producing organ in mammals and consequently intestinal-derived ammonia is regarded as the source of hyperammonemia after ingestion of large amounts of protein or an upper gastrointestinal (GI) bleed (15). However, since the liver has the capability to scavenge portal ammonia either by urea synthesis or by glutamine synthesis, not all intestinal-derived ammonia reaches the systemic circulation.

Hyperammonemia has been associated with an impaired capability of the liver to remove ammonia. This can be due to portosystemic shunting which prohibits exposure of portal blood to the liver cells. In addition it has been suggested that reduction of hepatocellular functional capacity by chronic or acute liver disease reduces hepatic ammonia clearance and increases splanchnic ammonia release (6). However, while the detrimental effects of portosystemic shunting on hepatic ammonia clearance is evident (7), data on "hepatocellular dysfunction" are less convincing since hepatocytes appear to have a considerable functional reserve. Accordingly, recent studies from our group showed no net splanchnic ammonia release in patients with chronic liver disease (8). Instead, hyperammonemia appeared to be related to increased renal ammonia production. These observations were recognized as an indication that the treatment of hyperammonemia should probably include modulation of renal ammonia metabolism $(5,9,10)$. The potential importance of renal ammonia metabolism for systemic ammonia levels is nicely exemplified by the aggravation of hepatic encephalopathy by hypokalemia, which leads to increased ammonia production in the proximal tubule $(11,12)$.

Presently no data on hepatic and renal ammonia metabolism in humans with a non-cirrhotic, non-shunted liver are at hand. This is due to limited accessibility of the portal vein in humans. In patients undergoing liver surgery for colorectal liver metastases, the non-tumorous parenchyma is generally well-preserved and no portosystemic shunting is present. Simultaneously the portal, hepatic and renal veins are relatively easily accessible for blood sampling. Moreover, major hepatectomy provides an excellent opportunity to study the hepatocellular response to an increased metabolic burden after an acute and substantial loss of functional liver mass. 


\section{Methods}

\section{Patients}

Twenty-one patients (4 Females) without liver dysfunction, renal failure or metabolic disease undergoing upper $\mathrm{Gl}$ surgery (17 liver resections, 1 gastrectomy, 1 duodenal resection, 2 pancreaticoduodenectomies) were studied after an overnight fast (12 hours) (Table 1). None of the patients were jaundiced and none of them had been on chemotherapy, radiotherapy or other oncological treatment in the last 4 weeks preceding the operation. Patients were on their standard oral diets in the pre-study period. One patient used amiloride/hydrochlorothiazide (5/50 mg/day) and one patient used penicillin (500 mg/day) for erysipelas. These drugs may affect renal and intestinal ammonia metabolism, but the data from these patients did not show extreme values in the present study. Patient characteristics are summarized in Table 1. The study was approved by the Medical Ethical Committee, University Hospital Maastricht and each subject gave written informed consent.

Table 1. Patient Characteristics

\begin{tabular}{ll}
\hline Parameter & Median (range) \\
Male/Female & $17 / 4^{\mathrm{A}}$ \\
Colorectal cancer liver metastases/Melanoma liver metastasis// & $15 / 1 / 2 / 1 / 2^{\mathrm{A}}$ \\
Pancreatic cancer/Gastric cancer/Benign disease & \\
Age (years) & $62(28-76)$ \\
Weight $(\mathrm{kg})$ & $91(63-134)$ \\
BMI $\left(\mathrm{kg} / \mathrm{cm}^{2}\right)$ & $29.2(22.5-40.0)$ \\
AST $(\mathrm{IU} / \mathrm{L})$ & $23(15-35)$ \\
PT $(\mathrm{s})$ & $10.6(9.7-11.6)$ \\
Creatinine $(\mu \mathrm{M})$ & $85(55-105)$ \\
Urea $(\mathrm{mM})$ & $5.1(3.2-6.8)$ \\
\hline
\end{tabular}

${ }^{A}$ absolute numbers

\section{Anesthesia and surgery}

All patients were anesthetised according to departmental routines using isoflurane and propofol and epidural catheter analgesia. Central venous and radial artery catheters were placed for monitoring arterial and central venous blood pressure. Urine output was monitored by transurethral catheterization. Body temperature was kept constant using a Bair Hugger system (Arizant 
Healthcare Inc. Eden Prairie, MN). Blood sampling was performed within one hour from the start of the operation, before organ transection. In cases requiring liver resection, some additional dissection was required to expose the right renal vein. In cases of peripancreatic dissection, some additional time was spent to expose the suprahepatic veins if necessary.

\section{Assessment of ammonia flux across the gut, liver and kidney}

After exposure of the right renal vein, the portal vein and a major hepatic vein, before organ transection, intestinal, renal and hepatic blood flows were measured as described elsewhere $(13,14)$. Immediately thereafter, $5 \mathrm{mls}$ blood were drawn from these vessels by direct puncture. Simultaneously $5 \mathrm{mls}$ arterial blood were drawn from the radial artery catheter. Net organ fluxes were calculated as arteriovenous concentration difference times organ plasma flow. Splanchnic flux was calculated as hepatic venous - arterial concentration difference times splanchnic flow (portal + hepatic artery flow). Hepatic flux was calculated by subtracting intestinal flux from splanchnic flux. Flux was expressed as $\mu \mathrm{mol} / \mathrm{kg}$ body weight $/ \mathrm{h}(13,14)$.

\section{Duplex flow measurement}

Organ blood flow was measured by means of colour Doppler ultrasound (Aloka Prosound SSD 5000, Aloka Co., Ltd, Tokyo, Japan). Briefly, time-averaged mean velocities of the blood stream and cross-sectional area of the portal vein, hepatic artery and right renal vein were measured. Blood flow was calculated by multiplying the cross-sectional area of the vessel with the velocity of the blood stream. Portal venous and hepatic arterial blood flows were measured before their hilar bifurcations. Plasma flow was calculated by correcting blood flow for hematocrit $(\mathrm{PF}=\mathrm{BF} \times(1-\mathrm{Ht}))$. Hepatic (and splanchnic) plasma flow was calculated by adding up plasma flow in the portal vein and hepatic artery. Total renal flow was calculated by multiplying the flow through the right kidney by two.

\section{Blood processing and laboratory analyses}

After withdrawal, blood was immediately transferred to pre-chilled heparinized tubes (BD Vacutainer, Becton, Dickinson and co., Franklin Lakes, NJ) and put on ice. Whole blood was centrifuged at $4000 \times \mathrm{G}$ and plasma was deproteinized using sulphosalicylic acid (SSA) for amino acid analysis and trichloroacetic acid (TCA) for ammonia analysis as described before (7). $\mathrm{pH}$ was measured immediately using an automated analyser (GEM Premier 3000, Instrumentation 
Laboratory, Breda, the Netherlands). Amino acids were measured by HPLC, ammonia by a kinetic enzyme assay as detailed before $(7,15)$.

\section{Effects of major hepatectomy on interorgan ammonia flux}

Seven of the 21 patients underwent major hepatectomy (resection of 3 or more liver segments $(\approx 50 \%$ liver volume)). In these patients blood sampling was repeated immediately following hepatectomy to study the effects of major hepatectomy on hepatic ammonia clearance and systemic ammonia production.

\section{Statistics}

Data are presented as mean (SEM). Arteriovenous concentration differences were tested versus zero using a one-sample t-test with a theoretical mean of zero, correlations were calculated using Pearson's test. A p-value of $<0.05$ was regarded to indicate statistical significance. Statistical calculations were made using Prism 4.0 for Windows (GraphPad Software Inc. San Diego, CA).

\section{Results}

\section{Patients}

At the time of baseline blood sampling ( $<1$ hour following laparotomy) blood loss was negligible, urinary output $62.7(8.8) \mathrm{mls} / \mathrm{h}$ and arterial $\mathrm{pH} 7.38(0.02)$. Blood flows measured with Doppler ultrasound were 799 (130) $\mathrm{mls} / \mathrm{min}$ (portal), 1247 (156) $\mathrm{mls} / \mathrm{min}$ (hepatosplanchnic) and 768 (99) $\mathrm{mls} / \mathrm{min}$ (kidneys) which is in agreement with our previous data (16).

\section{Splanchnic ammonia exchange}

At baseline steady state blood sampling, the intestines released ammonia at a similar rate as they consumed glutamine, underlining the stoichiometric relationship between intestinal glutamine and ammonia metabolism (Table 2). Intestinal ammonia release was equalled by hepatic ammonia uptake (Figure 1), so that at baseline net splanchnic ammonia release was not significantly different from zero (Figure 2). Consequently at steady state in humans without portosystemic shunting the contribution of the splanchnic area and hence the intestines to systemic ammonia release appears to be negligible. 


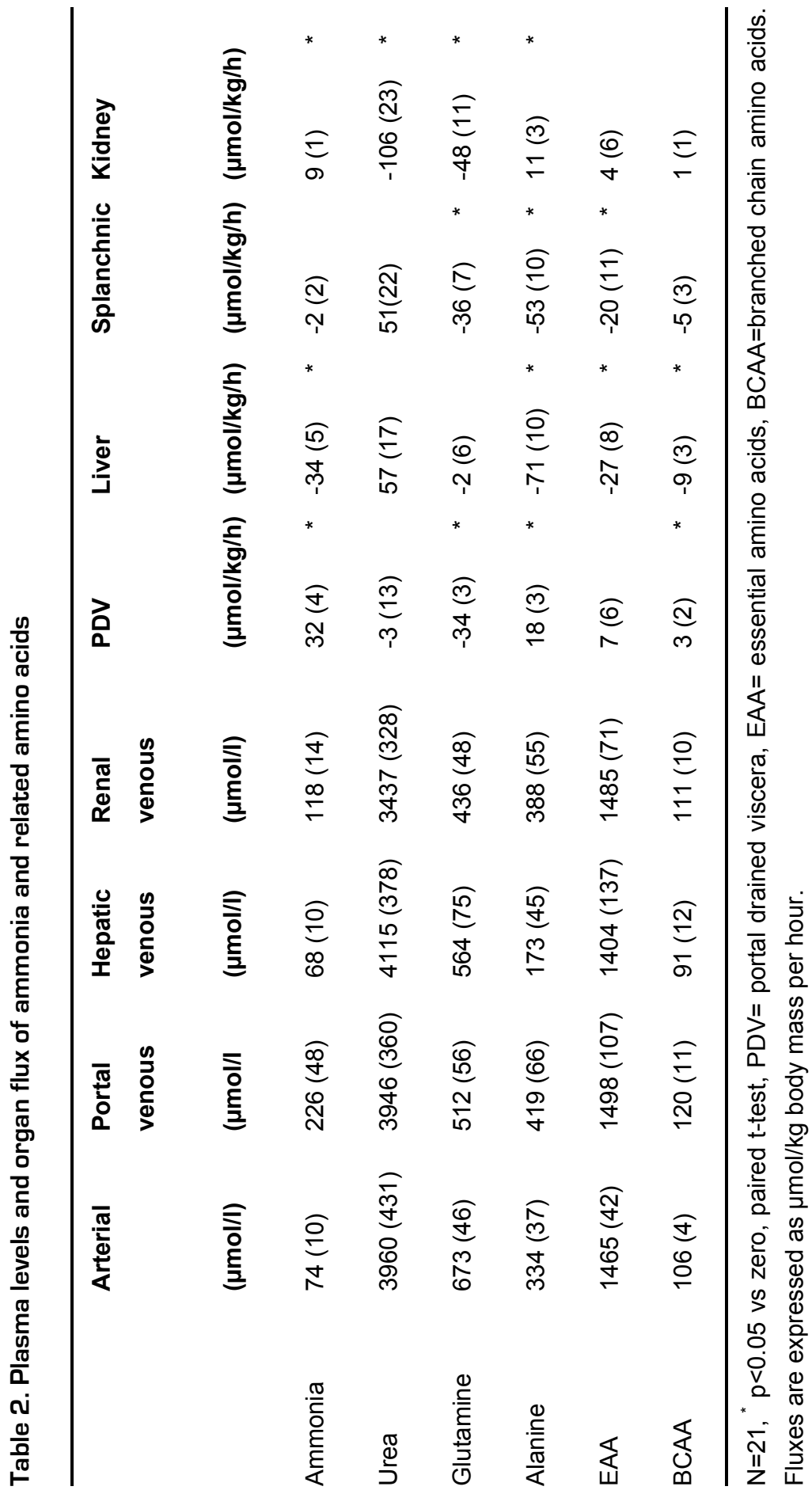




\section{Renal ammonia release into the systemic circulation}

The kidneys released ammonia into the renal vein and the systemic circulation

(Figure 2). The kidneys consumed glutamine at a rate that was quantitatively comparable with intestinal glutamine utilization. However, in contrast to the 1:1 stoichiometry between glutamine uptake and ammonia release observed in the gut, renal glutamine uptake exceeded systemic ammonia release by the kidneys 5 -fold.

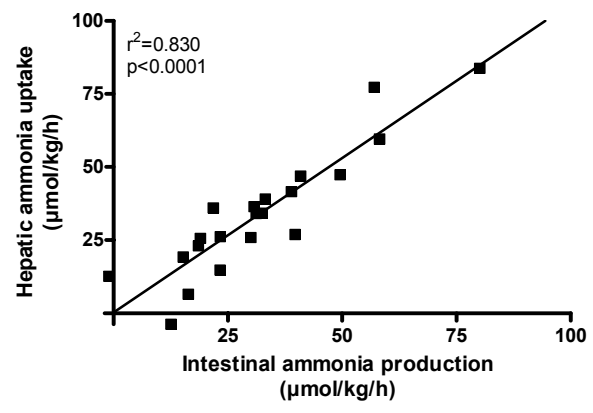

Figure 1. Relation between intestinal ammonia release and hepatic ammonia uptake. The close correlation between intestinal ammonia production and hepatic ammonia uptake evidences that hepatic ammonia clearance prohibits the escape of intestinal derived ammonia to the svstemic circulation.

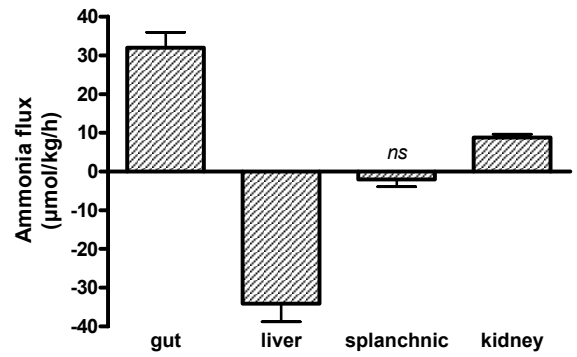

Figure 2. Splanchnic and renal ammonia flux. Ammonia flux across the splanchnic organs (gut and liver) and kidneys was measured in 21 surgical patients with a normal liver function and without portosystemic shunting. Intestinal ammonia production is equalled by hepatic ammonia uptake, rendering net splanchnic ammonia release insignificant. The kidney significantly adds ammonia to the systemic circulation. 


\section{Effects of major hepatectomy on amino acid metabolism}

In the seven patients undergoing major hepatectomy, blood sampling was repeated immediately following removal of the resection specimen. At this time point systemic plasma concentrations of most amino acids were significantly increased (Table 3). This increase was most outspoken for alanine (average 1.4 times baseline value). Simultaneously, transintestinal (Table 4, Figure 3a) and transsplanchnic (Table 5, Figure 3b) arteriovenous concentration gradients for all amino acids were not significantly different from baseline values.

Table 3. Changes in arterial amino acid concentrations after major hepatectomy

\begin{tabular}{llll}
\hline & Baseline & after major hepatectomy & p-value \\
Ammonia & $53(3.3)$ & $64(1.8)$ & 0.044 \\
Glutamate & $103(14.3)$ & $77(10.1)$ & 0.059 \\
Glutamine & $782(66.4)$ & $606(39.9)$ & 0.063 \\
Alanine & $392(58.4)$ & $566(58.1)$ & 0.002 \\
Methionine & $23(1.6)$ & $30(1.4)$ & $<0.001$ \\
BCAA & $362(23.3)$ & $377(23.0)$ & 0.299 \\
AAA & $128(9.6)$ & $162(9.8)$ & 0.009 \\
EAA & $827(47.7)$ & $925(57.6)$ & 0.098 \\
NEAA & $1914(114.5)$ & $2054(84.8)$ & 0.307 \\
\hline
\end{tabular}

Arterial amino acid concentrations in patients undergoing major hepatectomy $(n=7)$, values are mean (SEM) in $\mu \mathrm{mol} / \mathrm{l}$, The $\mathrm{p}$-value was calculated using a paired t-test. $B C A A=$ branched chain amino acids, $A A A=$ aromatic amino acids, $E A A=$ essential

\section{Effects of major hepatectomy on splanchnic and renal ammonia exchange}

Following major hepatectomy arterial ammonia concentrations were increased, whereas transintestinal ammonia gradients were not significantly different from baseline values. Despite increased portal ammonia concentrations and reduced liver volume, net transsplanchnic concentration gradients following major hepatectomy remained not significantly different from zero which implies that the liver removed all ammonia from the portal. The difference between renal venous and arterial ammonia concentration (RV-A) also remained unchanged (33.2 (5.7) $\mu \mathrm{mol} / /$ before vs. 30.1 (8.9) $\mu \mathrm{mol} / \mathrm{l}$ after major hepatectomy, $\mathrm{p}=0.67$ ). 


\section{Discussion}

The present study was designed to study the role of the intestines, liver and kidney in ammonia homeostasis in humans without portosystemic shunting. While data on interorgan ammonia metabolism in various animal models as well as in humans with liver disease are already available, such data in humans with a functionally normal liver have been lacking. We were able to obtain these data by sampling blood from the portal, hepatic and renal veins from patients undergoing upper gastrointestinal surgery. We also studied the effect of an acute reduction of functional liver mass on remnant metabolic liver function and interorgan ammonia exchange.

In line with previous data the intestines released ammonia into the portal vein. At steady state baseline sampling, intestinal ammonia production however, appeared to be of minor importance for systemic ammonia release in patients with a normal liver since the liver effectively extracted ammonia at a rate that exactly equalled intestinal ammonia production. This led to a zero net balance across the whole splanchnic area at baseline. Also in line with literature data (17-20), the kidneys were found to release ammonia to the systemic circulation. Since most solid organs e.g. lungs (21), brain (22), and skeletal muscle (7) are net ammonia consumers, the kidneys appear to be very important for systemic ammonia release in healthy humans and probably play a hitherto underestimated role in the regulation of systemic ammonia concentration.

Renal ammonia is derived from glutamine and approximately $40-50 \%$ of all glutamine is converted to ammonia by the kidney (19). Subsequently ammonia is either released into the urine or into the renal vein. The balance between renal venous and urinary ammonia excretion is determined by acid-base status, with acidosis stimulating urinary ammonia excretion and alkalosis stimulating renal venous ammonia excretion. Unfortunately we were unable to assess urinary ammonia excretion for several reasons, including the inaccuracy of the exact assessment of diuresis during a short interval and urease activity of bacteria colonizing urine collection devices.

In seven patients undergoing major liver resection ( $\geq 3$ liver segments) blood sampling was repeated following liver resection. After major hepatectomy a marked increase was found in the arterial and portal plasma concentration of most amino acids and ammonia. This was particularly true for the aromatic amino acids, for alanine, the most important amino-nitrogen donor for hepatic ureagenesis and for methionine. Arterial plasma concentrations of branched chain amino acids remained unchanged. The resulting amino acid profile resembles the profile that can be found in patients with chronic liver disease (hyperaminoacidemia with an increased ratio between aromatic and branched 
chain amino acids) (23). In addition we found decreased arterial glutamine levels after hepatectomy, which is an unexpected finding since these data appear to contrast with previous data showing increased glutamine levels following liver resection (24).

In addition, we found a $21 \%$ increase of systemic ammonia levels immediately following major hepatectomy. Such an increase was not found in the aforementioned study (24) where ammonia levels were normalized after liver resection. The major difference between the two studies was the timepoint at which systemic amino acid and ammonia levels were measured (seconds to minutes after removal of the specimen in the present study versus hours in the previous one). This suggests that major liver resection disturbs glutamine and ammonia homeostasis temporarily but that a new steady state is established within hours. In this new steady state, ammonia removal by the liver is kept constant despite increased influx of ammonia. The exact cause and nature of the changes in systemic ammonia and glutamine levels immediately following liver resection remains unclear from the present study. Potential explanations include a temporary reduction of hepatic ammonia uptake due to reduced liver mass and temporary disturbance of the hepatic blood flow during liver transection, such changes would facilitate increased release of (intestinalderived) ammonia to the systemic circulation. This is however not supported by changes in splanchnic ammonia release in the present study at the timepoints measured. It is known that the liver has a tremendous capacity of ureagenesis due to the high $\mathrm{Km}$ of the urea cycle enzymes, leading to a rapid increase of hepatic ammonia clearance after an increased portal ammonia load, even in patients with liver disease $(8,25,26)$.

Liver surgery is accompanied by manipulation of the liver and its blood supply, leading to disturbances in hepatic perfusion (27-29) and probably to some portovenous shunting and increased ammonia levels. Alternative explanations for the observations of increased ammonia and decreased glutamine and glutamate levels may be a decreased glutamine synthetase activity in other organs for example in skeletal muscle. Along this line of reasoning, hyperaminoacidemiea may lead to increased ammonia production elsewhere in the body.

For practical reasons blood flow measurements could not be repeated following major hepatectomy. However total portal blood flow is not affected by major hepatectomy in patients with an otherwise normal liver (16). Therefore concentration gradients are not expected to be influenced by changes in blood flow through the entire hepatosplanchnic bed. Portal blood flow per gram liver however, increases following major hepatectomy, proportionate to the resected volume (16). Consequently ammonia and amino acid supply and metabolism per gram liver increased vastly, immediately following hepatectomy. 
The increased metabolic rate per gram liver is probably crucial to preserve vital functions such as ureagenesis, protein synthesis and gluconeogenesis. According to simple biochemical principles, reduction of enzyme availability can be overcome by increasing substrate supply to maintain activity rate. This probably also underlies changes following major hepatectomy where total liver function is preserved (unchanged transsplanchnic amino acid concentration gradients and ureagenesis (24)) at the cost of increased substrate supply (increased systemic (and portal) amino acid concentrations and increased blood flow per gram liver).

The relative increase in glutamine supply may additionally support the adaptation in ureagenesis because hepatic glutaminase, located predominantly in periportal hepatocytes, has the extraordinary characteristic of being activated by its product ammonia (30-32). Thus, in addition to the ammonia taken up from the portal blood, ammonia generated locally from glutamine breakdown has a feed-forward effect on hepatic urea synthesis $(30,31)$. Kaiser et al. (32) suggested that this enhanced local ammonia formation may act as a compensatory mechanism for maintenance of a life-compatible urea-cycle flux in a situation of (temporarily) reduced urea synthetic capacity.

In summary, because at metabolic steady state, the liver removes an equal amount of ammonia from the circulation as added by the intestines, the net contribution of the splanchnic area to systemic ammonia release is probably only minor. Other organs, presumably the kidneys are more important for systemic ammonia release than the intestines. This holds true even after an acute reduction of over $50 \%$ of functional liver mass. Such a reduction does not influence transhepatic amino acid concentration gradients and ammonia flux, despite an acute increase of the portal nitrogen load per gram liver. These data provide additional insights in the pathophysiology of hyperammonemia in liver disease. Given the large adaptive capacity of hepatocytes, hepatocellular dysfunction may be of lesser importance in the pathogenesis of hyperammonemia than generally believed. In support of this proposition, it has been shown that hepatic venous ammonia concentrations equal arterial ammonia concentrations in patients with chronic liver disease $(1,7)$, providing additional evidence for preserved hepatocellular ammonia clearance in the diseased liver. The important role of the kidneys in the regulation of systemic ammonia release may indicate that therapies aimed at reducing systemic ammonia levels should not only be addressed at intestinal ammonia production but also on renal ammonia production and excretion $(5,9,10)$. 


\section{References}

1. Plauth $M$, Roske $A E$, Romaniuk $P$, Roth $E$, Ziebig $R$, Lochs $H$. Post-feeding hyperammonaemia in patients with transjugular intrahepatic portosystemic shunt and liver cirrhosis: role of small intestinal ammonia release and route of nutrient administration. Gut 2000;46:849-855.

2. Sherlock S: Hepatic encephalopathy. In: Diseases of the liver and biliary system. Oxford: Blackwell scientific publications, 1989; 95-115.

3. Zeneroli ML, Avallone R, Corsi L, Venturini I, Baraldi C, Baraldi M. Management of hepatic encephalopathy: role of rifaximin. Chemotherapy 2005;51 Suppl 1:90-95.

4. Riordan SM, Williams R. Treatment of hepatic encephalopathy. N Engl J Med 1997;337:473479.

5. Shawcross $D$, Jalan $R$. Dispelling myths in the treatment of hepatic encephalopathy. Lancet 2005;365:431-433.

6. Sherlock S: Hepato-cellular failure. In: Diseases of the liver and biliary system. Oxford: Blackwell scientific publications, 1989; 80-94.

7. Olde Damink SW, Jalan R, Redhead DN, Hayes PC, Deutz NE, Soeters PB. Interorgan ammonia and amino acid metabolism in metabolically stable patients with cirrhosis and a TIPSS. Hepatology 2002;36:1163-1171.

8. Olde Damink SW, Jalan R, Deutz NE, Redhead DN, Dejong CH, Hynd P, Jalan RA, et al. The kidney plays a major role in the hyperammonemia seen after simulated or actual Gl bleeding in patients with cirrhosis. Hepatology 2003;37:1277-1285.

9. Elias E. Cerebral changes following simulation of a $G 1$ bleed support the ammonia/glutamine/brain swelling hypothesis but may result from renal rather than intestinal ammonia production. Hepatology 2003;37:1239-1240.

10. Elias E. Liver failure and liver disease. Hepatology 2006;43:S239-S242.

11. Tizianello A, Garibotto G, Robaudo C, Saffioti S, Pontremoli R, Bruzzone M, Deferrari G. Renal ammoniagenesis in humans with chronic potassium depletion. Kidney Int 1991;40:772778.

12. Gabduzda GJ, Hall PW, 3rd. Relation of potassium depletion to renal ammonium metabolism and hepatic coma. Medicine (Baltimore) 1966;45:481-490.

13. van de Poll MCG, Siroen MP, van Leeuwen PA, Soeters PB, Melis GC, Boelens PG, Deutz $N E P$, et al. Interorgan amino acid exchange in humans: consequences for arginine and citrulline metabolism. Am J Clin Nutr 2007;85:167-172.

14. van de Poll MCG, Ligthart-Melis GC, Boelens PG, Deutz NE, van Leeuwen PAM, Dejong CHC. Intestinal and hepatic metabolism of glutamine and citrulline in humans. J Physiol 2007;581:819-827.

15. van Eijk HM, Rooyakkers DR, Deutz NE. Rapid routine determination of amino acids in plasma by high-performance liquid chromatography with a 2-3 microns Spherisorb ODS II column. J Chromatogr 1993;620:143-148.

16. Schindl MJ, Millar A, Redhead DN, Fearon $\mathrm{KCH}$, Ross JA, Dejong CHC, Garden OJ, et al. The adaptive response of the reticulo-endothelial system to major liver resection in man. Ann Surg 2006;243:507-514.

17. van de Poll MCG, Soeters PB, Deutz NEP, Fearon KC, Dejong CHC. Renal metabolism of amino acids: its role in interorgan amino acid exchange. Am J Clin Nutr 2004;79:185-197.

18. Owen EE, Tyor MP, Flanagan JF, Berry JN. The kidney as a source of blood ammonia in patients with liver disease: the effect of acetazolamide. J. Clin. Invest. 1960;39:288-294.

19. Tizianello A, De Ferrari G, Garibotto G, Gurreri G, Robaudo C. Renal metabolism of amino acids and ammonia in subjects with normal renal function and in patients with chronic renal insufficiency. J Clin Invest 1980;65:1162-1173. 
20. Owen EE, Robinson RR. Amino acid extraction and ammonia metabolism by the kidney during prolonged administration of ammonium chloride. J. Clin. Invest. 1963;42:263-276.

21. Cooper AJ, Freed BR. Metabolism of [(13)N]ammonia in rat lung. Neurochem Int 2005;47:103-118.

22. Jalan R, Olde Damink SW, Deutz NE, Lee A, Hayes PC. Moderate hypothermia for uncontrolled intracranial hypertension in acute liver failure. Lancet 1999;354:1164-1168.

23. Dejong $\mathrm{CH}$, van de Poll MC, Soeters PB, Jalan R, Olde Damink SW. Aromatic amino acid metabolism during liver failure. J Nutr 2007;137:1579S-1585S; discussion 1597S-1598S.

24. van de Poll MCG, Wigmore SJ, Redhead DN, Beets-Tan RGH, Garden OJ, Greve J-WM, Soeters $P B$, et al. Effect of major liver resection on hepatic ureagenesis in humans. Am J Physiol Gastrointest Liver Physiol 2007;293:956-962.

25. Vilstrup $H$. Synthesis of urea after stimulation with amino acids: relation to liver function. Gut 1980;21:990-995.

26. Hamberg $O$, Nielsen $K$, Vilstrup $H$. Effects of an increase in protein intake on hepatic efficacy for urea synthesis in healthy subjects and in patients with cirrhosis. J Hepatol 1992;14:237243.

27. Kainuma M, Fujiwara Y, Kimura N, Shitaokoshi A, Nakashima K, Shimada Y. Monitoring hepatic venous hemoglobin oxygen saturation in patients undergoing liver surgery. Anesthesiology 1991;74:49-52.

28. van de Poll MC, Derikx JPM, Buurman WA, Peters WHM, Roelofs HMJ, Wigmore SJ, Dejong CHC. Liver manipulation causes hepatocyte injury and precedes systemic inflammation in patients undergoing liver resection. World J Surg 2007:2033-2038.

29. Chouker A, Martignoni A, Schauer RJ, Dugas M, Schachtner T, Kaufmann I, Setzer F, et al. aGluthathione S-transferase as an early marker of hepatic ischemia/reperfusion injury after liver resection. World J Surg 2005;29:528-534.

30. Haussinger D. Regulation of hepatic ammonia metabolism: the intercellular glutamine cycle. Adv Enzyme Regul 1986;25:159-180.

31. Welbourne TC. Hepatic glutaminase flux regulation of glutamine homeostasis. Biol. Chem. Hoppe Seyler 1986;367:301-305.

32. Kaiser S, Gerok W, Haussinger D. Ammonia and glutamine metabolism in liver slices: new aspects on the pathogenesis of hyperammonemia in chronic liver disease. Eur J Clin Invest 1988; 18:535-542. 


\section{Chapter 4}

\section{Interorgan exchange of glutamine, citrulline and arginine}

MCG van de Poll, MPC Siroen, PAM van Leeuwen, PB Soeters, GC Melis, PG Boelens, NEP Deutz, CHC Dejong 


\section{Abstract}

The liver plays a central role in amino acid metabolism. However, because of limited accessibility of the portal vein, human data on this subject are scarce. We studied hepatic amino acid metabolism in noncirrhotic fasting patients undergoing liver surgery. Twenty patients undergoing hepatectomy for colorectal metastases in a normal liver were studied. Before resection, blood was sampled from a radial artery, portal vein, hepatic vein, and renal vein. Organ blood flow was measured by duplex ultrasound scan. The intestine consumed glutamine and released citrulline. Citrulline was taken up by the kidney. This was accompanied by renal arginine release, which supports the view that glutamine is a precursor for arginine synthesis through an intestinalrenal pathway. The liver was found to extract citrulline from this pathway at a rate that was dependent on intestinal citrulline release $(p<0.0001)$ and hepatic citrulline influx $(p=0.03)$. Fractional hepatic extractions of citrulline $(8.4 \%)$ and arginine (11.5\%) were not significantly different. Eighty-eight percent of arginine reaching the liver passed it unchanged. Splanchnic citrulline release could account for one-third of renal citrulline uptake. This is the first study of hepatic and interorgan amino acid metabolism in humans with a normal liver. The data indicate that glutamine is a precursor of ornithine, which can be converted to citrulline by the intestine; citrulline is transformed in the kidneys to arginine. Hepatic citrulline uptake limits the amount of gut-derived citrulline reaching the kidney. These findings may have implications for interventions aimed at increasing systemic arginine concentrations. 


\section{Introduction}

The liver plays a central role in amino acid metabolism. Because of its anatomical relation to the gut, the liver receives compounds absorbed or released by the gut through the portal vein before they gain access to the systemic circulation. Most data about hepatic amino acid metabolism originate from animal research, and, although many similarities exist between these studies, inconsistencies between studies suggest that important qualitative and quantitative differences also exist among species (1-4). The in vivo study of hepatic amino acid uptake and release requires blood sampling from among others the portal vein which is difficult to access in humans. As a consequence human studies on the role of the liver in this context are scarce. In fact, the available human data come from studies in patients with liver disease and a transjugular intrahepatic portosystemic shunt $(4,5)$, through which the portal vein can be accessed by a percutaneous transluminal approach. To our knowledge no in vivo data about hepatic amino acid metabolism in humans with a normal liver exist. In patients undergoing surgery for colorectal liver metastases, the function and structure of the nontumorous parenchyma is generally preserved. In addition, the hepatic veins, portal vein, and renal veins are relatively easily accessible for blood sampling. We studied interorgan amino acid exchange among the gut, liver, and kidneys in patients without portosystemic shunting, cirrhosis, or both undergoing liver surgery. On the basis of our current research interest, special attention was paid to the metabolism of glutamine, citrulline, and arginine (6-8). Arginine is a pluripotent amino acid (9), and supplementation may prove beneficial in certain conditions (8). It is generally assumed that arginine synthesis is the endpoint of an interorgan pathway that involves the conversion of glutamine to glutamate, ornithine, and citrulline by the intestine and the conversion of citrulline to arginine by the kidneys $(6,7,10-14)$. The relation among glutamine, citrulline, and arginine provides a basis for the theory that the established clinical effects of glutamine (15) may partly rely on its role as a precursor of arginine.

The effectiveness of enteral arginine supplementation has been questioned, because the high hepatic activity of the enzyme arginase (EC 3.5.3.1), which breaks down arginine to urea, is thought to prohibit the release of enteraladministered arginine to the systemic circulation $(16,17)$. In contrast, citrulline is believed to pass the liver without significant uptake $(7,10,12,16)$. In this light it has been suggested that enteral citrulline as a precursor for renal arginine synthesis may be more effective than enteral arginine to raise systemic arginine concentrations, without inducing hepatic nitrogen loss $(12,18)$. Insight into the interorgan conversion of glutamine to citrulline and of citrulline to arginine in 
humans is needed to clarify normal human physiology. This knowledge may be applied to optimize dietary supplementation of these amino acids.

\section{Subjects and methods}

\section{Patients}

The study population consisted of 20 patients undergoing partial liver resection because of colorectal metastases. No patients were jaundiced, and none of them had been on chemotherapy, radiotherapy, or medical treatment for their tumors in the $4 \mathrm{wk}$ preceding the operation. Patients were excluded if the tumor volume exceeded $10 \%$ of total liver volume. Preoperatively, serum aspartate aminotransferase, creatinine, glucose, and albumin were measured routinely by the local clinical chemistry laboratory. Patients consumed their standard oral nutrition in the prestudy period. Oral intake was ceased at 2000 on the day before surgery, and all patients were transported to the operating theater at $\approx 0800$. Patient characteristics are summarized in Table 1 . Permission for the study was granted by the Medical Ethical Committee of the VU University Medical Center. Written informed consent was obtained from each participant.

Table 1. Demographic characteristics of the subjects

\begin{tabular}{ll}
\hline Variable & Value \\
& (n=15 M, 5 F) \\
Age $(\mathrm{y})$ & $65(37-79)$ \\
Height $(\mathrm{cm})$ & $173(153-192)$ \\
Bilirubin $(\mu \mathrm{mol} / \mathrm{L})$ & $8(5-13)$ \\
Aspartate aminotransferase $(\mathrm{IU} / \mathrm{L})$ & $21(16-53)$ \\
Prothrombin time $(\mathrm{s})$ & $1(1-1.2)$ \\
Creatinine $(\mu \mathrm{mol} / \mathrm{L})$ & $88(72-99)$ \\
Urea $(\mathrm{mmol} / \mathrm{L})$ & $5.3(3.1-6.1)$ \\
Albumin $(\mathrm{g} / \mathrm{L})$ & $39(31-45)$ \\
C-reactive protein $(\mathrm{mg} / \mathrm{L})$ & $4(1-35)$ \\
\hline
\end{tabular}

All values are median; range in parentheses.

\section{Anesthesia}

Anesthesia was applied according to institutional routines with the use of isoflurane and propofol. All patients had a thoracic epidural catheter inserted for 
preoperative and postoperative analgesia and indwelling catheters in a jugular vein and a radial artery for monitoring arterial and central venous blood pressure. Urine output was monitored by transurethral catheterization. Body temperature was kept constant with the use of a Bair Hugger system (Arizant Healthcare Inc, Eden Prairie, MN).

\section{Surgical procedure and blood sampling}

Surgical procedures were conducted as described previously (19) and were commenced with a bilateral subcostal incision. After dissection of the teres hepatis ligament, the procedure was continued with dissection of the falciform ligament and further mobilization of the liver as appropriate to deal with the surgical disorder followed by intraoperative ultrasonography (IOUS). Immediately after IOUS, blood was sampled from the right renal vein, the portal vein, and one of the hepatic veins by direct puncture. Simultaneously, arterial blood was drawn from the radial artery catheter.

\section{Duplex flow measurement}

During IOUS organ blood flow was measured by means of color Doppler ultrasound scanning (Aloka Prosound SSD 5000; Aloka Co, Ltd, Tokyo, Japan). Time-averaged mean velocities of the bloodstream and cross-sectional area of the portal vein, hepatic artery, and right renal vein were measured as described before (20). The renal vein, portal vein, and hepatic artery were traced with the use of a sterile transducer (5-10 MHz linear UST-579T-7,5; Aloka). For accurate measurements, care was taken to keep the angle between the ultrasonic beam direction and blood flow direction below $60^{\circ}$. The crosssectional area of the vessel was calculated by drawing an area ellipse at the same point as where the velocity was measured. Portal venous and hepatic arterial blood flows were measured proximal to their hilar bifurcations. In case of an accessory hepatic artery, both arteries were assessed.

\section{Blood processing and laboratory analysis}

Blood samples were transferred to prechilled heparin-containing blood collection tubes (Vacutainer; Becton Dickinson, Franklin Lakes, NJ). A glass capillary was filled with arterial whole blood and centrifuged at high speed $(10000 \times \mathrm{g})$ for $5 \mathrm{~min}$ at room temperature to determine hematocrit with the use of a hematocrit reader. The remainder of the heparinized blood was centrifuged at $4^{\circ} \mathrm{C}$ at $4000 \times \mathrm{g}$ for $10 \mathrm{~min}$ to separate plasma. Plasma was processed and amino acids were measured with the use of HPLC as described previously (21). 


\section{Calculations for plasma flow}

Blood flows in the portal vein, renal vein, and hepatic artery were calculated by multiplying the time-averaged velocity of the bloodstream with the crosssectional area of the vessel. Plasma flows were calculated from measured blood flow and hematocrit]plasma flow = blood flow $\mathrm{x}(1-$ hematocrit $)$ ]. Splanchnic (hepatic) plasma flow was calculated as portal plasma flow plus hepatic arterial plasma flow. Total renal plasma flow was estimated by multiplying right renal plasma flow with a factor of 2 .

\section{Calculations for amino acid flux}

Organ amino acid fluxes were calculated as organ plasma flow multiplied by the product of subtracting arterial plasma amino acid concentration from venous plasma amino acid concentration. Portal, renal, and hepatic venous plasma concentrations of amino acid were used to calculate fluxes across the intestine, kidneys, and splanchnic area (comprising portal-drained viscera and the liver), respectively. Hepatic amino acid fluxes were calculated by subtracting intestinal amino acid flux from corresponding splanchnic amino acid fluxes. Positive fluxes indicate net amino acid release; negative fluxes indicate net uptake.

\section{Calculations for amino acid influx and fractional extractions}

Amino acid influx, the rate at which an amino acid is supplied to an organ by the circulation, was calculated by multiplying arterial plasma amino acid concentrations with portal or renal plasma flow (intestinal and renal influx, respectively). Hepatic amino acid influx was calculated as (portal plasma flow $x$ portal amino acid concentration) + (hepatic arterial plasma flow $\mathrm{x}$ arterial amino acid concentration). In cases of negative amino acid flux (net amino acid uptake), fractional amino acid extractions were calculated from net amino acid uptake (net uptake $=$ negative net flux $x-1$ ) and amino acid influx as described by Remesy et al (1): (fractional extraction $=$ amino acid uptake/net influx $x$ $100 \%)$. This calculation enables the expression of organ-specific uptake of an amino acid in relation to its influx and represents the percentage of amino acid influx that is actually taken up from the bloodstream.

\section{Statistics}

Data are presented as means (SEM) unless stated otherwise. Differences in arteriovenous concentrations were tested against zero with the use of a onesample $t$ test with a theoretical mean of zero. Correlations were calculated with 
the use of Pearson's test. A p value $<0.05$ was used to indicate statistical significance. Statistical calculations were performed with the use of PRISM 4.0 for WINDOWS (GraphPad Software Inc, San Diego, CA).

\section{Results}

\section{Plasma flow}

Mean plasma flows in the portal vein and hepatic artery were found to be 320 (42) and 110 (23) $\mathrm{mL} / \mathrm{min}$, respectively. Hepatosplanchnic plasma flow amounted to 430 (47) $\mathrm{mL} / \mathrm{min}$. Renal plasma flow (2 kidneys) equaled 606 (112) $\mathrm{mL} / \mathrm{min}$. These values are in accordance with our previous data (20).

\section{Amino acid flux}

\section{Intestinal glutamine metabolism}

Glutamine was taken up by the gut (Figure 1) with a fractional extraction of 12.0 (1.5)\%. No correlation was observed between arterial glutamine concentrations and intestinal glutamine uptake $\left(r^{2}=0.005\right)$. Citrulline was produced by the intestine, and intestinal citrulline release accounted for $\approx 13 \%$ of intestinal glutamine metabolism (Figure 1). Citrulline release did not correlate with glutamine uptake $\left(r^{2}=0.013\right)$.

\section{Citrulline exchange between the intestine and the liver}

Surprisingly, the liver was found to take up citrulline (Figure 1). Hepatic citrulline uptake appeared to depend on hepatic citrulline influx $(r 2=0.23)$ (Figure $2 A)$ and correlated strongly with intestinal citrulline release $\left(r^{2}=0.59\right)$ (Figure $\left.2 B\right)$. As a consequence of hepatic citrulline uptake, net splanchnic citrulline release was considerably less than intestinal citrulline release and equaled only $1.1(0.2)$ $\mu \mathrm{mol} / \mathrm{kg} / \mathrm{h}$ ( $45 \%$ of intestinal citrulline release) (Figure 1).

\section{Arginine exchange between the intestine and the liver}

Intestinal arginine flux was not significantly different from zero, whereas the splanchnic area as a whole (and hence the liver) significantly removed arginine from the circulation. Hepatic arginine uptake did not correlate with arginine influx $\left(r^{2}=0.08\right)$ (Figure $\left.2 C\right)$.

Data on absolute and fractional uptake of citrulline and arginine by the liver are presented in Figure 3. The influx of arginine to the liver $(23.9(1.4) \mu \mathrm{mol} / \mathrm{kg} / \mathrm{h})$ exceeded the influx of citrulline $(14.0(0.8) \mu \mathrm{mol} / \mathrm{kg} / \mathrm{h})$. In addition, the absolute 
uptake of arginine by the liver $(2.7(0.5) \mu \mathrm{mol} / \mathrm{kg} / \mathrm{h})$ was significantly higher than the absolute uptake of citrulline $(1.3(0.3) \mu \mathrm{mol} / \mathrm{kg} / \mathrm{h})$. From influx and absolute uptake, the fractional hepatic extractions of arginine and citrulline were calculated $(11.5(2.0) \%$ and $8.4(2.3) \%$, respectively). These values were not significantly different.

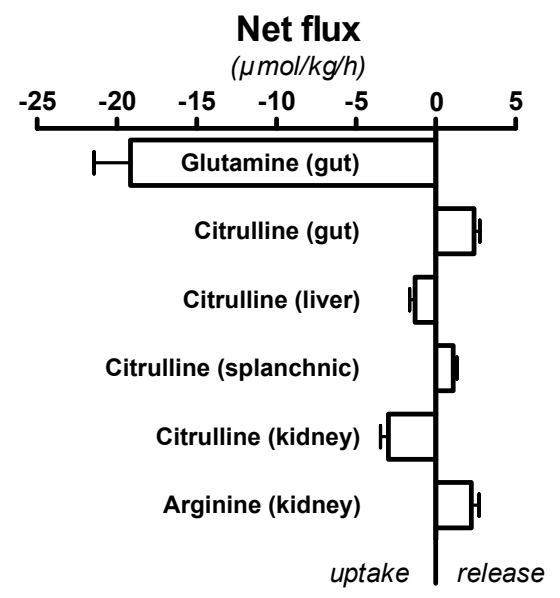

Figure 1 . Mean ( $\pm S E M)$ fluxes through the interorgan pathway of arginine synthesis postabsorptively in humans undergoing surgery $(n=20)$. All fluxes are significantly different from zero $(p<0.05$, one sample $t$ test). Glutamine is taken up by the intestine. Intestinal citrulline release accounts for $12 \%$ of intestinal glutamine uptake. The liver consumes citrulline in quantities equaling $55 \%$ of intestinal citrulline release. Renal citrulline uptake exceeds splanchnic citrulline release 3-fold and approximates renal arginine release.

\section{Renal citrulline and arginine metabolism}

Renal citrulline uptake correlated significantly with arterial citrulline concentrations $\left(r^{2}=0.63, p<0.0001\right.$; fractional extraction: 23.9 (3.3)\%). Renal citrulline uptake was not significantly different from intestinal citrulline release $(p=0.36)$, but because of hepatic citrulline extraction, which reduced net splanchnic citrulline release, renal citrulline uptake $(3.0(0.5) \mu \mathrm{mol} / \mathrm{kg} / \mathrm{h}$ ) exceeded splanchnic citrulline release (1.1 (0.2) $\mu \mathrm{mol} / \mathrm{kg} / \mathrm{h}$ ) almost 3 -fold $(p=0.008$, renal citrulline uptake compared with splanchnic citrulline release). A significant correlation $\left(r^{2}=0.26, p=0.026\right)$ was observed between renal citrulline uptake and arginine release. The rates of renal citrulline uptake and arginine release were not significantly different. Fluxes of amino acids through the intestinal-hepatic-renal pathway of glutamine-citrulline-arginine conversion are graphically summarized in Figure 1. Intestinal, hepatic, and renal amino acid fluxes are summarized in Table 2. 


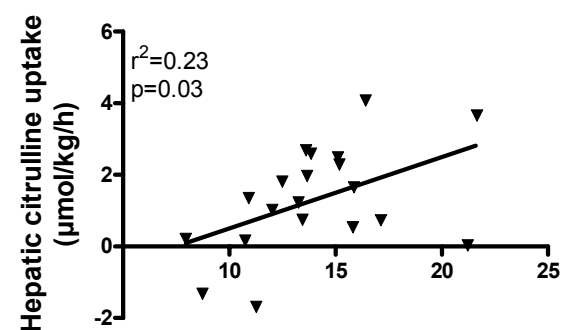

Hepatic citrulline influx $(\mu \mathrm{mol} / \mathrm{kg} / \mathrm{h})$

A

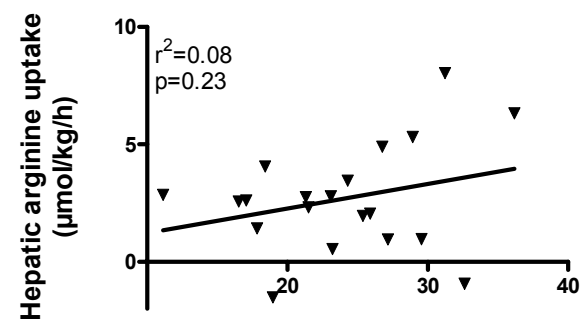

Hepatic arginine influx $(\mu \mathrm{mol} / \mathrm{kg} / \mathrm{h})$

C

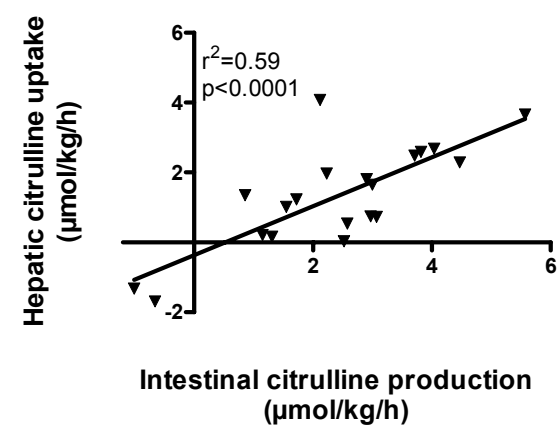

B

Figure 2. Correlation between hepatic influx and hepatic uptake of citrulline and arginine postabsorptively in humans undergoing surgery $(n=20)$. There was a significant correlation between hepatic citrulline uptake and hepatic citrulline influx $(A)$ and between hepatic citrulline uptake and intestinal citrulline release (B), which suggests that hepatic citrulline uptake depends on its influx. A similar correlation between hepatic arginine uptake and arginine influx is lacking (C; Pearson's test).

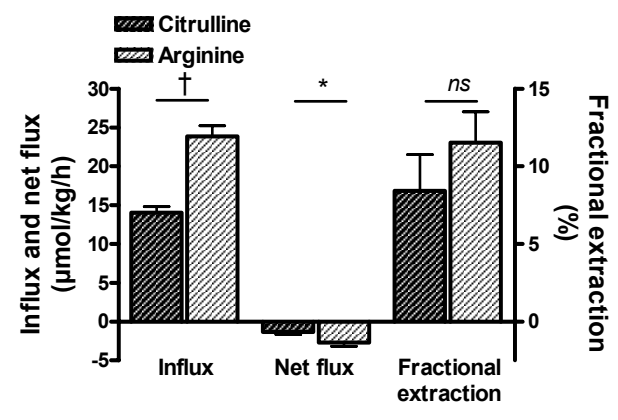

Figure 3. Mean ( $\pm S E M)$ hepatic influx (portal + arterial), net flux, and fractional extraction of citrulline and arginine postabsorptively in humans $(n=20)$ undergoing surgery.

$\dagger$, *Significant difference between citrulline and arginine (paired t test): $\dagger^{\dagger} p<0.0001,{ }^{*} p=0.026$. $N S(p=0.349)$. 
Table 2. Net amino acid flux across the intestine, liver, splanchnic area, and kidneys postabsorptively in humans undergoing surgery

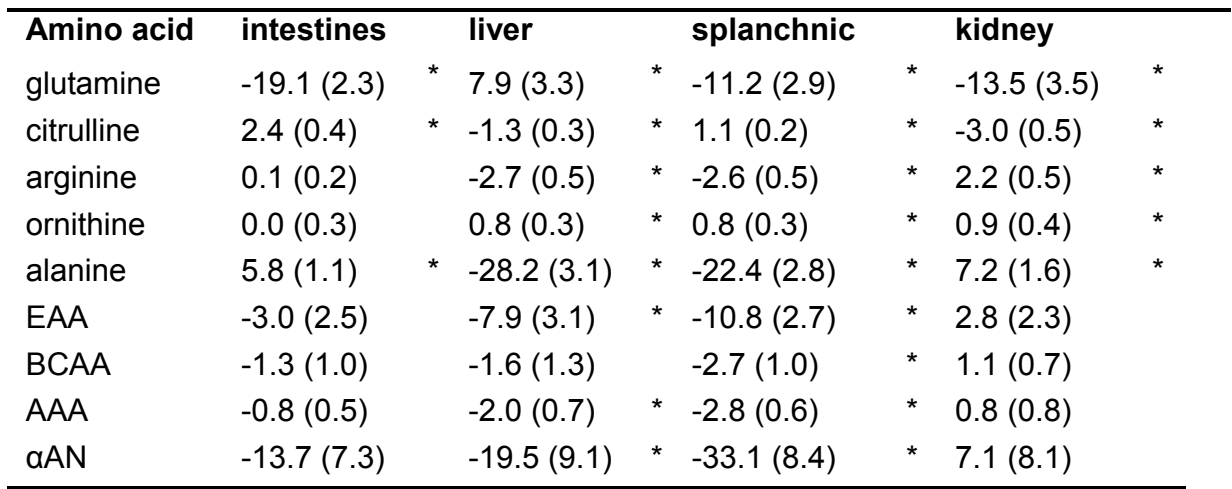

EAA, essential amino acids; NEAA, nonessential amino acids; $\alpha$-AN, $\alpha$-amino nitrogen, sum of amino acids; BCAA, branched-chain amino acids; AAA, aromatic amino acids.

* Significantly different from zero, $P<0.05$ (one-sample $t$ test).

\section{Discussion}

This is the first study about amino acid exchange among the intestine, the liver, and the kidney in humans without parenchymal liver disease. We found intestinal uptake of glutamine which is a confirmation of previous data obtained in humans with and without cirrhosis $(4,22)$. Intestinal uptake of glutamine was accompanied by citrulline release. The splanchnic area released citrulline, and citrulline was taken up by the kidneys. Renal citrulline uptake in turn was followed by arginine release. Thus, the present study confirms in humans the existence of the glutamine-citrulline-arginine pathway in vivo. In addition it shows some new findings that are potentially important for everyday clinical practice.

Hepatic arginine uptake has been ascribed to the activity of arginase, the final enzyme of the urea cycle. However, there is little exchange between extracellular (and even cytosolic) amino acids and amino acids that are formed and broken down within the urea cycle $(26,27)$, suggesting that plasma arginine does not gain access to hepatic arginase. The absence of a relation between hepatic arginine influx and uptake also suggests that hepatic arginine uptake is an orchestrated process that is not limited by substrate supply but rather by substrate demand. This supports the view that hepatic arginine uptake does not 
simply result from arginine capture by arginase, but rather serves specific purposes (eg, protein synthesis).

The available literature on hepatic citrulline metabolism is scarce. The only study that specifically concerned hepatic citrulline metabolism was performed in isolated, perfused rat livers and showed that $<10 \%$ of radioactive-labeled citrulline was removed from the perfusate after $\approx 40$ passes $(10)$. In vivo hepatic citrulline uptake has been observed before in rats (1) but not in mice (2) and pigs (3). In a recent study from our group (4) hepatic citrulline uptake was observed in metabolically stable patients with liver cirrhosis. Because hepatic citrulline metabolism is a virtually unexplored area, its physiologic importance is unclear.

The only known fate of citrulline is its conversion to arginine by the subsequent actions of the enzymes argininosuccinate synthetase (EC 6.3.4.5) and argininosuccinate lyase (EC 4.3.2.1) $(12,24)$. It, therefore, seems reasonable to assume that hepatic citrulline uptake serves de novo synthesis of arginine which may enhance arginine availability for intracellular processes such as nitric oxide synthesis. In fact, this hypothesis was formulated previously by Pastor et al (26), but they qualified it as unlikely "because citrulline is poorly taken up by hepatocytes." Judging from the present results this is not the case. All patients were studied in the fasted state, which hampers direct translation of the present findings to situations of enteral supplementation of glutamine, citrulline, or arginine or ad libitum eating. In the first place enterally administered amino acids are subject to first-pass intestinal metabolism that modifies the amino acid composition of a feed before it is released into the portal vein (28). Intestinal arginine extraction depends on the amount of protein in the habitual diet $(7,16$, 17). In subjects ingesting sufficient amounts of protein, $60-100 \%$ of enteraladministered arginine is released into the portal vein unchanged. It has been suggested that, only after prolonged protein deprivation, enzymes are expressed in the gut that convert arginine to citrulline on absorption $(29,30)$. Effectively this means that during enteral arginine administration to nondepleted subjects or during ad libitum eating, the gut becomes an arginine-releasing organ. Human data on intestinal citrulline extraction are lacking, but a recent mouse experiment applying stable isotopes showed that, despite the intestine being net producers of citrulline, they also take up a considerable amount of citrulline from the circulation (46\% of intestinal influx) (31). This finding suggests that the gut can take up and metabolize citrulline, but it does not necessarily mean that intestinal substrate utilization is similar if supplied by the gut lumen or by the circulation. In addition, feeding stimulates hepatic protein synthesis and hence hepatic amino acid uptake, but, because this is accompanied by an increased portal amino acid flux, it remains to be seen whether the fractional 
hepatic amino acid extraction is different in the fed state compared with the fasted state.

In conclusion, this is the first study of the role of the liver in interorgan amino acid metabolism in humans with a structurally normal liver that did not involve portosystemic shunting. The data support the existence of an interorgan pathway of arginine synthesis involving intestinal glutamine to citrulline conversion and renal citrulline to arginine conversion. A substantial proportion of renal citrulline uptake is derived from other than splanchnic processes, presumably systemic NOS activity. The liver takes up citrulline, which limits the release of gut-derived citrulline to the systemic circulation. This may impair the efficacy of enteral citrulline supplementation. 


\section{References}

1. Remesy C, Demigne C, Aufrere J. Inter-organ relationships between glucose, lactate and amino acids in rats fed on high-carbohydrate or high-protein diets. Biochem J 1978;170:321-9.

2. Hallemeesch MM, Ten Have GA, Deutz NE. Metabolic flux measurements across portal drained viscera, liver, kidney and hindquarter in mice. Lab Anim 2001;35:101-10.

3. Bruins MJ, Deutz NE, Soeters PB. Aspects of organ protein, amino acid and glucose metabolism in a porcine model of hypermetabolic sepsis. Clin Sci (Lond) 2003;104:127-41.

4. Olde Damink SW, Jalan R, Redhead DN, Hayes PC, Deutz NE, Soeters PB. Interorgan ammonia and amino acid metabolism in metabolically stable patients with cirrhosis and a TIPSS. Hepatology 2002;36:1163-71.

5. Owen OE, Reichle FA, Mozzoli MA, et al. Hepatic, gut, and renal substrate flux rates in patients with hepatic cirrhosis. J Clin Invest 1981;68:240-52.

6. Boelens PG, van Leeuwen PA, Dejong CH, Deutz NE. Intestinal renal metabolism of Lcitrulline and $L$-arginine following enteral or parenteral infusion of $L$-alanyl-L-[2,15N]glutamine or L-[2,15N]glutamine in mice. Am J Physiol Gastrointest Liver Physiol 2005;289:G679-85.

7. van de Poll MCG, Soeters PB, Deutz NEP, Fearon KC, Dejong CHC. Renal metabolism of amino acids: its role in interorgan amino acid exchange. Am J Clin Nutr 2004;79:185-97.

8. Luiking YC, Poeze M, Dejong CH, Ramsay G, Deutz NE. Sepsis: an arginine deficiency state? Crit Care Med 2004;32:2135-45.

9. Morris SM, Jr. Recent advances in arginine metabolism. Curr Opin Clin Nutr Metab Care 2004;7:45-51.

10. Windmueller HG, Spaeth AE. Source and fate of circulating citrulline. Am.J.Physiol. 1981;241:E473-E480.

11. Mistry SK, Greenfeld Z, Morris SM, Jr., Baylis C. The 'intestinal-renal' arginine biosynthetic axis in the aging rat. Mech Ageing Dev 2002;123:1159-65.

12. Curis E, Nicolis I, Moinard C, et al. Almost all about citrulline in mammals. Amino Acids 2005.

13. Brosnan ME, Brosnan JT. Renal arginine metabolism. J Nutr 2004;134:2791S-2795S; discussion 2796S-2797S.

14. Brosnan JT. Interorgan amino acid transport and its regulation. J Nutr 2003;133:2068S2072S.

15. Melis GC, ter Wengel N, Boelens PG, van Leeuwen PA. Glutamine: recent developments in research on the clinical significance of glutamine. Curr Opin Clin Nutr Metab Care 2004;7:5970.

16. Cynober. Can arginine and ornithine support gut functions? Gut 1994;Suppl 1:S42-S45.

17. Cynober L, Le Boucher J, Vasson M-P. Arginine metabolism in mammals. J.Nutr.Biochem. 1995;6:402-413.

18. Osowska S, Moinard C, Neveux N, Loi C, Cynober L. Citrulline increases arginine pools and restores nitrogen balance after massive intestinal resection. Gut 2004;53:1781-6.

19. Dejong CHC, Garden OJ. Neoplasms of the liver. In: Majid AA, Kingsnorth A, eds. Advanced surgical practice. London: Greenwich Medical Media, 2003:146-156.

20. Siroen MP, van der Sijp JR, Teerlink $T$, van Schaik C, Nijveldt RJ, van Leeuwen PA. The human liver clears both asymmetric and symmetric dimethylarginine. Hepatology 2005;41:559-65.

21. van Eijk HM, Rooyakkers DR, Deutz NE. Rapid routine determination of amino acids in plasma by high-performance liquid chromatography with a 2-3 microns Spherisorb ODS II column. J Chromatogr 1993;620:143-8.

22. van der Hulst RR, von Meyenfeldt MF, Deutz NE, Soeters PB. Glutamine extraction by the gut is reduced in depleted [corrected] patients with gastrointestinal cancer. Ann Surg $1997 ; 225: 112-21$. 
23. Darmaun D, Matthews DE, Bier DM. Glutamine and glutamate kinetics in humans. Am J Physiol 1986;251:E117-26.

24. Husson A, Brasse-Lagnel C, Fairand A, Renouf S, Lavoinne A. Argininosuccinate synthetase from the urea cycle to the citrulline-NO cycle. Eur J Biochem 2003;270:1887-99.

25. Castillo L, Beaumier L, Ajami AM, Young VR. Whole body nitric oxide synthesis in healthy men determined from $\left[{ }^{15} \mathrm{~N}\right]$ arginine-to- $\left[{ }^{15} \mathrm{~N}\right] c$ citrulline labeling. Proc Natl Acad Sci U S A 1996;93:11460-5.

26. Pastor CM, Morris SM, Jr., Billiar TR. Sources of arginine for induced nitric oxide synthesis in the isolated perfused liver. Am J Physiol 1995;269:G861-6.

27. Cheung CW, Cohen NS, Raijman L. Channeling of urea cycle intermediates in situ in permeabilized hepatocytes. J Biol Chem 1989;264:4038-44.

28. Wu G. Intestinal mucosal amino acid catabolism. J Nutr 1998;128:1249-52.

29. Windmueller HG, Spaeth AE. Metabolism of absorbed aspartate, asparagine, and arginine by rat small intestine in vivo. Arch Biochem Biophys 1976;175:670-6.

30. Stoll B, Henry J, Reeds PJ, Yu H, Jahoor F, Burrin DG. Catabolism dominates the first-pass intestinal metabolism of dietary essential amino acids in milk protein-fed piglets. $J$ Nutr 1998;128:606-14.

31. Vissers $Y L$, Hallemeesch $M M$, Soeters $P B$, Lamers $W H$, Deutz NE. NOS2 deficiency increases intestinal metabolism both in nonstimulated and endotoxemic mice. Am J Physiol Gastrointest Liver Physiol 2004;286:G747-51. 


\section{Chapter 5}

\section{Intestinal and hepatic}

metabolism of

isotopically labelled glutamine and

\section{citrulline}

MCG van de Poll, GC Ligthart-Melis, PG Boelens, NEP Deutz, PAM van Leeuwen, CHC Dejong 


\section{Abstract}

Glutamine plays an important role in nitrogen homeostasis and intestinal substrate supply. It has been suggested that glutamine is a precursor for arginine through an intestinal-renal pathway involving inter-organ transport of citrulline. The importance of intestinal glutamine metabolism for endogenous arginine synthesis in humans, however, has remained unaddressed. The aim of this study was to investigate the intestinal conversion of glutamine to citrulline and the effect of the liver on splanchnic citrulline metabolism in humans. Eight patients undergoing upper gastrointestinal surgery received a primed continuous intravenous infusion of $\left[2-{ }^{15} \mathrm{~N}\right]$ glutamine and [ureido- ${ }^{13} \mathrm{C}-$ ${ }^{2} \mathrm{H}_{2}$ ]citrulline. Arterial, portal venous and hepatic venous blood were sampled and portal and hepatic blood flows were measured. Organ specific amino acid uptake (disposal), production and net balance, as well as whole body rates of plasma appearance were calculated according to established methods. The intestines consumed glutamine at a rate that was dependent on glutamine supply. Approximately $13 \%$ of glutamine taken up by the intestines was converted to citrulline. Quantitatively glutamine was the only important precursor for intestinal citrulline release. Both glutamine and citrulline were consumed and produced by the liver, but net hepatic flux of both amino acids was not significantly different from zero. Plasma glutamine was the precursor of $80 \%$ of plasma citrulline and plasma citrulline in turn was the precursor of $10 \%$ of plasma arginine. In conclusion, glutamine is an important precursor for the synthesis of arginine after intestinal conversion to citrulline in humans. 


\section{Introduction}

The amino acid glutamine is well known for its pivotal role in nitrogen homeostasis and intestinal energy supply. From animal experiments $(1,2)$ and some human studies $(3,4)$ it has become clear that the gut is an important player in whole body glutamine metabolism. Glutamine is degraded by the intestines by means of the enzyme glutaminase, yielding glutamate and ammonia. Subsequently ammonia is released in the portal vein, and the glutamate is subsequently metabolized by the intestine, mostly to $\alpha$ ketoglutarate or alanine (1) In addition glutamate can be converted to ornithine and subsequently to citrulline. By the conversion of glutamine to citrulline, glutamine metabolized by the intestines can become a precursor for the synthesis of arginine elsewhere in the body (5). Arginine is the precursor for the pluripotent signalling molecule nitric oxide and as such is important in the regulation of amongst others organ perfusion, immune function and wound healing. Although it is generally conceived that the gut is the principal organ for citrulline synthesis, the contribution of the gut to whole body glutamine turnover and whole body citrulline synthesis has not yet been quantified in man.

Table 1. Patient characteristics

\begin{tabular}{|c|c|c|}
\hline & Mean & SEM \\
\hline Age (year) & 60 & 2 \\
\hline Length (cm) & 173 & 4 \\
\hline Weight (kg) & 92 & 6 \\
\hline Body mass index (BMI) & 30 & 1 \\
\hline Fat free mass $(\mathrm{kg})$ & 67 & 4 \\
\hline AST (IU/I) & 24 & 3 \\
\hline Alkaline phosphatase (IU/I) & 152 & 44 \\
\hline Bilirubine $(\mu \mathrm{mol} / \mathrm{l})$ & 15 & 1 \\
\hline APTT (s) & 28 & 1 \\
\hline INR & 1 & 0 \\
\hline Urea $(\mathrm{mmol} / \mathrm{l})$ & 4.5 & 0.3 \\
\hline Creatinine $(\mu \mathrm{mol} / \mathrm{l})$ & 81 & 6 \\
\hline Albumin $(g / l)$ & 37 & 6 \\
\hline C-reactive protein (mg/l) & 5.8 & 3.0 \\
\hline Glucose (mmol/l) & 6.1 & 0.5 \\
\hline
\end{tabular}

Surgical procedures used were $6 \mathrm{x}$ hepatectomy, $1 \mathrm{x}$ pancreaticoduodenectomy and 1 $x$ duodenectomy. AST, aspartate amino transferase; APPT, activated partial thromboplastin time: INR. international normalized ratio. 
Moreover the potential role of the liver in modulating the release of intestinally derived citrulline to the systemic circulation is generally neglected, since early in vitro studies suggested that the liver is inert towards citrulline passing through its vascular bed (6). We showed recently, however, that the human liver is capable of taking up a substantial amount of intestinally derived citrulline (7).

The aim of the present study was to quantify the intestinal conversion of glutamine to citrulline and to study hepatic metabolism of citrulline in man. Studies were conducted in patients undergoing upper gastrointestinal surgery, which enabled access to intra-abdominal vessels. This allowed us to sample blood from the portal and hepatic veins and to measure intestinal and hepatic blood flows to quantify net amino acid flux. By simultaneous stable isotope infusion we were also able to study the absolute uptake (disposal) and absolute release (production) of glutamine and citrulline by the intestines and the liver as well as the whole body plasma rates of appearance of these amino acids.

\section{Methods}

\section{Patients}

Eight patients undergoing gastrointestinal surgery (6 liver resections, 1 pancreaticoduodenectomy, 1 duodenectomy) at the University Hospital Maastricht were studied. All but one of the patients were operated on for malignant disease. On the day of admission routine blood tests were performed, a dietary questionnaire was obtained by a dietician and body composition was measured. Patients with known parenchymal liver disease, inborn errors of metabolism, diabetes mellitus type I or cancer cachexia were excluded from the study. Patient characteristics are presented in Table 1. Oral intake except for water was ceased at $20.00 \mathrm{~h}$ on the day of admission and all patients were transported to the operation theatre at approximately $07.30 \mathrm{~h}$ the next day. The study was approved by the Medical Ethical committee of the University Hospital Maastricht, all patients gave written informed consent, and the study conformed to the Declaration of Helsinki.

\section{Stable isotope study}

Isotopes. $\left[2-{ }^{15} \mathrm{~N}\right] \mathrm{Glutamine}$ was obtained from Cambridge Isotope Laboratories (Woburn, MA, USA) and [ureido- ${ }^{13} \mathrm{C}-{ }^{2} \mathrm{H}_{2}$ ]citrulline from ARC laboratories (Apeldoorn, the Netherlands). Both tracers were dissolved in sterile water, and thereafter sodium chloride was added to create an isotonic solution. Sterility and 
non-pyrogenity were tested and confirmed by the hospital pharmacy. Before the experiment aliquots of the stock solution were diluted in normal saline to obtain the final infusion solution.

Table 2. Tracer dosages

\begin{tabular}{lll}
\hline & Infusion rate $(\boldsymbol{\mu m o l} / \mathbf{k g} / \mathbf{h})$ & Priming $(\boldsymbol{\mu m o l} / \mathbf{k g})$ \\
$\mathrm{L}-\left[2-{ }^{15} \mathrm{~N}\right]$ Glutamine & 15.8 & 18.7 \\
$\mathrm{~L}-\left[\right.$ ureido- $\left.{ }^{13} \mathrm{C}-{ }^{2} \mathrm{H}_{2}\right]$ Citrulline & 0.14 & 0.43 \\
\hline
\end{tabular}

\section{Study protocol}

Anaesthetic management was in accordance with institutional routines and included placement of two peripheral venous catheters, an epidural catheter for pre- and postoperative analgesia, an arterial line, and a central venous line. Anaesthesia was maintained using isoflurane and propofol. After induction of anaesthesia, an additional peripheral venous catheter was placed in an antecubital vein for tracer infusion. This catheter was kept patent with normal saline until the start of the tracer infusion. After laparotomy a baseline blood sample was drawn from the arterial line, followed by the start of a primed continuous intravenous tracer infusion (dosages in Table 2). Blood samples were drawn from the arterial line every 30 min for the following $2 \mathrm{~h}$. After $1 \mathrm{~h}$, when based upon prior experience an isotopic steady state was known to be present, blood was drawn from the portal vein and the middle hepatic vein by direct puncture, simultaneously with arterial blood sampling. Blood sampling occurred before organ transection to resemble the physiological situation as closely as possible. Blood was collected in prechilled heparinized vacuum tubes (BD Vacutainer, Franklin Lakes, NJ, USA) and placed on ice. Within $1 \mathrm{~h}$, blood was centrifuged (10 $\mathrm{min}, 4000 \mathrm{~g}, 4^{\circ} \mathrm{C}$ ) and $500 \mu \mathrm{l}$ of plasma were added to 80 mg dry sulphosalicylic acid (Across Inc., Geel, Belgium) to precipitate plasma proteins. After vortex mixing, deproteinized plasma samples were snap frozen in liquid nitrogen and stored at $-80^{\circ} \mathrm{C}$ until analysis. Before centrifugation, haematocrit of each blood sample was determined using a micro capillary centrifuge.

\section{Duplex flow measurement}

Hepatic and intestinal blood flows were measured by means of colour Doppler ultrasound (Aloka Prosound SSD 5000, Aloka Co., Ltd, Tokyo, Japan) as described before (8). Briefly, time-averaged mean velocities of the blood stream and cross-sectional area of the portal vein and hepatic artery were measured 
before their hilar bifurcations. Blood flow was calculated by multiplying the cross-sectional area of the vessel by the velocity of the blood stream. Plasma flow (PF) was calculated by correcting blood flow (BF) for haematocrit $(\mathrm{Ht})$ : $\mathrm{PF}=$ BF x $(1-\mathrm{Ht})$. Hepatic (and splanchnic) plasma flow was calculated by adding up plasma flows in the portal vein and hepatic artery. Mean blood flows were used to calculate organ fluxes.

\section{Laboratory analysis}

Amino acid concentrations in deproteinized samples and infusates were measured using high performance liquid chromatography as described elsewhere (9). Glutamine, citrulline and arginine enrichments were measured by liquid chromatography-mass spectrometry (10). Coefficients of variation were $2.7 \%$ for $\left[{ }^{15} \mathrm{~N}\right]$ glutamine enrichments, $5.9 \%$ for $\left[{ }^{15} \mathrm{~N}\right]$ citrulline enrichments, $25 \%$ for $\left[{ }^{13} \mathrm{C}^{2}{ }^{2} \mathrm{H}_{2}\right]$ citrulline enrichments and $<2 \%$ for amino acid concentrations. Arterial $\mathrm{pH}$ and $\mathrm{HCO}_{3}^{-}$were measured by an automated analyser (GEM Premier 3000, Instrumentation Laboratory, Breda, the Netherlands).

\section{Calculations}

Isotopic enrichment was expressed as tracer-to-tracee ratio (TTR,\%), taking into account the contribution of overlapping isotopomer distributions of the tracee and tracers with lower masses to the measured TTR as described by (11) Metabolic fluxes and conversions were calculated using established formulas for radioactive and stable isotopic tracers as described in detail by (12). In summary, whole body plasma rates of appearance of the tracee (Q) were calculated from the infusion rate of the tracer (IR) and the corresponding arterial enrichment $\left(\mathrm{TTR}_{\mathrm{A}}\right)$ :

$\mathrm{Q}=\mathrm{IR} / \mathrm{TTR} \mathrm{R}_{\mathrm{A}}$

The whole body conversion of plasma glutamine (gln) to plasma citrulline (cit) (Qgln-cit) was calculated from arterial $\left[{ }^{15} \mathrm{~N}\right]$ glutamine enrichment $\left(T T R^{15} \mathrm{Ng} / \mathrm{n}\right)$, arterial $\left[{ }^{15} \mathrm{~N}\right]$ citrulline enrichment $\left(T_{T R}{ }^{15} \mathrm{Ncit}\right)$ and citrulline plasma rate of appearance (Qcit) calculated from $\left[{ }^{13} \mathrm{C}^{2}{ }^{2} \mathrm{H}_{2}\right]$ citrulline infusion rate and TTRA using eqn (1):

Qgln-cit $=\left(T T R_{15 \text { Nit }} / T T R_{15 \text { Ngln }}\right) \times Q_{\text {gln-cit }}$

Net amino acid fluxes across the portal drained viscera (PDV) and the splanchnic area were calculated from arterial $[\mathrm{A}]$ and venous $[\mathrm{V}]$ concentrations 
(PDV: portal vein, splanchnic area: hepatic vein) and from portal and splanchnic plasma flow (pf), respectively.

Net flux $=([\mathrm{V}]-[\mathrm{A}]) \times \mathrm{pf}$

Accordingly, a negative flux indicates organ specific net uptake whereas a positive flux indicates net release. Unidirectional absolute organ specific amino acid uptake (disposal) by the PDV and the splanchnic area was calculated from arteriovenous $(A-V)$ balances of the infused tracers (tracer net balance, tNB) and from venous enrichments $\left(T_{T R}\right)$ of the infused tracers, which most accurately represents intracellular enrichment (13), needed to convert tracer uptake (tNB) to unidirectional tracee uptake (disposal):

$\mathrm{tNB}=\left[\left(\mathrm{TTR}_{\mathrm{A}} \times[\mathrm{A}]\right)-\left(\mathrm{TTR}_{\mathrm{V}}\right) \times[\mathrm{V}]\right) \times \mathrm{pf}$

Disposal $=\mathrm{tNB} / \mathrm{TTR}_{\mathrm{V}}$

Since organ specific net balance is the resultant of disposal and organ specific production, organ specific production can be calculated from net flux (eqn (3)) and disposal (eqn (5)):

Production $=$ net flux + disposal

The intestinal conversion of glutamine to citrulline $\left(Q_{g \mid n-c i t, P D V}\right)$ was calculated from the PDV tracer net balance of $\left[{ }^{15} \mathrm{~N}\right]$ citrulline ( $\mathrm{tNB}_{15 \mathrm{Ncit}}, \mathrm{PDV}$ ) (eqn (4) and the arterial enrichment of $\left[{ }^{15} \mathrm{~N}\right]$ glutamine $\left(\mathrm{TTR}_{15 \mathrm{Ngln}}\right)$, corrected for the extraction of $\left[{ }^{15} \mathrm{~N}\right]$ citrulline reaching the PDV through the circulation:

$F E=t N B / T T R_{A} \times[A] \times p f$

$\mathrm{Q}_{\mathrm{gln} \text {-cit, } P D V}=\left(\mathrm{tNB}_{15 \mathrm{Ncit}}-\mathrm{FE} \times[\mathrm{A}]_{\mathrm{cit}} \times \mathrm{TTR}_{\mathrm{A} 15 \mathrm{Ncit}} \times \mathrm{pf}\right) / \mathrm{TTR}_{15 \mathrm{Ngln}}$

Hepatic amino acid metabolism was quantified by subtracting PDV net flux, disposal and production from their corresponding splanchnic values.

\section{Data analysis}

In depth analysis of raw data revealed perceptibly too low arterial enrichments of $\left[{ }^{13} \mathrm{C}-{ }^{2} \mathrm{H}_{2}\right]$ citrulline in two cases (arterial enrichment below venous enrichments and below adjacent arterial enrichments) and too low portal $\left[{ }^{13} \mathrm{C}-\right.$ ${ }^{2} \mathrm{H}_{2}$ ]citrulline enrichments in two other cases (portal enrichment below hepatic 
venous enrichment). The perceptibly erroneous arterial values were replaced by the average enrichment of two adjacent arterial samples. For ethical reasons the portal vein was sampled only once and no substitute values could be deduced from repeated measures in the two latter cases. Substitute values for portal $\left[{ }^{13} \mathrm{C}^{2} \mathrm{H}_{2}\right]$ citrulline enrichment in these two cases were chosen so that $\left[{ }^{13} \mathrm{C}^{2}{ }^{2} \mathrm{H}_{2}\right]$ citrulline balance across the PDV (eqn (4)) was zero, which equalled the average value in the other subjects. No obvious erroneous values were found in other samples and for other isotopic enrichments.

\section{Statistics}

Arterial enrichment curves were fitted to calculate a mean steady state value per individual. Arteriovenous gradients were tested versus a theoretical mean of zero using a one sample t test. Correlations were tested using Pearson's test. Results are expressed as means (SEM) All statistical calculations were performed using Prism 4.0 for Windows (GraphPad Software Inc., San Diego, CA, USA). A $p$ value $<0.05$ was considered to indicate statistical significance.

\section{Results}

Isotopic enrichments of glutamine and citrulline

Within 30 min isotopic steady state was achieved for both administered tracers (Figures $1 \mathrm{~A}$ and $\mathrm{B}$ ), which is in keeping with previous data from our group. Based upon arterial enrichments at steady state, it was calculated that whole body glutamine plasma rate of appearance was $240(15) \mu \mathrm{mol} / \mathrm{kg} / \mathrm{h}$ and whole body citrulline plasma rate of appearance was $6.2(0.7) \mu \mathrm{mol} / \mathrm{kg} / \mathrm{h}$. During the experiment citrulline enrichment could be detected at mass $+1(m+1)$ (Figure $1 \mathrm{~A})$, reflecting the conversion of $\left[{ }^{15} \mathrm{~N}\right]$ glutamine to $\left[{ }^{15} \mathrm{~N}\right]$ citrulline. Average citrulline enrichment enrichment at $m+1$ was $5.7(0.4) \%$. The ratio between arterial $\left[{ }^{15} \mathrm{~N}\right]$ citrulline and $\left[{ }^{15} \mathrm{~N}\right]$ glutamine enrichments indicates that approximately $80 \%$ of plasma citrulline is derived from plasma glutamine. According to eqn (2) this comes down to a conversion rate of $5.1(0.7)$ $\mu \mathrm{mol} / \mathrm{kg} / \mathrm{h}$. 


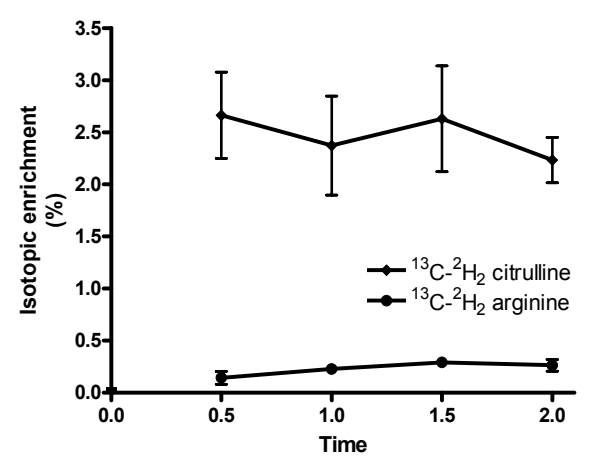

(h)

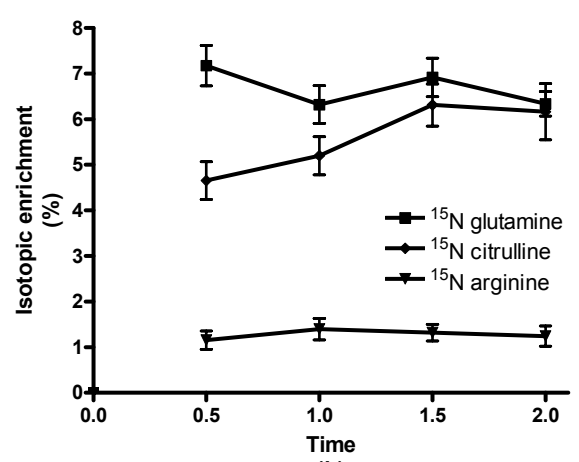

(h)

Figure 1. Eight patients undergoing upper gastrointestinal surgery received a primed, continuous intravenous infusion of [2-15N]glutamine $(A)$ and [ureido-13C-2H2]citrulline (B). Within $30 \mathrm{~min}$ an isotopic steady state was achieved for both administered tracers. During the experiment significant enrichments of isotopically labelled end products [15N]citrulline $(B)$ and [13C-2H2]arginine (B) occurred. The ratio between product enrichment and precursor enrichment represents the contribution of the precursor to whole body plasma rate of appearance of the product according to eqn (2).

Qualitative relationships between glutamine, citrulline and arginine

During the study significant enrichments of arginine were found in arterial plasma at $m+1$ (Figure $1 \mathrm{~A}$ ) and $\mathrm{m}+3$ (Figure 1B), reflecting the conversion of $\left[{ }^{15} \mathrm{~N}\right]$ glutamine to $\left[{ }^{15} \mathrm{~N}\right] \mathrm{citrulline}$ and $\left[{ }^{15} \mathrm{~N}\right]$ arginine and the conversion of $\left[{ }^{13} \mathrm{C}-\right.$ ${ }^{2} \mathrm{H}_{2}$ ]citrulline to $\left[{ }^{13} \mathrm{C}^{2} \mathrm{H}_{2}\right.$ ]arginine, respectively. The ratio between arginine $\mathrm{m}+3$ and citrulline $m+3(0.10(0.02))$ indicates that approximately $10 \%$ of arginine released in the circulation is newly formed from plasma citrulline.

\section{Flow measurements}

Duplex flow measurements yielded mean portal venous and hepatic arterial blood flows of 836 (143) $\mathrm{ml} / \mathrm{min}$ and $442(85) \mathrm{ml} / \mathrm{min}$, respectively. Mean blood flows were in agreement with data in the literature $(8,14)$.

\section{Glutamine and citrulline metabolism across the portal drained viscera}

Net amino acid flux across an organ (arteriovenous concentration gradient times plasma flow) is the resultant of absolute unidirectional uptake (disposal) and absolute unidirectional release (production). Disposal can be measured by 
stable isotope techniques since appropriately chosen isotopic tracers cannot be produced within the body. From the organ specific disposal calculated from tracer data and the organ specific net flux, absolute production rates can be quantified for organs that simultaneously consume and produce a single amino acid. As expected, net glutamine uptake by the PDV was observed (Figure 2). Absolute PDV glutamine uptake (disposal) calculated from $\left[{ }^{15} \mathrm{~N}\right]$ glutamine data was 45 (9) $\mu \mathrm{mol} / \mathrm{kg} / \mathrm{h}$ and could account for $19 \%$ of plasma glutamine turnover. In addition to their substantial glutamine uptake, the PDV tended to produce glutamine and release it to the portal vein $(17$ (8) $\mu \mathrm{mol} / \mathrm{kg} / \mathrm{h}$ ). This value, however, was not statistically different from zero $(p=0.07)$. Tracer data further revealed that glutamine disposal by the PDV was significantly correlated with glutamine supply with a fractional extraction of $0.15(0.03)$. No such correlation was found between glutamine supply and net glutamine flux (Figure 3). Thirteen per cent of glutamine taken up by the PDV was converted to citrulline (Figure 2). The balance of $\left[{ }^{13} \mathrm{C}^{-}{ }^{2} \mathrm{H}_{2}\right]$ citrulline across the PDV and hence PDV citrulline disposal (extraction) was not significantly different from zero (Figure 4). This indicates that net PDV citrulline flux equals total citrulline production (Figure 4). The production of citrulline derived from glutamine equalled the total production of citrulline, showing that glutamine is quantitatively the only important precursor for citrulline produced by the PDV (Figure 4). There was an excellent agreement between total PDV citrulline production (calculated from $\left[{ }^{13} \mathrm{C}-{ }^{2} \mathrm{H}_{2}\right]$ citrulline, eqn (6)) and citrulline released from the PDV, derived from glutamine (calculated

\section{Glutamine PDV}

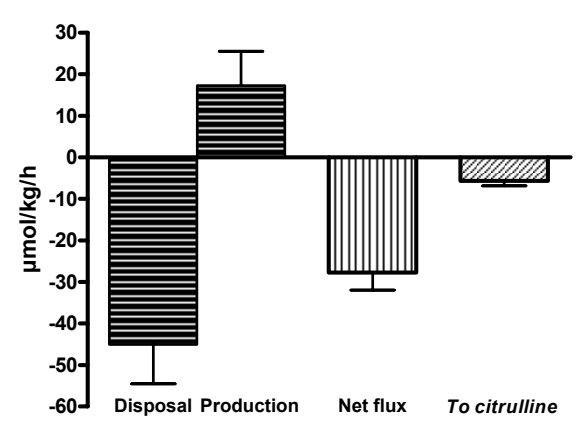

Figure 2. Portal drained viscera glutamine metabolism in eight patients undergoing upper gastrointestinal surgery. The PDV disposed glutamine from the circulation $(p=0.004$ versus zero) and simultaneously tended to produce glutamine and release it into the portal vein $(p=0.07$ versus zero). Glutamine net flux and PDV glutamine-to-citrulline conversion were both significantly different from zero $(p=0.0003$ and $p=0.013$, respectively). Thirteen per cent of intestinal glutamine uptake was used for citrulline production. 
from $\left[{ }^{15} \mathrm{~N}\right]$ citrulline and $\left[{ }^{15} \mathrm{~N}\right]$ glutamine data, eqn (8)). No release of $\left[{ }^{13} \mathrm{C}-2 \mathrm{H}_{2}\right]$ or $\left[{ }^{15} \mathrm{~N}\right]$ arginine by the PDV was found.

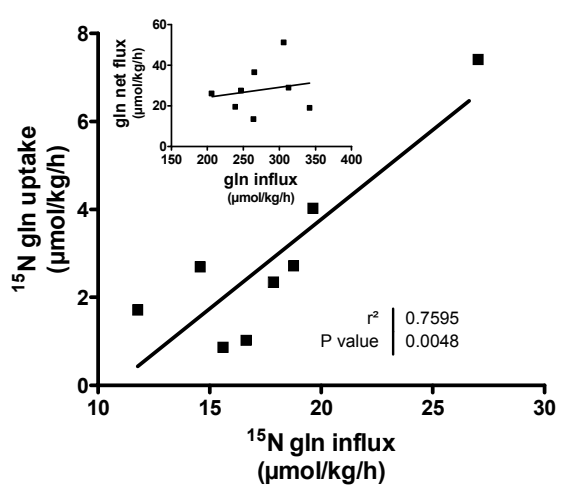

Figure 3. Fractional extraction of glutamine by the portal drained viscera in eight patients undergoing upper gastrointestinal surgery. $\left[^{15} \mathrm{~N}\right] \mathrm{Glutamine}$ uptake, representing unidirectional glutamine disposal, was related to $\left[^{15} \mathrm{~N}\right]$ glutamine influx, evidencing that PDV glutamine disposal is related to PDV glutamine influx. PDV net flux, which is the resultant of PDV glutamine disposal and production, is not related to glutamine influx (inset).

Citrulline PDV

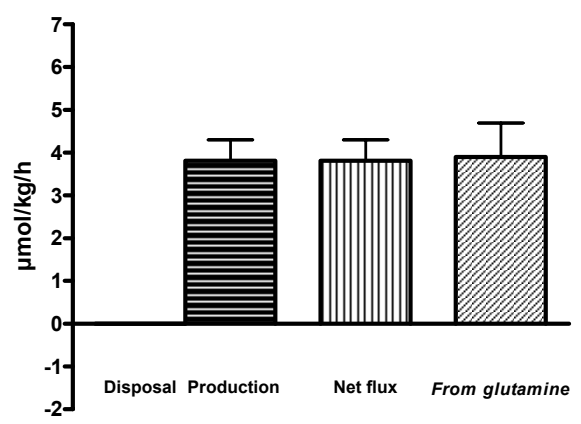

Figure 4. Citrulline metabolism by the portal drained viscera in eight patients undergoing upper gastrointestinal surgery. No PDV citrulline disposal was found, whereas the PDV released citrulline into the portal vein (production and net flux both $p<0.005$ versus zero). Quantitatively glutamine was the only important precursor for PDV citrulline production.

\section{Splanchnic and hepatic glutamine and citrulline metabolism}

Arterial $\mathrm{pH}$ during sampling of hepatic venous blood was 7.4 (0.03). Net splanchnic glutamine flux (Figure 5A) was similar to net PDV glutamine flux, 
indicating that net hepatic glutamine flux was not significantly different from zero (Figure 5B). Tracer data, however, revealed that this zero net balance was the resultant of very active glutamine uptake and glutamine release by the liver (Figure 5B). Hepatic glutamine release (73 (22) $\mu \mathrm{mol} / \mathrm{kg} / \mathrm{h}$ ) could account for about $30 \%$ of total plasma glutamine appearance. Net splanchnic citrulline flux (Figure 6A) was dominated by intestinal citrulline production, resulting in a hepatic citrulline net flux that was not significantly different from zero. Tracer data, however, show that the liver is capable of taking up citrulline (hepatic citrulline disposal; $p=0.046$ versus zero). This suggests that the net balance of citrulline across the liver, like that of glutamine, is determined by the opposing

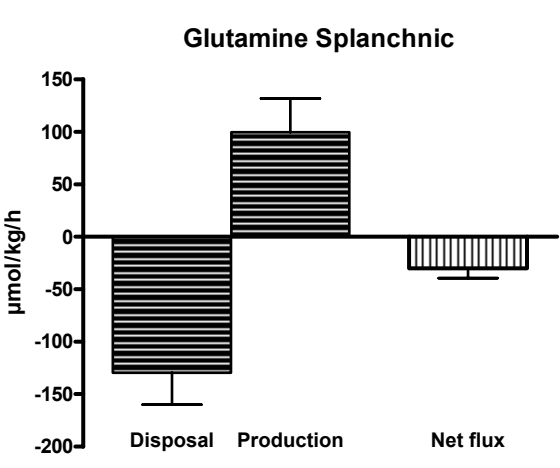

A

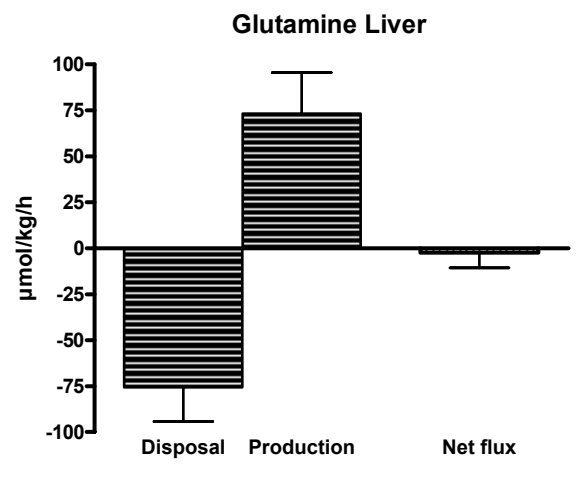

$B$

Figure 5. Splanchnic $(A)$ and hepatic $(B)$ glutamine metabolism in eight patients undergoing upper gastrointestinal surgery. The splanchnic area simultaneously disposed and produced glutamine, leading to net glutamine consumption (all $p<0.02$ versus zero). Splanchnic glutamine net flux was determined by PDV glutamine net flux. The liver simultaneously disposed and released large amounts of glutamine (both $p<0.02$ ), resulting in a zero net balance.

effects of active hepatic citrulline uptake and similarly active hepatic release, although hepatic citrulline release failed to reach statistical significance $(p=0.138)$ (Figure 6B). No hepatic release of $\left[{ }^{15} \mathrm{~N}\right]$ citrulline, $\left[{ }^{13} \mathrm{C}-{ }^{2} \mathrm{H}_{2}\right]$ arginine or $\left[{ }^{15} \mathrm{~N}\right]$ arginine was found.

\section{Discussion}

This study was set up to address the role of the intestines and the liver in the metabolism of glutamine and citrulline in humans. Net fluxes of glutamine and citrulline across these organs are the resultant of both uptake and production, 

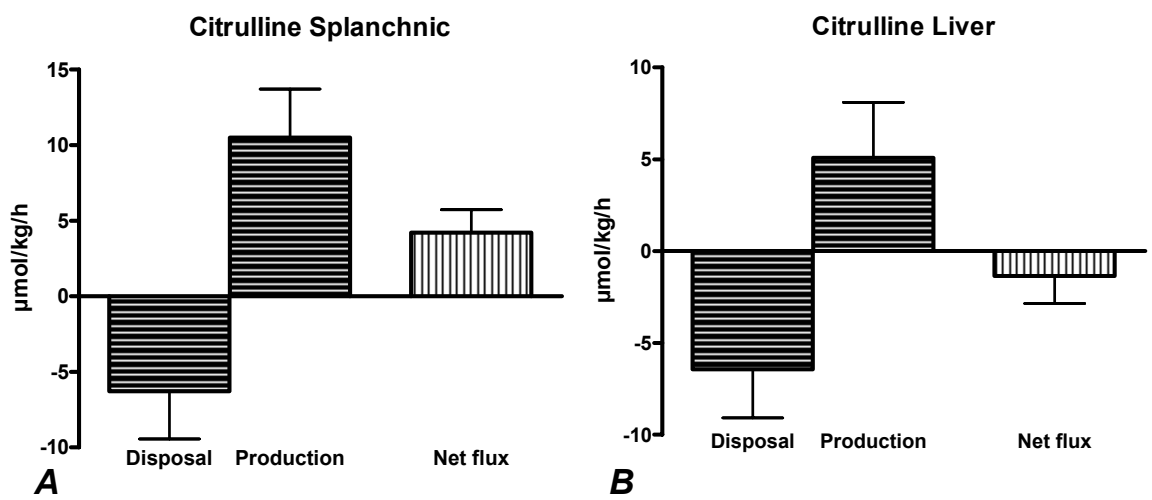

Figure 6. Splanchnic (A) and hepatic (B) citrulline metabolism in eight patients undergoing upper gastrointestinal surgery. The splanchnic area tended to simultaneously dispose of and produce citrulline ( $p=0.085$ and $p=0.014$ versus zero, respectively). Net splanchnic citrulline flux ( $p=0.027$ versus zero) was determined by PDV net flux. The liver disposed a considerable amount of citrulline ( $p=0.039$ versus zero). However, both hepatic citrulline production and hepatic net flux failed to reach statistical significance.

and therefore assessment of net fluxes may not give reliable information about the absolute unidirectional uptake (disposal) or absolute unidirectional release (production). We used stable isotope techniques to unravel the contribution of both unidirectional disposal and unidirectional release to net organ flux. Whole body rate of plasma appearance of glutamine $(240 \mu \mathrm{mol} / \mathrm{kg} / \mathrm{h})$ was in the range typically reported in the literature (15-18). Also in agreement with data in the literature (1-4), we show that the PDV take up glutamine from the circulation. Interestingly, tracer data revealed that absolute unidirectional glutamine disposal by the portal drained viscera is related to glutamine supply, a phenomenon that could not be detected before by measurement of net fluxes $(3,4)$. This observation is of interest because it indicates that intestinal glutamine metabolism is regulated by glutamine supply in non-depleted humans.

The liver simultaneously disposed of and released glutamine, ultimately leading to a zero net balance. This high bidirectional flux enables the liver to respond rapidly to changes in nitrogen metabolism and acid-base balance. Mechanisms of hepatic glutamine uptake and release have been disentangled in depth. Both processes occur in different parts of the lobule by zonation of glutamine metabolizing enzymes (19). Glutaminase is primarily located in periportal hepatocytes and serves the provision of nitrogen and carbon for ureagenesis and gluconeogenesis, respectively. Glutamine synthetase is expressed in perivenous hepatocytes and is suggested to function as an ammonia overflow trap that serves hepatic ammonia detoxification under conditions of diminished 
hepatic ureagenesis, such as during acidosis (20). Arterial $\mathrm{pH}$ in our patients was normal and also ureagenesis is not affected by this type of surgery (21). This shows that also under physiological conditions the liver is a key organ in glutamine homeostasis that accounts for approximately $30 \%$ of whole body plasma glutamine release in humans. However, we cannot rule out that these numbers may be somewhat different in human subjects without malignant disease. Unfortunately this subject category is virtually inaccessible with the currently applied methods.

Glutamine is a known precursor of citrulline. We found a rate of appearance of citrulline in plasma of $6.2 \mu \mathrm{mol} / \mathrm{kg} / \mathrm{h}$. That is approximately $35 \%$ lower than values reported by $(5,22)$, which to our knowledge are so far the only published human data. Unpublished data from our own group have yielded whole body rates of plasma appearance of citrulline varying between 13.4 and 22.0 $\mu \mathrm{mol} / \mathrm{kg} / \mathrm{h}$ (23). Against this background it should be noted that splanchnic unidirectional citrulline production exceeded the calculated whole body plasma rate of appearance of citrulline. Hence the value for whole body citrulline flux obtained in the present study may be an underestimate of the true plasma rate of appearance of citrulline. Further studies are needed to elucidate this. The conversion of glutamine to citrulline has not been quantified before in vivo in man. From the ratio between $\left[{ }^{15} \mathrm{~N}\right]$ glutamine and $\left[{ }^{15} \mathrm{~N}\right]$ citrulline plasma enrichments, however, it can be concluded that approximately $80 \%$ of plasma citrulline is immediately derived from plasma glutamine. Although measurement of $\left[{ }^{13} \mathrm{C}^{2} \mathrm{H}_{2}\right]$ citrulline enrichment yielded slightly more variable data than measurement of $\left[{ }^{15} \mathrm{~N}\right]$ glutamine and $\left[{ }^{15} \mathrm{~N}\right]$ citrulline enrichment, the validity of the resulting data was confirmed by the excellent agreement between PDV citrulline production calculated from $\left[{ }^{13} \mathrm{C}^{2} \mathrm{H}_{2}\right]$ citrulline data and from $\left[{ }^{15} \mathrm{~N}\right]$ citrulline data. In the present study, no significant net flux of citrulline across the liver was observed, although there was a trend towards net hepatic uptake of citrulline. Absolute unidirectional hepatic citrulline uptake, measured by tracer data, however, was significant and coincided with a trend towards hepatic citrulline release. Studies in animals (24) and in humans with liver cirrhosis (4) have previously demonstrated the capability of the liver to take up citrulline. Recent data on humans with a normal non-cirrhotic liver are in keeping with this (7). Since unidirectional hepatic citrulline uptake has not been recognized, mechanisms regulating hepatic citrulline uptake and release are unknown. This observation requires further study and is subject to ongoing investigation in our group.

Since citrulline is the precursor for arginine synthesis it can be conceived that arginine is an ultimate product of glutamine metabolism. This is supported by the observation of increased arginine levels during glutamine supplementation $(25,26)$. The conversion of glutamine to arginine is thought to be effected in an 
inter-organ pathway involving intestinal glutamine to citrulline and renal citrulline to arginine conversion $(6,20,27,28)$, but the existence of this pathway and its potential significance has not been quantified before in vivo in humans. We now show that the human gut indeed converts glutamine to citrulline. In addition, significant enrichments of arginine at $\mathrm{m}+1$ and $\mathrm{m}+3$ were found in arterial plasma. This reflects the conversion of plasma citrulline to plasma arginine and confirms that glutamine is a precursor for arginine de novo synthesis. The ratio between citrulline $m+3$ and arginine $m+3(0.10)$ indicates that approximately $10 \%$ of plasma arginine is derived from citrulline via de novo synthesis (probably in the kidney) (7), which is in agreement with data in the literature (5), the remainder probably being derived from protein breakdown (23). Interestingly, the ratio between arginine $\mathrm{m}+1$ and glutamine $\mathrm{m}+1(0.19)$ exceeded the ratio between citrulline $m+1$ and arginine $m+1$ by a factor of 2 . This probably indicates that the interorgan transport of citrulline is not the only way to transfer the amino nitrogen atom of glutamine to arginine. Most likely these data are explained by a pathway involving the conversion of $\left[{ }^{15} \mathrm{~N}\right]$ glutamine to $\left[{ }^{15} \mathrm{~N}\right] g$ lutamate and subsequent transamination of $\left[{ }^{15} \mathrm{~N}\right]$ glutamate. Subsequent transamination reactions ultimately can lead to the formation of $\left[{ }^{15} \mathrm{~N}\right]$ aspartate, which can become the precursor for $\left[{ }^{15} \mathrm{~N}\right]$ argininosuccinate and [guanido- $\left.{ }^{15} \mathrm{~N}\right]$ arginine (in contrast to amino$\left[{ }^{15} \mathrm{~N}\right]$ arginine, derived from the glutamine-citrulline-arginine pathway). It has been suggested that the availability of nitrogen donors for argininosuccinate synthesis limits the endogenous synthesis rate of arginine (29).

In conclusion, this is the first human study that quantifies the role of the intestines and the liver in the conversion of glutamine to citrulline and arginine. Plasma glutamine can account for approximately $80 \%$ of plasma citrulline production. The intestines account for the major part of this conversion although splanchnic citrulline release to the systemic circulation may be limited by hepatic citrulline extraction. Plasma citrulline accounts for $10 \%$ of plasma arginine release. Intestinal glutamine metabolism is crucial for endogenous arginine synthesis in humans. 


\section{References}

1. Windmueller HG, Spaeth AE. Uptake and metabolism of plasma glutamine by the small intestine. J Biol Chem 1974;249:5070-9.

2. Boelens PG, van Leeuwen PA, Dejong CH, Deutz NE. Intestinal renal metabolism of Lcitrulline and L-arginine following enteral or parenteral infusion of $L$-alanyl-L- $\left[2,{ }^{15} \mathrm{~N}\right] g /$ lutamine or L-[2, $\left.{ }^{15} \mathrm{~N}\right] g$ lutamine in mice. Am J Physiol Gastrointest Liver Physiol 2005;289:G679-85.

3. van der Hulst RR, von Meyenfeldt MF, Deutz NE, Soeters PB. Glutamine extraction by the gut is reduced in depleted [corrected] patients with gastrointestinal cancer. Ann Surg 1997;225:112-21.

4. Olde Damink SW, Jalan R, Redhead DN, Hayes PC, Deutz NE, Soeters PB. Interorgan ammonia and amino acid metabolism in metabolically stable patients with cirrhosis and a TIPSS. Hepatology 2002;36:1163-71.

5. Castillo L, Beaumier L, Ajami AM, Young VR. Whole body nitric oxide synthesis in healthy men determined from $\left[{ }^{15} \mathrm{~N}\right]$ arginine-to- $\left[{ }^{15} \mathrm{~N}\right] c$ citrulline labeling. Proc Natl Acad Sci U S A 1996;93:11460-5.

6. Windmueller HG, Spaeth AE. Source and fate of circulating citrulline. Am.J.Physiol. 1981;241:E473-E480

7. van de Poll MCG, Siroen MP, van Leeuwen PA, et al. Interorgan amino acid exchange in humans: consequences for arginine and citrulline metabolism. Am J Clin Nutr 2007;85:16772.

8. Siroen MP, van der Sijp JR, Teerlink $T$, van Schaik C, Nijveldt RJ, van Leeuwen PA. The human liver clears both asymmetric and symmetric dimethylarginine. Hepatology 2005;41:559-65.

9. van Eijk HM, Rooyakkers DR, Deutz NE. Rapid routine determination of amino acids in plasma by high-performance liquid chromatography with a 2-3 microns Spherisorb ODS II column. J Chromatogr 1993;620:143-8.

10. van Eijk HM, Rooyakkers DR, Soeters PB, Deutz NE. Determination of amino acid isotope enrichment using liquid chromatography-mass spectrometry. Anal Biochem 1999;271:8-17.

11. Vogt JA, Chapman TE, Wagner DA, Young VR, Burke JF. Determination of the isotope enrichment of one or a mixture of two stable labelled tracers of the same compound using the complete isotopomer distribution of an ion fragment; theory and application to in vivo human tracer studies. Biol Mass Spectrom 1993;22:600-12.

12. Bruins MJ, Soeters PB, Lamers WH, Deutz NE. L-arginine supplementation in pigs decreases liver protein turnover and increases hindquarter protein turnover both during and after endotoxemia. Am J Clin Nutr 2002;75:1031-44.

13. Biolo G, Fleming RY, Maggi SP, Wolfe RR. Transmembrane transport and intracellular kinetics of amino acids in human skeletal muscle. Am J Physiol 1995;268:E75-84.

14. Schindl MJ, Millar A, Redhead DN, et al. The adaptive response of the reticulo-endothelial system to major liver resection in man. Ann Surg 2006;243:507-14.

15. Van Acker BA, Hulsewe KW, Wagenmakers AJ, et al. Absence of glutamine isotopic steady state: implications for the assessment of whole-body glutamine production rate. Clin Sci (Lond) 1998;95:339-46.

16. van Acker BA, Hulsewe KW, Wagenmakers AJ, Soeters PB, von Meyenfeldt MF. Glutamine appearance rate in plasma is not increased after gastrointestinal surgery in humans. J Nutr 2000;130:1566-71.

17. Bourreille A, Humbert B, Maugere P, Galmiche JP, Darmaun D. Glutamine metabolism in Crohn's disease: a stable isotope study. Clin Nutr 2004;23:1167-75.

18. Raj DS, Welbourne $T$, Dominic EA, Waters $D$, Wolfe R, Ferrando A. Glutamine kinetics and protein turnover in end-stage renal disease. Am J Physiol Endocrinol Metab 2005;288:E37-46. 
19. Haussinger $D$, Sies $H$, Gerok W. Functional hepatocyte heterogeneity in ammonia metabolism. The intercellular glutamine cycle. J Hepatol 1985;1:3-14.

20. van de Poll MCG, Soeters PB, Deutz NEP, Fearon KC, Dejong CHC. Renal metabolism of amino acids: its role in interorgan amino acid exchange. Am J Clin Nutr 2004;79:185-97.

21. Dejong CHC, Dowidar N, Wigmore SJ, et al. Virtual hepatectomy and in vivo urea synthesis in patients with colorectal liver metastases. HPB 2001;3:114.

22. Castillo L, Sanchez M, Vogt J, et al. Plasma arginine, citrulline, and ornithine kinetics in adults, with observations on nitric oxide synthesis. Am J Physiol 1995;268:E360-7.

23. Luiking YC, Deutz NE. Isotopic investigation of nitric oxide metabolism in disease. Curr Opin Clin Nutr Metab Care 2003;6:103-8.

24. Remesy C, Demigne C, Aufrere J. Inter-organ relationships between glucose, lactate and amino acids in rats fed on high-carbohydrate or high-protein diets. Biochem J 1978;170:321-9.

25. Houdijk APJ, van Leeuwen PAM, Teerlink T, et al. Glutamine-enriched enteral diet increases renal arginine production. JPEN 1994;18:422-426.

26. Melis GC, Boelens PG, van der Sijp JR, et al. The feeding route (enteral or parenteral) affects the plasma response of the dipetide Ala-GIn and the amino acids glutamine, citrulline and arginine, with the administration of Ala-GIn in preoperative patients. Br J Nutr 2005;94:19-26.

27. Cynober. Can arginine and ornithine support gut functions? Gut 1994; Suppl 1:S42-S45.

28. Mistry SK, Greenfeld Z, Morris SM, Jr., Baylis C. The 'intestinal-renal' arginine biosynthetic axis in the aging rat. Mech Ageing Dev 2002;123:1159-65.

29. Dhanakoti SN, Brosnan JT, Herzberg GR, Brosnan ME. Renal arginine synthesis: studies in vitro and in vivo. Am J Physiol 1990;259:E437-42. 



\section{Chapter 6}

\section{Causes of}

\section{hepatocellular injury}

during liver surgery

MCG van de Poll, JPM Derikx, WA Buurman, WHM Peters HMJ Roelofs, SJ Wigmore, CHC Dejong 


\section{Abstract}

Liver failure following liver surgery is caused by an insufficient functioning remnant cell mass. This can be due to insufficient liver volume and can be aggravated by additional cell death during or after surgery. The aim of this study was to elucidate the causes of hepatocellular injury in patients undergoing liver resection. Markers of hepatocyte injury (AST, GSTa, and L-FABP) and inflammation (IL-6) were measured in plasma of patients undergoing liver resection with and without intermittent inflow occlusion. To study the separate involvement of the intestines and the liver in systemic L-FABP release, arteriovenous concentration differences for L-FABP were measured. During liver manipulation, liver injury markers increased significantly. Arterial plasma levels and transhepatic and transintestinal concentration gradients of L-FABP indicated that this increase was exclusively due to hepatic and not due to intestinal release. Intermittent hepatic inflow occlusion, anesthesia, and liver transection did not further enhance arterial L-FABP and GSTa levels. Hepatocyte injury was followed by an inflammatory response. This study shows that liver manipulation is a leading cause of hepatocyte injury during liver surgery. A potential causal relation between liver manipulation and systemic inflammation remains to be established; but since the inflammatory response is apparently initiated early during major abdominal surgery, interventions aimed at reducing postoperative inflammation and related complications should be started early during surgery or beforehand. 


\section{Introduction}

Liver failure is a severe complication of liver surgery, occurring when there is insufficient remnant cell mass postoperatively. This can be due to excessive resection, leaving a too small remnant liver volume, but in some cases liver failure occurs in patients with a seemingly sufficient remnant liver volume (1). In these cases the functional capacity of the remaining cell mass is probably impaired by secondary processes. Recognition and modulation of factors impairing cell survival is crucial to enhance liver function following liver surgery. In this context much attention has been paid to the effects of ischemia and reperfusion.

Ischemia-reperfusion is a frequently encountered phenomenon in liver resection, caused by temporary occlusion of blood flow to the liver (Pringle maneuver), which is a popular way to reduce blood loss during parenchymal liver transection. Ischemia-reperfusion induces energy depletion and generation of reactive oxygen species. Although several endogenous protection mechanisms aimed at supporting cell survival are activated during ischemiareperfusion (2), excessive energy depletion or oxidative stress ultimately results in apoptotic or necrotic cell death.

Interestingly, it has been shown that plasma levels of markers for hepatocellular injury increase before liver transection and before application of the Pringle maneuver, suggesting that factors other than ischemia-reperfusion may cause hepatocyte demise during liver surgery (3). In this context a role has been proposed for the hepatotoxic effects of anesthesia (4), the effects of systemic inflammation, probably secondary to intestinal manipulation (5), and the effects of manipulation of the liver itself during perihepatic dissection and mobilization (6). The aim of this study was to elucidate the causes of early hepatocellular injury in patients undergoing liver resection.

\section{Methods}

\section{Patients}

Patients undergoing liver resection for secondary tumors in an otherwise healthy liver were studied (Table 1). All patients were anesthetized according to institutional routines using isoflurane and propofol. Surgery was commenced using a subcostal bilateral incision. Olivier retractors (Copharm, Abcoude, 
Table 1. Patient characteristics

\begin{tabular}{lll}
\hline & Hepatectomy w/o IPM (n=11) & Hepatectomy with IPM (n=9) \\
Age $(\mathrm{yr})$ & $57(36-72)$ & $54(33-75)$ \\
Male: Female & $9: 2$ & $5: 4$ \\
AST $(\mathrm{IU} / \mathrm{L})$ & $26(13-40)$ & $23(7-37)$ \\
LDH $(\mathrm{IU} / \mathrm{L})$ & $337(1-558)$ & $377(295-490)$ \\
Albumin $(\mathrm{g} / \mathrm{L})$ & $39.0(33.9-43.9)$ & $37.6(33.7-43.9)$ \\
CRP $(\mathrm{mg} / \mathrm{L})$ & $3.5(<1.0-8.7)$ & $5.0(<1.0-8.7)$ \\
Bilirubin $(\mu \mathrm{mol} / \mathrm{L})$ & $13.4(7.7-18.7)$ & $12.9(8.4-21)$ \\
\hline
\end{tabular}

IPM=intermittent Pringle maneuver. Blood chemistry was obtained during routine assessment one day preoperatively. Values are expressed as median (range).

the Netherlands) or Omni-Tracts were used to improve exposure. Before parenchymal division the liver was mobilized as described elsewhere, followed by intraoperative ultrasound (7). Cholecystectomy was performed routinely before liver transection. All patients had indwelling radial artery catheters placed for continuous monitoring of arterial blood pressure and blood sampling. Patients were nonrandomly assigned to one of two protocols (described below). Assignment was based upon the surgeon's preference of using the Pringle maneuver or not. If applied, an intermittent Pringle maneuver (15 min of ischemia, $5 \mathrm{~min}$ of reperfusion) was used by rubberband ligation of the hepatoduodenal ligament.

\section{Effects of intermittent Pringle maneuver on hepatocellular injury}

From nine patients undergoing liver resection with intermittent Pringle maneuver, arterial blood was sampled preoperatively before and after each period of $15 \mathrm{~min}$ of ischemia and $5 \mathrm{~min}$ of reperfusion and 90 minutes postoperatively. Systemic concentrations of two markers of hepatocellular injury, aspartate amino transferase (AST) and glutathione-s-transferase- $\alpha$ (GSTa), were measured as well as plasma levels of liver-type fatty acid binding protein (L-FABP). Methods of blood processing and laboratory analyses are described below. In addition, plasma levels of the inflammatory cytokine interleukin-6 (IL-6) were measured as described below.

\section{Source and fate of L-FABP}

From ten patients undergoing liver resection without the Pringle maneuver, arterial blood was sampled preoperatively and before liver transection. 
Simultaneous with the second arterial blood sample, blood was drawn from the portal vein, a hepatic vein, and the right renal vein by direct puncture to assess concentration gradients across organs. It should be noted that at this timepoint surgical procedures were identical in all patients, irrespective of the eventual application of a Pringle maneuver. L-FABP plasma concentrations were measured as described below and arteriovenous concentration differences were calculated to study the contribution of the intestines and the liver to systemic L-FABP release and to study renal clearance of L-FABP. Renal clearance was calculated by dividing the arteriovenous concentration gradient by the arterial concentration (uptake/influx). This quotient was multiplied by the percentage of blood flowing through the kidney to calculate fractional plasma clearance.

\section{Effects of anesthesia and intestinal manipulation}

To differentiate the effects of anesthesia induction, laparotomy, and intestinal manipulation from the effects of liver manipulation, a control group consisting of four patients undergoing lower abdominal surgery (1 rectopexia, 2 proctectomy, 1 sigmoidal resection) was studied. Plasma was sampled before surgery and at 40-min intervals during surgery to determine L-FABP concentrations.

\section{Blood processing and analysis}

Blood samples were collected in prechilled EDTA vacuum tubes (BD vacutainer, Becton Dickinson Diagnostics, Aalst, Belgium) and kept on ice. Blood was centrifuged at $4000 \mathrm{~g}$ for $10 \mathrm{~min}$. Plasma was immediately stored at $80^{\circ} \mathrm{C}$ until analysis. L-FABP and IL-6 were determined using commercially available enzyme-linked immunosorbent assays (ELISA) (kindly provided by Hycult Biotechnology, Uden, The Netherlands), GSTa was measured by ELISA as described earlier $(8,9)$. AST was determined by the clinical chemistry laboratory of the University Hospital Maastricht.

\section{Ethics}

The studies were approved by the Medical Ethics Committee of the University Hospital Maastricht and all subjects gave written informed consent.

\section{Statistics}

Normality of all data obtained was verified by Lillieford's test (all $p>0.10$ ). Data are presented as mean with standard error of the mean (SEM). A paired $t$ test 
was used to test the significance of changes in the various plasma concentrations. Arteriovenous concentration gradients were tested versus a theoretical mean of zero using a one-sample $t$ test (10). Pearson's test for correlations was used to test the significance of correlations. Statistical calculations were made using Prism 4.0 for Windows (GraphPad Software Inc., San Diego, CA). A p value less than 0.05 was considered to indicate statistical significance.

\section{Results}

\section{Patient outcome}

No signs of organ failure or other major complications were observed postoperatively during the hospital stay of all patients.

Estimation of hepatocellular injury and intestinal injury after organ manipulation

\section{Systemic levels of damage markers}

During assessment of resectability, prior to organ transection, mean arterial LFABP plasma concentration increased 55-fold $(p=0.002)$ (Figure 1A). Surprisingly, arterial L-FABP levels did not change significantly during subsequent intermittent Pringle maneuver, indicating that neither intermittent ischemia-reperfusion nor liver transection significantly aggravated the hepatocellular injury caused by early perioperative processes. Immediately postoperatively, systemic L-FABP levels were found to be decreasing. Systemic plasma levels of GSTa (Figure 1B) and AST (Figure 1C) also increased significantly before liver transection and before ischemia-reperfusion.

\section{Effects of lower abdominal surgery on liver injury}

In patients undergoing lower abdominal surgery, the mean L-FABP concentration remained below $15 \mathrm{ng} / \mathrm{ml}$, underlining the effect of direct manipulation of the liver on the elevation of L-FABP plasma levels during liver surgery (Figure 2).

\section{Organ-specific FABP release.}

Since L-FABP is expressed in both the liver and the intestines, we performed an organ balance analysis to reveal the origin of circulating L-FABP. The data show that L-FABP was specifically released from the liver and not from the 
intestines. In addition, organ balance analysis showed an active renal uptake of L-FABP from circulation (Figure 3).
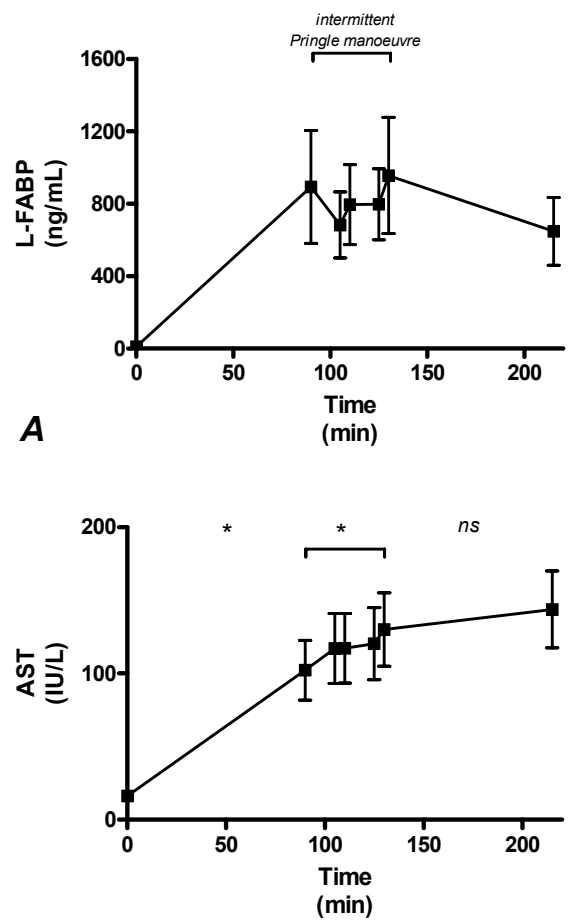

C decreased immediately postoperatively ( $p=0.03$ and $p=0.004$, respectively). $\quad\left({ }^{*}=p<0.05\right.$, ns=not significant; I=ischemia, $R=$ reperfusion).

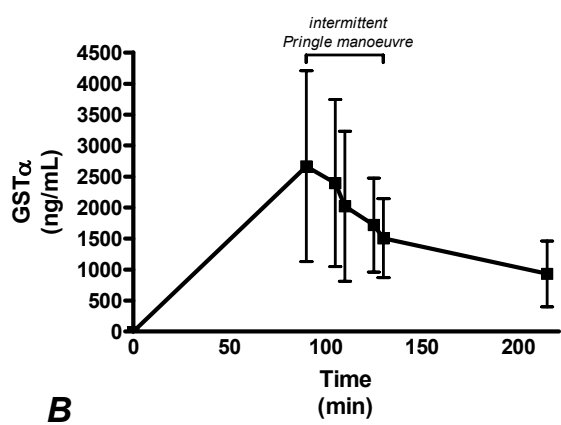

Figure 1. Mean (SEM) arterial L-FABP (A), GSTa (B) and AST (C) levels in patients undergoing liver surgery with intermittent Pringle manoeuvre ( $n=9)$. Plasma levels of all liver injury markers increased early during surgery, during liver manipulation $(p<0.05)$. Intermittent Pringle manoeuvre $\left(2 \times 15^{\prime}\right.$ ischemia and 5 ' reperfusion) did not cause significant changes in arterial L-FABP or GSTa levels, whereas AST gradually kept increasing. L-FABP and GSTa levels 


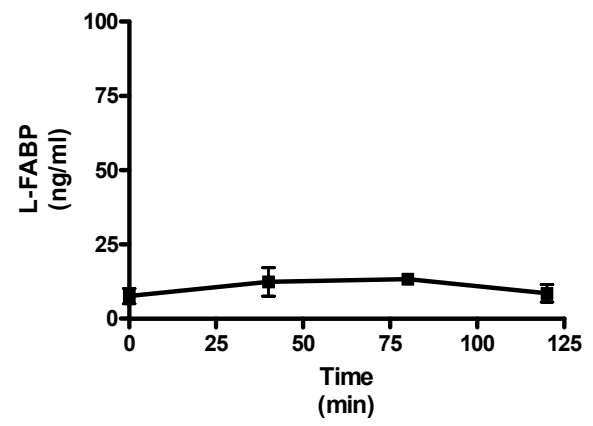

Figure 2. Mean (SEM) plasma L-FABP levels in four patients undergoing lower abdominal surgery without manipulation of the liver. No changes in L-FABP concentration were observed

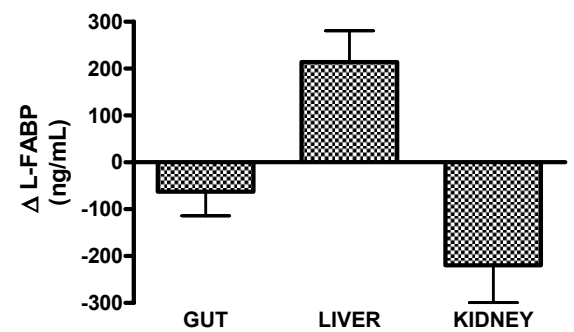

Figure 3. Mean (SEM) arteriovenous concentration gradients of L-FABP across the intestines (portal vein minus artery), the liver (hepatic vein minus portal vein), and the kidney in patients undergoing liver resection $(n=10)$. L-FABP was specifically released from the liver ( $p<0.0001$ vs. zero) and removed from circulation by the kidneys $(p<0.0001$ vs. zero)

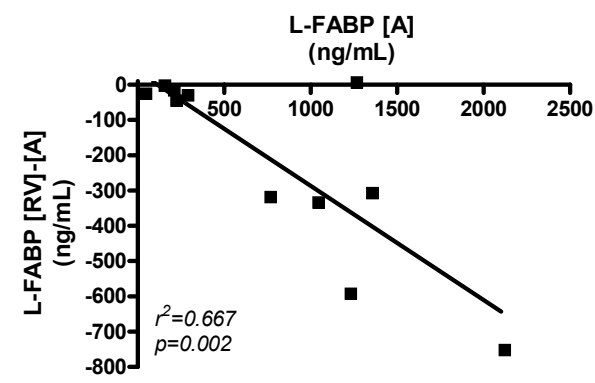

Figure 4. Fractional renal clearance of $L-F A B P$ in patients undergoing liver resection ( $n=$ 10). From the fractional renal extraction of FABPs (approximately $30 \%$ ) and renal blood flow (22\% of total blood volume per minute) (12), a plasma half-life of FABPs of 11 min can be calculated. $[A]=$ arterial concentration, $[R V]=$ renal venous concentration 
Interleukin-6 levels during liver surgery with intermittent Pringle maneuver

The inflammatory response to liver surgery was investigated using IL-6 as a parameter. Arterial IL-6 levels remained unaltered during manipulation of the liver, when L-FABP, AST, and GSTa levels were increasing. In contrast, a significant increase of systemic IL-6 plasma levels was found after $15 \mathrm{~min}$ of hepatic inflow occlusion (Figure 5). This increase was progressive throughout the remainder of the study period.

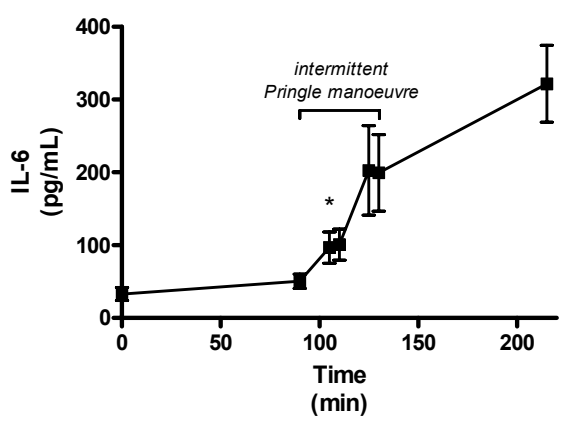

Figure 5. Mean (SEM) arterial IL-6 concentration before, during, and after liver resection with intermittent Pringle maneuver $(n=9)$. * =first timepoint where $p<0.05$ vs. baseline; I=ischemia. $R=$ reperfusion

\section{Discussion}

The present study was designed to determine the cause of early hepatocellular injury during liver resection. Previous publications already showed elevated plasma levels of markers of liver damage prior to liver transection and hepatic inflow occlusion $(3,6)$. These observations suggested that mechanisms other than ischemia-reperfusion injury could contribute to peri- and postoperative cell death and organ dysfunction. We showed that direct manipulation of the liver during surgery is a leading cause of hepatocellular injury.

Arterial L-FABP and GSTa plasma levels increased following the start of the operation and reached a plateau before liver transection and ischemiareperfusion. Surprisingly, we found no additional effect of organ transection or intermittent Pringle maneuver on these increased L-FABP and GSTa plasma levels. The apparent resistance of the liver to an ischemic insult however, is in 
line with previous data by Figueras et al. (13) who showed no effect of the extent of inflow occlusion in patients with a normal liver, although in their study livers of patients with cirrhosis appeared to be more vulnerable to hepatic inflow occlusion. In addition, other authors who showed a progressive release of GSTa following a Pringle maneuver applied prolonged and continuous inflow occlusion (6), which is known to aggravate hepatocellular injury compared to the intermittent Pringle maneuver (14).

Previous authors who observed an early increase in plasma concentrations of transaminases and GSTa have ascribed this phenomenon to the hepatotoxic effects of anesthesia (4), systemic inflammation after intestinal manipulation (5), and the effects of manipulation of the liver itself during perihepatic dissection and mobilization (6). We were able to rule out the first two factors as potential causes of early hepatocyte injury since a similar increase of L-FABP plasma concentrations did not occur in patients undergoing lower intestinal surgery. These patients were anesthetized in a similar manner as the patients undergoing liver resection and underwent extensive intestinal manipulation.

By elimination of other potential causes, it thus must be concluded that increasing L-FABP levels occurs during and due to liver manipulation in patients undergoing liver resection. By measuring concentration gradients across the intestines and the liver, we were able to show that the increased L-FABP levels during liver manipulation are exclusively due to $L-F A B P$ release from the liver. Some intestinal L-FABP release could have been expected when L-FABP, which is also expressed by the intestines, would have been released from injured enterocytes, but the absence of intestinal L-FABP release clearly indicates that organ manipulation during liver resection results in hepatocellular injury without causing intestinal injury.

Finally, we were able to rule out systemic inflammation as a leading cause of hepatocellular injury since L-FABP peak levels were reached already before the onset of the inflammatory response. Arterial IL- 6 plasma levels increased between 90 and 125 min after laparotomy, which approximates the established time lag between an inflammatory stimulus and IL-6 release (15). This suggests that the inflammatory response is triggered by an early event during the operation.

According to the "danger model" hypothesis of Matzinger (16), cell injury leads to the release of immunostimulatory proteins or nucleotides, so-called danger signals, that activate the immune system and induce systemic inflammation (17). In line with this theory, we consider that early hepatocyte damage due to liver manipulation could give rise to the release of such "danger signals" and contribute to systemic inflammation. Consequently, liver manipulation-induced hepatocyte injury may be a trigger for the inflammatory response to surgery. Mechanistic proof for this theory, however, is difficult to obtain in vivo. 
Both L-FABP and GSTa decreased immediately following surgery, in contrast to the more classic marker of hepatocyte injury, AST. The ongoing increase of plasma levels of such markers following liver surgery has been regarded as a sign of ongoing hepatocellular injury and impending liver failure (18). Our study shows that the late postoperative peak of AST is more likely to be a reflection of slow leakage than of ongoing injury, since the leakage of small-molecular proteins L-FABP and GST $\alpha$ decreased within $90 \mathrm{~min}$. As a consequence, LFABP and GSTa are probably more sensitive for detecting ongoing hepatocyte injury and impending liver failure than AST. To prove this assumption, however, a large prospective study is needed. The rapid decline of L-FABP and GSTa is a result of their rapid renal clearance. Arterial renal venous concentration gradients showed that the kidneys remove approximately $30 \%$ of L-FABP in a single pass, leading to a calculated L-FABP half-life of $11 \mathrm{~min}$.

We did not explore potential mechanisms of liver manipulation-induced cell injury. Earlier studies showed that liver mobilization and assessment of resectability significantly reduced hepatic venous oxygen saturation $(19,20)$. This could also be a cause of hepatocyte damage in our case, although we did not measure hepatic oxygen saturation. It is not clear whether hepatic oxygen saturation decreased due to physical obstruction of the blood stream or whether it decreased secondary to other processes $(21,22)$. Alternatively, cell damage may occur as a direct consequence of mechanical impact (23).

In summary, it was previously believed that vascular occlusion and parenchymal transection were the major reasons for hepatocyte injury during liver surgery. This study demonstrates that liver manipulation is a leading cause of hepatocyte injury during liver surgery. A potential causal relation between liver manipulation and systemic inflammation remains to be established. However, since the inflammatory cascade is apparently initiated early during major abdominal surgery, interventions aimed at reducing postoperative inflammation and related complications should be started early during surgery or beforehand.

\section{Acknowledgments}

The authors thank M Hadfoune and AA van Bijnen for their skillful help in our laboratory 


\section{References}

1. Wigmore SJ, Redhead DN, Yan XJ, et al. Virtual hepatic resection using three-dimensional reconstruction of helical computed tomography angioportograms. Ann Surg 2001;233:221-6.

2. Patel A, van de Poll MC, Greve JW, et al. Early stress protein gene expression in a human model of ischemic preconditioning. Transplantation 2004;78:1479-87.

3. Boschetto $A$, Dondero $F$, Tonini $V$, et al. Intra-operative liver injury is not only related to vascular clamping [abstract]. HPB 2005: P25.

4. Clarke RS, Doggart JR, Lavery T. Changes in liver function after different types of surgery. $\mathrm{Br}$ J Anaesth 1976;48:119-28.

5. Hiki N, Shimizu N, Yamaguchi $H$, et al. Manipulation of the small intestine as a cause of the increased inflammatory response after open compared with laparoscopic surgery. Br J Surg 2006;93:195-204.

6. Chouker A, Martignoni A, Schauer RJ, et al. a-Gluthathione S-transferase as an early marker of hepatic ischemia/reperfusion injury after liver resection. World J Surg 2005;29:528-34.

7. Dejong CHC, Garden OJ. Neoplasms of the liver. In: Majid AA, Kingsnorth A, eds. Advanced surgical practice. London: Greenwich Medical Media, 2003:146-156.

8. Mulder TP, Peters WH, Court DA, Jansen JB. Sandwich ELISA for glutathione S-transferase Alpha 1-1: plasma concentrations in controls and in patients with gastrointestinal disorders. Clin Chem 1996;42:416-9.

9. Steegers EA, Mulder TP, Bisseling JG, Delemarre FM, Peters WH. Glutathione S-transferase alpha as marker for hepatocellular damage in pre-eclampsia and HELLP syndrome. Lancet 1995;345:1571-2.

10. Motulsky HJ. Comparing a mean or median to a theoretical value. Prism 4 Statistics Guide; Statistical analyses for laboratory and clinical researchers. San Diego, CA, 2003:35-39.

11. van de Poll MCG, Siroen MP, van Leeuwen PA, et al. Interorgan amino acid exchange in humans: consequences for arginine and citrulline metabolism. Am J Clin Nutr 2007;85:16772.

12. Riddez L, Hahn RG, Brismar B, Strandberg A, Svensen C, Hedenstierna G. Central and regional hemodynamics during acute hypovolemia and volume substitution in volunteers. Crit Care Med 1997;25:635-40.

13. Figueras J, Llado $L$, Ruiz $D$, et al. Complete versus selective portal triad clamping for minor liver resections: a prospective randomized trial. Ann Surg 2005;241:582-90.

14. Belghiti J, Noun R, Malafosse $R$, et al. Continuous versus intermittent portal triad clamping for liver resection: a controlled study. Ann Surg 1999;229:369-75.

15. Lin E, Calvano SE, Lowry SF. Inflammatory cytokines and cell response in surgery. Surgery 2000;127:117-26.

16. Matzinger $P$. The danger model: a renewed sense of self. Science 2002;296:301-5.

17. Barrat FJ, Meeker T, Gregorio J, et al. Nucleic acids of mammalian origin can act as endogenous ligands for Toll-like receptors and may promote systemic lupus erythematosus. $J$ Exp Med 2005;202:1131-9.

18. Panis Y, McMullan DM, Emond JC. Progressive necrosis after hepatectomy and the pathophysiology of liver failure after massive resection. Surgery 1997;121:142-9.

19. Kretzschmar M, Kruger A, Schirrmeister W. Hepatic ischemia-reperfusion syndrome after partial liver resection (LR): hepatic venous oxygen saturation, enzyme pattern, reduced and oxidized glutathione, procalcitonin and interleukin-6. Exp Toxicol Pathol 2003;54:423-31.

20. Kainuma M, Fujiwara Y, Kimura N, Shitaokoshi A, Nakashima K, Shimada Y. Monitoring hepatic venous hemoglobin oxygen saturation in patients undergoing liver surgery. Anesthesiology 1991;74:49-52. 
21. Schemmer P, Enomoto N, Bradford BU, et al. Activated Kupffer cells cause a hypermetabolic state after gentle in situ manipulation of liver in rats. Am J Physiol Gastrointest Liver Physiol 2001;280:G1076-82.

22. Schemmer P, Enomoto N, Bradford BU, Bunzendahl H, Raleigh JA, Thurman RG. Autonomic nervous system and gut-derived endotoxin: involvement in activation of Kupffer cells after in situ organ manipulation. World J Surg 2001;25:399-406.

23. Lazarowski ER, Homolya L, Boucher RC, Harden TK. Direct demonstration of mechanically induced release of cellular UTP and its implication for uridine nucleotide receptor activation. J Biol Chem 1997;272:24348-54. 



\section{Chapter 7}

\section{Hepatocellular injury,}

arginase-1 release

and plasma arginase

activity during liver

\section{surgery}

MCG van de Poll, SJP Hanssen, M Berbée, NEP Deutz $D$ Monbaliu, WA Buurman, CHC Dejong 


\section{Abstract}

Arginine is an important substrate in health and disease. It is a commonly held view that arginase- 1 release from injured erythrocytes and hepatocytes leads to arginine breakdown; however, the true relationship between plasma arginase-1 concentration and activity has remained unaddressed. In the present study, blood was sampled from patients undergoing liver resection, a known cause of hepatocyte injury and arginase-1 release, to determine arginase-1, arginine and ornithine plasma levels. Arginase activity was assessed in vitro by measuring changes in arginine and ornithine plasma levels during incubation of plasma and whole-blood samples at $37^{\circ} \mathrm{C}$. Arginase-1 plasma levels increased 8-10fold during liver resection, whereas arginine and ornithine levels remained unchanged. In accordance with these in vivo findings, arginine and ornithine levels remained unchanged in plasma incubated at $37^{\circ} \mathrm{C}$ irrespective of the arginase-1 concentration. In contrast, arginine plasma level in whole blood decreased significantly during incubation, with ornithine increasing stoichiometrically. These changes were irrespective of arginase-1 plasma levels and were explained by arginase activity present in intact erythrocytes. Next, plasma samples with 1000 -fold normal arginase-1 concentrations were obtained from patients undergoing cadaveric liver transplantation. A significant decrease in arginine plasma levels occurred in vivo and in vitro. In contrast with commonly held views, moderately increased arginase-1 plasma levels do not affect plasma arginine. Very high plasma arginase-1 levels are required to induce potential clinical relevant effects. 


\section{Introduction}

The amino acid arginine is an important substrate for protein synthesis and for the production of agmatine and creatine (1). It is best known, however, as the precursor for the imunoregulatory and vasoactive molecule NO, although the conversion into NO represents only $1 \%$ of arginine plasma flux (2). Quantitatively, arginine plasma flux is determined by arginine intake, endogenous arginine synthesis and protein breakdown on one side and protein synthesis and arginine catabolism by the enzyme arginase on the other side (3). Arginase converts arginine into urea and ornithine, and arginase activity accounts for $10 \%$ of total plasma arginine turnover (4). Arginase exists in two isoforms with only $58 \%$ sequence identity (5). Arginase- 1 is a cytosolic protein, predominantly found in the liver and to a lesser extent in erythrocytes (6). Arginase-2 is located in mitochondria and more ubiquitously present (5), among others in the kidneys and the spleen, but not in mature erythrocytes $(6,7)$. Hepatic arginase- 1 activity serves urea synthesis and nitrogen homoeostasis. In the liver, ornithine is recycled to citrulline and back to arginine.Owing to compartmentalization of this urea cycle, plasma arginine is not a substrate for hepatic arginase- $1(8,9)$. Ornithine generated outside the urea cycle can be converted into proline, an important constituent of collagen, and into polyamines, which are important for cell proliferation (1). Changes in protein turnover, arginine intake or arginase activity can affect arginine plasma levels (3). Arginine deficiency may result in microcirculatory disturbances, pulmonary and systemic hypertension $(10,11)$, disturbed collagen synthesis and wound healing (12), impaired immune function $(13,14)$ and in the onset of postoperative infections (15). Injury to arginase-1-expressing cells, such as hepatocytes and erythrocytes, leads to arginase- 1 release into the circulation and increased arginase-1 plasma levels $(10,11,16-19)$. It is generally believed that such an increase leads to plasma arginine breakdown compromising arginine availability, potentially leading to microcirculatory dysfunction $(10,11)$ and immune suppression $(19,20)$. Alternatively, regarding its effect on cell proliferation, arginine depletion by exogenous arginase may become a promising anticancer treatment (21). The true relationship between the concentration of arginase- 1 in plasma and its actual activity, however, has never been verified. The aim of the present study was to investigate the effects of arginase-1 release on arginine plasma levels, using liver surgery (resection and transplantation) as a model of hepatocyte injury and arginase-1 release, and to establish the potential significance of circulating arginase- 1 in arginine metabolism. 


\section{Materials and Methods}

\section{Patients}

Patients undergoing liver resection for secondary malignancies in an otherwise normal liver $(n=16)$ were studied (Table 1$)$. A routinely placed peripheral arterial catheter was used for blood sampling. Informed consent was obtained from every participant, and the research protocol was approved by the Institutional Medical Ethical Committee. Arginase-1 protein release and indices of in vivo arginase enzyme activity during liver resection Arginase-1 release and its effect on arginine and ornithine levels were studied in vivo in ten patients undergoing hepatectomy with intermittent hepatic inflow occlusion (Pringle manoeuvre) (22). Arterial blood was sampled pre-operatively, before liver transection, before and after each event of an intermittent Pringle manoeuvre $(2 \times 15 \mathrm{~min}$ of ischemia and $5 \mathrm{~min}$ of reperfusion) and $90 \mathrm{~min}$ post-operatively. Blood was collected in prechilled heparinized vacuum tubes (Becton Dickinson), immediately placed on ice and processed as described below.

Table 1. patient characteristics - liver resection

\begin{tabular}{lll}
\hline Surgical trauma & $\begin{array}{l}\text { In vivo study }(\mathbf{n}=\mathbf{1 0}) \\
\text { Liver resection with } \\
\text { intermittent Pringle manoeuvre }\end{array}$ & $\begin{array}{l}\text { In vitro study }(\mathbf{n}=\mathbf{6}) \\
\text { Liver mobilization/ } \\
\text { manipulation prior to liver } \\
\text { resection }\end{array}$ \\
Gender (M/F) & $5 / 5$ & $3 / 3$ \\
Age (years) & $50(33-75)$ & $54(36-74)$ \\
Colorectal/Other liver & $8 / 2$ & $6 / 0$ \\
metastases & & \\
AST $(I U / L)$ & $23(7-37)$ & $34(8-59)$ \\
LDH $(I U / L)$ & $360(295-490)$ & $387(351-422)$ \\
Creatinine $(\mu \mathrm{mol} / \mathrm{l})$ & $103(67-118)$ & $93(56-106)$ \\
\hline
\end{tabular}

In vitro arginase enzyme activity in whole blood and plasma after liver manipulation

To study the effect of plasma arginase activity, separate from other processes regulating arginine levels in vivo, plasma samples with various arginase-1 levels were incubated. In addition, arginase activity was assessed in corresponding whole-blood samples. Arterial blood was obtained from six patients undergoing liver resection, pre-operatively and after liver manipulation (before liver 
transection), when, based upon prior experience, peak arginase-1 concentrations were already expected (23).

\section{Pre-incubation blood processing}

Blood was collected in two $4 \mathrm{ml}$ heparin tubes (Becton Dickinson). One tube was centrifuged $\left(4000 \mathrm{~g}, 20^{\circ} \mathrm{C}, 5 \mathrm{~min}\right)$ to obtain plasma. The plasma was removed and transferred to clean tubes for incubation. The wholeblood samples were incubated without any further processing.

\section{Incubation}

Incubations were performed immediately after sampling. Plasma and wholeblood samples were divided into three aliquots per fraction which were incubated for 0,20 or $40 \mathrm{~min}$ at $37^{\circ} \mathrm{C}$. Thereafter, samples were placed on ice and processed immediately as described below. Arginase-1, arginine, ornithine and other amino acid concentrations were measured as described below. Arginase activity was expressed as the increment in ornithine concentration/min. Since kinetic assays like these do not discriminate between the activities of different isoenzymes, the term arginase activity will be used without further specification when referring to the data from this assay.

\section{Arginase-1 protein release and plasma arginase enzyme activity after liver transplantation}

Roth et al. (16) described a decrease in plasma arginine levels from \pm 100 $\mu \mathrm{mol} / \mathrm{l}$ to $\pm 4 \mu \mathrm{mol} / /$ within $30 \mathrm{~min}$ following cadaveric liver transplantation, which was ascribed to arginase release from the graft and overwhelming plasma arginase activity. Ethical permission was granted to include four patients undergoing cadaveric liver transplantation at the University Hospital, Leuven, Belgium (Table 2) as optimal positive controls for the present study. Arterial blood was drawn into heparin tubes (Becton Dickinson) pre-operatively, at the end of the anhepatic phase, and 3, 20 and 60 min following reperfusion of the graft. Whole blood was centrifuged at $4000 \mathrm{~g}$ for $5 \mathrm{~min}$. Argininase-1, arginine, ornithine and other amino acid concentrations were measured in all samples. Plasma obtained $3 \mathrm{~min}$ following reperfusion was incubated at $37^{\circ} \mathrm{C}$ for $25-40$ (mean 30 ) min to assess plasma arginase activity as described above. 


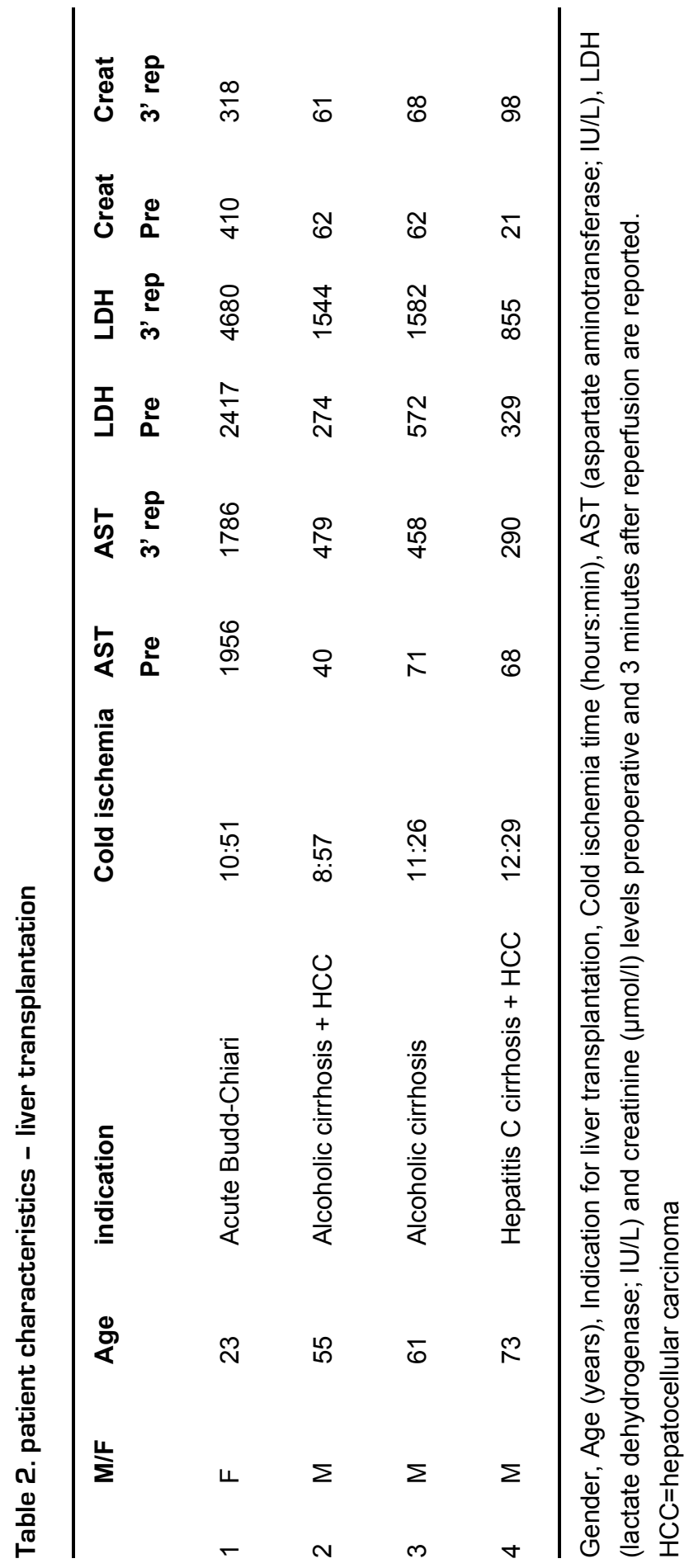


Relationship between arginase activity and arginase-1 concentration in plasma

\section{Plasma arginase activity at physiological arginine concentrations}

Aliquots of a plasma sample from one liver transplant recipient, obtained immediately following reperfusion (arginase-1 concentration, $25 \mu \mathrm{g} / \mathrm{ml}$ ), were mixed with aliquots of a plasma sample obtained from a healthy subject (arginase-1 concentration below detection limit of $10 \mathrm{ng} / \mathrm{ml}$ ). By this means, an arginase-1 dilution curve ranging from $25 \mu \mathrm{g} / \mathrm{ml}$ to $195 \mathrm{ng} / \mathrm{ml}$ was created. Before mixing, PBS ( $\mathrm{pH} 7.4$ ) containing $85 \mathrm{mmol} / \mathrm{l}$ arginine was added to the 'healthy' plasma aliquots. The volume of arginine-enriched PBS added to each aliquot was adjusted so that the final arginine concentration after mixing equalled $85 \mu \mathrm{mol} / /$ in each sample. Accordingly, plasma samples were created containing various arginase- 1 and equal arginine concentrations, the maximum concentration of PBS in these samples was $<0.1 \%$. All samples were immediately incubated at $37^{\circ} \mathrm{C}$ for 0,5 or $30 \mathrm{~min}$.

\section{Plasma arginase activity at above- Km arginine concentrations}

In a similar fashion as described above, plasma aliquots containing various concentrations of arginase-1 and $20 \mathrm{mmol} / \mathrm{l}$ arginine were created. However, in this case, arginine was dissolved directly in the 'healthy' plasma aliquots to avoid dilution of the plasma with PBS. Eventually plasma samples were created containing 15000,1500 or $150 \mathrm{ng} / \mathrm{ml}$ arginase- 1 with $20 \mathrm{mmol} / \mathrm{l}$ arginine. These samples were immediately incubated at $37^{\circ} \mathrm{C}$ for 0,5 or $30 \mathrm{~min}$.

\section{Arginase-1 concentration in erythrocytes}

Blood was obtained from five healthy volunteers in vacuum tubes containing EDTA (Becton Dickinson). To remove plasma and mononuclear cells, a protocol described previously was applied using a separation fluid (Lymphoprep 1.077; Axis-Shield) (24). A total of $1 \mathrm{ml}$ of packed erythrocytes was added to $74 \mathrm{ml}$ of distilled water and gently shaken for $10 \mathrm{~min}$ to induce $100 \%$ haemolysis (25). The homogenate was centrifuged $\left(4000 \mathrm{~g}, 20^{\circ} \mathrm{C}, 15 \mathrm{~min}\right)$, and the supernatant was assayed for arginase- 1 .

\section{Post-incubation sample processing and laboratory analysis}

Whole-blood samples were centrifuged $\left(4000 \mathrm{~g}, 4^{\circ} \mathrm{C}, 5 \mathrm{~min}\right)$ to obtain plasma. A total of $100 \mu \mathrm{l}$ of plasma was deproteinized with $8 \mathrm{mg}$ of SSA (sulphosalicylic acid) and stored at $-80^{\circ} \mathrm{C}$, the remainder was stored untreated $\left(-80^{\circ} \mathrm{C}\right)$. Amino acid levels were analysed in SSA-deproteinized samples by HPLC, as 
described previously (26). Arginase-1 concentrations were measured in untreated samples using an ELISA (27) (kindly provided by Hycult Biotechnology). The detection limit of this assay is $10 \mathrm{ng} / \mathrm{ml}$ arginase-1.

\section{Statistics}

Changes in amino acid and arginase-1 concentrations in vivo and in vitro were tested using a paired Student's $t$ test or one-way ANOVA for repeated measures when more than two serial observations were available. Statistical calculations were made using Prism 4.0 for Windows (GraphPad Software). Results are expressed as means (S.E.M.), with patient characteristics expressed as medians (range). A $P$ value $<0.05$ was considered to indicate statistical significance.

\section{Results}

\section{Effects of liver manipulation and warm ischemia}

As expected, mean arginase-1 plasma levels increased significantly during liver manipulation (8-fold), before hepatic inflow occlusion (Figure 1A). Despite this, plasma concentrations of arginine and ornithine remained unchanged during the same period (Figure 1B). During inflow occlusion, no further significant changes in arginase-1 plasma levels were observed (Figure 1A). At the same time, plasma levels of arginine (and most other amino acids; results not shown) increased. Ornithine concentrations remained unchanged (Figure 1B). At 90 min post-operatively, the mean arginase-1 plasma concentration decreased to $17 \%$ of the last measured intra-operative value. From this, an arginase-1 plasma half life of less than $1 \mathrm{~h}$ was calculated.

\section{In vitro arginase activity}

Blood was sampled from six patients undergoing liver resection pre-operatively and after liver manipulation. Pre-operative arterial arginase-1 plasma levels were $18.1(8.0) \mathrm{ng} / \mathrm{ml}$. In line with the results mentioned above, arginase-1 plasma levels increased significantly during liver manipulation [10-fold to 184 (54) $\mathrm{ng} / \mathrm{ml}$, without affecting arginine and ornithine levels in vivo $(p=0.72$ and $\mathrm{p}=0.16$ respectively; Figure 2 ). 


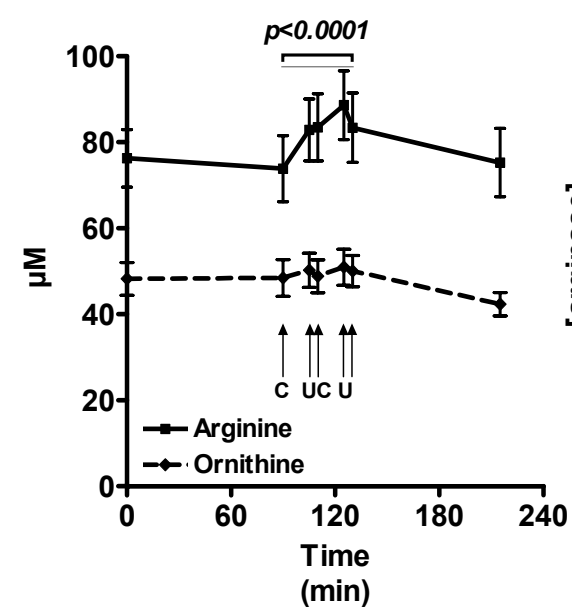

$\boldsymbol{A}$

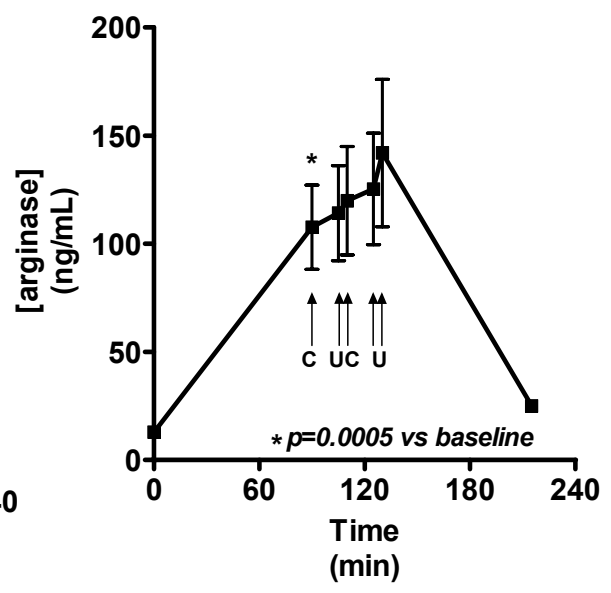

B

Figure 1. Arterial arginase-1 $(A)$ and arginine and ornithine $(B)$ concentrations were measured in 10 patients undergoing partial hepatectomy with intermittent Pringle manoeuvre (15' clamping, 5' reperfusion; clamping $(C)$ /unclamping $(U)$ indicated by arrows). Arginase-1 levels increased from the start of the procedure $(p=0.0005)$, without affecting arginine levels $(p=0.43)$. A significant increase of arginine levels was observed during hepatic pedicle clamping $(p<0.0001)$, most likely due to abolishment of hepatic amino acid

\section{Plasma}

Incubation of pre-operatively collected plasma samples for $40 \mathrm{~min}$ at $37^{\circ} \mathrm{C}$ did not lead to changes in arginine and ornithine concentrations $(p=0.26$; Figure $2 A)$. In accordance with the in vivo findings, no significant changes in arginine and ornithine concentrations were observed during the incubation of plasma samples containing a 10-fold increased arginase- 1 concentration $(p=0.33$; Figure $2 \mathrm{~B}$ ). Plasma concentrations of other amino acids were not affected by in vitro incubation (Table 3).

\section{Whole blood}

Arginase-1 plasma levels in incubated whole blood remained stable (results not shown), ruling out a potential increase in arginase activity due to haemolysis. After 40 min of incubation, a significant decrease in arginine concentrations with a concomitant increase in ornithine concentrations was found in plasma of all the wholeblood samples, irrespective of the amount of arginase- 1 in the plasma (Figure 2C and 2D). These highly significant changes were not found for other amino acids (Table 4). 


\section{Plasma}
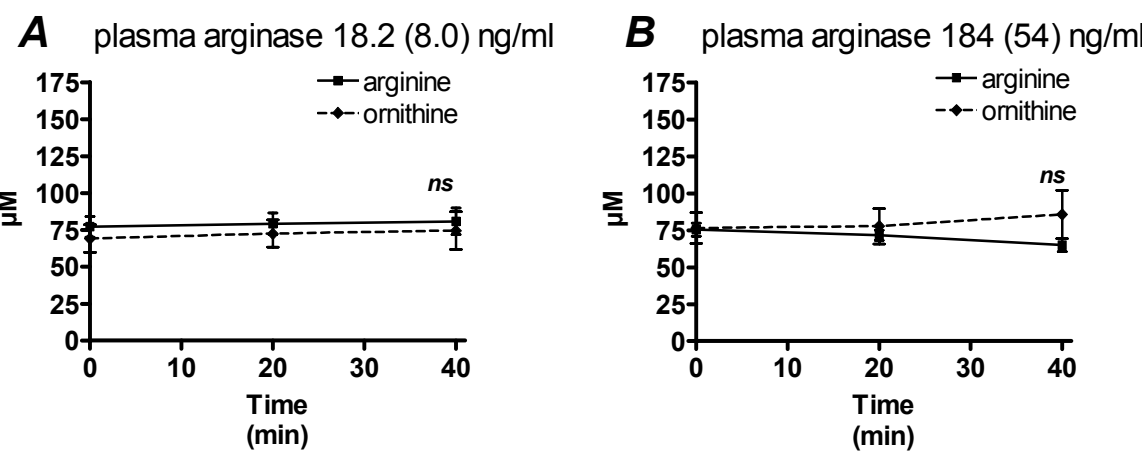

\section{Whole blood}

C plasma arginase $18.2(8.0) \mathrm{ng} / \mathrm{ml}$
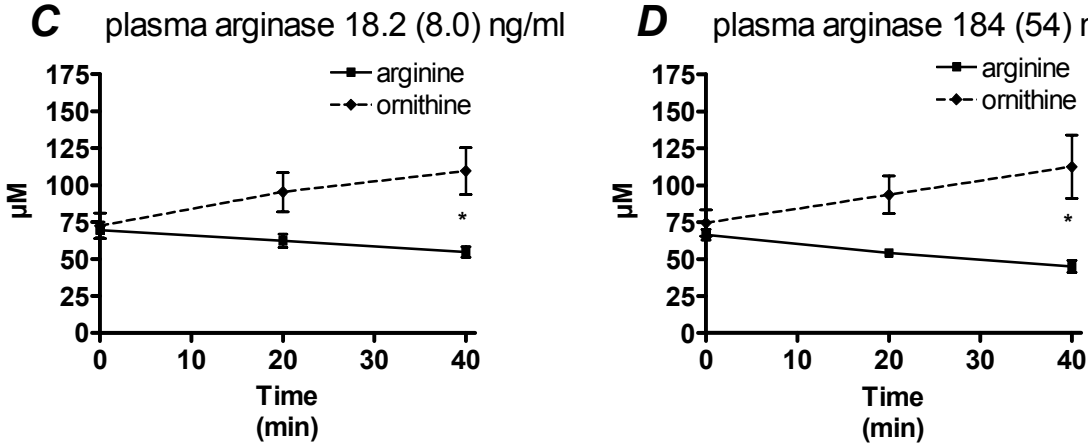

Figure 2. Blood was drawn from 6 patients undergoing liver resection immediately before surgery $(A, C)$ and after liver manipulation $(B, D)$. Mean (SEM) preoperative arginase-1 plasma concentration was 18.2 (8.0) $\mathrm{ng} / \mathrm{mL}$, which increased to 184 (54) $\mathrm{ng} / \mathrm{mL}$ following liver manipulation (10-fold increase, $p=0.028)$, without affecting arginine and ornithine levels in vivo ( $p=0.72$ and $p=0.16$, respectively). Plasma, whole blood and erythrocytes suspended in PBS $+80 \mu \mathrm{mol} / \mathrm{l}$ arginine obtained before and during surgery were incubated for 0,20 and 40 minutes at $37^{\circ} \mathrm{C}$. No significant changes in arginine and ornithine concentration were found in plasma $(A, B)$ irrespective of the amount of arginase1 in the samples. Arginine concentrations in whole blood $(C, D)$ decreased significantly. Decreasing arginine levels were accompanied by stoichiometric increases of ornithine levels in all cases, indicating arginase activity. The amount of extracellular arginase-1 in the incubated whole blood samples did not influence the amount of ornithine formed. * $p<0.005$ 
Table 3. Changes in plasma amino acid concentrations during incubation of plasma

\begin{tabular}{|c|c|c|c|c|c|}
\hline & \multirow{2}{*}{$\begin{array}{l}\text { concentration } \\
(\mu \mathrm{mol} / \mathrm{l})\end{array}$} & \multicolumn{2}{|c|}{ absolute increase } & \multicolumn{2}{|c|}{ relative increase } \\
\hline & & $(\mu \mathrm{mol} / \mathrm{l})$ & p-value & $(\%)$ & p-value \\
\hline Glutamate & $114(9.3)$ & $2.3(2.9)$ & 0.451 & $3.0(3.1)$ & 0.350 \\
\hline Asparagine & $68(11.7)$ & $4.3(2.2)$ & 0.083 & $4.6(2.8)$ & 0.130 \\
\hline Serine & $137(14.3)$ & $2.6(2.7)$ & 0.355 & $1.3(1.8)$ & 0.481 \\
\hline Glutamine & $626(52.9)$ & $11.6(12.5)$ & 0.372 & $1.7(2.3)$ & 0.481 \\
\hline Histidine & $188(105.1)$ & $0.6(5.3)$ & 0.915 & $-5.7(9.8)$ & 0.573 \\
\hline Glycine & $329(40.3)$ & $9.8(8.7)$ & 0.287 & $8.8(12.5)$ & 0.496 \\
\hline Threonine & $155(18.9)$ & $0.5(4.4)$ & 0.911 & $-1.3(2.8)$ & 0.653 \\
\hline Citrulline & $40(2.7)$ & $0.7(1.0)$ & 0.526 & $1.3(2.3)$ & 0.582 \\
\hline Alanine & $404(38.5)$ & $12.8(8.3)$ & 0.148 & $3.2(2.2)$ & 0.187 \\
\hline Taurine & $61(7.5)$ & $2.1(1.2)$ & 0.113 & $10.2(8.2)$ & 0.237 \\
\hline a-amino butyric acid & $17(1.3)$ & $0.7(0.4)$ & 0.136 & $3.7(2.3)$ & 0.140 \\
\hline Tyrosine & $84(15.6)$ & $6.6(5.4)$ & 0.246 & $5.1(4.4)$ & 0.272 \\
\hline Valine & $156(12.0)$ & $7.5(5.1)$ & 0.173 & $3.2(2.7)$ & 0.273 \\
\hline Methionine & $38(11.1)$ & $1.5(0.8)$ & 0.098 & $2.8(2.3)$ & 0.265 \\
\hline Isoleucine & $52(3.5)$ & $2.3(1.5)$ & 0.157 & $3.5(2.6)$ & 0.207 \\
\hline Phenylalanine & $68(11.5$ & $2.0(1.2)$ & 0.122 & $2.2(1.7)$ & 0.213 \\
\hline Tryptophane & $51(7.5)$ & $1.3(1.3)$ & 0.370 & $3.7(3.1)$ & 0.251 \\
\hline Leucine & $101(8.5)$ & $4.3(2.2)$ & 0.075 & $3.2(2.0)$ & 0.134 \\
\hline Lysine & $212(19.0)$ & $8.0(5.8)$ & 0.193 & $2.8(2.6)$ & 0.313 \\
\hline$\Sigma \mathrm{AA}$ & $3073(291.4)$ & $90.3(61.7)$ & 0.171 & $2.3(2.0)$ & 0.283 \\
\hline$\Sigma$ Arginine \& & $161(10.0)$ & $4.8(3.7)$ & 0.219 & $1.7(2.1)$ & 0.424 \\
\hline Ornithine & & & & & \\
\hline
\end{tabular}

Pooled data of all plasma incubation experiments. Plasma was obtained from patients undergoing liver resection before liver manipulation $(n=6)$, after liver manipulation $(n=6)$ and after liver transplantation $(n=4)$. Arterial concentrations before incubation are given as well as absolute $(\mu \mathrm{mol} / \mathrm{l})$ and relative (\%) increases at the end of the incubation (mean 37.5 minutes). Results were similar for all three experiments except for changes in arginine and ornithine concentrations in plasma obtained after liver transplantation. Changes in arginine and ornithine concentrations during the various experiments are presented in Figures 2 and $3 \mathrm{C}$. The sum of arginine and ornithine concentrations remained unchanged during all experiments. Data are presented as mean (SEM), absolute and relative changes were tested vs. zero by a one-sample t-test. $\Sigma A A=$ sum of all amino acids, $\Sigma$ Arginine $\&$ Ornithine $=$ sum of arginine and ornithine concentrations. 
Table 4. Changes in plasma amino acid concentrations during incubation of whole blood

\begin{tabular}{|c|c|c|c|c|c|}
\hline & \multirow{2}{*}{$\begin{array}{l}\text { concentration } \\
(\mu \mathrm{mol} / \mathrm{l})\end{array}$} & \multicolumn{2}{|c|}{ absolute increase } & \multicolumn{2}{|c|}{ relative increase } \\
\hline & & $(\mu \mathrm{mol} / \mathrm{l})$ & $p$-value & $(\%)$ & $p$-value \\
\hline Glutamate & $109(6.8)$ & $9.6(4.7)$ & 0.078 & $8.3(4.0)$ & 0.077 \\
\hline Asparagine & $43(2.0)$ & $3.8(1.7)$ & 0.066 & $7.7(3.8)$ & 0.079 \\
\hline Serine & $118(10.7)$ & $3.6(5.3)$ & 0.514 & $1.7(4.4)$ & 0.711 \\
\hline Glutamine & $527(9.3)$ & $3.1(23.6)$ & 0.898 & $0.5(4.5)$ & 0.924 \\
\hline Histidine & $61(13.7)$ & $6.3(4.4)$ & 0.196 & $6.6(5.2)$ & 0.247 \\
\hline Glycine & $305(53.0)$ & $45.9(41.8)$ & 0.308 & $55.4(41.3)$ & 0.221 \\
\hline Threonine & $117(9.5)$ & $4.1(5.0)$ & 0.433 & $2.0(4.8)$ & 0.692 \\
\hline Citrulline & $39(3.0)$ & $1.0(1.1)$ & 0.394 & $2.2(2.7)$ & 0.437 \\
\hline Arginine & $68(3.1)$ & $-18.3(2.2)$ & $<0.001$ & $-26.7(3.1)$ & $<0.001$ \\
\hline Alanine & $321(26.0)$ & $28.4(14.6)$ & 0.094 & $9.3(4.2)$ & 0.062 \\
\hline $\begin{array}{l}\text { Taurine } \\
\text { a-amino }\end{array}$ & $58(5.3)$ & $-1.4(10.9)$ & 0.903 & $3.2(16.3)$ & 0.850 \\
\hline butyric acid & $14(0.8)$ & $1.3(0.5)$ & 0.049 & $8.4(3.4)$ & 0.043 \\
\hline Tyrosine & $49(2.9)$ & $2.1(1.7)$ & 0.239 & $3.5(3.3)$ & 0.327 \\
\hline Valine & $148(11.0)$ & $9.3(5.3)$ & 0.127 & $5.0(3.2)$ & 0.161 \\
\hline Methionine & $16(0.9)$ & $0.5(0.5)$ & 0.351 & $2.3(3.0)$ & 0.473 \\
\hline Isoleucine & $46(3.6)$ & $2.9(1.6)$ & 0.111 & $4.6(3.3)$ & 0.209 \\
\hline Phenylalanine & $43(2.6)$ & $1.9(1.3)$ & 0.201 & $4.0(3.0)$ & 0.214 \\
\hline Tryptophane & $34(4.0)$ & $2.1(2.3)$ & 0.391 & $7.8(8.7)$ & 0.401 \\
\hline Leucine & $85(7.4)$ & $7.3(2.9)$ & 0.042 & $7.1(2.9)$ & 0.045 \\
\hline Ornithine & $73(5.9)$ & $37.6(7.5)$ & $<0.001$ & $45.1(5.8)$ & $<0.001$ \\
\hline Lysine & $167(14.1)$ & $19.0(11.2)$ & 0.132 & $10.0(5.2)$ & 0.094 \\
\hline$\Sigma \mathrm{AA}$ & $2445(111.6)$ & $172.1(105.1)$ & 0.145 & $6.9(4.3)$ & 0.153 \\
\hline $\begin{array}{l}\Sigma \text { Arginine \& } \\
\text { Ornithine }\end{array}$ & $145(8.5)$ & $19.3(7.4)$ & 0.024 & $12.0(4.1)$ & 0.015 \\
\hline
\end{tabular}

Pooled data of all whole blood incubation experiments. Whole blood was obtained from patient undergoing liver resection before liver manipulation $(n=6)$ and after liver manipulation $(n=6)$. Arterial concentrations before incubation are given as well as absolute $(\mu \mathrm{mol} / \mathrm{l})$ and relative $(\%)$ increases at the end of the incubation (mean 37.5 minutes). Results were similar for both experiments. Data are presented as mean (SEM), absolute and relative changes were tested vs. zero by a one-sample t-test. $\Sigma A A=$ sum of all amino acids, $\Sigma$ Arginine $\&$ Ornithine $=$ sum of arginine and ornithine concentrations. 


\section{Plasma arginase activity after liver transplantation}

\section{In vivo arginase-1 levels and indices of arginase activity}

After reperfusion, plasma arginase-1 levels increased rapidly to 1000 -fold normal values (Figure $3 \mathrm{~A}$ ). In addition, we observed a rapid decline in plasma arginine levels with a concomitant increase in the plasma levels of ornithine (Figure 3A). A one-phase exponential decay curve fitted along the mean arginase-1 concentrations 3,20 and 60 min post-reperfusion resulted in a calculated plasma half life of approx. $40 \mathrm{~min}$. Within $3 \mathrm{~min}$ following reperfusion, in vivo arginine plasma levels were relatively stabilized (Figure 3B). Plasma concentrations of other amino acids that depend on the liver for their plasma clearance, such as alanine and methionine, also declined following reperfusion of the liver, although not as steeply as arginine concentrations (Figure 3B).

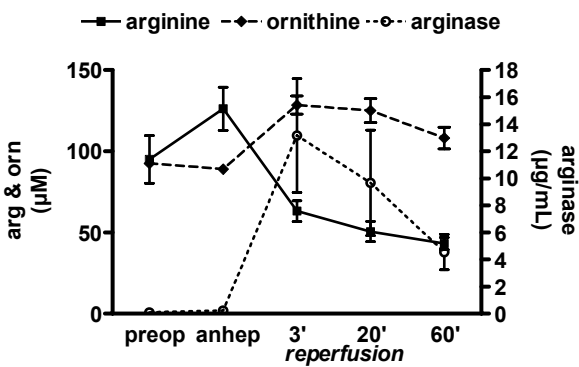

$\boldsymbol{A}$

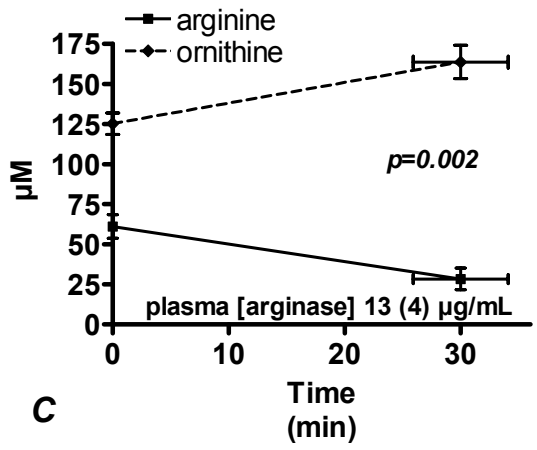

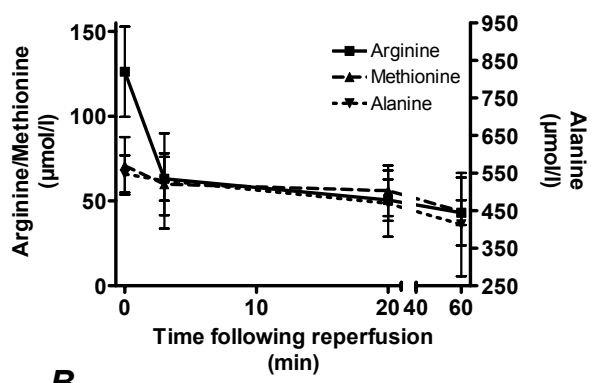

B

Figure 3. A. Arterial arginase-1, arginine and ornithine concentrations were measured in 4 patients undergoing cadaveric liver transplantation. Preoperative arginase-1 levels were elevated above reference values, reflecting underlying liver disease eventually necessitating liver transplantation. Immediately following reperfusion a large increase of plasma arginase-1 levels occurred $(p=0.008)$. This was accompanied by a sharp decrease of arginine $(p<0.0001)$ and concomitant increase of ornithine levels $(p=0.0003)$. $B$. The decline in plasma arginine levels was most outspoken in

the first three minutes, where after arginine levels remained relatively stable. C. Incubation of plasma samples drawn 3 minutes following reperfusion of the liver graft (containing a mean (SEM) arginase-1 concentration of $13(4.2) \mu \mathrm{g} / \mathrm{mL}$ ) led to a significant decrease of arginine levels with a concomitant increase of ornithine levels $(p=0.002)$, proving plasma arginase activity. 
In vitro arginase activity after liver transplantation

Incubation of plasma sampled 3 min following liver transplantation [arginase-1, $13.2(4.2 \mu \mathrm{g} / \mathrm{ml})]$ at $37^{\circ} \mathrm{C}$ for $30 \mathrm{~min}$ resulted in a significant decrease in plasma arginine concentration [from $61.1(7.4)$ to 28.4 (6.7) $\mu \mathrm{mol} / \mathrm{l}$ ]. This was accompanied by a similar increase in ornithine concentration [from 125.2 (6.6) to 163.7 (10.4) $\mu \mathrm{mol} / / ; \mathrm{P}=0.002$; Figure $3 \mathrm{C}$ ). Other amino acids remained unaffected (Table 3).

Relationship between arginase enzyme activity and arginase1 protein concentrations in plasma

\section{Plasma arginase activity at physiological arginine concentrations}

Plasma samples containing different arginase-1 levels were incubated for 5 and $30 \mathrm{~min}$ at $37^{\circ} \mathrm{C}$ in the presence of $85 \mu \mathrm{mol} / \mathrm{l}$ arginine.At this arginine concentration, the relationship between arginase-1 concentration and arginase activity appeared to be non-linear, with a lower specific activity (activity/unit of enzyme) at higher arginase-1 concentrations. Below an arginase-1 concentration of $1.6 \mu \mathrm{g} / \mathrm{ml}$, however, there was in fact a linear relationship between arginase-1 concentration and arginase activity $\left(r^{2}=0.99\right)$ (Figure 4A). After $30 \mathrm{~min}$ of incubation with an initial arginine concentration of $85 \mu \mathrm{mol} / \mathrm{l}$, arginine plasma levels decreased dependent on the arginase-1 level. At arginase-1 levels below $2 \mu \mathrm{g} / \mathrm{ml}$ and an initial arginine concentration of 85 $\mu \mathrm{mol} / \mathrm{I}$, arginine levels decreased less than $10 \%$ within 30 min (Figure 4B).

\section{Plasma arginase activity at above- Km arginine concentrations}

Plasma with various amounts of arginase-1was incubated in the presence of 20 $\mathrm{mmol} / \mathrm{l}$ arginine, which is well above the $\mathrm{Km}$ for arginase- 1 . This resulted in an enduring linear ornithine formation (Figure $4 \mathrm{C}$ ), showing that the intrinsic activity of the enzyme in isolated plasma was preserved during in vitro incubation.

\section{Arginase-1 concentration in erythrocytes}

Erythrocyte arginase-1 concentration, measured by ELISA, was $17.0(1.1) \mu \mathrm{g} / \mathrm{ml}$ of erythrocytes.

\section{Discussion}

Increased plasma arginase-1 activity is frequently suggested as a cause of low arginine plasma levels in patients with hepatocellular or erythrocyte injury (10, 

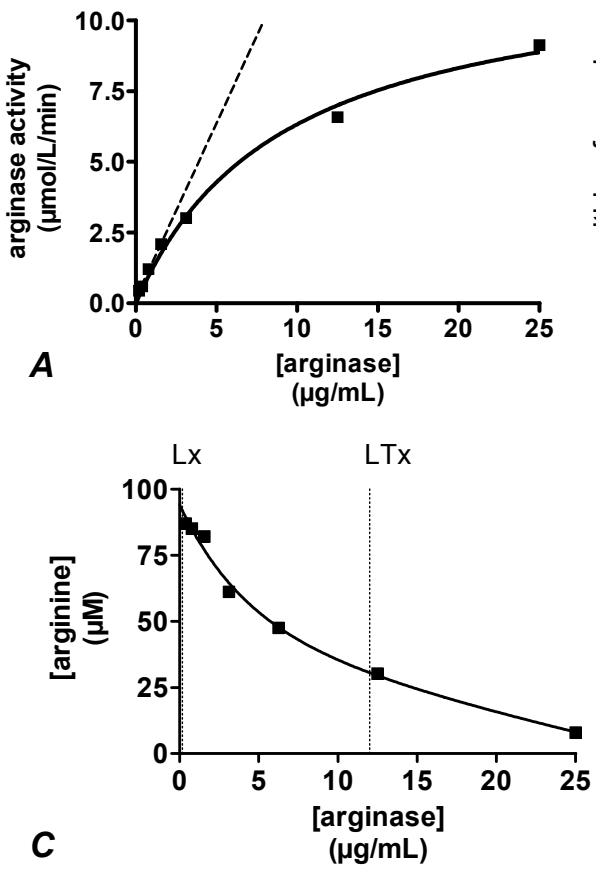

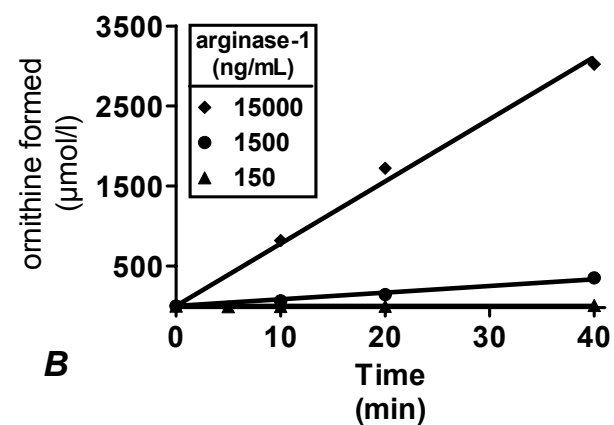

Figure 4. Plasma samples with varying arginase-1 concentrations were created by mixing plasma from a liver transplant recipient ([arginase-1] 25 $\mu \mathrm{g} / \mathrm{mL}$ ) and from a healthy volunteer ([arginase-1] below $10 \mathrm{ng} / \mathrm{mL}$ ). Starting arginine levels were adjusted by adding arginine and samples were incubated at $37^{\circ} \mathrm{C}$. A. Plasma samples were incubated for 5 minutes in the presence of $85 \mu \mathrm{mol} / \mathrm{l}$ arginine, which approximates the normal arginine concentration in human plasma. The

data show that arginase activity was related to arginase-1 concentration; however the formation of ornithine at the highest arginase-1 concentrations was rapidly limited by decreasing substrate availability. The dashed line indicates the theoretical relation between arginase-1 concentration and arginase activity at a constant arginine concentration of 85 $\mu \mathrm{mol} / \mathrm{l}$. B. Plasma samples with varying concentrations of arginase-1 were incubated in the presence of $85 \mu \mathrm{mol} / \mathrm{l}$ arginine for 20 minutes. During this period arginine plasma levels decreased dependent on the arginase-1 plasma level. At arginase-1 levels below 2,000 $\mathrm{ng} / \mathrm{ml}$, the decrease of arginine levels in 20 minutes was below 10\%. Below an arginine plasma level of $50 \mu \mathrm{mol} / \mathrm{l}$, arginase activity rapidly becomes limited by substrate availability. $L x$ indicates mean arginase-1 levels reached during liver resection, LTx indicates mean arginase-1 levels reached after liver transplantation. C. Plasma samples with varying concentrations of arginase-1 were incubated in the presence of $20 \mathrm{mmol} / \mathrm{l}$ arginine, which maintained substrate availability above $\mathrm{Km}$ values during the incubation. In this experiment the ornithine formation rate remained unchanged showing that the intrinsic activity of the enzyme was maintained during the incubations.

$11,16,17,20,28,29)$. This could be clinically relevant, since low arginine levels may induce immunological and microcirculatory dysfunction $(14,30,31)$. The results from the present study, however, show that a potentially relevant effect of plasma arginase- 1 on arginine metabolism only occurs when very high arginase- 1 concentrations are reached. We were able to study the relationship between plasma arginase-1 levels and plasma arginase activity by the application of a recently developed ELISA (27) that allows exact quantification 
of the arginase-1 concentration in plasma. Arginase- 1 was released from the liver into the plasma in patients undergoing liver resection, leading to an 8- fold increase in circulating arginase-1, without affecting arginine and ornithine plasma levels. These findings show no evidence for increased arginase activity, despite increased arginase-1 plasma levels. From these results alone, however, it cannot be ruled out that actual arginase activity was compensated for by other mechanisms regulating plasma arginine and ornithine levels. Plasma arginine levels are regulated in vivo by protein breakdown and endogenous arginine synthesis. The latter occurs in the kidney, where citrulline, derived from intestinal glutamine metabolism, becomes converted into arginine $(9,32)$. We have demonstrated recently that endogenous arginine synthesis remains unchanged during liver surgery (32). Quantitatively, arginine clearance is determined primarily by protein synthesis. This is illustrated by the increased plasma levels of arginine and most other amino acids during hepatic inflow occlusion, reflecting abolishment of hepatic protein synthesis. Ornithine concentrations remained unchanged, which is in line with the absence of physiological hepatic ornithine uptake (9).

To study plasma arginase activity isolated from in vivo regulatory mechanisms, plasma and whole-blood samples were incubated in vitro. In agreement with the in vivo results, no significant changes in arginine and ornithine concentrations were found during incubation of plasma samples with a mean arginase-1 concentration of $185 \mathrm{ng} / \mathrm{ml}$. To explore whether plasma arginase activity was dependent on factors present in whole blood, but not in plasma, whole-blood samples were incubated at $37^{\circ} \mathrm{C}$ for $40 \mathrm{~min}$. A significant increase in ornithine was found, accompanied by a similar decrease in arginine. No changeswere found in the plasma concentrations of other amino acids such as glutamate, an ornithine precursor, or citrulline, an arginine product. This strongly suggests that the observed changes actually specifically reflect arginase activity. Whole-blood arginase activity, however, was not related to the arginase-1 plasma concentration, which underlines that plasma arginase-1 does not affect plasma arginine levels. More likely, whole-blood arginase activity occurs in the cellular fraction (erythrocytes and/or leucocytes).

Several studies have reported arginase activity in plasma in clinical settings, which seemingly conflicts with our findings. Roth and co-workers $(11,16)$ have shown that liver transplantation leads to an immediate decrease in plasma arginine to virtually zero with a stoichiometric increase of plasma ornithine, which is highly indicative of arginase activity. We were able to reproduce these findings, although the decrease in arginine levels was not as great as described by Roth et al. Moreover, plasma concentrations of other amino acids, such as methionine and alanine, decreased as well, reflecting restoration of liver function. Nonetheless, the specific steep decline of arginine in the first $3 \mathrm{~min}$ 
following reperfusion and the simultaneous increase in ornithine levels is in fact highly indicative of arginase activity. Arginase-1 plasma levels were 100-fold higher after liver transplantation than during liver resection and 1000 -fold higher than normal reference values. In vitro assessment of plasma obtained 3 min following transplantation revealed specific and stoichiometric changes in arginine and ornithine concentrations that were related to the arginase-1 concentration. Arginase activity/ug of arginase-1 (specific activity) appeared to decline at increasing arginase-1 concentrations. This is probably due to the high initial reaction velocity at high arginase-1 concentrations, leading to a rapid decline in arginine concentration and arginase activity. In samples with an arginase- 1 concentration $<1.5 \mu \mathrm{g} / \mathrm{ml}$,

arginine depletion did not occur. At these low enzyme concentrations, there was a linear relationship between plasma arginase-1 concentration and arginase activity. Moreover incubation of plasma samples with $20 \mathrm{mmol} / \mathrm{l}$ arginine (above the $\mathrm{Km}$ ) showed that the intrinsic activity of the enzyme was preserved during incubation. Theoretically, the activity of arginase-1 at low enzyme and/or substrate concentrations may be limited by endogenous arginase inhibition. The most potent endogenous arginase inhibitor known is NOHA ( $\mathrm{N \omega}$ - hydroxy-larginine), an intermediate of NO synthesis. However, regarding the high NOHA concentrations required to cause arginase inhibition (IC50 $\approx 400 \mu \mathrm{mol} / \mathrm{l})(33)$, it appears unlikely that any of the presently known arginase inhibitors affected the present results. Owing to limited availability of methods to quantify arginase $(-1$ and -2) protein content in biological samples, various semi-quantitative arginase activity assays, relying on supraphysiological $\mathrm{pH}$ and arginine concentrations, have been developed $(20,34)$. The widespread use of such biochemical assays has led to the interchangeable use of the terms arginase activity and arginase concentration. The in vitro experiments in the present study were designed to study arginase activity under physiological conditions, rather than to quantify plasma levels of arginase. The results show that detection of arginase activity in a plasma sample under optimal biochemical conditions does not necessarily imply that arginase is active in plasma under physiological conditions.

Currently, there is growing interest in the role of arginine and arginase in haemolytic anaemia $(10,34)$. In a previous study $(10)$, it was reported that haemolytic patients with sickle cell anaemia had reduced arginine levels and a 5 -fold increase in plasma arginase activity, measured by a semi-quantitative assay. In the same study, it was found that erythrocyte arginase activity was increased similarly. Another study (34) reported a 14-fold increase in erythrocyte arginase activity in sickle cell disease, measured semiquantitatively. In the light of our present results, which show that a considerable amount of plasma arginine catabolism is performed by arginase- 1 within the 
intact erythrocyte, it can be speculated that increased arginase activity in the blood of sickle cell patients should be ascribed to increased arginase activity in the cellular fraction, rather than to increased arginase levels in plasma. Finally, it has been suggested that increased circulating arginase concentrations disturb arginine metabolism following blood transfusion due to haemolysis of stored erythrocytes (20). We found that normal erythrocytes contain $17 \mu \mathrm{g}$ of arginase$1 / \mathrm{ml}$ of cells. Therefore 1 unit of erythrocyte concentrate $(300 \mathrm{ml})$ contains 5.1 $\mathrm{mg}$ of arginase-1. Considering a distribution volume of 3 litres (plasma volume) for these erythrocytes after transfusion, 1 unit of packed erythrocytes can increase arginase-1 plasma levels with $1.7 \mu \mathrm{g} / \mathrm{ml}$ in the extreme situation of $100 \%$ haemolysis of the transfused erythrocytes. This theoretical example shows that plasma arginase- 1 activity during blood transfusion will probably not affect arginine metabolism substantially. This assumption is confirmed further by clinical observations in patients receiving massive blood transfusion during thoracoabdominal aorta surgery, showing moderate changes in plasma arginase-1 concentrations but no changes in plasma arginine concentrations (S. J. P. Hanssen, M. C. G. van de Poll and W. A. Buurman, unpublished work). In conclusion, increased plasma levels of arginase-1 occurring during liver resection do not lead to arginine breakdown. The threshold beyond which the plasma level of arginase-1 significantly affects plasma arginine concentration is probably rarely reached in clinical practice, with the exceptions of liver transplantation.

\section{Acknowledgments}

We thank Dr J. Rosing (Department of Biochemistry, Maastricht University, Maastricht, The Netherlands), Dr W.H. Lamers (Department of Anatomy and Embryology, Maastricht University, Maastricht, The Netherlands) and Dr A.J. Meijer (Department of Biochemistry, University of Amsterdam, Amsterdam, The Netherlands) for fruitful discussions. 


\section{References}

1. Wu G, Morris SM, Jr. Arginine metabolism: nitric oxide and beyond. Biochem J 1998;336 ( Pt 1):1-17.

2. Castillo L, Beaumier L, Ajami AM, Young VR. Whole body nitric oxide synthesis in healthy men determined from $\left[{ }^{15} \mathrm{~N}\right]$ arginine-to- $\left[{ }^{15} \mathrm{~N}\right] c$ citrulline labeling. Proc Natl Acad Sci U S A 1996;93:11460-5.

3. Castillo L, Chapman TE, Sanchez M, et al. Plasma arginine and citrulline kinetics in adults given adequate and arginine-free diets. Proc Natl Acad Sci U S A 1993;90:7749-53.

4. Castillo L, Sanchez M, Vogt J, et al. Plasma arginine, citrulline, and ornithine kinetics in adults, with observations on nitric oxide synthesis. Am J Physiol 1995;268:E360-7.

5. Morris SM, Jr., Bhamidipati D, Kepka-Lenhart D. Human type II arginase: sequence analysis and tissue-specific expression. Gene 1997;193:157-61.

6. Kim PS, lyer RK, Lu KV, et al. Expression of the liver form of arginase in erythrocytes. Mol Genet Metab 2002;76:100-10.

7. Grody WW, Argyle C, Kern RM, et al. Differential expression of the two human arginase genes in hyperargininemia. Enzymatic, pathologic, and molecular analysis. J Clin Invest 1989;83:602-9.

8. Cheung CW, Cohen NS, Raijman L. Channeling of urea cycle intermediates in situ in permeabilized hepatocytes. J Biol Chem 1989;264:4038-44.

9. van de Poll MCG, Siroen MP, van Leeuwen PA, et al. Interorgan amino acid exchange in humans: consequences for arginine and citrulline metabolism. Am J Clin Nutr 2007;85:16772.

10. Morris CR, Kato GJ, Poljakovic $M$, et al. Dysregulated arginine metabolism, hemolysisassociated pulmonary hypertension, and mortality in sickle cell disease. JAMA 2005;294:81 90.

11. Langle $F$, Steininger $R$, Roth $R$, et al. L-arginine deficiency and hemodynamic changes as a result of arginase efflux following orthotopic liver transplantation. Transplant Proc 1995;27:2872-3.

12. Debats IB, Booi D, Deutz NE, Buurman WA, Boeckx WD, van der Hulst RR. Infected Chronic Wounds Show Different Local and Systemic Arginine Conversion Compared With Acute Wounds. J Surg Res 2006;134:205-14.

13. Luiking YC, Poeze M, Dejong CH, Ramsay G, Deutz NE. Sepsis: an arginine deficiency state? Crit Care Med 2004;32:2135-45.

14. Makarenkova VP, Bansal V, Matta BM, Perez LA, Ochoa JB. CD11b+/Gr-1+ myeloid suppressor cells cause $T$ cell dysfunction after traumatic stress. J Immunol 2006;176:2085-94.

15. Braga M, Gianotti L, Vignali A, Carlo VD. Preoperative oral arginine and $n-3$ fatty acid supplementation improves the immunometabolic host response and outcome after colorectal resection for cancer. Surgery 2002;132:805-14.

16. Roth $E$, Steininger $R$, Winkler $S$, et al. L-arginine deficiency after liver transplantation as an effect of arginase efflux from the graft. Transplantation 1994;57:665-9.

17. Cheng PN, Leung YC, Lo WH, Tsui SM, Lam KC. Remission of hepatocellular carcinoma with arginine depletion induced by systemic release of endogenous hepatic arginase due to transhepatic arterial embolisation, augmented by high-dose insulin: arginase as a potential drug candidate for hepatocellular carcinoma. Cancer Lett 2005;224:67-80.

18. Cacciatore L, Antoniello $S$, Valentino B, De Ritis F. Arginase activity, arginine and ornithine of plasma in experimental liver damage. Enzyme 1974;17:269-75.

19. Houdijk AP, Teerlink T, Visser JJ, van Lambalgen AA, van Leeuwen PA. Arginine deficiency in bile duct-ligated rats after surgery: the role of plasma arginase and gut endotoxin restriction. Gastroenterology 1997;113:1375-83. 
20. Prins HA, Houdijk AP, Nijveldt RJ, et al. Arginase release from red blood cells: possible link in transfusion induced immune suppression? Shock 2001;16:113-5.

21. Wheatley $D N$. Controlling cancer by restricting arginine availability--arginine-catabolizing enzymes as anticancer agents. Anticancer Drugs 2004;15:825-33.

22. Patel A, van de Poll MC, Greve JW, et al. Early stress protein gene expression in a human model of ischemic preconditioning. Transplantation 2004;78:1479-87.

23. van de Poll MC, Derikx JPM, Buurman WA, et al. Liver manipulation causes hepatocyte injury and precedes systemic inflammation in patients undergoing liver resection. World J Surg 2007:2033-8.

24. Boyum A, Lovhaug D, Tresland L, Nordlie EM. Separation of leucocytes: improved cell purity by fine adjustments of gradient medium density and osmolality. Scand J Immunol 1991;34:697-712.

25. Krzyzaniak JF, Raymond DM, Yalkowsky SH. Lysis of human red blood cells 1: Effect of contact time on water induced hemolysis. PDA J Pharm Sci Technol 1996;50:223-6.

26. van Eijk HM, Rooyakkers DR, Deutz NE. Rapid routine determination of amino acids in plasma by high-performance liquid chromatography with a 2-3 microns Spherisorb ODS II column. J Chromatogr 1993;620:143-8.

27. Ikemoto M, Tsunekawa S, Awane $M$, et al. A useful ELISA system for human liver-type arginase, and its utility in diagnosis of liver diseases. Clin Biochem 2001;34:455-61.

28. Morris CR, Poljakovic M, Lavrisha L, Machado L, Kuypers FA, Morris SM, Jr. Decreased arginine bioavailability and increased serum arginase activity in asthma. Am J Respir Crit Care Med 2004;170:148-53.

29. Rother RP, Bell L, Hillmen P, Gladwin MT. The clinical sequelae of intravascular hemolysis and extracellular plasma hemoglobin: a novel mechanism of human disease. JAMA 2005;293:1653-62.

30. de Jonge WJ, Kwikkers $K L$, te Velde $A A$, et al. Arginine deficiency affects early $B$ cell maturation and lymphoid organ development in transgenic mice. J Clin Invest 2002;110:153948.

31. Luiking YC, Poeze M, Ramsay G, Deutz NE. The role of arginine in infection and sepsis. JPEN J Parenter Enteral Nutr 2005;29:S70-4.

32. van de Poll MCG, Ligthart-Melis GC, Boelens PG, Deutz NE, van Leeuwen PAM, Dejong CHC. Intestinal and hepatic metabolism of glutamine and citrulline in humans. J Physiol 2007;581:819-827.

33. Tenu JP, Lepoivre M, Moali C, Brollo M, Mansuy D, Boucher JL. Effects of the new arginase inhibitor N(omega)-hydroxy-nor-L-arginine on NO synthase activity in murine macrophages. Nitric Oxide 1999;3:427-38.

34. Iyamu EW, Cecil R, Parkin L, Woods G, Ohene-Frempong K, Asakura T. Modulation of erythrocyte arginase activity in sickle cell disease patients during hydroxyurea therapy. $\mathrm{Br} \mathrm{J}$ Haematol 2005;131:389-94. 


\section{Chapter 8}

\section{Glutathione oxidation}

\section{and oxidative stress}

\section{during intermittent}

Pringle manoeuvre 


\section{Abstract}

Oxidative stress mediates cell injury during ischemia-reperfusion. On the other hand experimental data suggest that reactive oxygen species induce processes leading to ischemic preconditioning. The extent and source of oxidative stress and its effect on antioxidant status in the human liver during intermittent ischemia and reperfusion remains ill-defined.

Liver biopsies, arterial and hepatic venous blood samples were taken from 10 patients undergoing hepatectomy with intermittent Pringle manoeuvre. Plasma malondialdehyde and hepatic glutathione disulfide (GSSG) levels were measured as markers of oxidative stress, plasma uric acid as a marker of xanthine oxidase activity. In addition, changes in hepatosplanchnic consumption of plasma antioxidants and hepatic levels of carotenoids and glutathione (GSH) were measured.

After ischemia, hepatosplanchnic release of MDA and increased hepatic GSSG levels were found. This was accompanied by release of uric acid, reflecting xanthine oxidase activity. During reperfusion ongoing oxidative stress was evidenced by further increases in hepatic GSSG content and hepatosplanchnic MDA release. Uric acid release was minimal during reperfusion. A gradual decline of plasma antioxidant capacity and net hepatosplanchnic antioxidant uptake was observed upon prolonged cumulative ischemia.

Oxidative stress occurs during hepatic ischemia in man mainly due to xanthine oxidase activity. The gradual decline of plasma antioxidant capacity and net hepatosplanchnic antioxidant uptake during prolonged cumulative ischemia, interestingly did preserve both hydrophilic and lipophilic hepatic antioxidant levels. Decreasing plasma levels and net hepatosplanchnic uptake of plasma antioxidants may warrant antioxidant supplementation although it should be clarified to what extent limitation of oxidative stress compromises ROSdependent pathways of ischemic preconditioning. 


\section{Introduction}

Minimization of blood loss during liver resection is essential to limit complications. To diminish blood loss during liver resection hepatic inflow occlusion or "Pringle manoeuvre", was introduced by JH Pringle in 1908 (1). However, the Pringle manoeuvre leads to hepatic ischemia-reperfusion injury. Ischemia is characterized by ATP depletion and necrotic cell death (2), subsequent reperfusion aggravates cell injury. An important factor in this process is the formation of reactive oxygen species (ROS) immediately after reperfusion $(3,4)$. This leads to peroxidation of membrane phospholipids (5) and oxidative damage to intracellular proteins (4). Classically, the generation of ROS has been ascribed to an increased conversion of xanthine dehydrogenase into xanthine oxidase during ischemia (6), but concern about the validity of this concept has been raised $(3,7)$. More recently, attention has moved to the mitochondrial respiratory chain as the principal source of ROS during ischemia and reperfusion $(3,8)$, although the hypothesis that xanthine oxidase activity is an important source of ROS formation during hepatic ischemia-reperfusion is still debated (9).

ROS oxidize glutathione (GSH) to glutathione disulfide (GSSG) (10) which renders cells prone to cell death (11-13). Endogenous and exogenous antioxidants offer protection against the action of ROS, consequently antioxidants may become depleted during excessive oxidative stress. Most data on hepatic ischemia reperfusion damage are derived from animal studies, which generally rely on prolonged continuous ischemia to render maximal effects. The severity of these models complicates immediate translation of these results to human clinical practice. Altough ROS formation is generally associated with cell death as outlined above, recent data suggest that ROS are important signal molecules that activate transcription factors such as HIF-1 $\alpha$ which mediate heat shock protein expression and other processes leading to ischemic preconditioning (14). Only few studies are currently at hand concerning the occurrence and extent of oxidative stress during short term intermittent warm hepatic ischemia and reperfusion in clinical practice.

Aim of the present study was to investigate the occurrence of oxidative stress in humans undergoing liver resection with intermittent Pringle manoeuvre. Emphasis was placed on sources of ROS formation and on changes in exogenous and endogenous antioxidant status. 


\section{Materials and Methods}

\section{Patients}

Ten patients (male:female 6:4) undergoing partial hepatectomy for secondary liver malignancies (colorectal cancer $(n=9)$, insulinoma $(n=1)$ ) were studied after an overnight fast. All patients had normal liver function as assessed by preoperative laboratory parameters. They were on their standard diets in the pre-study period. Patient characteristics are summarized in Table 1.

Table 1. Patient characteristics

\begin{tabular}{lll}
\hline & Median (range) & Reference values \\
Gender $(\mathrm{M} / \mathrm{F})$ & $6 / 4^{*}$ & \\
Age (years) & $58(52-71)$ & \\
AST $(\mathrm{IU} / \mathrm{L})$ & $21(6-35)$ & $<35$ \\
Bilirubin $(\mu \mathrm{M})$ & $11.8(7.3-17.6)$ & $2.0-17$ \\
PT $(\mathrm{s})$ & $10.4(9.8-11.9)$ & $9.9-11.5$ \\
Creatinine $(\mu \mathrm{M})$ & $80(67-116)$ & $53-110$ \\
Urea $(\mathrm{mM})$ & $4.5(2.3-6.6)$ & $3.0-7.0$ \\
\hline
\end{tabular}

* ratio, $\mathrm{AST}=$ aspartate amino transferase, $\mathrm{PT}=$ prothrombin time

\section{Anesthesia and surgical procedure}

All patients had radial artery and central venous catheters inserted preoperatively to monitor arterial and central venous blood pressure as part of standard anesthetic care. Surgical procedures were performed as detailed elsewhere (15). Liver surgery was performed using a Cavitron Ultrasonic Surgical Aspirator (Valleylab, Tyco healthcare, Boulder, CO, USA) and electrocautery or ligation of vessels as appropriate.

\section{Intermittent Pringle manoeuvre}

During liver transection, an intermittent Pringle manoeuvre was applied by tightening a rubber tube around the entire hepatoduodenal ligament (total Pringle manoeuvre) or selectively around the left or right portal vein and hepatic artery as considered appropriate for the intended resection (selective Pringle manoeuvre, $n=4)$. At least two cycles of 15 minutes occlusion of the portal vein and hepatic artery and 5 minutes reperfusion were required to complete hepatic transection. 


\section{Sample collection}

Using the same approach as we have published recently (16), liver biopsies and blood samples were taken prior to and following ischemia and after reperfusion according to the schedule shown in Figure 1. Liver-tissue samples (approximately $200 \mathrm{mg}$ ) were excised with a scalpel from nontumorous regions of the liver, distant from the transection plane. Simultaneously blood was drawn from the arterial line and from a hepatic vein that was draining the (post)ischemic part of the liver, allowing the measurement of AV differences across the hepatosplanchnic bed. Post-ischemia blood samples were taken immediately after hepatic blood flow was restored.

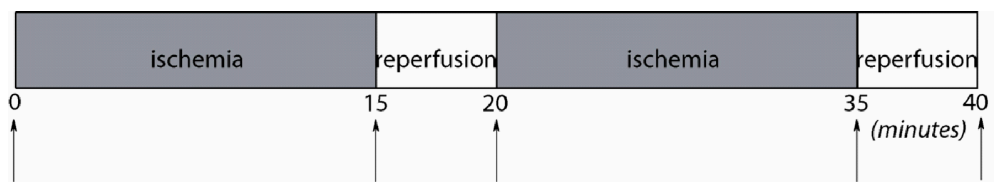

Figure 1. Schematic representation of the protocol. An intermittent Pringle manoeuvre (15'5' schedule) was applied during liver transection in 10 patients undergoing liver resection for secondary tumors in an otherwise normal liver. Before and after each event, arterial and hepatic venous blood was drawn and liver biopsies were taken (arrows). Post-ischemia blood samples were drawn seconds after restoration of hepatic blood flow, liver biopsies immediately prior to reperfusion.

\section{Sample processing}

Blood was collected into EDTA containing tubes (Becton, Dickinson Vacutainer, Franklin Lakes, NJ,USA). All blood samples were immediately put on ice, and kept on ice during sample preparation. Plasma was obtained by centrifugation $\left(800 \times \mathrm{g}\right.$ for $10 \mathrm{~min}$ at $4^{\circ} \mathrm{C}$ ) and stored at $-80^{\circ} \mathrm{C}$ until analysis. Liver biopsies were divided in two pieces and rapidly frozen in liquid nitrogen. Prior to analyses liver biopsies were homogenized in milliQ water (150 $\mathrm{mg}$ tissue $/ \mathrm{ml}$ )

\section{Laboratory analyses}

\section{Chemicals}

2,2'-azinobis(3-ethylbenzthiazoline-6-sulfonic acid) (ABTS), uric acid and butylated hydroxytoluene (BHT) were obtained from Sigma Chemical Co., St. Louis, USA. 2,2'-azino-bis(2-amidinopropane) dihydrochloride (ABAP) was obtained from Brunschwig Chemicals, Amsterdam, The Netherlands. All chemicals were of analytical purity. 


\section{MDA assay}

The assay is based on the formation of a coloured adduct of MDA-like breakdown products of lipids with 2-thiobarbituric acid (TBA) $(17,18)$. One hundred $\mu \mathrm{l}$ of plasma was added to $1 \mathrm{ml}$ of reagent (containing $0.012 \mathrm{~mol} / \mathrm{l} \mathrm{TBA}$, $0.32 \mathrm{~mol} / \mathrm{l}$ o-phosphoric acid, $0.68 \mathrm{mmol} / / \mathrm{BHT}$ and $0.01 \%(\mathrm{~m} / \mathrm{v})$ EDTA). The mixture was incubated for 1 hour at $100^{\circ} \mathrm{C}$ in a water bath. After cooling, the TBA-product was extracted with $500 \mu \mathrm{l}$ butanol. Thirty $\mu \mathrm{l}$ of the butanol layer was injected on an HPLC system (Agilent, Palo Alto, CA, USA) equipped with a fluorescence detector, set on an excitation wavelength of $532 \mathrm{~nm}$ and emission wavelength of $553 \mathrm{~nm}$, and a Nucleosil C18 column, $150 \times 3.2 \mathrm{~mm}$, particle size $5 \mu \mathrm{m}$ (Supelco Inc., Bellefonte, PA, USA). Samples were eluted with $65 \%(\mathrm{v} / \mathrm{v})$ MilliQ, $35 \%(\mathrm{v} / \mathrm{v})$ methanol, containing $0.05 \%$ trifluoric acid. A calibration curve was constructed using malonaldehyde bis(diethylacetal) as standard.

\section{Uric acid assay}

Uric acid, the reaction product of xanthine oxidase activity was determined using an HPLC method described by Lux et al. (19)

\section{Plasma antioxidant capacity [TEAC] assay}

Plasma antioxidant capacity was assayed as described by Fischer et al. (20) Briefly, $950 \mu \mathrm{l}$ of $\mathrm{ABTS}^{+}{ }^{+}$radical solution was incubated for 1 minute at $37^{\circ} \mathrm{C}$, thereafter $50 \mu \mathrm{l}$ deproteinized plasma was added. After 5 minutes incubation the absorption at $734 \mathrm{~nm}$ was measured. The decrease in absorption after 5 minutes relative to blank (buffer) was related to that of trolox calibrators. The resulting value is expressed as trolox equivalent antioxidant capacity (TEAC). Since TEAC is partly determined by uric acid concentration, the raw data from this assay were corrected for the uric acid content of the sample (plasma antioxidant capacity $=$ TEAC - [uric acid]).

\section{Hepatic GSH and GSSG content}

GSH and GSSG concentrations were measured in the supernatant of homogenized liver biopsies as described by Anderson (21). Total protein concentrations in the homogenates was measured using the bicinchoninic acid method as described by Smith et al. (22). Final concentrations of GSH and GSSG were expressed per $\mathrm{mg}$ protein.

\section{Hepatic levels of carotenoids and $\alpha$-tocopherol}

The analysis of the concentrations of the different carotenoids and tocopherols in the supernatant of homogenized liver biopsies was performed as described by Broekmans et al. (23). Liver biopsies were homogenized in MilliQ (150 mg 
tissue per $\mathrm{mL}$. Final concentrations of carotenoids and alpha tocopherol were expressed per mg protein.

\section{Statistics}

Values are expressed as mean (SEM). Overall changes in plasma and tissue levels, during the experiment were assessed by one-way ANOVA and Bonferroni post-testing, comparing values at each timepoint with baseline.

For arteriovenous gradients a fictive timepoint with an arteriovenous gradient of zero was included in the ANOVA and Bonferroni post-testing was performed for values at each timepoint versus baseline as well as versus this theoretical zero gradient. This approach is in fact a modification of the one-sample t-test which calculates whether the mean of a study population significantly differs from a theoretical value (24) and is frequently used in organ balance studies (25). This approach allows the simultaneous calculation of the difference of arteriovenous gradients at multiple timepoints both versus baseline and zero using a single statistic test while correcting for multiple comparisons. Statistics were performed using GraphPad Prism 4.0 for Windows (GraphPad Software, San Diego, CA, USA). A p-value $<0.05$ was considered to indicate statistical significance.

\section{Results}

\section{MDA in plasma}

The mean arterial plasma level of malondialdehyde (MDA), was $1.2(0.1) \mu \mathrm{mol} / \mathrm{l}$. This systemic level did not change significantly during the intermittent Pringle manoeuvre (Figure 2A). In contrast, the hepatosplanchnic MDA gradient tended to increase already after 15 minutes ischemia $(95 \% \mathrm{Cl}$ of the mean increase vs baseline: $-0.10-0.26 \mu \mathrm{mol} / \mathrm{l}$, Bonferroni's test), indicating the occurrence of oxidative stress and lipid peroxidation during ischemia. After a cumulative ischemia time of 30 minutes, hepatosplanchnic MDA release tended to remain elevated above baseline values $(95 \% \mathrm{Cl}$ of the mean increase vs baseline: $0.05-0.31 \mu \mathrm{mol} / \mathrm{l}$, Bonferroni's test) during the second reperfusion period (Figure 2B).

\section{Hepatosplanchnic uric acid release}

Mean (SEM) arterial plasma level of uric acid (250 (16) $\mu \mathrm{mol} / \mathrm{l}$ at baseline) increased significantly after 15 minutes of hepatic ischemia (Figure $3 \mathrm{~A}$ ). Hepatosplanchnic uric acid release, indicative of xanthine oxidase activity, was 
not significantly different from zero at baseline, but increased significantly following both periods of '15' hepatic ischemia. Upon reperfusion hepatosplanchnic uric acid release returned to baseline values (Figure 3B).

MDA

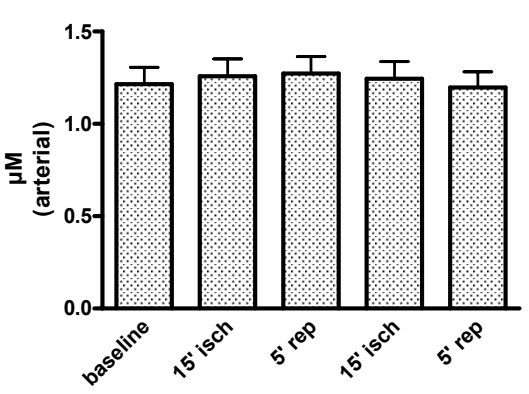

MDA

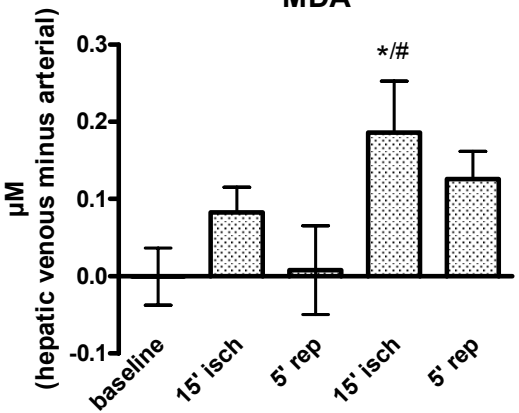

B

Figure 2. A. Systemic malondialdehyde (MDA) levels in 10 patients undergoing liver resection with intermittent Pringle manoeuvre. No significant changes in systemic plasma levels were observed. B. Assessment of arteriovenous MDA concentration gradients revealed a significant increase in hepatosplanchnic lipid peroxidation during intermittent Pringle manoeuvre, particularly after the second period of 15 minutes ischemia. ${ }^{*}=p<0.05$ vs baseline, \# $=p<0.05$ vs zero (One-way ANOVA with Bonferroni's post-test for multiple comparisons).

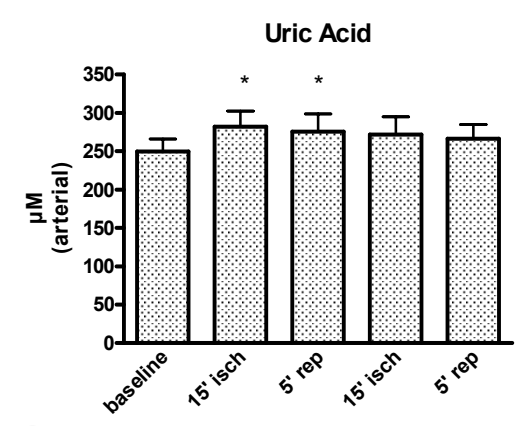

$A$ patients undergoing liver resection with intermittent Pringle manoeuvre Systemic uric acid patients undergoing liver resection with intermittent Pringle manoeuvre. Systemic uric acid levels increased after 15 minutes of hepatic ischemia. B. hepatosplanchnic gradients of uric acid. At baseline uric acid release was not significantly different from zero. Arteriovenous concentration gradients revealed significant changes in hepatosplanchnic uric acid release after hepatic ischemia. ${ }^{*}=p<0.05$ vs baseline, $\#=p<0.05$ vs zero (One-way ANOVA with 


\section{Plasma antioxidant capacity during intermittent Pringle manoeuvre}

A gradual decline of plasma antioxidant capacity (TEAC - [uric acid]) was found during the experiment (Figure 4A). At baseline there was a negative hepatic venous-arterial gradient of plasma antioxidant capacity, indicating net hepatosplanchnic uptake of antioxidants from the plasma. Net hepatosplanchnic uptake however, disappeared gradually during the intermittent Pringle manoeuvre (Figure 4B).

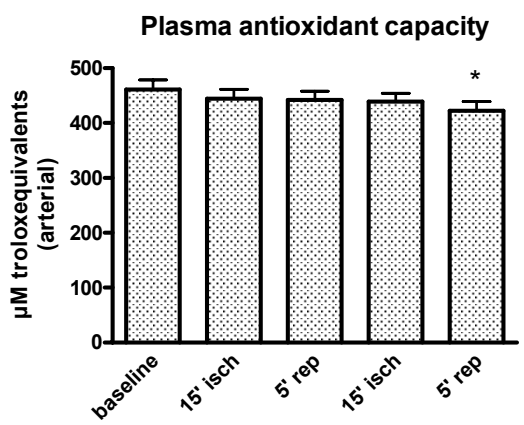

A

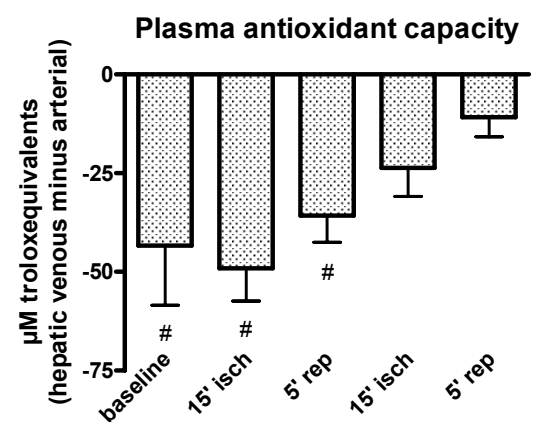

B

Figure 4. A. Systemic levels of plasma antioxidant capacity ((TEAC - [uric acid]), see Methods) in 10 patients undergoing liver resection with intermittent Pringle manoeuvre. Showing. During the study a gradual decline of systemic antioxidant capacity was observed. B. Hepatosplanchnic net balance of plasma antioxidant capacity showed a gradual decrease of net hepatosplanchnic antioxidant uptake during prolonged cumulative ischemia-reperfusion.

GSH and GSSG during intermittent hepatic ischemia and reperfusion

Hepatic tissue GSH content increased significantly during hepatic inflow occlusion and returned to baseline values during reperfusion (Figure 5A), no evidence for GSH depletion was found. Also hepatic GSSG content increased significantly after $15^{\prime}$ ischemia but tended to keep increasing after 5 ' reperfusion $(95 \% \mathrm{Cl}$ of the mean increase vs baseline: $-0.03-0.74 \mu \mathrm{mol} / \mathrm{g}$ protein, Bonferroni's test). Thereafter a rapid decline of hepatic GSSG content was found, resulting in a return to baseline values (Figure 5B). The ratio 
GSSG:GSH, indicative for cellular redox state showed a transient increasing tendency during the study (Figure $5 \mathrm{C}$ ).

\section{Carotenoids and $\alpha$-tocopherol}

Lycopene and $\beta$-carotene were the most abundant carotenoids in the liver (mean (SEM)) $61.8(20.5) \mathrm{nmol} / \mathrm{g}$ protein and 16.6 (2.8) $\mathrm{nmol} / \mathrm{g}$ protein respectively. Expressed per gram liver hepatic carotenoids levels were found to be $0.5(0.09) \mathrm{nmol} / \mathrm{g}$ liver for lutein, 7.5 (2.4) nmol/g liver for lycopene and 2.0 $(0.4) \mathrm{nmol} / \mathrm{g}$ liver for $\beta$-carotene, these values are in approximate agreement with previous human data $(26,27)$. Hepatic tissue levels of carotenoids and $\alpha-$ tocopherol were not significantly affected by intermittent hepatic ischemia and reperfusion (Table 2).

GSH

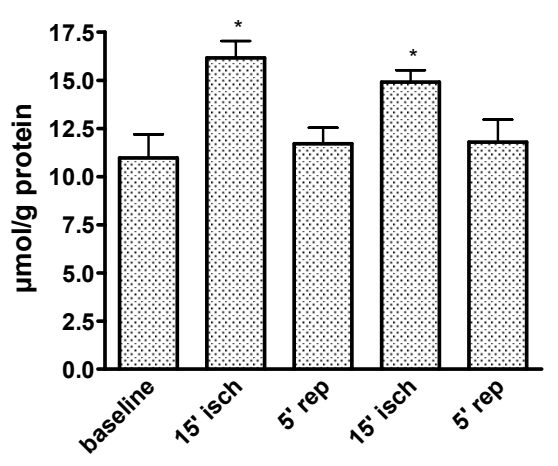

A

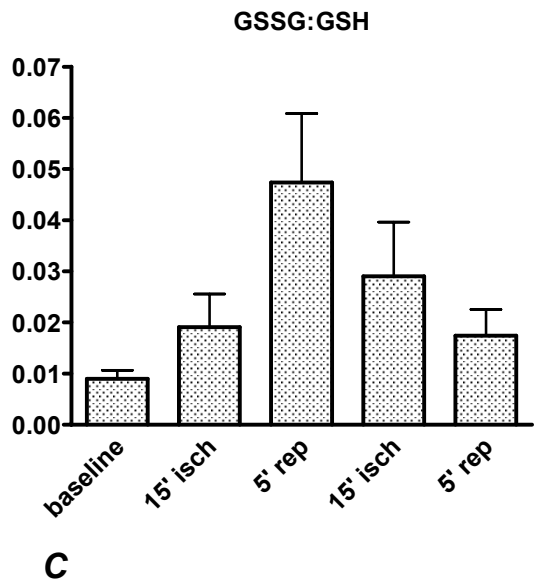

GSSG

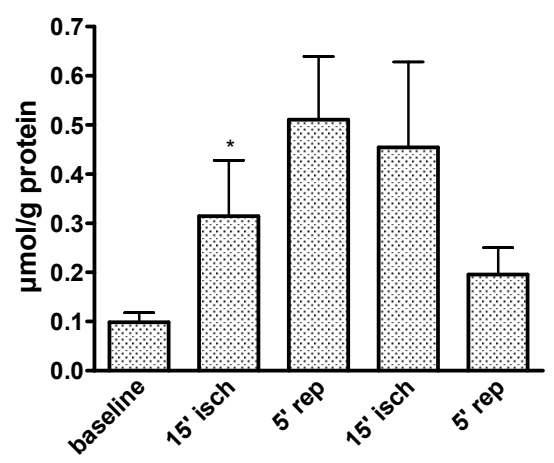

B

Figure 5. A. Hepatic GSH content in 10 patients undergoing liver resection with intermittent Pringle manoeuvre. $B$. Hepatic GSSG content in 10 patients undergoing liver resection with intermittent Pringle manoeuvre. C. Ratio between hepatic GSH content and GSSG content (GSH:GSSG) in 10 patients undergoing liver resection with intermittent Pringle manoeuvre. * = $p<0.05$ vs baseline, (One-way ANOVA with Bonferroni's post-test for multiple comparisons). 


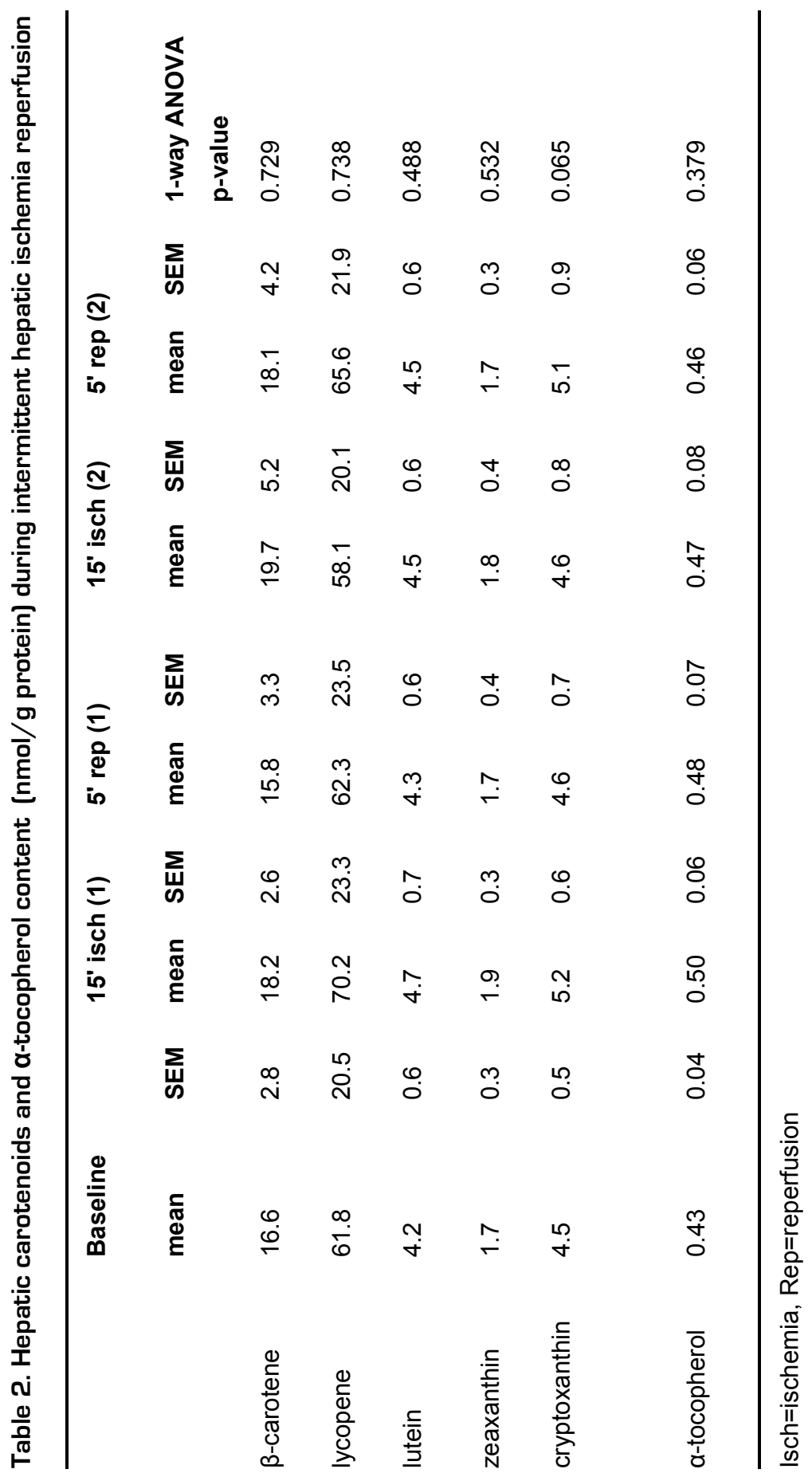




\section{Discussion}

According to our knowledge, this is the first study which meticulously describes the development of oxidative stress during hepatic ischemia and reperfusion and its effect on antioxidant status in humans. During the Pringle manoeuvre the hepatoduodenal ligament is temporarily ligated, resulting in total obstruction of both portal venous and hepatic arterial inflow and in an obstruction of biliary outflow. As pointed out earlier, human studies on this subject are scarce and are limited to the description of changes in systemic plasma markers of oxidative stress. In these studies no changes in malondialdehyde and GSH levels could be detected in peripheral blood (28). By measuring transorgan gradients and by taking liver biopsies however, we could reveal a profound effect of ischemia and reperfusion on hepatic oxidative stress and antioxidant status. No differences were observed between cases where a selective or a complete hepatic inflow occlusion was used. In addition it may be expected that the intermittent hepatic inflow occlusion provided some ischemic preconditioning during the second period of ischemia (16). This may hamper translation of the present findings to situations where a similar cumulative ischemic period is applied in a continuous fashion. Most likely prolonged ischemia exaggerates oxidative stress upon reperfusion (5).

Lipid peroxidation, evidenced by MDA release, occurred already during ischemia, within 15 minutes of hepatic inflow occlusion. Moreover, we simultaneously observed a significant increase of hepatosplanchnic release of uric acid. Uric acid is generated upon oxidation of xanthine by xanthine oxidase, yielding equimolar amounts of uric acid and superoxide anion radicals (6). These data suggest that oxidative stress and lipid peroxidation occurs within 15 minutes of hepatic ischemia in vivo in humans and that xanthine oxidase forms a significant source of ROS during ischemia. The occurrence of lipid peroxidation and xanthine oxidase activity during ischemia may appear paradoxal since these processes are considered to depend on the presence of molecular oxygen. However, hypoxic ROS generation has been observed previously in vitro in heart (29), lung (30) and murine macrophages (31). Alternatively, it has been suggested that retrograde perfusion from the hepatic veins sustains some blood and oxygen supply to the liver during the Pringle manoeuvre (32). In vivo studies in rats also showed progressive lipid peroxidation during continuous ischemia up to 120 minutes (5). Hepatosplanchnic MDA and uric acid release ceased within 5 minutes of reperfusion following the initial 15 minutes of hepatic ischemia, suggesting that xanthine oxidase activity during reperfusion is limited. During reperfusion however, a marked increase in the oxidation of GSH to GSSG was observed as 
evidenced by increasing GSSG levels and an increased GSSG:GSH ratio. These data suggest ongoing or additional oxidative stress which must probably be ascribed to other ROS generating systems than xanthine oxidase, presumably the mitochondrial respiratory chain $(3,8)$.

After a second period of 15 minutes hepatic ischemia (again leading to significant release of uric acid and MDA), MDA was persistently released during reperfusion, reflecting a sustained lipid peroxidation within the hepatosplanchnic area after a cumulative ischemia time of 30 minutes. In contrast, uric acid release rapidly returned to baseline values during reperfusion. Thus our data consistently suggest that xanthine oxidase may particularly be involved in ROS generation during ischemia. Hepatic GSSG content returned to baseline values during the second cycle of the intermittent Pringle manoeuvre. A possible explanation for this somewhat surprising observation is an increased activity of the enzyme glutathione reductase. An increased efflux of GSSG during oxidative stress has been demonstrated in rats (33). However, hepatocellular GSSG efflux, will probably not decrease total hepatic GSSG content during ischemia, since the absence of blood and bile flow prohibits drainage of GSSG accumulated in these extracellular fluids.

Subsequently, we studied the consequences of the intermittent Pringle manoeuvre on some important antioxidants, i.e. GSH, plasma antioxidants and hepatic carotenoids and $\alpha$-tocopherol. An additionally unexpected finding was the increase in hepatic GSH content during ischemia. Since hepatic GSH content rapidly decreased to normal values during reperfusion this transient increase of GSH content during inflow occlusion must probably be ascribed to the accumulation of constitutively synthesized GSH during inflow occlusion, due to absence of hepatic blood flow and the consequent absent washout, which is restored upon restoration of blood and bile flow. Our data show no evidence for the occurrence of hepatic GSH depletion during the intermittent Pringle manoeuvre. Important lipophilic antioxidants are carotenoids and a-tocopherol. Carotenoids are derived from vegetable intake and are stored intracellularly. In line with data on hepatic (hydrophilic) GSH levels, we found no time-dependent effects of intermittent Pringle manoeuvre on hepatic levels of lipophilic carotenoids and $\alpha$-tocopherol. A substantial amount of the body's antioxidant system is present in plasma as amongst others glutathione, albumin, bilirubin and ascorbic acid (34). Upon progressive ischemia systemic plasma antioxidant capacity gradually declined (approximately $10 \%$ after 30 minutes ischemia and 10 minutes reperfusion). At baseline there was a negative hepatosplanchnic balance of plasma antioxidant capacity, indicating hepatosplanchnic uptake of antioxidants from the plasma. Simultaneously with decreasing plasma antioxidant capacity, this net uptake declined and ultimately disappeared throughout the study. One may speculate that this decreasing hepatosplanchnic 
net uptake of hydrophilic antioxidants is causally related to equally diminishing arterial antioxidant concentration.

When considering the effects of ischemia and reperfusion on ROS formation and antioxidant status, it must be realized that ROS also are important signalling molecules. In line with this recent data suggest that oxidative stress may lead to a rapid induction of cytoprotective pathways during intermittent Pringle manoeuvre and ischemic preconditioning (14). Therefore, in future studies concerning antioxidant supplementation during liver ischemia changes in the induction and expression of cytoprotective mechanisms should be assessed as well as changes in hepatocellular integrity and liver function.

In conclusion, short term hepatic ischemia and reperfusion in man leads to xanthine oxidase activity and lipid peroxidation within 15 minutes. Prolonged cumulative ischemia-reperfusion injury leads to sustained oxidative stress, demonstrated by lipid peroxidation and to systemic antioxidant depletion. The observed gradual decline of plasma antioxidant capacity and net hepatosplanchnic antioxidant uptake during prolonged cumulative ischemia, interestingly did preserve both hydrophilic and lipophilic hepatic antioxidant levels. Decreasing plasma levels and net hepatosplanchnic uptake of plasma antioxidants may warrant antioxidant supplementation when cumulative ischemia time exceeds 30 minutes although potential deleterious effects of antioxidant supplementation on ischemic preconditioning should not be disregarded. 


\section{References}

1. Pringle JH. Notes on the arrest of hepatic hemorrhage due to trauma. Ann Surg 1908;48:5419.

2. Malhi H, Gores GJ, Lemasters JJ. Apoptosis and necrosis in the liver: A tale of two deaths? Hepatology 2006;43:S31-44.

3. de Groot $\mathrm{H}$, Brecht $M$. Reoxygenation injury in rat hepatocytes: mediation by $\mathrm{O} 2 / \mathrm{H} 2 \mathrm{O} 2$ liberated by sources other than xanthine oxidase. Biol Chem Hoppe Seyler 1991;372:35-41.

4. Caraceni P, De Maria N, Ryu HS, et al. Proteins but not nucleic acids are molecular targets for the free radical attack during reoxygenation of rat hepatocytes. Free Radic Biol Med 1997;23:339-44.

5. Fukai M, Hayashi T, Yokota R, et al. Lipid peroxidation during ischemia depends on ischemia time in warm ischemia and reperfusion of rat liver. Free Radic Biol Med 2005;38:1372-81.

6. Granger DN, Rutili G, McCord JM. Superoxide radicals in feline intestinal ischemia. Gastroenterology 1981;81:22-9.

7. Jaeschke $H$. Xanthine oxidase-induced oxidant stress during hepatic ischemia-reperfusion: are we coming full circle after 20 years? Hepatology 2002;36:761-3.

8. Jezek P, Hlavata L. Mitochondria in homeostasis of reactive oxygen species in cell, tissues, and organism. Int J Biochem Cell Biol 2005;37:2478-503.

9. Fernandez L, Heredia N, Grande L, et al. Preconditioning protects liver and lung damage in rat liver transplantation: role of xanthine/xanthine oxidase. Hepatology 2002;36:562-72.

10. Anderson ME. Glutathione: an overview of biosynthesis and modulation. Chem Biol Interact 1998;111-112:1-14.

11. Nagai H, Matsumaru K, Feng G, Kaplowitz N. Reduced glutathione depletion causes necrosis and sensitization to tumor necrosis factor-alpha-induced apoptosis in cultured mouse hepatocytes. Hepatology 2002;36:55-64.

12. Pias EK, Aw TY. Early redox imbalance mediates hydroperoxide-induced apoptosis in mitotic competent undifferentiated PC-12 cells. Cell Death Differ 2002;9:1007-16.

13. Chen T, Pearce LL, Peterson J, Stoyanovsky D, Billiar TR. Glutathione depletion renders rat hepatocytes sensitive to nitric oxide donor-mediated toxicity. Hepatology 2005;42:598-607.

14. Chandel NS, McClintock DS, Feliciano CE, et al. Reactive oxygen species generated at mitochondrial complex III stabilize hypoxia-inducible factor-1alpha during hypoxia: a mechanism of O2 sensing. J Biol Chem 2000;275:25130-8.

15. Dejong CHC, Garden OJ. Neoplasms of the liver. In: Majid AA, Kingsnorth A, eds. Advanced surgical practice. London: Greenwich Medical Media, 2003:146-156.

16. Patel A, van de Poll MC, Greve JW, et al. Early stress protein gene expression in a human model of ischemic preconditioning. Transplantation 2004;78:1479-87.

17. Lepage G, Munoz G, Champagne J, Roy CC. Preparative steps necessary for the accurate measurement of malondialdehyde by high-performance liquid chromatography. Anal Biochem 1991;197:277-83.

18. Guillen-Sans R, Guzman-Chozas M. The thiobarbituric acid (TBA) reaction in foods: a review. Crit Rev Food Sci Nutr 1998;38:315-30.

19. Lux O, Naidoo D, Salonikas C. Improved HPLC method for the simultaneous measurement of allantoin and uric acid in plasma. Ann Clin Biochem 1992;29 (Pt 6):674-5.

20. Fischer MA, Gransier TJ, Beckers LM, Bekers O, Bast A, Haenen GR. Determination of the antioxidant capacity in blood. Clin Chem Lab Med 2005;43:735-40.

21. Anderson ME. Determination of glutathione and glutathione disulfide in biological samples. Methods in Enzymology 1995;113:548 - 555.

22. Smith PK, Krohn RI, Hermanson GT, et al. Measurement of protein using bicinchoninic acid. Anal Biochem 1985;150:76-85. 
23. Broekmans WM, Berendschot TT, Klopping-Ketelaars IA, et al. Macular pigment density in relation to serum and adipose tissue concentrations of lutein and serum concentrations of zeaxanthin. Am J Clin Nutr 2002;76:595-603.

24. Motulsky HJ. Prism 4 Statistics Guide; Statistical analyses for laboratory and clinical researchers. San Diego, CA, 2003.

25. van de Poll MCG, Siroen MP, van Leeuwen PA, et al. Interorgan amino acid exchange in humans: consequences for arginine and citrulline metabolism. Am J Clin Nutr 2007;85:16772.

26. Tanumihardjo SA, Furr HC, Amedee-Manesme O, Olson JA. Retinyl ester (vitamin A ester) and carotenoid composition in human liver. Int J Vitam Nutr Res 1990;60:307-13.

27. Schmitz HH, Poor CL, Wellman RB, Erdman JW, Jr. Concentrations of selected carotenoids and vitamin A in human liver, kidney and lung tissue. J Nutr 1991;121:1613-21.

28. Vriens MR, Marinelli A, Harinck HI, Zwinderman $\mathrm{KH}$, van de Velde CJ. The role of allopurinol in human liver ischemia/reperfusion injury: a prospective randomized clinical trial. Hepatogastroenterology 2002;49.

29. Lesnefsky EJ, Hoppel CL. Ischemia-reperfusion injury in the aged heart: role of mitochondria. Arch Biochem Biophys 2003;420:287-97.

30. Paddenberg $R$, Ishaq $B$, Goldenberg $A$, et al. Essential role of complex II of the respiratory chain in hypoxia-induced ROS generation in the pulmonary vasculature. Am J Physiol Lung Cell Mol Physiol 2003;284:L710-9.

31. Palacios-Callender M, Quintero M, Hollis VS, Springett RJ, Moncada S. Endogenous NO regulates superoxide production at low oxygen concentrations by modifying the redox state of cytochrome c oxidase. Proc Natl Acad Sci U S A 2004;101:7630-5.

32. Smyrniotis V, Kostopanagiotou G, Lolis E, et al. Effects of hepatovenous back flow on ischemic- reperfusion injuries in liver resections with the pringle maneuver. J Am Coll Surg 2003;197:949-54.

33. Masuda Y, Ozaki M, Aoki S. K(+)-driven sinusoidal efflux of glutathione disulfide under oxidative stress in the perfused rat liver. FEBS Lett 1993;334:109-13.

34. Cao G, Prior RL. Comparison of different analytical methods for assessing total antioxidant capacity of human serum. Clin Chem 1998;44:1309-15. 


\section{Chapter 9}

\section{Expression of cell chaperones during intermittent Pringle manoeuvre}

A Patel, MCG van de Poll, JWM Greve, WA Buurman, KCH Fearon SJ McNally, WM Harrison, JA Ross, OJ Garden CHC Dejong, SJ Wigmore 


\section{Abstract}

Intermittent clamping of the porta hepatis $(\mathrm{PHC})$ is commonly performed during liver surgery to reduce blood loss and has been reported to precondition livers resulting in improved outcome after liver surgery (humans) and transplantation (animals). This study investigated the early expression of cytoprotective stress proteins during ischemia-reperfusion induced by PHC. Liver samples were taken before and after each event in a two-cycle ischemia-reperfusion protocol using 15 minutes of PHC followed by 5 minutes of reperfusion. Liver tissue was analyzed by real-time polymerase chain reaction for heme oxygenase (HO)-1 and heat shock protein (HSP)-70 mRNA expression. Extracted protein was analyzed by Western blot for HO-1, and HSP-70 and nuclear extracts were analyzed by DNA mobility shift assay for hypoxia inducible factor (HIF)-1 $\alpha$ and heat shock factor (HSF)-1. Within minutes of PHC, significant increases in HO-1 mRNA expression were detected, and these were maintained throughout the protocol $(P<0.01)$. Protein expression of HO-1 $(P<0.03)$ and $\mathrm{HO}-1$ activity $(P<0.05)$ were similarly increased between the start and end of ischemiareperfusion (40 minutes). Binding of active HIF-1 $\alpha$ to its consensus sequence was increased within 15 minutes of the start of the ischemia-reperfusion cycle. Although evidence of the transcriptionally active form of HSF-1 was detected at the same time point, this was not reflected in measurable changes in HSP-70 mRNA or protein. In conclusion, expression of the cytoprotective protein HO-1 is significantly up-regulated in the liver within minutes of PHC. It is likely that $\mathrm{HO}-1$ contributes to the early protective effects of ischemic preconditioning. 


\section{Introduction}

Intermittent porta hepatis clamping $(\mathrm{PHC})$ resulting in arterial and portal venous inflow occlusion is commonly used during liver surgery to reduce blood loss during transection of the parenchyma. Because it is known that exposing organs to brief periods of ischemia followed by reperfusion can confer protection from subsequent ischemia-reperfusion (I/R) injury, a potential side effect of this maneuver may be that the liver is better protected against subsequent injury. This phenomenon, called ischemic preconditioning (IPC), was first demonstrated by Murry et al. (1) in 1986 using a model of canine myocardial I/R. Since then, IPC has been demonstrated in numerous other organs (e.g., the brain, small intestine, skeletal muscle, and liver) $(2,3)$. Because the process of human liver transplantation involves a period of ischemia followed by reperfusion, the potential protective effect of IPC has attracted considerable interest as a means of reducing nonimmunologic graft injury associated with transplantation.

In the liver, IPC has been shown to decrease hepatocellular and endothelial cell injury, increase intracellular adenosine triphosphate (ATP) and oxygenation, improve microcirculation, and modulate inflammatory responses (2). Much of this work has been extrapolated from animal models; however, recently Clavien et al. (4) demonstrated for the first time the protective effect of IPC in the human liver. In this study, IPC improved postoperative liver function, indicated by decreased transaminase levels, which are sensitive markers of liver injury (4). The same group went on to demonstrate that, in a murine model, IPC before liver transection was superior to both continuous- and intermittent-inflow occlusion in terms of optimizing postoperative liver function and protected animals from normally lethal periods of hepatic ischemia (5). The beneficial effects of IPC have now been confirmed in a randomized, controlled trial of 100 patients undergoing liver resection (6). Animal models have also demonstrated improved graft function after IPC in a liver-transplant model (7-9).

However, although its beneficial clinical effects are becoming well established, the mechanisms underlying IPCinduced protection remain ill-defined. IPC confers early protection, which starts within minutes and lasts 2 to 3 hours, and delayed protection, which develops 12 to 24 hours later and lasts 2 to 3 days (3). The disparate time scales suggest the involvement of different molecular events. Several potential mediators have been proposed, including alteration in metabolic pathways such as inducible nitric oxide synthase and adenosine and transcriptional activation of molecular chaperones such as the heat shock protein (HSP) family $(10,11)$, but as yet no unifying mechanistic theory exists. 
This study investigated the effects of intermittent PHC in a human model of IPC on the early expression of cytoprotective proteins HSP-70 and heme oxygenase (HO)-1 in human liver. In addition, the activity of two transcription factors that are known to regulate the HO-1 and HSP-70 gene expression, hypoxia inducible factor (HIF)-1 $\alpha$ and heat shock transcription factor (HSF)-1, respectively, were studied.

\section{Methods}

\section{Patients}

Eight patients undergoing liver resection with curative intent for colorectal hepatic metastases were studied. Details of patients and operative procedures are given in Table 1. All patients gave written informed consent, and the study was approved by the Ethical Committees of the University Hospital Maastricht and Lothian Region. All patients had normal preoperative liver function and had no evidence of hepatic cirrhosis or of extrahepatic disease. Preoperative workup and operative procedures were performed as detailed elsewhere (12). In each case, laparotomy was performed followed by intraoperative ultrasonographic assessment of the liver. Once resectability had been confirmed, the appropriate mobilization of the liver was performed as a prelude to hepatic parenchymal transection, which was undertaken using Cavitron Ultrasonic Surgical Aspirator and diathermy or ligation of vessels as appropriate. During liver transection, PHC was performed. Two cycles of 15minute arterial and portal venous clamping and 5-minute reperfusion were required to complete hepatic transection. Liver-tissue samples were excised without the use of electrocautery from nontumorous regions of the liver distant from the resection margin on the side of the liver that was preserved. The sampling schedule and median and ranges of cycles of ischemia and reperfusion are shown in Figure 1. Samples of approximately $500 \mathrm{mg}$ weight were taken from the liver before and at the end of each episode of ischemia and reperfusion. Liver tissue was rapidly frozen in liquid nitrogen, stored at $-80^{\circ} \mathrm{C}$, and shipped on dry ice to the laboratory for subsequent analysis.

\section{Protein isolation}

Frozen liver tissue was super cooled in liquid nitrogen and disaggregated to a powder using a dismembrator at $1600 \mathrm{rpm}$ for 1 minute (Braun, Germany). The 


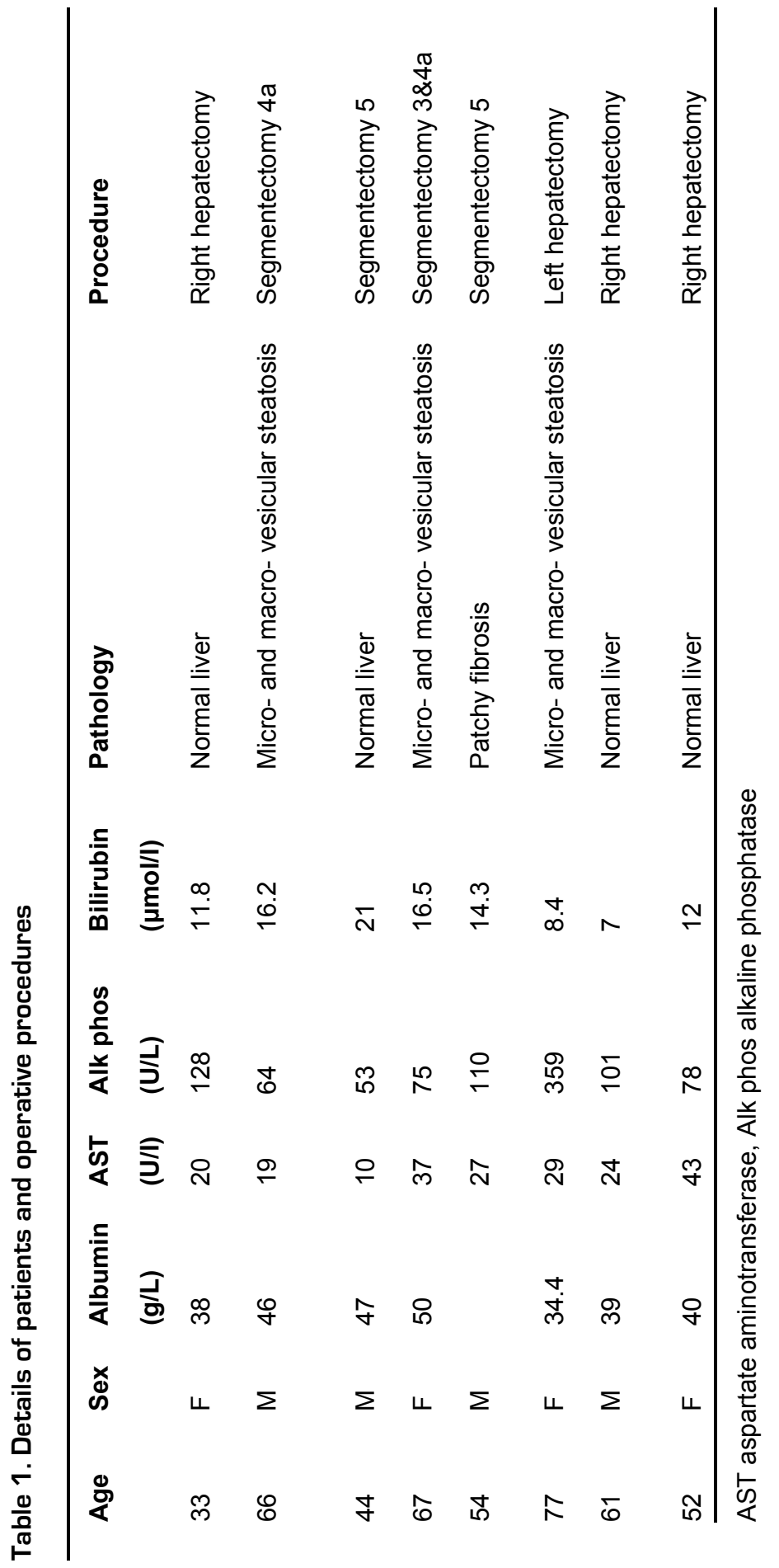




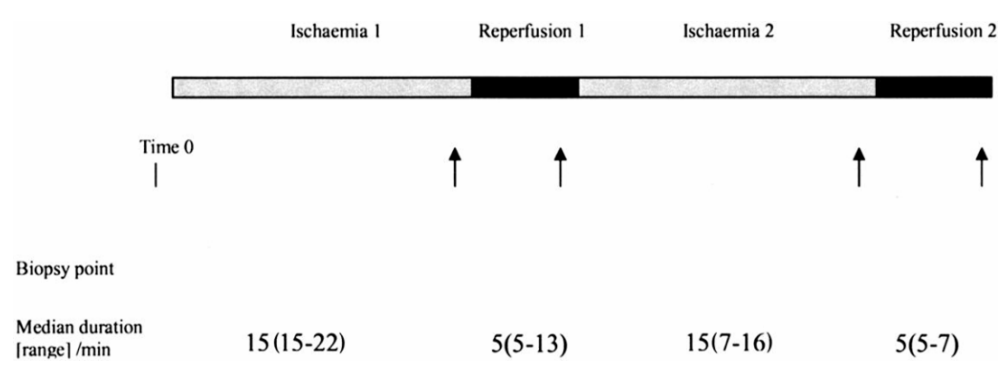

Figure 1. Experimental liver sampling protocol. After a period of surgical assessment and hepatic mobilization, liver tissue was excised and snap frozen before and after each period of portal pedicular clamping (ischemia) and clamp removal (reperfusion). Times are medians and ranqes, and sample points are indicated bv vertical arrows.

recovered tissue was solubilized in tissue homogenization buffer $(50 \mathrm{mMTris} \mathrm{pH}$ $7.4,20 \mathrm{mM} \mathrm{NaCl}, 10 \mathrm{mM} \mathrm{KCl}, 0.1 \mathrm{mM}$ dithiothreitol, $1 \mathrm{mM}$ EDTA, $1 \%$ sodium dodecyl sulphate) containing protease inhibitors. Protein concentrations were measured using a standard bichinichonic acid assay (Pierce, Chester, UK).

\section{Western blot}

Ten to $20 \mu \mathrm{g}$ of protein was loaded per lane of a $12.5 \%$ separating with a $5 \%$ stacking polyacrylamide gel in Laemli sample buffer. Proteins were transferred to nitrocellulose, and membranes were blocked with $5 \%$ nonfat milk and labelled with the appropriate primary antibody: rabbit polyclonal anti HO-1, mouse monoclonal anti HSP-27 (both Stressgen, Vancouver BC), rat polyclonal anti-GRP94, and mouse monoclonal anti-inducible HSP-70 C92 F34 (both kind gifts of Dr. WJ Welch, UCSF), all used at a concentration of 1:1000 in $1 \%$ bovine serum albumin tris buffered saline with $0.05 \%$ Tween 20 . Secondary antibodies were horseradish peroxidase (HRP)-conjugated anti-mouse (Upstate, Milton Keynes, UK) or rabbit (Santa Cruz, Wembley, UK) and were used at a concentration of 1:5000. Membranes were developed with ECL (Amersham, Chalfont St Giles, UK). Equality of loading was confirmed by probing membranes for $\beta$-actin, and bands were measured by densitometry.

\section{RNA isolation and fluorescence detection using real-time polymerase chain reaction}

Liver tissue was disaggregated in Ribolyser for $3 \times 20$ second runs with tubes chilled between cycles on ice. RNA extraction and purification was performed using a Fastgreen kit (Q-Biogene,Bingham, UK). RNA samples were treated 
with DNAase and then run as a template for a standard polymerase chain reaction (PCR) using $\beta$-actin primers to exclude the presence of contaminating DNA. RNA was then reverse transcribed to CDNA using avian myeloblastosis virus reverse transcriptase (Promega, Southampton, UK) and random decamers (Ambion, Huntingdon, UK). Fluorescence-detected real-time PCR was then performed using primers and probes specifically designed forhuman HO-1: forward primer 5'AGGGTGATAGAAGAGGCCAAGA, reverse primer 5' CAGCTCCTGCAACTCCTCAA and TAMRA labeled probe 6-FAMTGCGTTCCTGCTCAACATCCAGCT-TAMRA. For human HSP-70B, the following primers and probes were designed: forward $5^{\prime}$ CAGAGTGCTGCCAAAAACTC, reverse 5' CCTAAGGCTTTCCTCTTGCAAA, and probe 6-FAM-CTGGAGGCCCATGTCTTCCATGTGA- TAMRA. A standard reaction contained Taqman universal master mix $12.5 \mu \mathrm{L}$ (ABPI Biosystems, Warrington, UK), primer probe mix $7 \mu \mathrm{L}$ (primers $25 \mu \mathrm{M}$, Probe $5 \mu \mathrm{M}$ ), 18s primer probemix $1.25 \mu \mathrm{L}$, and water $1.75 \mu \mathrm{L}$ ), and cDNA template $2.5 \mu \mathrm{L}$. Samples were run on an ABPI Taqman and analyzed using Sequence Detector 7.1 (Applied Biosystems).

\section{Immunohistochemistry}

Formalin-fixed paraffin-embedded sections were taken of liver tissue at time 0 (before the ischemia reperfusion cycle) and after the second period of reperfusion. Antigen retrieval was performed using microwave heating in $10 \mathrm{mM}$ citrate buffer $\mathrm{pH} 6$ and endogenous peroxidase was blocked using normal swine serum 1:4. Test sections were probed with anti- HO-1 antibody (Stressgen) 1:1000 in 1:4 normal swine serum. Control sections were probed with a nonspecific antibody rabbit anti-mouse immunoglobulin $G$ (Dako Cytomation, Ely, UK) 1:1000 in 1:4 normal swine serum. The secondary antibody was a biotinylated swine anti-rabbit antibody (Dako). Slides were developed using biotinylated HRP and streptavidin (Dako), and the substrate was 3,3'-diaminobenzidine (Sigma, Poole, UK).

\section{DNA mobility shift assays}

Liver tissue was disaggregated in $10 \mathrm{mM}$ HEPES $\mathrm{pH} 7.9,10 \mathrm{mMKCl}, 10 \mathrm{mM}$ $\mathrm{Mg} \mathrm{Cl} 2,0.5 \mathrm{mM}$ DTT $0.1 \% \mathrm{NP} 40$, and proteinase inhibitors. After centrifugation, nuclear proteins were extracted from the supernatant using $20 \mathrm{mM}$ HEPES, 1.5 $\mathrm{mM} \mathrm{MgCl}$, $420 \mathrm{mM} \mathrm{NaCl}, 0.5 \mathrm{mM}$ dithiotreitol, $0.2 \mathrm{mM}$ EDTA, and proteinase inhibitors. HIF-1 $\alpha$ oligonucleotides 5'TCTGTACGTGACCACACTCACCTC and 5'GCGGTGAGTGTGGTCACGTACAGA were end labeled with digoxigenin (Roche, Lewes, UK) and annealed. Double-stranded oligonucleotides were 
incubated with nuclear lysates for 30 minutes at $25^{\circ} \mathrm{C}$. Control reactions using 20x molar excess of unlabelled consensus sequence or unlabelled mutant HIF1a oligonucleotide 5' TCTGTAAAAGACCACACTACCTC and supershift reactions using mouse monoclonal anti-HIF-1 $\alpha$ antibody (Santa Cruz) were run on each blot. Wild-type HSE forward 5' GATCTCGGCTGGAATATTCCCGACCTGGCAGCCGA and reverse 5' GATCTCGGCTGCCAGGTCGGGAATATTCCAGCCGA and mutant HSE forward 5'GATCTCGGCTTCAATATTGTCCACCTGGCAGCCGA and reverse 5'GATCTCGGCTGCCAGGTGGACAATATTGAAGCCGA were purchased (TAGN Ltd, Newcastle, UK). Twenty micrograms of each lysate was run per lane of 10 -well Biorad $0.5 \%$ TBE precast gels for 50 minutes at a $100 \mathrm{~V}$ constant voltage in a Biorad MiniProtean III system. Gels were transferred to positively charged PVDF membranes, blocked with CSPD, and probed with antidigoxigenin antibody (Roche).

\section{ATP concentrations}

Homogenized liver tissue before and after IPC was solubilized in nucleotide releasing buffer, and protein concentration was measured as described above. Samples of $20 \mu \mathrm{g}$ protein were mixed with luciferin and luciferase in the absence of exogenous ATP (Calbiochem, Beeston, UK). A standard curve of ATP was constructed in the range 10-6 to 10-1 mmole ATP. Samples were read in a plate luminometer for 10 seconds within the first minute of adding luciferinluciferase.

\section{Heme oxygenase activity assay}

$\mathrm{HO}$ activity was determined using a modification of a previously published method (13). HUH7cells were grown to $60 \%$ to $80 \%$ confluency in $75 \mathrm{~cm} 2$ flasks before treatment with $10 \mu \mathrm{M}$ curcumin or equivalent DMSO. Liver tissue lysates from before and at the end of the IPC protocol were resuspended in $220 \mu \mathrm{L}$ buffer $\mathrm{A}$ (100 mM potassium phosphate, $2 \mathrm{mM} \mathrm{MgCl} 2, \mathrm{pH} 7.4$ ) and subjected to three cycles of freeze thawing. As a source of biliverdin reductase, human liver cytosol was obtained by homogenizing samples of liver in buffer B (0.1 M sodium citrate, $10 \%$ glycerol, $\mathrm{pH} 5$ ) and collecting the supernatant after centrifugation at $105,000 \mathrm{~g}$ for 30 minutes. A $400 \mu \mathrm{L}$ reaction mixture containing $200 \mu \mathrm{L}$ test liver lysate, $1.5 \mathrm{mg}$ liver cytosol, $0.8 \mathrm{mM}$ NADPH, $2 \mathrm{mM}$ glucose 6 phosphate, 0.2 units glucose 6 phosphate dehydrogenase, and $20 \mu \mathrm{M}$ hemin was incubated in the dark at $37^{\circ} \mathrm{C}$ for 1 hour. The reaction was terminated by adding $400 \mu \mathrm{L}$ chloroform and vortexing for 20 seconds. The extracted Bilirubin was measured by the difference in absorption at 464 and $530 \mathrm{~nm}$, using an 
absorption coefficient of $40 \mathrm{mM}-1 \mathrm{~cm}-1$. Protein concentration of the cell suspension was determined as described above, and results expressed as pmoles of bilirubin formed per milligram of protein per hour.

\section{Glucose oxidase in vitro model of oxidative Injury}

To demonstrate the protective effect of $\mathrm{HO}$ in cells of a hepatocyte lineage, human hepatoma-7 cells were cultured in 96 -well plates with $10 \%$ fetal calf serum, $50 \mathrm{U} / \mathrm{mL}$ penicillin $\mathrm{G}$, and $50 \mu \mathrm{g} / \mathrm{mL}$ streptomycin. Cells were pretreated with the HO-1 inducer hemin in the presence or absence of the HO-1 inhibitor zinc protoporphyrin IX $(50 \mu \mathrm{M})$ and the carbon monoxide generating molecule dichloromethane $(0.1 \%)$ for 90 minutes and then challenged with fresh medium containing $10 \mu \mathrm{M}$ glucose oxidase, a dose sufficient to reduce cell viability by approximately $30 \%$. After 4-hour exposure, a methyltetrazolium (MTT) assay was performed. Ten microliters of MTT solution $(5 \mathrm{mg} / \mathrm{mL}$ in phosphate-buffered saline) was added to each well. After 4-hour incubation at $37^{\circ} \mathrm{C}, 150 \mu \mathrm{L}$ extraction buffer (10\% SDS, pH 3) was added and incubated overnight, following which, the optical densities were measured at $570 \mathrm{~nm}$ using a plate reader (Dynex MRXII, Dynatech). All treatments were performed in sextuplicate on each occasion. Results are expressed as percentage protection, which is calculated by the following formula: ([X/GO group]-1)x100. This represents the improvement in survival over the group that had received only glucose oxidase (i.e., no pretreatment).

\section{Statistical analysis}

Data are presented as means and standard deviations or individual values as appropriate. Statistical comparisons were made using the Mann-Whitney $U$ test or Kruskal-Wallis $\mathrm{H}$ tests as appropriate using SPSS V 11.0 (SPSS, Chicago IL).

\section{Results}

\section{Operative procedures and clinical outcome}

All patients had normal preoperative synthetic liver function and were not known to have evidence of any parenchymal liver disease. All patients had unilobar colorectal hepatic metastases and had not received chemotherapy in the 6 weeks preceding surgery. No patient experienced any adverse event during the 
IPC protocol (hypotension or haemorrhage). Individual patient details are given in Table 1.

\section{IPC induces HO-1 but not HSP-70 mRNA expression}

The expression of HO-1 and HSP-70 transcripts was investigated using realtime PCR performed on cDNA reverse transcribed from mRNA isolated from liver samples taken before portal clamping and after each subsequent episode of ischemia and reperfusion. There was significant and rapid induction of $\mathrm{HO}-1$ mRNA compared with time 0 immediately after the first period of hepatic ischemia (mean 15 minutes) (Figure 2A). This increased further after the first episode of reperfusion $(p<0.02)$. HO-1 expression was reduced slightly during the second period of ischemia but increased again after reperfusion. Individual patterns of gene expression varied in relation to the time and profile, but all demonstrated rapid increase in HO-1 expression. In contrast, HSP-70 mRNA expression was unaltered after the first period of ischemia or at subsequent time points during the I/R cycle.
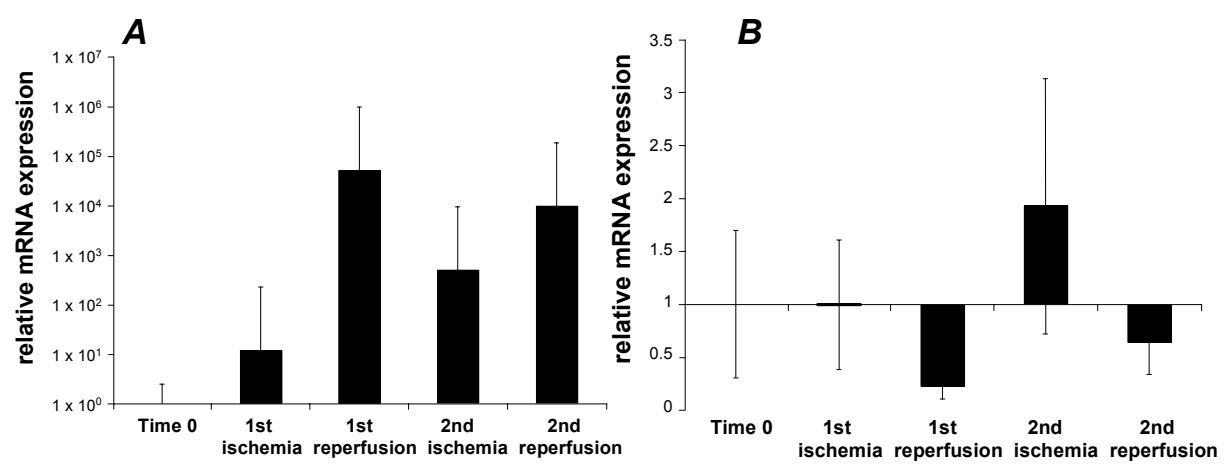

Figure 2. Heme oxygenase-1 but not heat shock protein (HSP)-70 mRNA expression is increased during ischemic preconditioning. RNA extracted from liver tissue sampled during key points in the ischemic preconditioning protocol was analyzed for mRNA expression by fluorescence detection real-time polymerase chain reaction. HO-1 expression $(A)$ increased rapidly after the start of the protocol $(p<0.02$ Kruskal-Wallis $H$ test), whereas no significant difference was observed in HSP-70 mRNA expression (B). Values are relative mRNA expressions

\section{HO-1 protein expression is increased after IPC}

In each patient, expression of HO-1 protein increased between the start of portal clamping and the time of the final sample median (40 minutes). The individual and overall responses were significantly different compared with time 


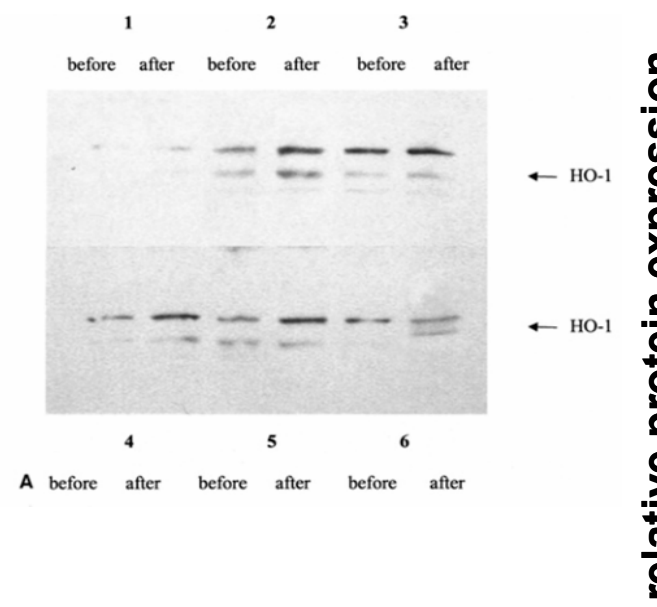

A

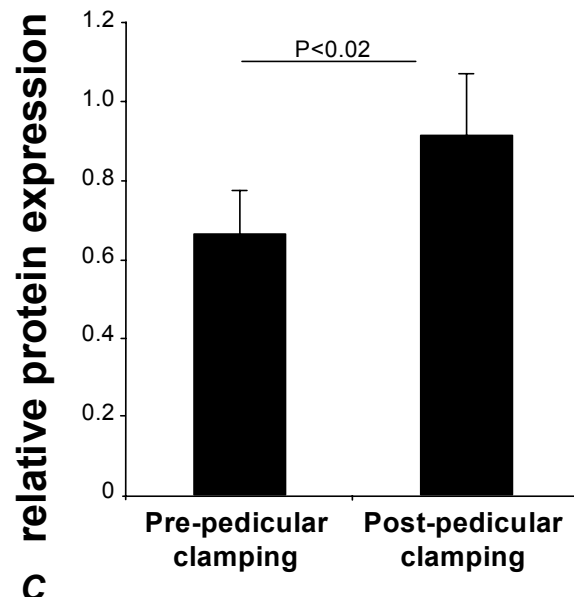

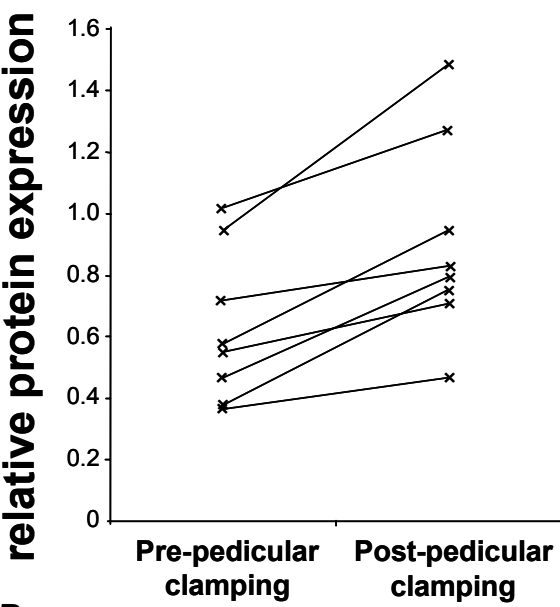

B

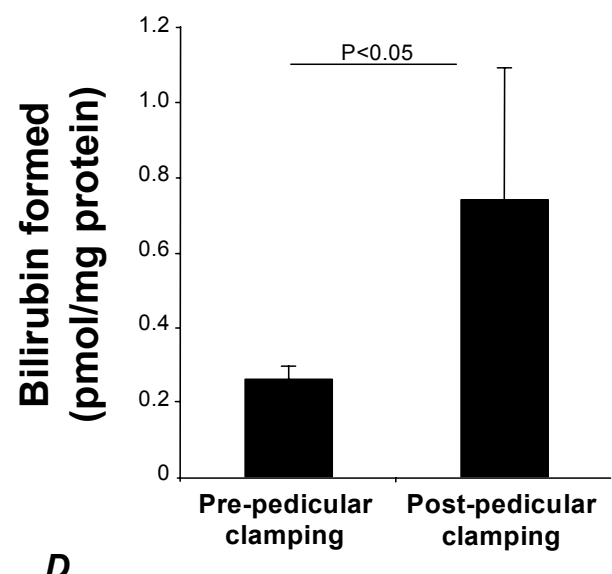

Figure 3. Heme oxygenase-1 (HO-1) protein expression is increased by ischemic preconditioning (IPC). Protein extracted from liver tissue sampled before and after IPC protocol was analyzed by Western blot for HO-1 protein expression. Representative Western blots for six patients (A). In each patient (A, B), HO-1 protein concentration increased. The overall difference for the study group in HO-1 expression before and after IPC (C) was statistically significant, as was the formation of bilirubin as a measure of HO-1 activity (D) (Mann-Whitney $U$ test).

0 , and representative blots are shown in Figure $3 \mathrm{~A}$ with individual (Figure $3 \mathrm{~B}$ ) and overall responses (Figure $3 \mathrm{C}, \mathrm{p}<0.03$ ). Changes in $\mathrm{HO}-1$ protein were associated with a 2.8-fold increase in $\mathrm{HO}$ activity over the same time period (Figure 3D) $(p<0.05)$. No change was evident in expression of either GRP94 (Figure 4A) $(p<0.09)$ or HSP-70 $(p<0.56)$ (Figure 4B) in Western blots corrected 
for loading by $\beta$-actin. By contrast with the changes observed in HO-1 expression, HSP-27 expression was reduced in all samples between the onset of $\mathrm{I} / \mathrm{R}$ cycles and the end (Figure $4 \mathrm{C})(\mathrm{p}<0.02)$.

\section{Early HO-1 protein expression is concentrated in Kupffer cells}

Control liver sections at time 0 before the onset of the portal ischemia showed sparse staining for HO-1 compared with identical sections stained with a nonspecific antibody (Figure 5A and 5B). The intensity of positive HO-1 staining was increased after portal clamping (Figure 5C and 5D) In addition, HO-1 expression appeared to be concentrated in a relatively small population of nonparenchymal cells distributed throughout the tissue section (Figure 5D). The cells exhibited a characteristic elongated, flattened shape and irregular dendritic appearance, suggestive of Kupffer cells.

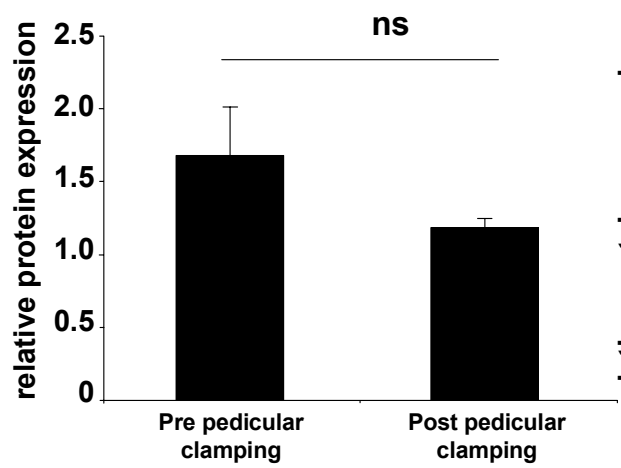

$\boldsymbol{A}$

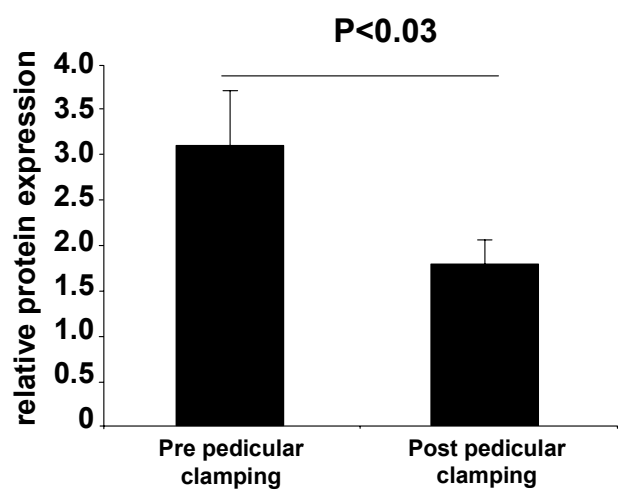

C

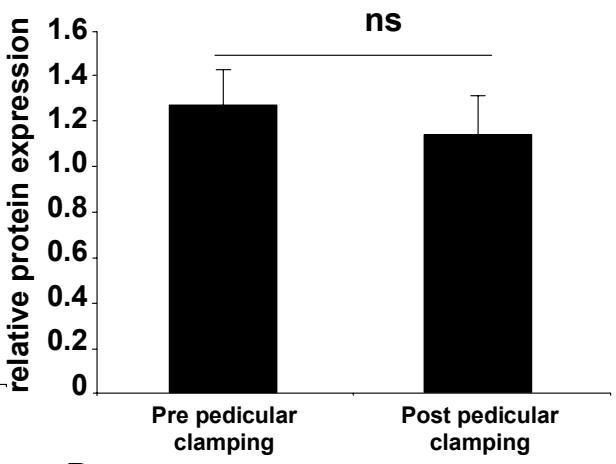

B

Figure 4. IPC has variable effects on the early expression of heat shock transcription factor-1 dependent stress proteins. Protein extracted from liver tissue sampled before and after IPC protocol analyzed by Western blot for glucose regulated protein 94 (a), inducible HSP-70 (b), and HSP-27 (c) protein expression. No significant overall difference was observed in the concentrations of GRP94 or inducible HSP-70 before and after IPC. There was a consistent and significant reduction in concentration in HSP-27 expression after IPC. 


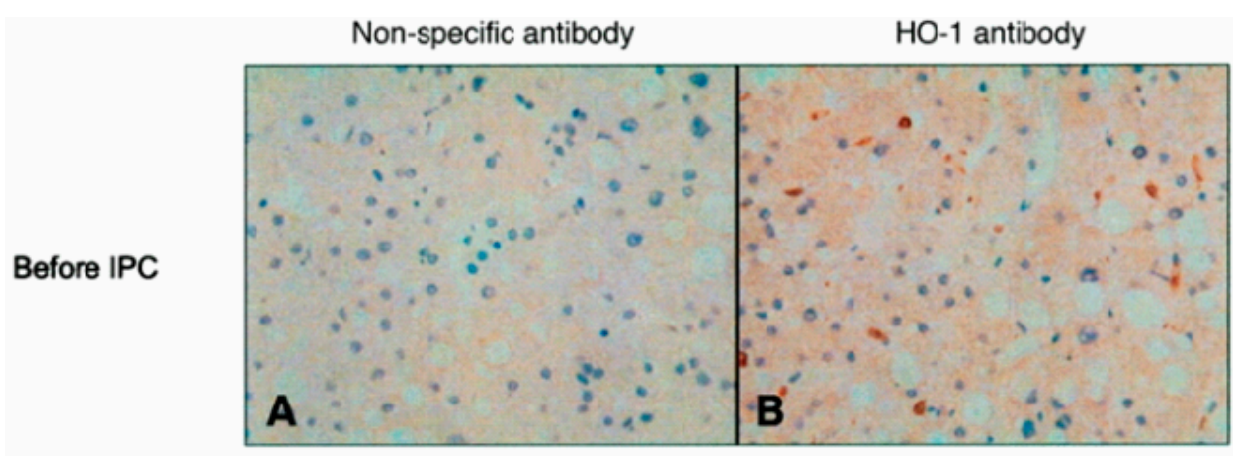

After IPC

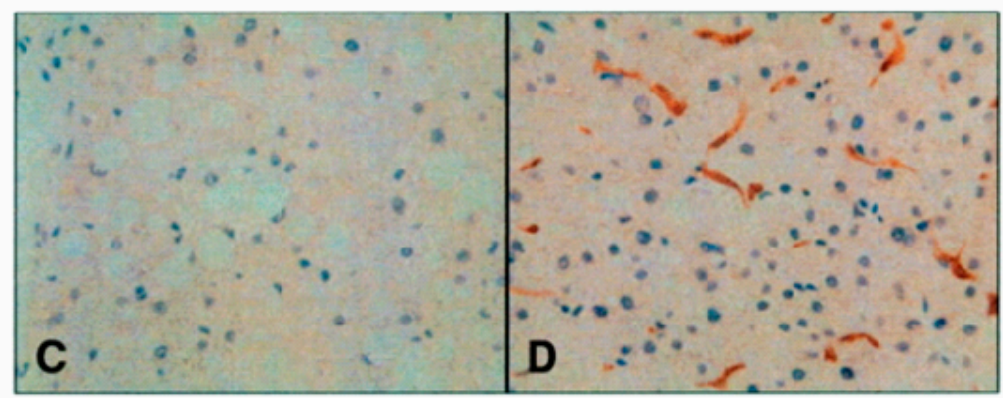

Figure 5. Early HO-1 expression during IPC is localized within Kupffer cells. Tissue sections of liver before and after IPC were stained with nonspecific control antibody ( $A$ and $C)$ or with antibody HO-1 ( $B$ and D). Representative sections. Before IPC, sparse staining was evident for HO-1 (B) compared with the nonspecific antibody control (A). After IPC, a population of cells stained positively for HO-1 (D) compared with control (C). Cells have the spatial distribution and morphologic appearance of Kupffer cells.

\section{HIF-1 $\alpha$ and HSF-1 activation is increased after IPC}

DNA mobility shift assays were performed to detect any changes in the levels of the activated DNA binding forms of HIF-1 $\alpha$ and HSF-1 after portal clamping. Nuclear extracts of liver biopsies taken before portal clamping and after the second ischemic episode were analyzed. In all subjects, the level of activated HIF-1 $1 \alpha$ after the second ischemic episode was greater than basal levels (time 0 ) (Figure 6A). In all subjects, liver extracts before IPC showed monomeric transcriptionally inactive forms of HSF-1. After IPC, the transcriptionally active trimeric band and intermediate dimeric bands were evident (Figure 6B).

\section{ATP is not significantly altered after IPC}

Luminometry using the luciferin-luciferase reaction demonstrated no significant change in ATP concentrations in liver tissue before and after IPC (Figure 7). The values of ATP detected fell within the measurable region of the standard 
curve and were in excess of two orders of magnitude greater than the minimum detectable ATP on the basis of our standard curve.

A

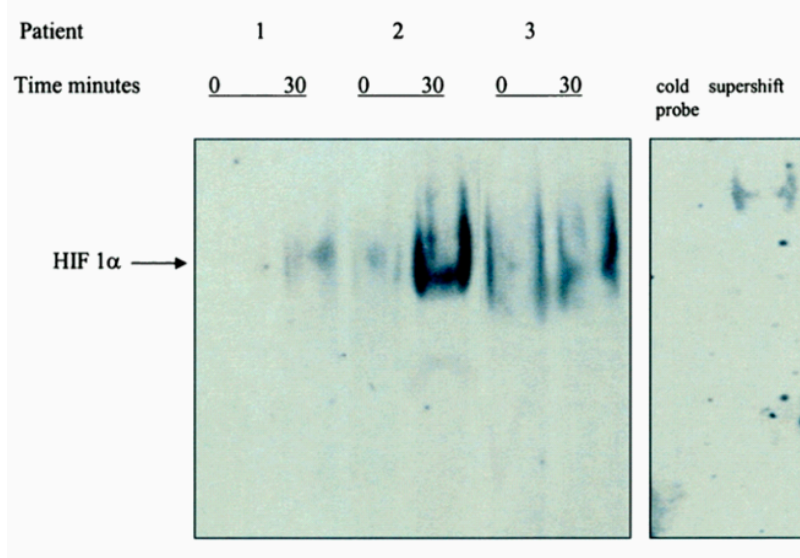

B

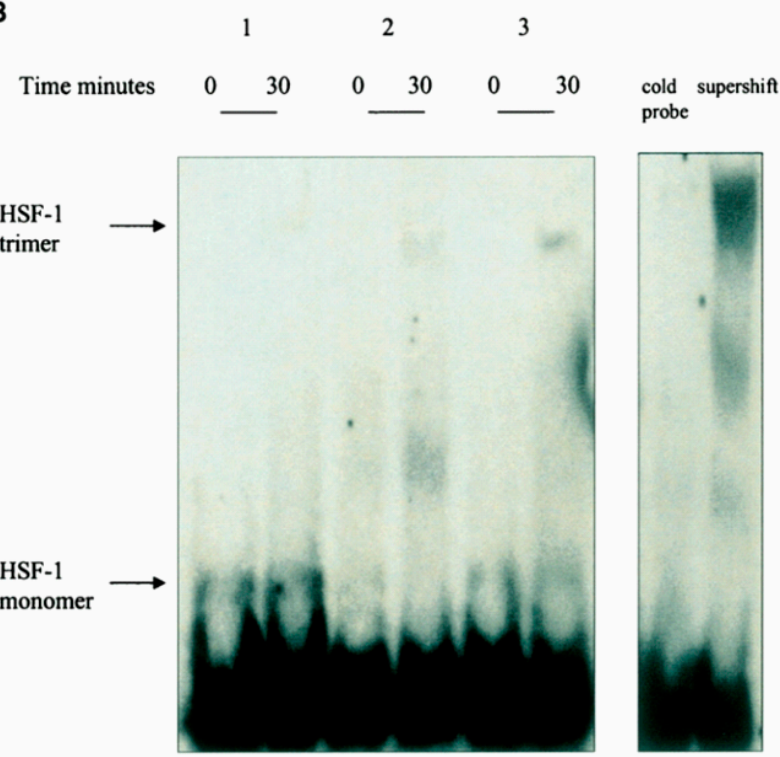

Figure 6. Hypoxia inducible factor (HIF)-1a and heat shock transcription factor (HSF)-1 are activated early during IPC. Nuclear protein extracted from liver sampled before and after 15 minutes of ischemia and 5 minutes of reperfusion was added to digoxigenin labeled HIF or HSF-1 dsDNA consensus sequence oligonucleotides. The reactions were run on 5\% TBE gels and developed by PVDF transfer and antidigoxigenin probing. (A) In each case, there was increased HIF binding to its consensus sequence after IPC compared with the initial time point. (B) Transcriptionally active trimeric form of HSF-1 was evident in all samples after IPC, but only inactive monomeric bands could be detected in control samples. 


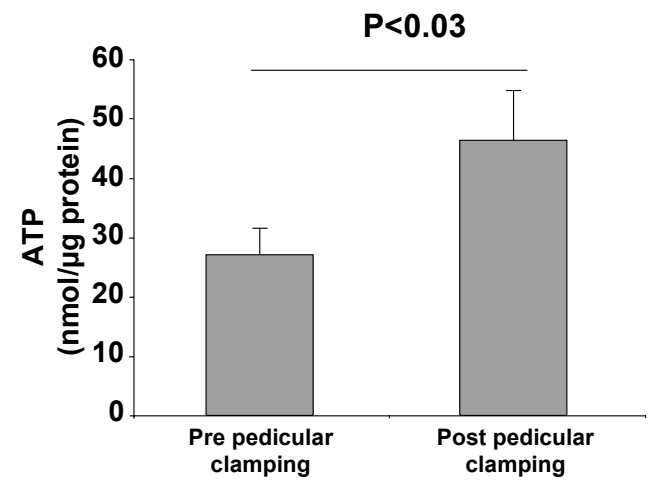

Figure 7. Ischemic preconditioning in the liver does not cause adenosine triphosphate (ATP) depletion. Livercell homogenates from before and after IPC protocol were standardized for protein concentration and reacted with luciferin and luciferase and light production measured. No significant change in cellular ATP concentrations detected.

\section{Heme Oxygenase-1 protects human hepatoma cells from oxidative injury}

Using an in vitro model of oxidative injury, pre-treatment of cells with the $\mathrm{HO}-1$ inducer hemin-conferred protection from glucose oxidase mediated cell injury (Figure 8$)(p<0.005)$. This protection could be inhibited by preincubating cells with hemin in the presence of the $\mathrm{HO}-1$ inhibitor zinc protoporphyrin IX $(p<0.05)$. The cell protection could be restored by addition of the carbon-monoxidegenerating molecule dichloromethane.

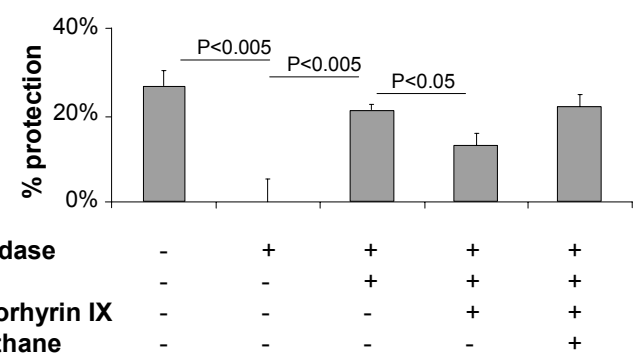

Figure 8. HO expression protects human hepatoma (Huh) cells form oxidative injury. Huh-7 cells were treated with glucose oxidase as a model of oxidative injury resulting in significant cell death as measured by MTT assay. Pretreatment of cells with the HO-1 inducer hemin resulted in significant cell protection compared with cells treated with glucose oxidase alone. This protection induced by hemin could be removed by addition of the HO-1 inhibitor zinc protoporphyrin IX and could be restored by co-incubation with dichloromethane, which generates carbon monoxide as a by product of the $\mathrm{HO}$ reaction. 


\section{Discussion}

In the present study, we demonstrate that intermittent $\mathrm{PHC}$ in humans stimulates increased $\mathrm{HO}-1$ expression and activity and that this is regulated at the level of gene transcription. Previous studies also report that most inducible HO-1 expression is controlled at the level of gene transcription $(14,15)$. HO-1 mRNAwas more elevated at the end of reperfusion than after ischemia. One explanation for this is that becasue hypoxia is the key inducer of HO-1, ischemia probably stimulates HO-1 expression, but mRNA synthesis is limited by the energy-depleted state of the cell. However, during reperfusion, cellular ATP pools are rapidly rejuvenated, thus permitting maximal HO-1 mRNA synthesis.

HIF-1 $\alpha$ is a hypoxia responsive helix-turn-helix transcription factor with a binding sequence in the HO-1 promoter (14). HIF-1a has been shown to coordinate hypoxia inducedHO-1 expression $(14,15)$ and is likely to be the transcriptional mediator of IPC-induced HO-1 response. Cai et al. (16) found that the cardioprotective effect of intermittent hypoxia was lost in HIF-1a-/- mice. Other candidate transcription factors include AP-1, which is known to be activated by hypoxia, and nuclear factor-kB, which is also activated by hypoxia, although at a later stage. The protective effects of $\mathrm{HO}-1$ against $\mathrm{I} / \mathrm{R}$ injury are probably mediated by the metabolites of the HO-1 catalysed degradation of heme, namely biliverdin (a powerful antioxidant) and $\mathrm{CO}$ (a regulator of nitric oxide synthase and vasodilator) (17-19). In the present study, increased expression of HO-1 was associated with a greater than 2.5-fold increase in HO-1 activity measured by enzymatic conversion of hemin to bilirubin. The apparent disparity between levels of HO-1 expression detected by Western blot and the greater increase in HO-1 enzyme activity is well known. It is possible that this is related to enzyme kinetics such that the relationship between HO-1 protein expression and activity is nonlinear; alternatively, it has been suggested that $\mathrm{HO}-2$ may undergo activation by way of phosphorylation of serine 79 with no change in HO-2 expression. During I/R, CO maintains the microvascular and portal blood flow by inhibiting the vasoconstriction associated with reperfusion $(20,21)$. Because much of the pathophysiology associated with $I / R$ injury is centred on microvascular disruption, $\mathrm{CO}$ generation is likely to confer significant benefits. Other proposed cytoprotective functions of $\mathrm{CO}$ include inhibition of platelet aggregation, down-regulation of pro-inflammatory cytokines, and inhibition of endothelial cell apoptosis (5). Interestingly, in a human model study of the effects of PHC clamping on liver surgery, Man et al. (22) found better preservation of the hepatic microcirculation in patients in whom PHC had been performed. 
Early HO-1 expression induced by PHC appeared to be most evident in Kupffer cells. Goda et al. (23) reported similar results in rat livers exposed to hypoxia. Conversely, Bauer et al. (24) found that although constitutive HO-1 was restricted to Kupffer cells, the stress-induced HO-1 response was apparent primarily in parenchymal cells. It is possible that these apparent discrepancies are related to time of sampling with early $\mathrm{HO}-1$ expression predominating in Kupffer and endothelial cells and later expression in hepatocytes.

The HO-1 system offers multiple cytoprotective properties that could contribute to the early protective effect of PHC. Previous work in this area supports this hypothesis. In animals over-expressing HO-1 liver transplants exhibited less macrophage infiltration, increased expression of anti-apoptotic protein, and decreased pro-apoptotic caspase-3 expression (25). HO-1 induction by pharmacologic means (e.g., cobalt protoporphyrin, hemin) or genetic modification leads to better preservation of tissue architecture, organ function, and graft survival $(26,27)$. The in vivo model of IPC used in the present study could not test the ability of $\mathrm{HO}-1$ to confer cell protection. The in vitro cell protection data presented in Figure 8 demonstrate that induction of $\mathrm{HO}-1$ is associated with cell protection and that this protection can be removed by coincubation with a specific HO-1 inhibitor. The restoration of cell protection resulting from treatment of cells, in which HO-1 has been inhibited, with a carbon monoxide generating molecule, confirm previous data that carbon monoxide, a byproduct of HO-1 activity, may be important for cell protection.

In relation to the classical stress response (heat shock response), we found that HSP-70 protein or mRNA was not induced early on in IPC. However, HSF-1, the principal transcriptional regulator of HSP-70 (28-30), was activated, suggesting an impending HSP-70 response. In the context of I/R, ATP depletion is believed to be a potential stimulus for HSF-1 activation (11). In an extreme model, Ohlmann et al. (15) found the up-regulation of HSP-70 to be higher and more rapid than that of HO-1 in rat hepatocyte cultures exposed to 4 hours of anoxia followed by reoxygenation. Boeri et al. (31) also found that 40 minutes of ischemia was sufficient to increase HSP-70 mRNA in human liver detected 1 to 2 hours later. Sampling times in the present study may not have allowed sufficient time to elapse for changes in HSP-70 protein to be detectable.

HSP-27 is also known as alpha B crystalline and is a small molecular weight HSP believed to be important in maintaining actin and tubulin filament associations in the stressed cell (32). In the present study, HSP-27 expression was consistently reduced in all patients after the $\mathrm{I} / \mathrm{R}$ cycle. The reason for this observation is unclear. It is possible that HSP-27 either moves to another compartment or is in some way consumed. A reduction in the endoplasmic reticulum chaperone GRP94 was detected after PHC, but this difference was not significant. 
In the recent, randomized, controlled trial of IPC in liver resectional surgery (6), patients who did not undergo IPC were found to have relative depletion of ATP compared with those who did undergo IPC. In the present study, there was certainly no evidence of ATP depletion at the end of 40 minutes of cyclical IPC, and indeed there was a nonsignificant increase in ATP concentration, supporting the observations of Clavien et al. (6). The mechanism of reduction of ATP concentrations in patients undergoing liver resection without IPC is uncertain but may reflect the greater metabolic cost of repairing a more severe injury.

Perhaps one of the most novel revelations of this study is the time scale of events. Within minutes of IPC, HIF-1 $\alpha$ was activated, and HO-1 mRNA and protein expression were significantly elevated. These results demonstrate that activation of the $\mathrm{HO}$ system occurs much earlier than was previously believed. Although it is possible that members of the classical HSPs contribute to cytoprotective effects of IPC, it is likely that their peak activity occurs somewhat later (hours rather than minutes) than that of HO-1. The efficiency of intermittent $\mathrm{PHC}$ in eliciting an HO-1 response is promising with respect to its clinical application, adding to its already favourable profile $(4-6,26)$. The importance of elucidating the mechanisms underlying IPC ultimately is to define an effective strategy for protecting the liver from $\mathrm{I} / \mathrm{R}$ and cold ischemic injury during liver surgery or transplantation. Previously, one focus has been toward developing pharmacologic preconditioning strategies; however, the efficacy, relative simplicity, and reproducibility of the IPC protocol used in this study may make it an effective and practical surgical alternative. Furthermore, the utility of using a liver-specific approach (IPC) rather than a systemic preconditioning strategy (pharmacologic) avoids potential objections to unknown effects that the latter approach may have on other organs, which may also be retrieved from the same donor for transplantation. 


\section{References}

1. Murry CE, Jennings RB, Reimer KA. Preconditioning with ischemia: a delay of lethal cell injury in ischemic myocardium. Circulation 1986;74:1124-36.

2. Koti RS, Seifalian AM, Davidson BR. Protection of the liver by ischemic preconditioning: a review of mechanisms and clinical applications. Dig Surg 2003;20:383-96.

3. Nilsson B, Friman S, Gustafsson BI, Delbro DS. Preconditioning protects against ischemia/reperfusion injury of the liver. J Gastrointest Surg 2000;4:44-9.

4. Clavien PA, Yadav S, Sindram D, Bentley RC. Protective effects of ischemic preconditioning for liver resection performed under inflow occlusion in humans. Ann Surg 2000;232:155-62.

5. Rudiger HA, Kang KJ, Sindram D, Riehle HM, Clavien PA. Comparison of ischemic preconditioning and intermittent and continuous inflow occlusion in the murine liver. Ann Surg 2002;235:400-7.

6. Clavien PA, Selzner M, Rudiger HA, et al. A prospective randomized study in 100 consecutive patients undergoing major liver resection with versus without ischemic preconditioning. Ann Surg 2003;238:843-50; discussion 851-2.

7. Serafin A, Fernandez-Zabalegui L, Prats N, Wu ZY, Rosello-Catafau J, Peralta C. Ischemic preconditioning: tolerance to hepatic ischemia-reperfusion injury. Histol Histopathol 2004;19:281-9.

8. Gong JP, Tu B, Wang W, Peng Y, Li SB, Yan LN. Protective effect of nitric oxide induced by ischemic preconditioning on reperfusion injury of rat liver graft. World $\mathrm{J}$ Gastroenterol 2004;10:73-6.

9. Berrevoet $F$, Schafer T, Vollmar B, Menger MD. Ischemic preconditioning: enough evidence to support clinical application in liver surgery and transplantation? Acta Chir Belg 2003;103:4859.

10. Jaeschke H. Molecular mechanisms of hepatic ischemia-reperfusion injury and preconditioning. Am J Physiol Gastrointest Liver Physiol 2003;284:G15-26.

11. Selzner N, Rudiger H, Graf R, Clavien PA. Protective strategies against ischemic injury of the liver. Gastroenterology 2003;125:917-36.

12. Wigmore SJ, Madhavan K, Currie EJ, Bartolo DC, Garden OJ. Does the subspecialty of the surgeon performing primary colonic resection influence the outcome of patients with hepatic metastases referred for resection? Ann Surg 1999;230:759-65; discussion 765-6.

13. Balogun $E$, Hoque $M$, Gong $P$, et al. Curcumin activates the haem oxygenase-1 gene via regulation of Nrf2 and the antioxidant-responsive element. Biochem J 2003;371:887-95.

14. Lee PJ, Jiang BH, Chin BY, et al. Hypoxia-inducible factor-1 mediates transcriptional activation of the heme oxygenase-1 gene in response to hypoxia. $J$ Biol Chem 1997;272:5375-81.

15. OhImann A, Giffhorn-Katz S, Becker I, Katz N, Immenschuh S. Regulation of heme oxygenase-1 gene expression by anoxia and reoxygenation in primary rat hepatocyte cultures. Exp Biol Med (Maywood) 2003;228:584-9.

16. Cai Z, Manalo DJ, Wei G, et al. Hearts from rodents exposed to intermittent hypoxia or erythropoietin are protected against ischemia-reperfusion injury. Circulation 2003;108:79-85.

17. Fondevila $C$, Katori $M$, Lassman $C$, et al. Biliverdin protects rat livers from ischemia/reperfusion injury. Transplant Proc 2003;35:1798-9.

18. Berberat $P O$, Katori $M$, Kaczmarek $E$, et al. Heavy chain ferritin acts as an antiapoptotic gene that protects livers from ischemia reperfusion injury. Faseb J 2003;17:1724-6.

19. Rensing H, Bauer I, Datene V, Patau C, Pannen BH, Bauer M. Differential expression pattern of heme oxygenase-1/heat shock protein 32 and nitric oxide synthase-Il and their impact on liver injury in a rat model of hemorrhage and resuscitation. Crit Care Med 1999;27:2766-75. 
20. Maines MD. The heme oxygenase system: a regulator of second messenger gases. Annu Rev Pharmacol Toxicol 1997;37:517-54.

21. Cutrin JC, Perrelli MG, Cavalieri B, Peralta C, Rosell Catafau J, Poli G. Microvascular dysfunction induced by reperfusion injury and protective effect of ischemic preconditioning. Free Radic Biol Med 2002;33:1200-8.

22. Man K, Lo CM, Liu CL, et al. Effects of the intermittent Pringle manoeuvre on hepatic gene expression and ultrastructure in a randomized clinical study. Br J Surg 2003;90:183-9.

23. Goda N, Suzuki K, Naito $M$, et al. Distribution of heme oxygenase isoforms in rat liver. Topographic basis for carbon monoxide-mediated microvascular relaxation. J Clin Invest 1998;101:604-12.

24. Bauer I, Wanner GA, Rensing $H$, et al. Expression pattern of heme oxygenase isoenzymes 1 and 2 in normal and stress-exposed rat liver. Hepatology 1998;27:829-38.

25. Uchida $Y$, Tamaki $T$, Tanaka $M$, et al. Induction of specific stress response increases resistance of rat liver allografts to cold ischemia and reperfusion injury. Transpl Int 2003;16:396-404.

26. Tsuchihashi S, Tamaki T, Tanaka M, et al. Pyrrolidine dithiocarbamate provides protection against hypothermic preservation and transplantation injury in the rat liver: the role of heme oxygenase-1. Surgery 2003;133:556-67.

27. Blydt-Hansen TD, Katori M, Lassman C, et al. Gene transfer-induced local heme oxygenase-1 overexpression protects rat kidney transplants from ischemia/reperfusion injury. J Am Soc Nephrol 2003;14:745-54.

28. Pirkkala L, Nykanen P, Sistonen L. Roles of the heat shock transcription factors in regulation of the heat shock response and beyond. Faseb J 2001;15:1118-31.

29. Sistonen L, Sarge KD, Morimoto RI. Human heat shock factors 1 and 2 are differentially activated and can synergistically induce hsp70 gene transcription. Mol Cell Biol 1994;14:208799.

30. Benjamin IJ, McMillan DR. Stress (heat shock) proteins: molecular chaperones in cardiovascular biology and disease. Circ Res 1998;83:117-32.

31. Boeri D, Dondero F, Storace D, Maiello M, Pasqualini M, Pellicci R. Heat-shock protein 70 favours human liver recovery from ischaemia-reperfusion. Eur J Clin Invest 2003;33:500-4. 
Chapter 10

General Discussion 


\section{Introduction}

Over the past decades liver resection has evolved from an infrequent and daring exercise to an established mainstay in the treatment of colorectal cancer liver metastases. Although mortality has decreased to below $5 \%$ in experienced centers, there is still a risk of post-resectional liver failure. Post hepatectomy liver failure may be defined as the inability of the remnant liver to meet functional demands. Since these demands are numerous, clinically liver failure is a syndrome that comprises coagulopathy, hypoglycaemia, hypoalbuminemia, and an inadequate acute phase response, hyperbilirubinemia, hyperammonemia, impaired reticuloendothelial function and frequently sepsis (1-3). In the light of the multiplicity of liver functions, it is unclear what liver functions are the first indicators of impending liver failure following liver resection and what are the most important functions leading to the almost invariable lethal outcome of liver failure.

\section{Nitrogen metabolism}

Ammonia clearance via urea synthesis is probably the best known aspect of hepatic nitrogen metabolism. Hepatic ammonia extraction prohibits the release of ammonia which is generated in large amounts in the intestines to the systemic circulation (chapter 3 ). It is a widespread assumption that the hyperammonemia seen in liver disease reflects an impaired capacity of hepatic urea synthesis and subsequent "overflow" of ammonia from the splanchnic area (gut and liver) (4). Data from chapters two and three however show clearly that the net release of ammonia from the splanchnic area to the systemic circulation is zero in humans with a normal functioning liver and that this does not change after major hepatectomy. Moreover, portal ammonia appears to be a relatively unimportant precursor for hepatic urea synthesis (chapters 2 and 3 ), which is rather driven by amino nitrogen flux $(5,6)$. In fact, the liver itself has to generate a considerable amount of ammonia by periportal glutaminase to supply the urea cycle with sufficient amounts of ammonia (7). Early changes in liver function following major hepatectomy include an impaired capacity for hepatic aminonitrogen clearance due to reduction of the amount of urea cycle enzymes (chapter 3). However, owing to the high $\mathrm{Km}$ of the urea cycle enzymes, the total rate of urea synthesis, and hence nitrogen balance can be maintained, albeit at the cost of increased amino acid levels.

Liver failure occurs when the remnant liver volume is too small. Signs, heralding liver failure may appear however before overt failure occurs. Increased amino 
acid levels appear to be an early reflection of liver dysfunction, already occurring when for example ammonia levels are still normal. Hitherto no data are at hand about the relation between pre- and post hepatectomy amino acid levels and clinical outcome. The potential application of post-hepatectomy amino levels or the assessment of amino acid levels during a pre-operative nitrogen challenge may become valuable tools for pre-operative assessment or post-operative monitoring.

Following major hepatectomy changes in either portal and/or hepatic blood flow are inevitable. It appears that in uncomplicated cases total portal blood flow is preserved, leading to an increased blood flow per gram liver $(3,8)$ (chapter 2). Failure of this adaptation is associated with increased morbidity and mortality (9). The increased blood flow per gram liver leads to sinusoidal shear stress and is probably facilitated by the differential changes in activity of the vasopressor Endothelin-1 and the vasodilator Nitric Oxide in the sinusoidal endothelium (10-12). Nitric Oxide is generated during the conversion of arginine to citrulline, consequently it is a commonly held view that modulation of plasma arginine levels affects NO synthesis. Arginine in turn is generated endogenously from citrulline. Classically it is thought that endogenous arginine synthesis occurs trough an interorgan pathway involving intestinal glutamine-to-citrulline conversion and renal citrulline-to-arginine conversion. The qualitative importance of glutamine as a precursor for endogenous synthesis of plasma arginine in humans becomes apparent from chapters 4 and 5 and from additional work from our group (13), showing that approximately $65 \%$ of endogenously generated arginine in the plasma is derived from plasma glutamine. Although intestinal-derived citrulline must pass the liver before reaching the kidney, the role of the liver in the interorgan exchange of glutamine, citrulline and arginine has been neglected since the early 1980's when Windmueller and Spaeth described the inability of the ex-vivo perfused rat liver to take up citrulline (14). Data from chapter four and five make clear however that the human liver is in fact very well capable of taking up citrulline, with a fractional extraction of $8.4 \%$. This observation was made both in subjects with and without liver metastases. Further research is warranted concerning the physiologic background of this phenomenon and concerning the cell type that metabolizes citrulline within the liver. It could be speculated that hepatic citrulline uptake serves nitric oxide production in hepatic resident macrophages (15). In addition, recent data show that citrulline may directly affect protein synthesis (16).

Since glutamine is an important precursor for plasma arginine further studies may be directed at investigating the effect of glutamine supplementation on renal arginine synthesis and plasma arginine levels. However, evidence is emerging that in NO producing cells such as macrophages, NOS is co-localized 
with argininosuccinate synthetase (ASS) and argininosuccinate lyase (ASL), catalyzing the formation of citrulline to arginine (17-19). In this way NOS, ASS and ASL form an "NO-cycle" maintaining intracellular arginine availability, only requiring the input of a single nitrogen atom. The existence of such an NO-cycle may shed new light on the importance of extracellular arginine availability as a rate-limiting factor for NO production.

\section{Hepatocellular injury}

A seemingly sufficient liver volume may become insufficient due to hepatocellular injury. Liver surgery is associated with a rise of serum levels of liver enzymes such as aspartate aminotransferase and lactate dehydrogenase (20). Peak levels of these markers of hepatocyte injury are reached on the first or second postoperative day which has been considered by some to reflect progressive necrosis following hepatectomy (21). Ischemia-reperfusion due to inflow occlusion of the liver is seen as the most important factor causing hepatocellular injury during and after liver surgery (22). In this thesis, effects of ischemia-reperfusion were studied in a clinical protocol consisting of partial hepatectomy with two consecutive periods of hepatic inflow occlusion, interrupted by a 5 minute reperfusion period.

Data from chapters six and seven show that peak levels of short-lived damage markers such as L-FABP and arginase- 1 are reached early during surgery and in fact before ischemia-reperfusion. These data indicate that liver manipulation is a leading cause of hepatocyte injury in these patients. Moreover the data underline the safety of limited intermittent inflow occlusion (23). Apart from loss of functional cell mass, cell injury may lead to the release of cytoplasmatic material to the surroundings of the damaged cell and to the plasma. It has been suggested that the enzyme arginase- 1 , which is released together with other cytoplasmatic debris from injured hepatocytes, can induce arginine deficiency and impaired NO synthesis (24). From chapter seven it becomes clear however that specific activity, peak levels and plasma half-life of arginase-1 levels are too low to cause a significant effect on arginine and NO metabolism.

It can thus be concluded that hepatocyte injury as well as its local and systemic consequences are minor when limits of twice fifteen minutes of hepatic inflow occlusion are observed. Already within the first fifteen minutes however, oxygen derived free radicals are produced (chapter 8 ). This is accompanied by an increased oxidation of glutathione (GSH) to glutathione disulfide (GSSG). During ischemia GSH levels increased almost 0.5 -fold which due to the absence of flow can only be explained by accumulation of newly synthesized 
GSH. This suggests that the turnover of hepatic glutathione vastly exceeds values estimated from animal studies that measured the incorporation rate of isotopically labelled precursors of glutathione. From these experiments a fractional GSH synthesis rate of approximately $400 \%$ was estimated in the liver of rats and pigs $(25,26)$. Our own efforts to quantify hepatic glutathione synthesis in humans (not reported in this thesis) were unsuccessful since we could not observe a consistent increase in hepatic GSH enrichment during a 4 hour $\left[{ }^{2} \mathrm{H}_{2}\right]$ glycine infusion. Possibly $\left[{ }^{2} \mathrm{H}_{2}\right]$ glycine has been an inappropriate tracer since the ${ }^{2} \mathrm{H}$ labels are easily released from glycine, but given the rapid increase of hepatic GSH concentration observed in chapter 8 , the failure may also have been attributable to the experimental design, which was unfit to measure synthesis rates highly exceeding those anticipated. Such an unexpectedly high GSH synthesis rate would easily prevent GSH depletion during oxidative stress. Simultaneously redox state is apparently well preserved, most likely due to increased biliary excretion of GSSG (25).

Expression of heat-shock proteins occurs as early as within twice fifteen minutes of intermittent hepatic inflow occlusion (chapter 9). In contrast with $\mathrm{GSH}$, which can be considered to play a constitutive cytoprotective role, heatshock protein expression can be considered as an inducible cytoprotective mechanism which may act synergistically with GSH to preserve hepatocyte integrity (27). Interesting in this context is the recognition that hypoxia-inducible factor 1-alpha (HIF-1 $\alpha$ ) is activated by reactive oxygen species (28). In the light of data from chapter 8 (early oxidative stress during hepatic ischemia) and chapter 9 (early HIF-1 $\alpha$ activiation during hepatic ischemia) it may be speculated that a modest degree of oxidative stress is an important trigger for cytoprotective heat-shock protein expression durgin the intermittent Pringle manoeuvre.

\section{Conclusions}

In conclusion, in this thesis changes in liver physiology following liver surgery are described. Physiological aspects of hepatic nitrogen metabolism include ammonia clearance at a rate that equals the rate of intestinal ammonia release and citrulline uptake. Early signs of liver dysfunction include decreased hepatic amino-nitrogen clearance with hyperaminoacidemia. Major hepatectomy does not lead to changes in hepatic ammonia clearance or urea synthesis. Although prolonged (cumulative) ischemia may ultimately compromise the functional capacity of the remnant liver, ischemia-reperfusion injury appears to be well tolerated when hepatic ischemia is limited to two periods of fifteen minutes. 
Hepatocellular integrity during intermittent ischemia-reperfusion may be preserved by endogenous constitutive or inducible cytoprotective mechanisms. Further research is needed to clarify whether modification of such mechanisms such as glutathione oxidation and heat-shock protein expression can improve outcome when prolonged hepatic ischemia is required to perform liver resection. 


\section{References}

1. Rahman SH, Evans J, Toogood GJ, Lodge PA, Prasad KR. Prognostic utility of postoperative C-reactive protein for posthepatectomy liver failure. Arch Surg 2008;143:247-253; discussion 253.

2. Schindl MJ, Redhead DN, Fearon KC, Garden OJ, Wigmore SJ. The value of residual liver volume as a predictor of hepatic dysfunction and infection after major liver resection. Gut 2005;54:289-296.

3. Schindl MJ, Millar A, Redhead DN, Fearon KCH, Ross JA, Dejong CHC, Garden OJ, et al. The adaptive response of the reticulo-endothelial system to major liver resection in man. Ann Surg 2006;243:507-514.

4. Sherlock S: Hepato-cellular failure. In: Diseases of the liver and biliary system. Oxford: Blackwell scientific publications, 1989; 80-94.

5. Rafoth $R J$, Onstad GR. Urea synthesis after oral protein ingestion in man. J Clin Invest 1975;56:1170-1174.

6. Vilstrup $H$. Synthesis of urea after stimulation with amino acids: relation to liver function. Gut 1980;21:990-995.

7. Haussinger D. Regulation of hepatic ammonia metabolism: the intercellular glutamine cycle. Adv Enzyme Regul 1986;25:159-180.

8. Kawasaki T, Moriyasu F, Kimura T, Someda H, Fukuda Y, Ozawa K. Changes in portal blood flow consequent to partial hepatectomy: Doppler estimation. Radiology 1991;180:373-377.

9. Bruix J, Castells A, Bosch J, Feu F, Fuster J, Garcia-Pagan JC, Visa J, et al. Surgical resection of hepatocellular carcinoma in cirrhotic patients: prognostic value of preoperative portal pressure. Gastroenterology 1996;111:1018-1022.

10. Schoen JM, Wang HH, Minuk GY, Lautt WW. Shear stress-induced nitric oxide release triggers the liver regeneration cascade. Nitric Oxide 2001;5:453-464.

11. Niiya T, Murakami M, Aoki T, Murai N, Shimizu Y, Kusano M. Immediate increase of portal pressure, reflecting sinusoidal shear stress, induced liver regeneration after partial hepatectomy. J Hepatobiliary Pancreat Surg 1999;6:275-280.

12. Pannen BH, Al-Adili F, Bauer M, Clemens MG, Geiger KK. Role of endothelins and nitric oxide in hepatic reperfusion injury in the rat. Hepatology 1998;27:755-764.

13. Ligthart-Melis GC, van de Poll MC, Boelens PG, Dejong CH, Deutz NE, van Leeuwen PA. Glutamine is an important precursor for de novo synthesis of arginine in humans. Am J Clin Nutr 2008;87:1282-1289.

14. Windmueller HG, Spaeth AE. Source and fate of circulating citrulline. Am.J.Physiol. 1981;241:E473-E480.

15. Pastor CM, Morris SM, Jr., Billiar TR. Sources of arginine for induced nitric oxide synthesis in the isolated perfused liver. Am J Physiol 1995;269:G861-866.

16. Moinard C, Cynober L. Citrulline: a new player in the control of nitrogen homeostasis. J Nutr 2007;137:1621S-1625S.

17. Husson A, Brasse-Lagnel C, Fairand A, Renouf S, Lavoinne A. Argininosuccinate synthetase from the urea cycle to the citrulline-NO cycle. Eur J Biochem 2003;270:1887-1899.

18. Nagasaki A, Gotoh T, Takeya M, Yu Y, Takiguchi M, Matsuzaki H, Takatsuki K, et al. Coinduction of nitric oxide synthase, argininosuccinate synthetase, and argininosuccinate lyase in lipopolysaccharide-treated rats. RNA blot, immunoblot, and immunohistochemical analyses. J Biol Chem 1996;271:2658-2662.

19. Nussler AK, Billiar TR, Liu ZZ, Morris SM, Jr. Coinduction of nitric oxide synthase and argininosuccinate synthetase in a murine macrophage cell line. Implications for regulation of nitric oxide production. J Biol Chem 1994;269:1257-1261. 
20. Aronsen KF, Ericsson B, Pihl B. Metabolic changes following major hepatic resection. Ann Surg 1969;169:102-110.

21. Panis Y, McMullan DM, Emond JC. Progressive necrosis after hepatectomy and the pathophysiology of liver failure after massive resection. Surgery 1997;121:142-149.

22. Belghiti J, Noun R, Malafosse R, Jagot P, Sauvanet A, Pierangeli F, Marty J, et al. Continuous versus intermittent portal triad clamping for liver resection: a controlled study. Ann Surg 1999;229:369-375.

23. Gurusamy KS, Kumar Y, Sharma D, Davidson BR. Methods of vascular occlusion for elective liver resections. Cochrane Database Syst Rev 2007:CD006409.

24. Morris SM, Jr. Arginine metabolism: boundaries of our knowledge. J Nutr 2007;137:1602S$1609 S$.

25. Jahoor F, Wykes LJ, Reeds PJ, Henry JF, del Rosario MP, Frazer ME. Protein-deficient pigs cannot maintain reduced glutathione homeostasis when subjected to the stress of inflammation. J Nutr 1995;125:1462-1472.

26. Capitan P, Malmezat $T$, Breuille D, Obled C. Gas chromatographic-mass spectrometric analysis of stable isotopes of cysteine and glutathione in biological samples. J Chromatogr $B$ Biomed Sci Appl 1999;732:127-135.

27. Pirkkala L, Nykanen $P$, Sistonen L. Roles of the heat shock transcription factors in regulation of the heat shock response and beyond. Faseb J 2001;15:1118-1131.

28. Tejima K, Arai M, Ikeda H, Tomiya T, Yanase M, Inoue $Y$, Nagashima $K$, et al. Ischemic preconditioning protects hepatocytes via reactive oxygen species derived from Kupffer cells in rats. Gastroenterology 2004;127:1488-1496. 
Chapter 11

Summary/

Samenvatting 


\section{Summary}

Colorectal liver metastases are a leading cause of death in the western world. Partial liver resection is currently the only potentially curative treatment option. Extensive liver resection may leave insufficient residual liver volume to sustain vital liver functions, but the maximum tolerated resectable volume is variable between individual patients. Increasing insights in functional changes following liver surgery and in causes of interindividual variation may ultimately lead to the development of tools that allow individual risk analysis. In chapter $\mathbf{1}$ an overview is presented concerning the development of the incidence of colorectal liver metastases throughout the past years and concerning the development of hepatic surgery at the University Hospital Maastricht. In addition factors impairing liver function following liver surgery as well as pathophysiological processes compensating for diminished liver function are reviewed.

Ammonia detoxification by urea synthesis is a vital metabolic pathway, almost completely limited to the liver. In view of this fact, a decrease of whole body urea synthesis could be expected following major liver resection. In chapter 2 however, data are presented showing that the capacity for urea synthesis per gram liver is sufficiently large to maintain ammonia clearance and urea production within one hour following major hepatectomy. Urea synthesis per gram liver increases proportionately to the resected liver volume and does not limit the liver volume that can be safely resected. However maintained ureagenesis is associated with an increased plasma level of a-amino-nitrogen which is an early indicator of hepatic dysfunction following liver resection.

In chapter 3 the crucial role of the liver in the exchange of nitrogenous compounds such as amino acids, ammonia and urea between various organs was investigated. Ammonia, produced by the gut from glutamine and transported to the liver by the portal vein, is completely removed from the circulation by the liver. This is the first time this observation has been made in humans with a normal liver. The kidneys release ammonia into the systemic circulation and as such account for all systemic ammonia release. Following major hepatectomy, hepatic ammonia clearance is maintained, which is in agreement with findings from chapter 2. Consequently, in this situation the kidneys still remain exclusively responsible for systemic ammonia release.

In chapters $\mathbf{4}$ and $\mathbf{5}$ advantage was taken of the opportunities provided by liver surgery to study the interorgan metabolic routing of the amino acid glutamine. Apart from the fact that glutamine serves as an end product of ammonia detoxification, glutamine supplementation has been shown to improve outcome after elective surgery, trauma and critical illness most likely because of its 
beneficial effects on immune function and inflammatory activity. Similar properties have been ascribed to the amino acid arginine. It has been suggested that glutamine is a precursor for arginine synthesis and that this conversion partly explains the beneficial effects of glutamine supplementation. During hepatic or pancreatic surgery blood was sampled from intra-abdominal vessels and amino acid tracers labelled with stable isotopes were infused. These studies showed that in humans glutamine is partly converted in the intestine to citrulline which in turn is partly extracted by the liver. Subsequently glutamine-derived citrulline is converted in the kidney to arginine.

Liver function following liver surgery may be impaired by hepatocellular injury. A well-known cause of hepatocyte injury is ischemia-reperfusion due to temporary obstruction of the blood flow to the liver (Pringle manoeuvre). But, other factors potentially leading to hepatocellular injury such as drug hepatotoxicity, liver manipulation and systemic inflammation in response to surgical trauma have not been addressed. In chapters 6 and 7 data are presented showing that manipulation of the liver during surgery leads to hepatocyte injury, evidenced by increased plasma levels of proteins such as liver type-fatty acid binding protein (L-FABP) and arginase-1 that are normally contained within hepatocytes. The increase of plasma levels of these proteins was even more prominent before the actual liver transection than during ischemia-reperfusion, suggesting that liver manipulation is in fact a leading cause of hepatocyte injury during liver surgery.

Within the hepatocyte the enzyme arginase- 1 converts the amino acid arginine to ornithine and urea as a part of the urea cycle. It has been described that increased plasma concentrations of arginase- 1 causes breakdown of plasma arginine. Since arginine is an important substrate for a wide array of physiological functions, arginine depletion due to inappropriate arginase-1 activity in plasma might have been deleterious for postoperative outcome following liver surgery. Data in chapter 7 however show that arginine levels are not affected by increased arginase- 1 levels during liver surgery and that the arginase- 1 concentration that is actually required to significantly reduce arginine plasma levels is rarely encountered in clinical practice with the exception of the liver transplantation setting.

Potential strategies to preserve cellular integrity following liver surgery include the supplementation of antioxidants that may become depleted during liver surgery. The formation of oxygen-derived free radicals is a universal characteristic of ischemia reperfusion. These highly reactive substances cause injury to cellular lipids, DNA and proteins, causing apoptotic cell death. Potential causes and the extent of oxidative stress as well as its effect on antioxidant status during intermittent hepatic ischemia-reperfusion has remained ill-defined. Data in chapter 8 show that an intermittently applied Pringle manoeuvre gives 
rise to the formation of free radicals during ischemia, due to increased xanthine oxidase activity but that xanthine oxidase is not involved in free radical generation during reperfusion. Intracellular concentrations of antioxidants such as glutathione and carotenoids are well maintained during the intermittent Pringle manoeuvre. In contrast, plasma concentrations of water-soluble antioxidants as well as their net hepatosplanchnic uptake decrease upon increasing cumulative ischemia time.

Aims of the studies described in chapter 9 were to describe the extent and time-course of the expression of several important heat shock proteins (HSP's) during the intermittent Pringle manoeuvre. HSP expression is an important endogenous protection mechanism against various forms of cellular stress, including ischemia-reperfusion. It was shown that during the intermittent Pringle manoeuvre the transcription factor hypoxia inducible factor- $1 \alpha$ (HIF-1 $\alpha$ ) is activated, followed by activation of the downstream pathway leading to Heme Oxygenase-1 (HO-1) formation. This protein had a significant protective effect on liver cells in vitro. We also found activation of the transcription factor heatshock factor-1 (HSF-1), albeit without significant changes in downstream pathways such as glucose regulated protein 94 (GRP-94) and HSP-70 expression.

\section{Final conclusions}

Surgical resection of colorectal liver metastases is an effective and safe treatment. Although resection of excessive amounts of functional liver volume will lead to liver insufficiency, the capacity of the liver for vital functions such as urea synthesis is sufficient to maintain homeostasis after major hepatectomy. In addition, liver surgery provides unique opportunities to carry out invasive studies of pathophysiological consequences of liver surgery itself and the role of the liver in human physiology. Such physiological studies resulted in new insights concerning the apparently inferior role of the intestines and the crucial role of the kidneys in the regulation of systemic ammonia release and concerning the hitherto unrecognized importance of the liver in the interorgan exchange of glutamine, citrulline and arginine. These insights may become valuable to further optimize metabolic support of patients dependent on artificial nutrition or patients with liver disease.

Cell survival is essential to maintain liver function following liver surgery. Liver manipulation during surgery appears to be an important cause of hepatocellular injury, evidenced by the release of L-FABP and arginase-1 into the plasma, even before the ischemia-reperfusion phase. Increased arginase-1 levels however, do not affect plasma arginine following liver resection. The effect of hepatic ischemia-reperfusion on hepatocellular injury appears to be limited 
when ischemia-reperfusion is applied intermittently. Under these conditions the liver is protected against cell injury and oxidative stress by endogenous hepatic antioxidants and by the uptake of water-soluble antioxidants from the plasma. In addition disturbance of cellular redox balance due to GSH oxidation early during hepatic ischemia is rapidly restored during intermittent hepatic ischemia, probably by increased GSSG reduction. Moreover the rapid induction of heat shock proteins, especially HO-1 is likely to contribute to the preservation of hepatocellular integrity during the intermittent Pringle manoeuvre. Antioxidant supplementation or HSP induction may become the basis for future interventions increasing cell survival following liver surgery. 


\section{Samenvatting}

Colorectale levermetastasen zijn een voorname doodsoorzaak in de westerse wereld. Een partiele leverresectie is momenteel de enige potentieel curatieve behandelingsmogelijkheid. Uitgebreide leverresectie kan onvoldoende resterend levervolume achterlaten om vitale leverfuncties te handhaven, maar het maximaal te verwijderen levervolume verschilt tussen individuele patienten. Groeiende inzichten in functionele veranderingen na leverchirurgie en in oorzaken van variaties tussen verschillende personen kunnen uiteindelijk leiden tot de ontwikkeling van middelen die individuele risico inschatting mogelijk maken. In hoofdstuk 1 wordt een overzicht gegeven van de ontwikkeling van het voorkomen van colorectale levermetasasen gedurende de laatste jaren en van de ontwikkeling van leverchirurgie in het academisch ziekenhuis Maastricht. Verder worden factoren besproken die de leverfunctie na leverchirurgie kunnen beperken alsmede pathofysiologische processen die compenseren voor een verminderde leverfunctie.

De ontgifting van ammoniak door ureum synthese is een vitaal metabool proces, dat bijna uitsluitend beperkt is tot de lever. Gezien dit gegeven zou na een grote leverresectie een afname verwacht kunnen worden in de ureum synthese. In hoofdstuk 2 echter wordt aangetoond dat de capaciteit voor ureum synthese per gram lever voldoende is om binnen één uur na een grote leverresectie de ammoniakklaring en ureum productie te handhaven. De ureum synthese per gram lever neemt evenredig toe met het gereseceerde lever volume en is dus geen beperkende factor voor het maximaal te reseceren lever volume. De handhaving van de ureumsynthese gaat echter wel gepaard met een toename van de plasmaconcentratie van aminozuren, wat een vroege indicator is van lever dysfunctie na leverresectie.

In hoofdstuk 3 onderzochten we de cruciale rol van de lever in de uitwisseling van stikstofhoudende stoffen als aminozuren, ammoniak en ureum tussen verschillende organen. Ammoniak, geproduceerd door de darm uit glutamine en getransporteerd naar de lever door de poortader, wordt door de lever volledig uit de circulatie verwijderd. Dit is de eerste keer dat deze observatie werd gedaan in mensen met een normale lever. De nieren geven ammoniak af aan de systemische circulatie en zorgen aldus voor alle systemische ammoniak afgifte. $\mathrm{Na}$ een grote leverresectie is de ammoniak klaring door de lever bewaard, wat overeenkomt met bevindingen uit hoofdstuk 2. Dientengevolge zijn de nieren in deze situatie nog steeds exclusief verantwoordelijk voor de systemische ammoniak afgifte.

In hoofdstukken $\mathbf{4}$ en $\mathbf{5}$ werd gebruik gemaakt van de unieke mogelijkheden die geboden worden door leverchirurgie om de interorgaan stofwisseling van 
het aminozuur glutamine te bestuderen. Afgezien van het gegeven dat glutamine dient als een eindproduct van de ontgifting van ammoniak, is aangetoond dat de toediening van glutamine de resultaten van electieve chirurgie, trauma en kritische ziekte verbetert, meest waarschijnlijk door de positieve effecten op de immuunfunctie en de inflammatoire activiteit. Soortgelijke eigenschappen worden toegeschreven aan het aminozuur arginine. Het is wel gesuggereerd dat glutamine een precursor is voor de synthese van arginine en dat deze omzetting de positieve effecten van glutamine deels kan verklaren. Tijdens buikoperaties aan de lever of alvleesklier werd bloed afgenomen uit bloedvaten in de buik en werden met stabiele isotopen gelabelde aminozuren toegediend. Deze studies toonden aan dat in de mens glutamine in de darm gedeeltelijk wordt omgezet in citrulline, wat daarna gedeeltelijk wordt opgenomen door de lever. Vervolgens wordt citrulline, afkomstig uit glutamine door de nier omgezet in arginine.

De functie van de lever na leverchirurgie kan beperkt worden door levercel schade. Een bekende oorzaak hiervan is ischemie-reperfusie door tijdelijke afsluiting van de bloedtoever naar de lever (Pringle manoeuvre). Maar, andere factoren die mogelijk leiden tot levercel schade zoals de schadelijkheid van medicijnen, lever manipulatie en systemische ontsteking ten gevolge van chirurgisch trauma waren nog niet uitgebreid bestudeerd. In hoofdstukken 6 en 7 worden data gepresenteerd die aantonen dat manipulatie van de lever tijdens chirurgie leidt tot levercel schade, blijkend uit een toename van de plasmaspiegels van eiwitten als liver type-fatty acid binding protein (L-FABP) en arginase-1 die zich normaal gezien binnen in de levercel bevinden. De toename van de plasmaspiegel van deze eiwitten was zelfs meer uitgesproken tijdens levermanipulatie dan tijdens ischemie-reperfusie, wat suggereert dat lever manipulatie inderdaad een belangrijke oorzaak is van levercel schade tijdens chirurgie.

Binnen de levercel zet het enzym arginase-1 het aminozuur arginine om in ornithine en ureum, als onderdeel van de ureum cyclus. $\mathrm{Er}$ is beschreven dat toegenomen plasmaspiegels van arginase-1 leiden tot de afbraak van arginine in het plasma. Omdat arginine een belangrijk substraat is voor een uitgebreid scala aan fysiologische functies, zou arginine depletie door ongepaste arginase activiteit in plasma nadelig kunnen zijn voor de uitkomst na leverchirurgie. Data in hoofdstuk 7 tonen echter aan dat arginine spiegels niet worden beïnvloed door toegenomen arginase-1 spiegels tijdens leverchirurgie en dat de arginase1 concentraties die daadwerkelijk nodig zijn om een belangrijke afname van arginine plasma spiegels te bewerkstelligen zelden voorkomen in de klinische praktijk, met een mogelijke uitzondering voor de lever transplantatie.

Onder de potentiële strategieën om de integriteit van cellen te bewaren tijdens leverchirurgie valt de toediening van antioxidanten die mogelijk uitgeput raken 
tijdens de operatie. De vorming van vrije zuurstof radicalen is een universeel verschijnsel tijdens ischemie-reperfusie. Deze zeer reactieve stoffen veroorzaken schade aan vetzuren, DNA en eiwitten in cellen, waardoor apoptotische celdood ontstaat. Over mogelijke oorzaken van oxidatieve stress en de gevolgen hiervan voor de anti-oxidant status tijdens leverchirurgie is weinig bekend. In hoofdstuk 8 wordt aangetoond dat een intermitterend toegepaste Pringle manoeuvre leidt tot de vorming van vrije radicalen tijdens ischemie, door een toegenomen activiteit van xanthine oxidase, maar dat xanthine oxidase niet betrokken is in de vorming van vrije radicalen tijdens reperfusie. De gehaltes van anti-oxidanten als glutathion en carotenoiden blijven goed in stand tijdens de intermitterende Pringle manoeuvre. De plasma spiegel van water-oplosbare antioxidanten daarentegen, alsmede de netto opname door het hepatosplanchnische gebied (darm en lever) neemt af naarmate de cummulatieve ischemie tijd toeneemt.

De studies die beschreven worden in hoofdstuk 9 hadden ten doel om de mate en het tijdsverloop van de expressie van verschillende heat shock proteins (HSP's) te beschrijven tijdens de intermitterende Pringle manoeuvre. HSP expressie is een belangrijk endogeen beschermingsmechanisme tegen verschillende vormen van cellulaire stress, waaronder ischemie-reperfusie. $\mathrm{Er}$ werd aangetoond dat tijdens de intermitterende Pringle manoeuvre de transcriptie factor hypoxia-inducible factor (HIF-1 $\alpha$ ) wordt geactiveerd, gevolgd door activatie van een stroomafwaartse route, leidend tot de vorming van Heme Oxygenase-1 (HO-1). Dit eiwit had een belangrijke beschermende werking op levercellen in vitro. Verder vonden we activatie van de transcriptie factor heatshock factor-1 (HSF-1), overigens zonder belangrijke veranderingen in stroomafwaartse processen zoals de expressie van glucose regulated protein (GRP-94) en HSP-70.

\section{Slotconclusies}

Chirurgische resectie van colorectale levermetastasen is een effectieve en veilige behandeling. Hoewel excessieve resectie van het functionele volume uiteindelijk zal leiden tot leverfalen, is de reserve capaciteit van de lever voor vitale functies als ureum synthese voldoende om de homeostase te bewaren na een grote leverresectie. Bovendien biedt leverchirurgie unieke mogelijkheden om invasieve onderzoeken uit te voeren naar de pathofysiologische gevolgen van leverchrirugie zelf, maar ook naar de rol van de lever in de menselijke fysiologie. Dergelijke fysiologische studies resulteerden in nieuwe inzichten over de klaarblijkelijk beperkte rol van de darmen en de cruciale rol van de nieren in de regulatie van systemische ammoniak afgifte en over het totnogtoe niet onderkende belang van de lever in het interorgaan transport van glutamine, 
citrulline en arginine. Deze inzichten kunnen van belang worden om de metabole ondersteuning te verfijnen van patiënten die afhankelijk zijn van kunstmatige voeding en van patiënten met leverziekten.

Het overleven van cellen is de sleutel voor waarborging van de leverfunctie na leverchirurgie. Levermanipulatie tijdens chirurgie lijkt een belangrijke oorzaak van levercel schade, blijkend uit het vrijkomen van L-FABP en arginase-1 in het plasma, zelfs voor de ischemie-reperfusie fase. Overigens, leiden deze verhoogde arginase-1 spiegels niet tot een arginine daling na leverresectie. Het effect van ischemie-reperfusie op levercel schade lijkt beperkt als de ischemiereperfusie intermitterend wordt toegepast. Onder deze omstandigheden is de lever beschermd tegen celschade en oxidatieve stress door endogene antioxidanten in de lever en de opname van water-oplosbare antioxidanten uit het plasma. Verder wordt de cellulaire redox balans die al snel tijdens ischemie wordt verstoord door GSH oxidatie weer snel hersteld, waarschijnlijk door toegenomen GSSG reductie. Bovendien draagt de snelle inductie van Heat Shock Proteins, vooral HO-1 waarschijnlijk bij aan het bewaren van de integriteit van de levercel tijdens de intermitterende Pringle manoeuvre. Antioxidant toediening of HSP inductie kunnen mogelijk de basis gaan vormen voor toekomstige interventies om de overleving van cellen na leverchirurgie te verbeteren. 



\section{Dankwoord}




\section{Dankwoord}

Het grootste deel van mijn studententijd heb ik doorgebracht buiten de collegebankjes. Toen tijdens de co-schappen mijn belangstelling voor de chirurgie werd gewekt besefte ik dan ook dat mijn CV behoorlijk opgepoetst moest worden om een kansje te maken op een opleidingsplaats. Na deze situatie uitgelegd te hebben aan professor Soeters kreeg ik de mogelijkheid om onderzoek te doen naar glutathion metabolisme bij kankerpatiënten. Niet veel later werd mij door dr Dejong de vraag voorgelegd of ik geen AIO wilde worden. Hoewel dit uiteraard oorspronkelijk niet de bedoeling was, liet ik mij in een aantal gesprekken toch enthousiasmeren om "het onderzoek" en niet "de kliniek" in te gaan. Het halen van de eindstreep van dit promotieonderzoek is geen individuele prestatie geweest, maar is mede te danken aan vele anderen. Kees Dejong, je enthousiasme en onvoorwaardelijke steun maken het bijzonder aangenaam en dankbaar om met je en voor je te werken. Ik hoop dat onze wegen nog lang parallel blijven lopen.

Peter Soeters, je was altijd de stabiele factor op de achtergrond. Ik ben vereerd één van je "kleinkinderen" te zijn en vind het jammer dat ik door je emeritaat niet ook het "echte werk" van je heb kunnen leren.

Wim Buurman, met name in de laatste fase van het onderzoek hebben we elkaar beter leren kennen en is er een prettige en vruchtbare samenwerking ontstaan. Bedankt voor de vrijheid en ruimte die ik kreeg in je lab.

De leden beoordelingscommissie, bedankt voor het kritisch lezen en becommentarieren van dit proefschrift

Allen met wie ik kortere of langere tijd de kamer heb gedeeld: Als student in het ziekenhuis met Yvette en Judith. Op de vierde met Yvonne, Juanita, Marieke en Valeria en na de verhuizing met Sylvia, Martien, Bart, Jacco, Nicole en Ruud. M'hamed, je hebt het het langst met me moeten uithouden, bedankt voor de scherpte in het politieke debat en voor vele hand- en spandiensten. Misha, hard werken als het moet, altijd in voor een feestje als het kan, en de volgende dag zonder gezeur op de fiets. Zo hoort het! Trudi, de "moeder-overste" van de kamer en het hele lab. Bedankt voor alle hulp, ik denk met warmte aan je terug. De anderen van het lab: Tim ondanks vele inspanningen heb je me het PCR-en niet kunnen leren, wat jou overigens niet te verwijten valt. Joep, bedankt voor het laatste duwtje om het L-FABP stuk op te schrijven. Bas, bedankt voor de samenwerking met het arginase stuk. Robert, Jeroen, Annemarie, Kim, Geertje, Tim, Maarten, Cees, Bart, bedankt voor de gezelligheid en collegialiteit. In het metabole lab zijn de afgelopen jaren teveel mensen gepasseerd om ze allen bij naam te noemen. Hans, de sole-survivor, bedankt voor het geduld met deze onstuimige AIO. Iris, altijd goed gezind, kom snel weer eens langs. 
De overige leverchirurgen: Marc Bemelmans, Ronald van Dam, Jan Willem Greve, bedankt voor de continue bereidwilligheid om nog even sampletje te nemen. Steven Olde Damink, je overweldigende enthousiasme en pragmatisme zijn een voorbeeld, ik hoop in de toekomst mee te kunnen helpen de erfenis van onze promotor te waarborgen.

Alle OK-assistenten, anesthesieverpleegkundigen, anesthesieassistenten en anesthesisten die hebben meegewerkt (of in sommige gevallen niet hebben tegengewerkt) bij de uitvoering van de verschillende studies.

Onze collega's uit de VU, Gerdien Melis, Paul van Leeuwen en Petra Boelens: met bloed zweet en tranen, misschien niet altijd volledig volgens plan en naar wens, maar uiteindelijk toch een mooi drieluik.

Steve Wigmore, thank you for the input in data acquisition, laboratory analysis and substantive and linguistic comments to four chapters of this thesis.

Wilbert Peeters en Hennie Roelofs, Ger Koek, Aalt Bast en Mark Fischer, dank voor samenwerking leidend tot hoofdstukken 6 en 8.

Roeland Ceulen, jouw betoog over de route naar de chirurgie in "Da Gepetto" eind 2000 , heeft mij de beslissende zet gegeven. Hoewel we elkaar (te) weinig zien, verdien je daarmee absoluut een plaats in mijn dankwoord.

Mijn paranimphen Esther en Tessa. Esther, mijn maatje in de eerste jaren van de studententijd. Avonden en nachtenlang deden we vooral weinig aan onze studie. Ik had er niets van willen missen. We zijn toch nog goed terechtgekomen en ik hoop binnenkort jouw promotie bij te wonen. Tessa, zonder het denk ik zelf door te hebben, heb jij me met jouw vlijt geinspireerd om eindelijk eens aan de slag te gaan. Uiteindelijk zie je dat het maar weinig uitmaakt of je eerst doctor of dokter wordt.

Papa en Willeke, mijn zus, het is ongelofelijk om te zien hoe jullie je al 15 jaar met zijn tweeën door het leven slaan. Dank voor de onvoorwaardelijke steun, ik kan me geen lievere familie wensen.

Mijn schoonfamilie. Naar (goed?) familiegebruik bemoeien jullie je werkelijk overal mee, zo ook met mijn onderzoeksvorderingen. Gatze, wetenschapper in hart en nieren, bedankt voor de oprechte interesse en waardevolle adviezen.

Anthe en Dorus, jullie laten me iedere dag zien wat echt belangrijk is in het leven: eten, drinken, plezier maken en slapen. Thuis komen bij jullie brengt alle beslommeringen meteen weer in de juiste proporties. Lieve Tanja, jij houdt me voortdurend met beide benen op de grond, ook al was dat in de laatste periode van mijn onderzoek soms een bijna onmogelijke opgave. Jij bracht mijn leven in een stroomversnelling en tegelijkertijd in een rustige haven. Hoewel ik het niet zo vaak zeg, ben ik je daar onuitsprekelijk dankbaar voor. 



\section{Curriculum Vitae}




\section{Curriculum Vitae}

Marcel Coenraad Gerhard van de Poll was born in Zwolle, the Netherlands, on August 15th 1976. After finishing athenaeum at the "Carolus Clusius College" in 1995, he attended Medical School at Maastricht University (then State University Limburg). In September 2002 he obtained his MD degree.

During his clerkships in 2001 he started his research eventually leading to the present thesis, supervised by Dr. C.H.C. Dejong and Prof. dr. P.B. Soeters. In 2004 he attained an AGIKO stipendium from the Netherlands Organisation for Health Research and Development. Since July 2006 he is working as a surgical resident at the University Hospital Maastricht (headed by Prof. dr. M.J.H.M. Jacobs and Prof. dr. J.W.M. Greve). Work underlying this thesis has been awarded with the gastroenterological student award (Dutch Gastroenterology Society, 2003), the national scholarship for clinical liver research (Dutch Hepatology Society, 2005), the NESPEN-award (Netherlands Society for Parenteral and Enteral Nutrition, 2006), and the Harry M. Vars Award (American Society for Parenteral and Enteral Nutrition, 2007). He is married to Tanja Lettinga and together they have a daughter (Anthe, 2004) and a son (Dorus, 2006). 


\section{Publications}




\section{Publications}

van de Poll MCG, Soeters PB, Deutz NEP, Fearon KCH, Dejong CHC. Renal amino acid metabolism: its role in inter-organ amino acid and nitrogen exchange. Am J Clin Nutr 2004;79:185197.

Soeters PB, van de Poll MCG, van Gemert WG, Dejong CHC. Amino acid adequacy in disease. J Nutr 2004;134:1575S-1582S

Patel A, van de Poll MCG, Greve JWM, Buurman WA, Fearon KCH, McNally SJ, Harrison EM, Ross JA, Garden OJ, Dejong CHC, Wigmore SJ. Early stress protein gene expression during intermittent portal ischemia-reperfusion in human liver surgery. Transplantation 2004;78:1479-87.

van de Poll MCG, Dejong CHC, Soeters PB. Adequate range for sulfur-containing amino acids and biomarkers for their excess: lessons from enteral and parenteral nutrition. J Nutr 2006;136:1694S7005

van de Poll MCG, Siroen MPC, van Leeuwen PAM, Soeters PB, Melis GC, Boelens PG, Deutz $N E P$, Dejong $C H C$. Interorgan amino acid exchange in man: Consequences for arginine and citrulline metabolism. Am J Clin Nutr 2007;85:167-72

van de Poll MCG, Ligthart-Melis GC, Boelens PG, Deutz NEP, van Leeuwen PAM, Dejong CHC. Intestinal and hepatic metabolism of glutamine and citrulline in humans. J Physiol 2007;581:819-27 Dejong CHC, van de Poll MCG, Soeters PB, Jalan R, Olde Damink SWM. Aromatic amino acid metabolism in liver failure. J Nutr 2007;1586S-1585S

Ligthart-Melis GC, van de Poll MCG, Dejong CHC, Boelens PG, Deutz NEP, van Leeuwen PAM. Does The Route Of Administration (enteral Or Parenteral) Of Isotopically Labelled L-glutamine Affect The Conversion Of $L-\left[2,{ }^{15} \mathrm{~N}\right]$ glutamine Into $L-\left[2,{ }^{15} \mathrm{~N}\right]$ arginine In Humans. JPEN 2007;31:34350

van de Poll MCG, Derikx JPM, Buurman WA, Peters WHM, Roelofs HMJ, Wigmore SJ, Dejong $\mathrm{CHC}$. Liver manipulation causes hepatocyte injury and precedes systemic inflammation in patients undergoing liver resection. World J Surg 2007;31:2215-21

Vermeulen MAR, van de Poll MCG, Ligthart-Melis GC, Dejong CHC, Boelens, PG, van Leeuwen $P A M$. Exogenous glutamine/arginine: A common denominator? Critical Care Medicine 2007;35:S568-76

Dello SWAG, van Dam RM, Slangen J, van de Poll MCG, Bemelmans MHA, Greve JWM, BeetsTan RGH, Wigmore SJ, Dejong CHC. Liver volumetry plug-and-play, do-it-yourself with ImageJ. World J Surg 2007;31:2215-21

van de Poll MCG, Wigmore SJ, Redhead DN, Beets-Tan RGH, Garden OJ, Greve JWM, Soeters $P B$, Deutz NE, Fearon $K C H$, Dejong $C H C$. Effect of major liver resection on hepatic ureagenesis in man. Am J Physiol: GI and Liver Physiol 2007;293:G956-62

van de Poll MCG, Hanssen SJP, Berbée M, Deutz NEP, Monbaliu D, Buurman WA, Dejong CHC. Elevated plasma arginase-1 does not affect plasma arginine in patients undergoing liver resection. Clin Sci 2008;114:243-9 
van de Poll MCG, Dejong CHC, Fischer MAJG, Bast A, Koek GH. Decreased hepatosplanchnic antioxidant uptake during hepatic ischemia-reperfusion in patients undergoing liver resection. Clin Sci 2008;114:553-60

Ligthart-Melis GC, van de Poll MCG, Boelens PG, Dejong CHC, Deutz NEP, van Leeuwen PAM. Glutamine is an important precursor for de novo synthesis of arginine in humans. Am J Clin Nutr 2008;87:1282-9

van de Poll MCG, Ligthart-Melis GC, Olde Damink SWM, van Leeuwen PAM, Beets-Tan RGH, Deutz NEP, Wigmore SJ, Soeters PB, Dejong CHC. Systemic ammonia release is determined by the kidney in humans without portosystemic shunting. Am J Physiol: Gl and Liver Physiol 2008 (in press)

van de Poll MCG, Soeters PB. Chirurgie. In Wiersinga J, Schimmer B, Levi MM, eds. Handboek voor de co-assistent. Houten: Bohn Stafleu Van Loghum, 2002. pp. 283-5

van de Poll MCG, Dejong CHC, Soeters PB. Acute buik bij volwassenen. In Mathus-Vliegen L, Muris J, Numans $M$, Starmans $R$, eds. Het Gastro-enterologie Formularium: een praktische leidraad. Houten: Bohn Stafleu Van Loghum, 2003. pp. 83-94

van de Poll MCG, Luiking YC, Dejong CHC, Soeters PB. Amino acids; specific functions. In Caballero B, Allen $L$ and Prentice A, eds. Encyclopedia of human nutrition. San Diego: Academic Press, 2nd ed 2005. pp. 92-100

Soeters PB, van de Poll MCG. Amino acids, protein and the gut. In van Gossum A, Bozetti $F$, eds. Home Parenteral Nutrition. Oxfordshire: CABI, 2006. pp. 234-58

van de Poll MCG, Luyer MDP, Dejong CHC. Plotselinge buikpijn bij volwassenen. In Muris JWM, Mathus-Vliegen EMH, Voorn ThB. Praktische Huisartsgeneeskunde. Houten: Bohn Stafleu Van Loghum. pp 92-103

van de Poll MCG, Olde Damink SWM, Dejong CHC. Interorgan Dynamics of amino acids. In D'Mello $F$, ed. Amino Acids in Human Nutrition and Health. Oxfordshire: CABI, 2009 (in preparation) 